Universidad de Lima

Facultad de Ingeniería y Arquitectura

Carrera de Ingeniería Industrial

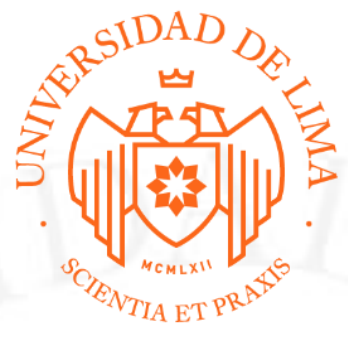

\title{
ESTUDIO DE PREFACTIBILIDAD PARA LA INSTALACIÓN DE UNA EMPRESA DEDICADAA LA TERCERIZACIÓN DE LA ADMINISTRACIÓN DEL SISTEMA DE SEGURIDAD Y SALUD EN EL TRABAJO AL RUBRO DE SERVICIOS MINEROS
}

Trabajo de investigación para optar el Título Profesional de Ingeniero Industrial

\author{
Diana Lettsy Vera Veliz
}

Código 20123206

Asesor

Pedro Arturo Salinas Pedemonte

Lima - Perú

Octubre de 2019 


\title{
PREFACTIBILITY STUDY FOR THE
}

\section{INSTALLATION OF A COMPANY DEDICATED}

TO THE SAFETY AND HEALTH

\author{
ADMINISTRATION'S OUTSOURCING AT \\ WORK FOR MINING SERVICES
}




\section{TABLA DE CONTENIDO}

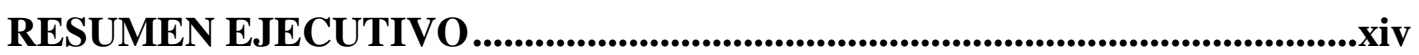

EXECUTIVE SUMMARY .............................................................................

INTRODUCCIÓN ..................................................................................................1

CAPITULO I: ASPECTOS GENERALES ...........................................................2

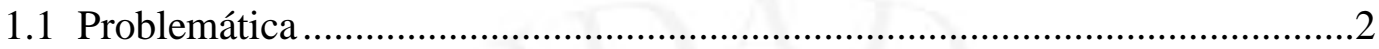

1.2 Objetivos de la investigación..................................................................

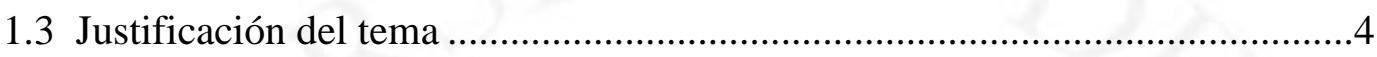

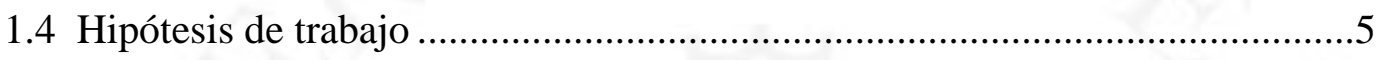

1.5 Marco referencial de la investigación.............................................................6

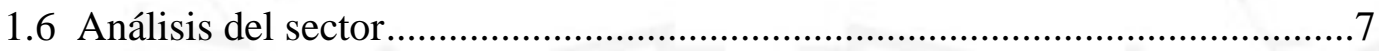

CAPITULO II: ESTUDIO DE MERCADO ..............................................10

2.1 Aspectos generales del estudio de mercado ............................................... 10

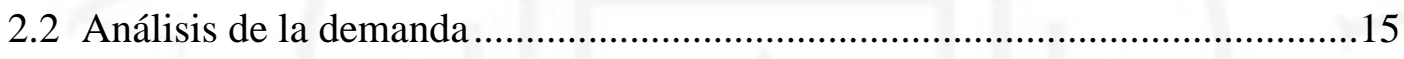

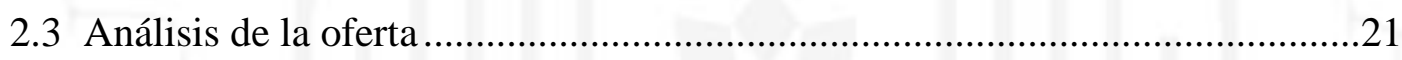

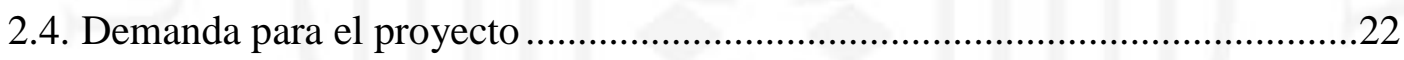

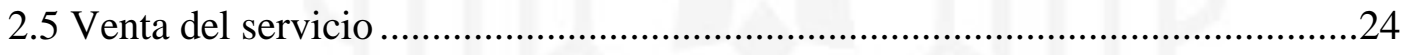

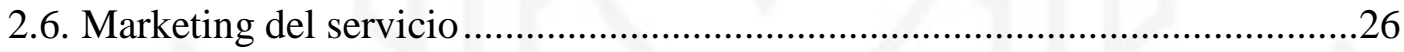

CAPÍTULO III. LOCALIZACIÓN DEL SERVICIO..........................................27

3.1 Análisis de los factores de localización ........................................................27

3.2 Posibles ubicaciones de acuerdo a factores predominantes..............................32

3.3 Evaluación y selección de la localización del servicio......................................37

CAPÍTULO IV. DIMENSIONAMIENTO DEL SERVICIO ............................40

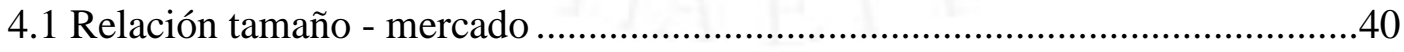

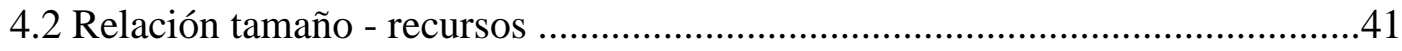

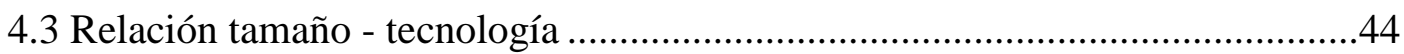

4.4 Relación tamaño - punto de equilibrio........................................................44

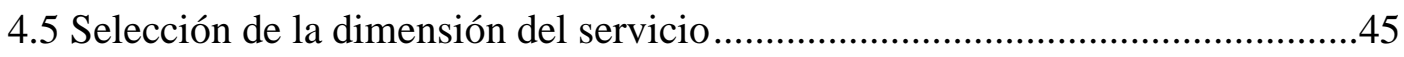

CAPÍTULO V. INGENIERÍA DEL PROYECTO...............................................47

5.1 Definición del servicio basada en sus características de operación...................47 
5.2 Tecnología existente y proceso de realización del servicio.............................47

5.3 Características de las instalaciones y equipo..............................................63

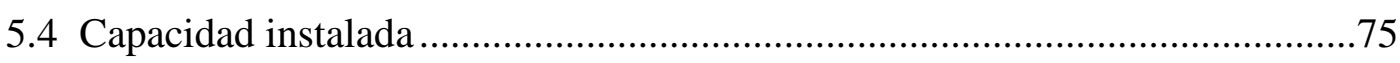

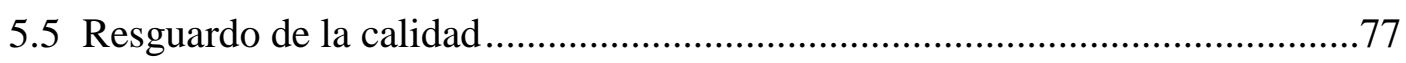

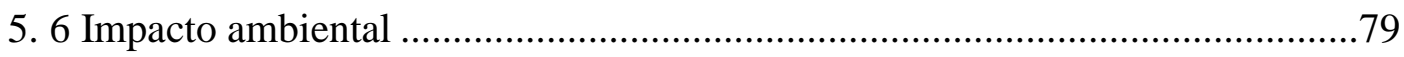

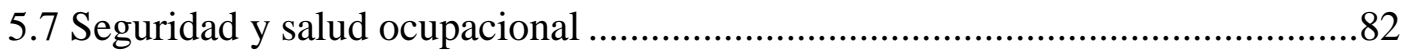

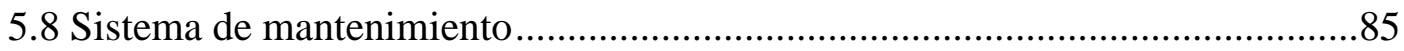

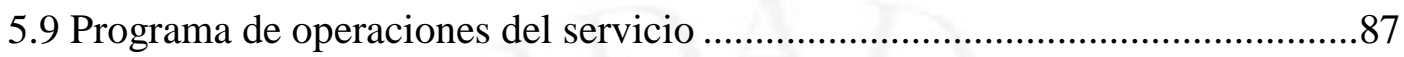

5.10Requerimiento de materiales, personal y servicios .......................................89

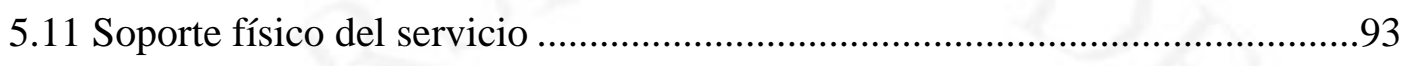

5.12Disposición de la instalación del servicio...................................................97

5.13 Cronograma de implementación del proyecto................................................104

CAPÍTULO VI. ORGANIZACIÓN ADMINISTRATIVA ..................................105

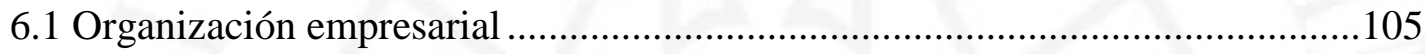

6.2 Requerimientos del personal directivo, administrativo y de soporte interno del

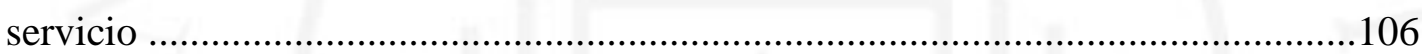

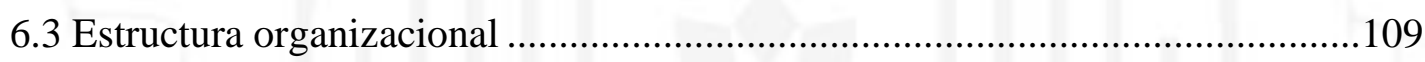

CAPÍTULO VII. ASPECTOS ECONÓMICOS......................................................111

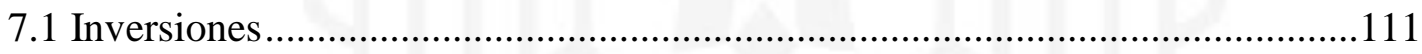

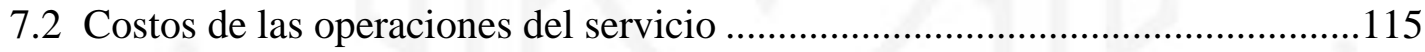

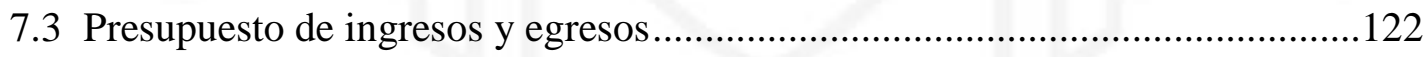

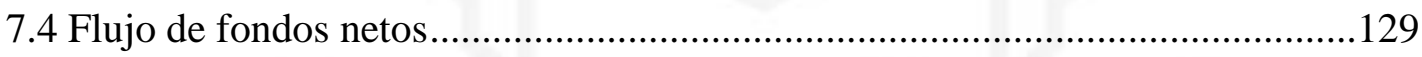

\section{CAPÍTULO VIII. EVALUACIÓN ECONÓMICA Y FINANCIERA}

DEL PROYECTO .................................................................................................134

8.1 Evaluación económica: VAN, TIR, B/C, PR ................................................134

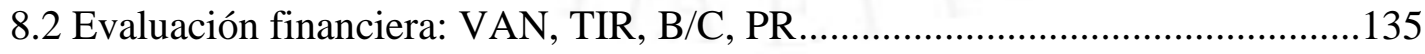

8.3 Análisis de los resultados económicos y financieros del proyecto.....................135

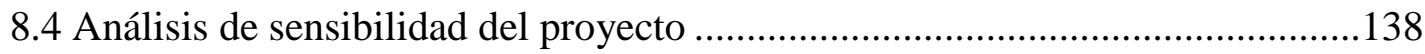

CAPÍTULO IX. EVALUACIÓN SOCIAL DEL PROYECTO ..........................139

9.1 Identificación de las zonas y comunidades de influencia del proyecto.............139

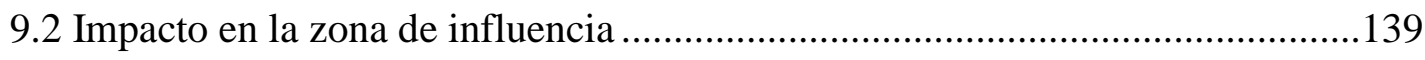

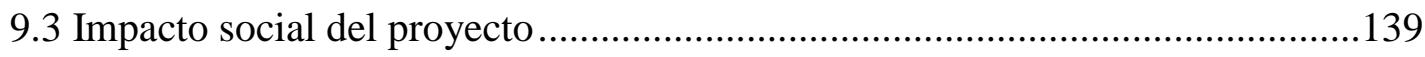




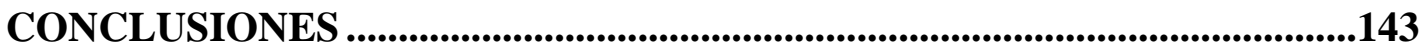

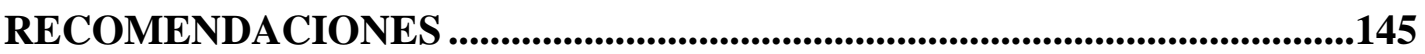

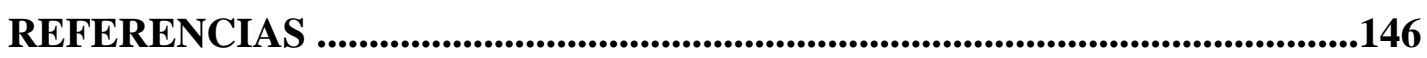

BIBLIOGRAFÍA .......................................................................................147

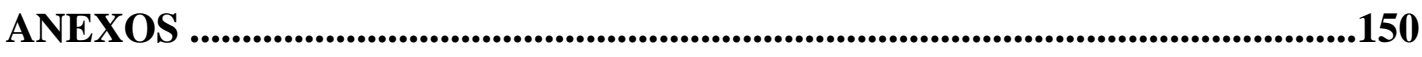




\section{ÍNDICE DE TABLAS}

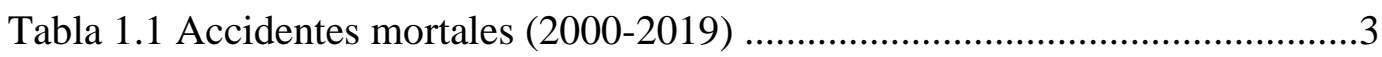

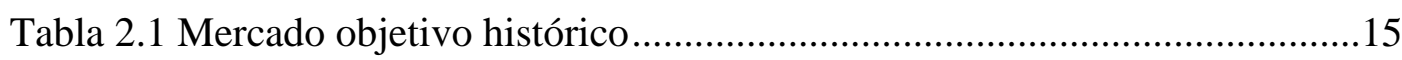

Tabla 2.2 Proyección de la demanda potencial al 2025 ......................................20

Tabla 2.3 Datos históricos para determinar el mercado meta............................... 23

Tabla 2.4 Mercado meta del proyecto (en número de empresas) ...........................23

Tabla 2.5 Demanda del proyecto (en número de empresas).................................24

Tabla 3.1 Cantidad de empresas contratistas mineras por distrito .........................27

Tabla 3.2 Percepción de inseguridad ciudadana (\%) por distrito ...........................28

Tabla 3.3 Evaluación se serenazgos y policías..................................................29

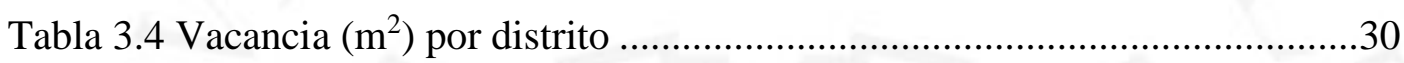

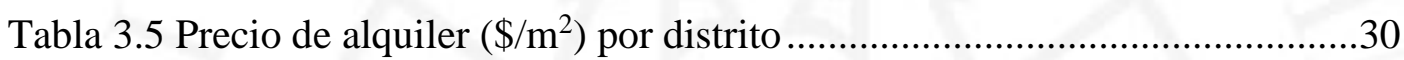

Tabla 3.6 Cantidad de estacionamientos por distrito................................................ 31

Tabla 3.7 Rango de precios del estacionamiento por distrito ................................31

Tabla 3.8 Tiempo de entrega y precios de licencia de funcionamiento por

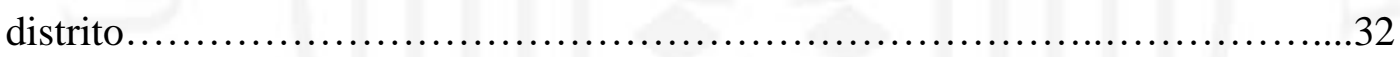

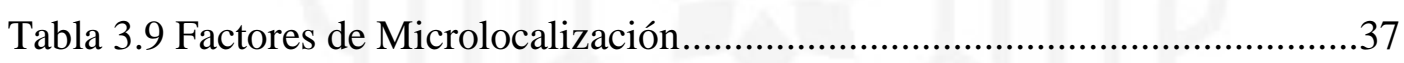

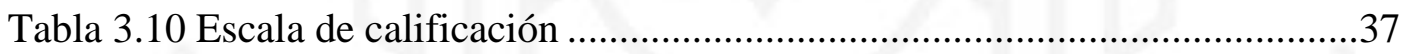

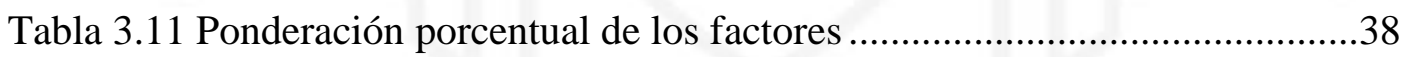

Tabla 3.12 Ranking de factores - Microlocalización ..............................................39

Tabla 4.1 Proyección tamaño - mercado.........................................................40

Tabla 4.2 Cantidad de egresados de carreras profesionales .................................4

Tabla 4.3 Cantidad de CV que cumplen requisitos ..............................................42

Tabla 4.4 Costos y precios aproximados del servicio .........................................44

Tabla 4.5 Cuadro comparativo de las dimensiones del servicio.............................46

Tabla $5.1 \mathrm{~N}^{\circ}$ de equipos, especialistas y empresas abarcadas proyectadas.............76

Tabla 5.2 Capacidad de atención de la empresa ....................................................76

Tabla $5.3 \mathrm{~N}^{\circ}$ de materiales necesarios proyectado ............................................ 77

Tabla 5.4 Impacto ambiental de la oficina principal .......................................... 80

Tabla 5.5 Impacto ambiental en la zona de trabajo ..............................................81 
Tabla 5.6 Control del impacto ambiental por la actividad de recrecimiento de

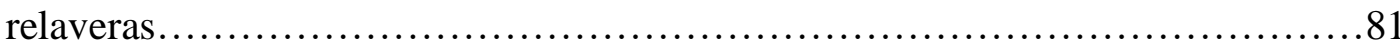

Tabla 5.7 Matriz Leopold del impacto ambiental en la zona de trabajo .................82

Tabla 5.8 Programa de Operaciones del servicio durante la vida útil .....................88

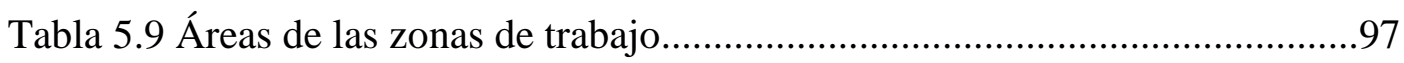

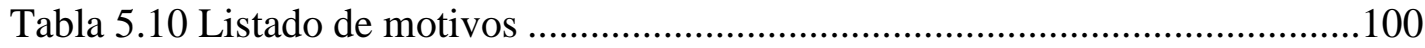

Tabla 5.11 Novel de proximidad de las áreas........................................................100

Tabla 5.12 Color de líneas para el diagrama relacional ........................................102

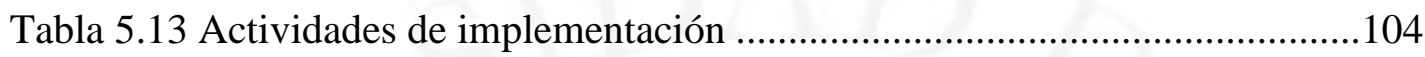

Tabla 6.1 Cantidad de trabajadores por año ........................................................ 110

Tabla 7.1 Inversión en trámites de constitución ......................................................111

Tabla 7.2 Inversión en garantía de alquiler ......................................................... 112

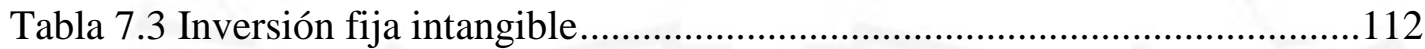

Tabla 7.4 Inversión en maquinaria y equipos ......................................................112

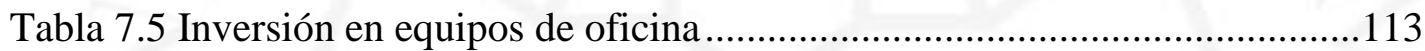

Tabla 7.6 Inversión en muebles y enseres ............................................................113

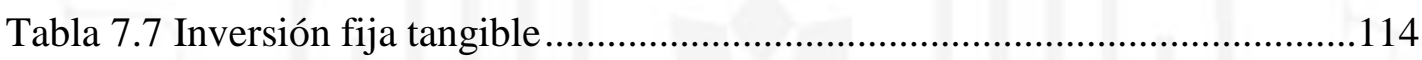

Tabla 7.8 Capital de trabajo para cubrir sueldos ...................................................114

Tabla 7.9 Capital de trabajo para cubrir servicios ................................................115

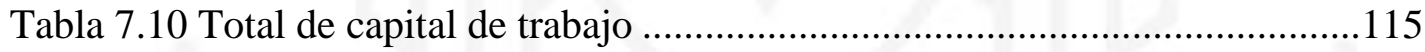

Tabla 7.11 Inversión total del proyecto ............................................................115

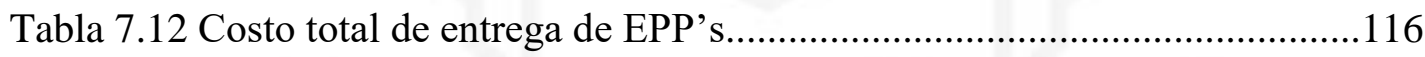

Tabla 7.13 Costo total de avisos, comisiones y otros ..........................................117

Tabla 7.14 Costo total de materiales del servicio ..................................................117

Tabla 7.15 Costo de los servicios de telefonía ...................................................117

Tabla 7.16 Costo de los servicios de terceros....................................................118

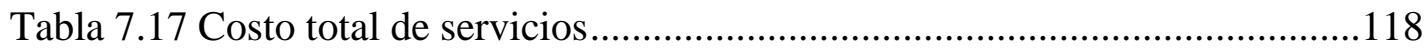

Tabla 7.18 Sueldos mano de obra directa............................................................119

Tabla 7.19 Sueldos mano de obra indirecta..........................................................120

Tabla 7.20 Costos de la mano de obra directa e indirecta ....................................121

Tabla 7.21 Presupuesto de ingresos por ventas ...................................................122

Tabla 7.22 Presupuesto de costos del servicio ....................................................122 
Tabla 7.23 Depreciación de activos tangibles y amortización de activos

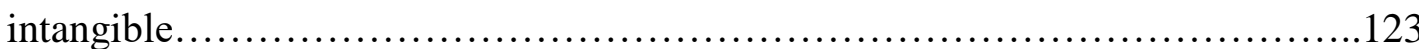

Tabla 7.24 Gastos por servicios básicos administrativos ......................................124

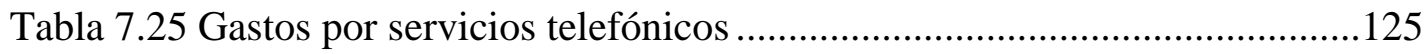

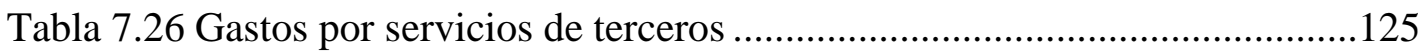

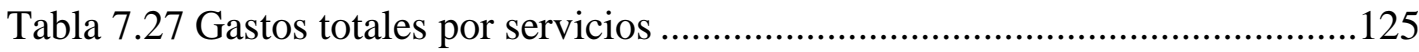

Tabla 7.28 Sueldos área administrativa ............................................................126

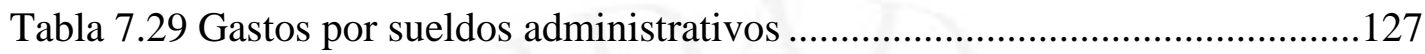

Tabla 7.30 Presupuesto de gastos operativos .........................................................128

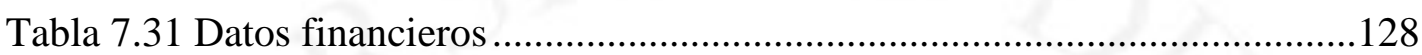

Tabla 7.32 Presupuestos de servicio a la deuda.....................................................129

Tabla 7.33 Estado de resultados 2019-2025 (expresado en S/.).............................131

Tabla 7.34 Flujo de fondos económicos (expresado en S/.) ..................................131

Tabla 7.35 Balance general al 01.2020 (expresado en S/)....................................132

Tabla 7.36 Flujo de fondos financieros (expresado en S/.) ....................................133

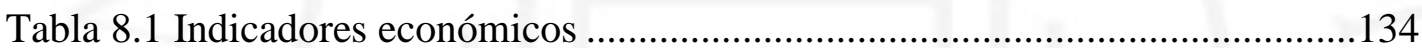

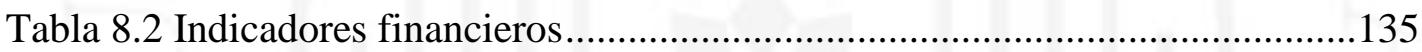

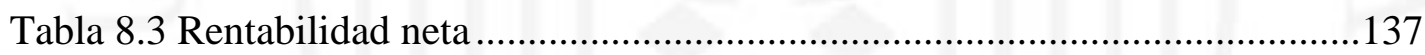

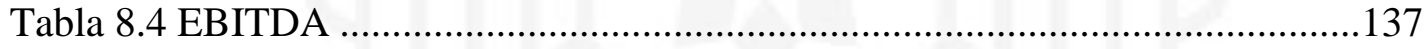

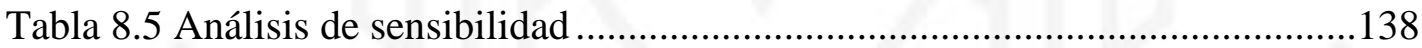

Tabla 9.1 Valor agregado del proyecto ............................................................. 140 


\section{ÍNDICE DE FIGURAS}

Figura 1.1 Ciclo de Deming ............................................................................

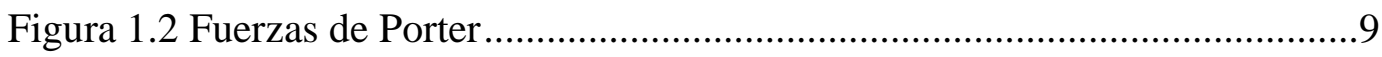

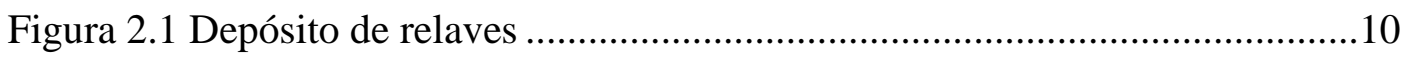

Figura 2.2 Prioridad en medidas de prevención y protección .................................13

Figura 2.3 ¿Cuántos trabajadores tiene su empresa? ............................................17

Figura 2.4 ¿Qué tipo de accidente tuvieron en el último año? ...............................18

Figura 2.5 ¿Tiene su empresa implementado un SGSST? ....................................18

Figura 2.6 ¿Estaría interesado en contratar los servicios para la Administración de su Sistema de Seguridad y Salud en el Trabajo? ..................................................19

Figura 2.7 Demanda proyectada con el método de regresión lineal.......................20

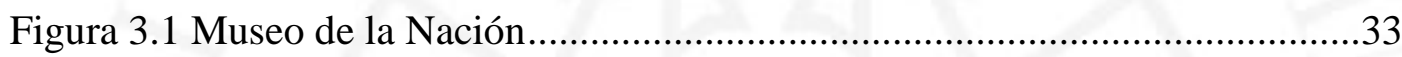

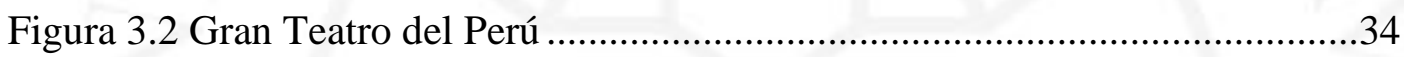

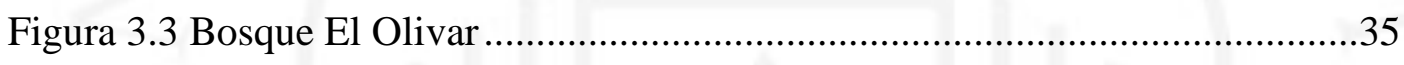

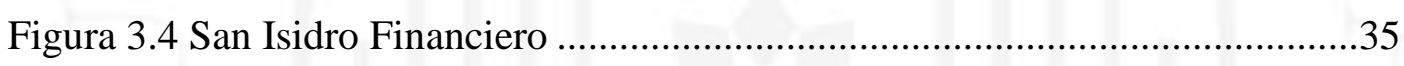

Figura 3.5 Parque de la Amistad "María Graña Ottone" ........................................36

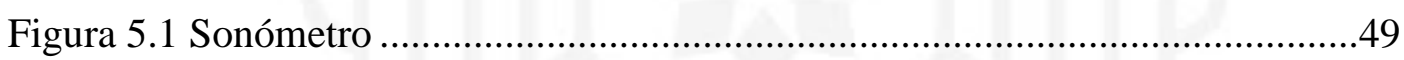

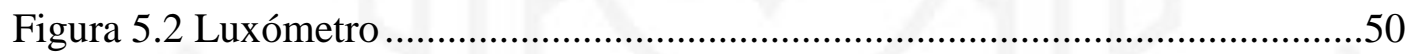

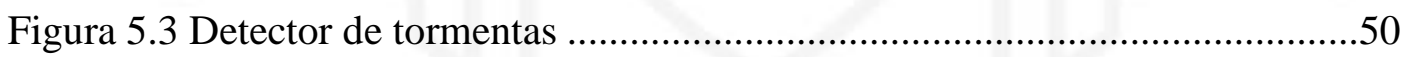

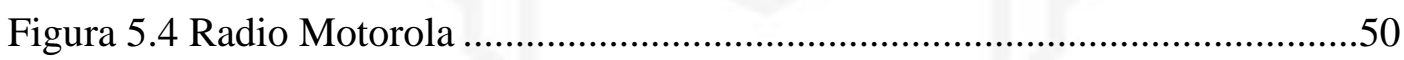

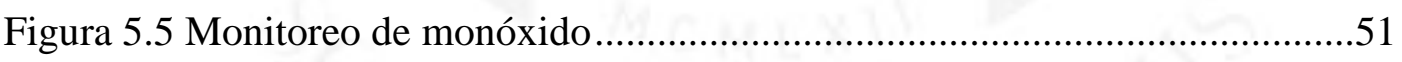

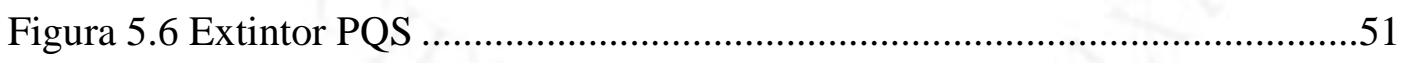

Figura 5.7 Flujograma de la confirmación del servicio de tercerización .................55

Figura 5.8 Flujograma de la implementación del Sistema de Gestión de Seguridad

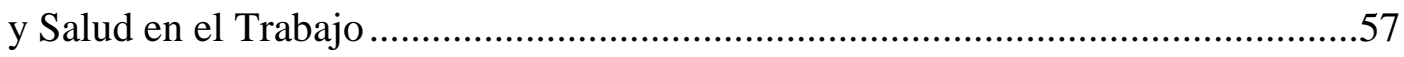

Figura 5.9 Flujograma de las actividades diarias realizadas por el equipo de

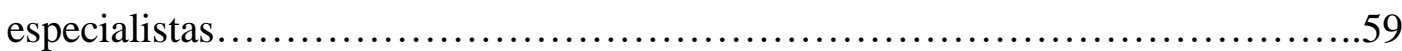

Figura 5.10 Flujograma para la solicitud de EPP'S al área logística de la empresa............................................................61

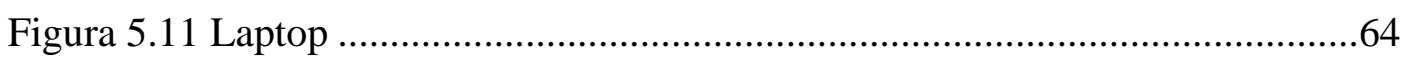




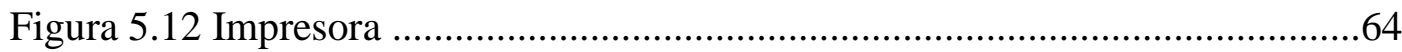

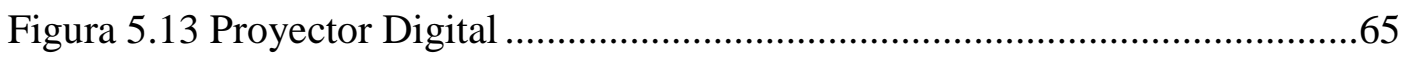

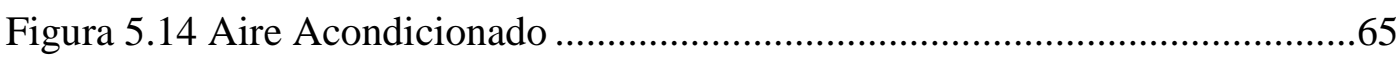

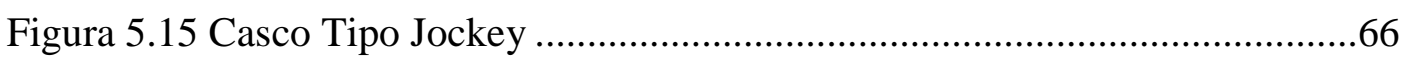

Figura 5.16 Botas de jebe con puntera de acero ..................................................66

Figura 5.17 Tafilete suspensión para casco ......................................................67

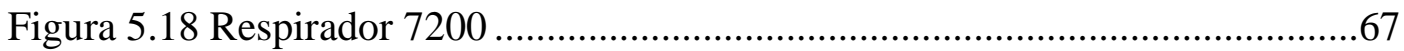

Figura 5.19 Guantes de cuero tipo mosquetero .................................................68

Figura 5.20 Mameluco naranja con cinta reflectiva ...........................................68

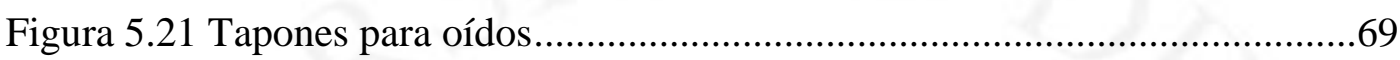

Figura 5.22 Arnés completo para respirador ....................................................69

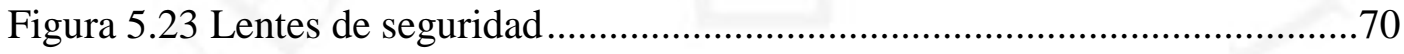

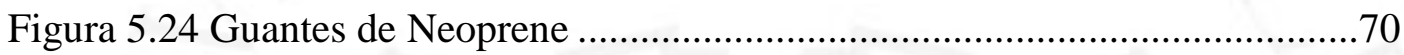

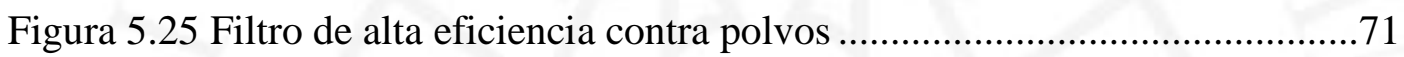

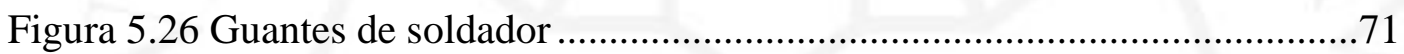

Figura 5.27 Correa de seguridad portalámparas de cuero ....................................72

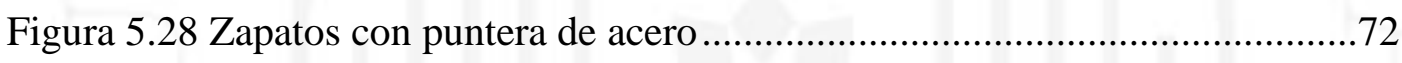

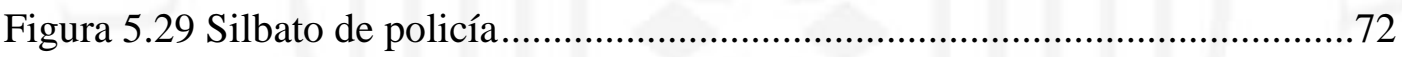

Figura 5.30 Luna clara para máscara de soldar ....................................................73

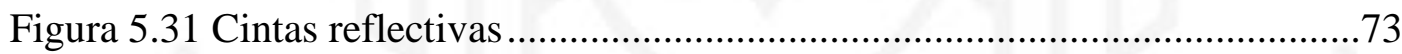

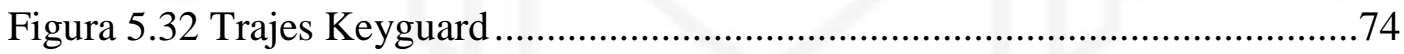

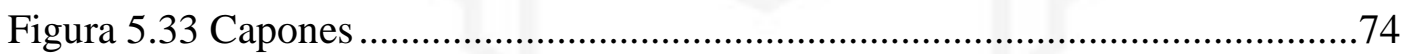

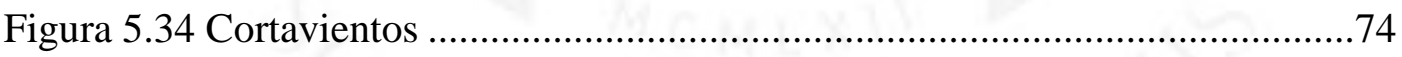

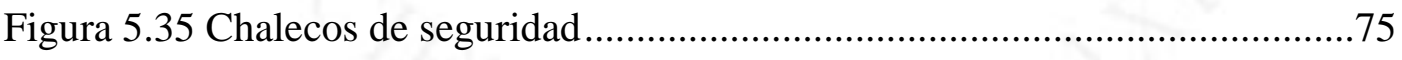

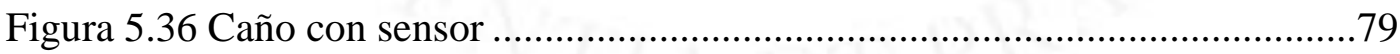

Figura 5.37 Tachos diferenciadores de sólidos ...................................................8

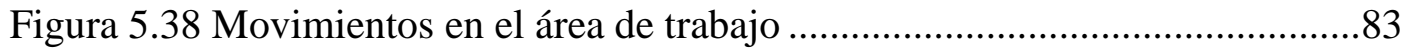

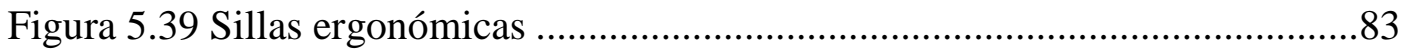

Figura 5.40 Uso de mouse y teclado independiente ...........................................84

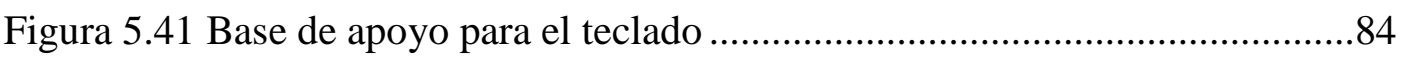

Figura 5.42 Postura adecuada durante el manejo de la laptop...............................85

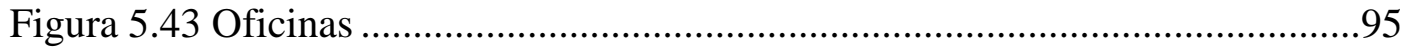




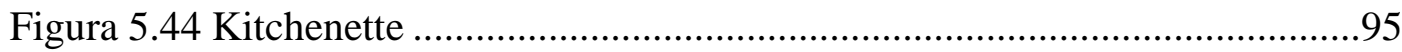

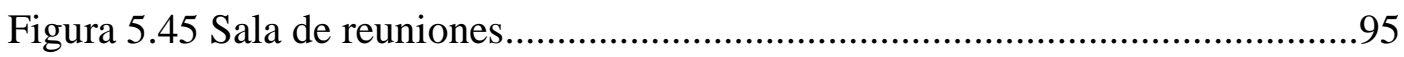

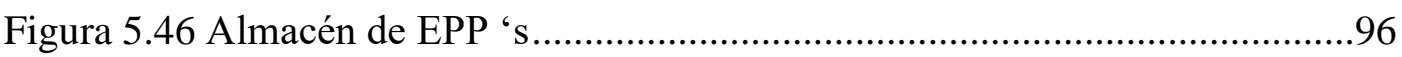

Figura 5.47 Señal de evacuación ....................................................................96

Figura 5.48 Estacionamientos internos.............................................................99

Figura 5.49 Plano de la oficina .......................................................................99

Figura 5.50 Tabla relacional para la disposición de las áreas ...................................101

Figura 5.51 Diagrama relacional para la disposición de áreas ................................102

Figura 5.52 Plano de las oficinas de la empresa......................................................103

Figura 5.53 Cronograma de implementación ...........................................................104

Figura 6.1 Organigrama de la empresa................................................................... 109 


\section{ÍNDICE DE ANEXOS}

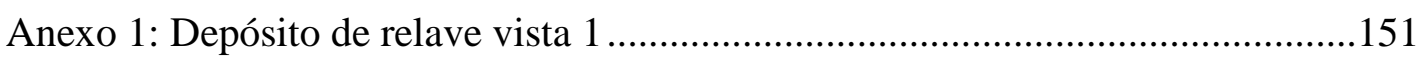

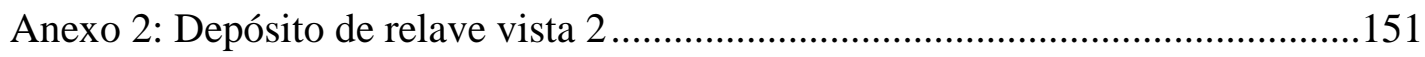

Anexo 3: Primera fase del proceso de recrecimiento de relavera............................151

Anexo 4: Segunda fase del proceso de recrecimiento de relavera .........................152

Anexo 5: Última fase del proceso de recrecimiento de relavera .............................152

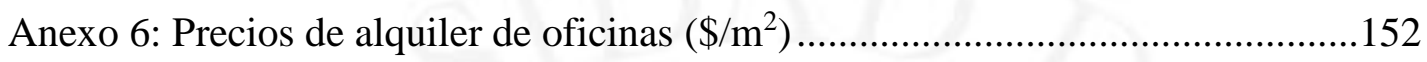

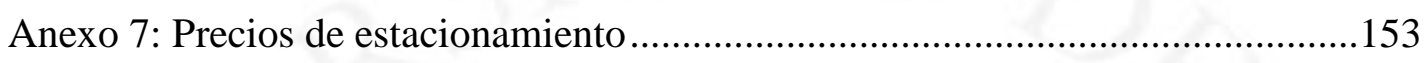

Anexo 8: Formato de encuesta para el estudio de mercado ....................................154

Anexo 9: Matriz de identificación de peligros y evaluación de riesgos (IPER)......155

Anexo 10: Muebles y enseres en la zona de trabajo...............................................157

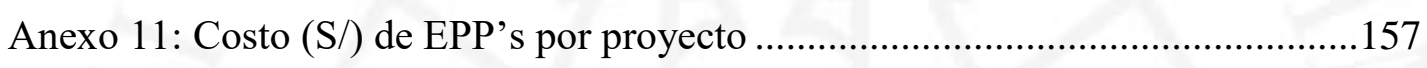

Anexo 12: Costo (S/) de servicios de telefonía móvil ............................................158

Anexo 13: Porcentaje de beneficios sociales mano de obra directa e indirecta ......159

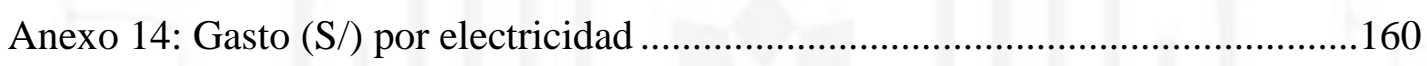

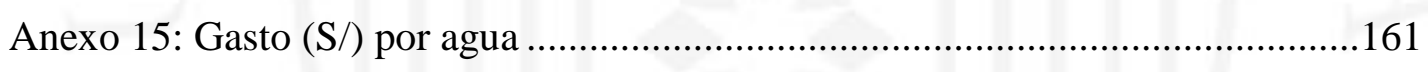

Anexo 16: Gasto (S/) por servicios de telefonía fijo .............................................162

Anexo 17: Gasto (S/) por servicios de telefonía móvil .........................................162

Anexo 18: Porcentaje de beneficios sociales sueldos administrativos ....................163

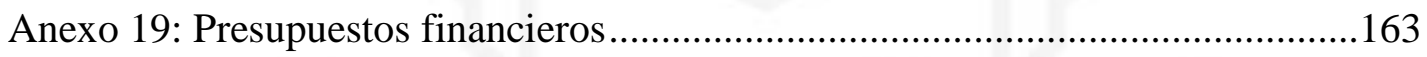




\section{RESUMEN EJECUTIVO}

El presente proyecto se enfoca en la administración de un sistema de seguridad y salud en el trabajo, que considera la implementación, monitoreo y control, tomando en cuenta la Ley N ${ }^{\circ} 29783$ "Ley de Seguridad y Salud en el Trabajo" y su modificatoria Ley $N^{\circ}$ 30222, cuyos reglamentos son Decreto Supremo N005-2012-TR y Decreto Supremo $\mathrm{N}^{\circ}$ 006-2014-TR respectivamente, las cuales mencionan que es obligatorio la implementación de sistemas de seguridad y salud en el trabajo para garantizar la protección del trabajador y su productividad en la empresa.

En el capítulo I se muestran los aspectos generales del estudio como objetivos generales y específicos, así como la hipótesis. Pese a la vigencia de la Ley $\mathrm{N}^{\circ} 29783$ (Ley de Seguridad y Salud en el Trabajo) desde el 2013, las estadísticas nos muestra que aún siguen existiendo accidentes en las empresas por ello es necesario fomentar una actitud proactiva y responsable hacia la seguridad en todos los niveles desde la participación de la gerencia hasta el personal, así como la adopción de medidas preventivas y correctivas para la seguridad y salud ocupacional. Por esta razón, el objetivo del proyecto cumple con la justificación social, técnica y económica.

En el capítulo II se muestra el estudio de mercado que detalla las principales características del servicio así como el área de influencia, que es la ciudad de Lima, asimismo, se analiza la demanda conformada por empresas contratistas mineras cuya actividad es la construcción y crecimiento de depósitos de relave, para el año 2025 la demanda será de 6 empresas, la cual se obtuvo mediante estudios cualitativos y cuantitativos.

Determinada la demanda del proyecto se realiza la localización del servicio en el capítulo III mediante el método ranking de factores, en el que se consideró variables como cercanía a las oficinas de clientes potenciales, seguridad ciudadana, disponibilidad de áreas de oficina, costo por $\mathrm{m}^{2}$, facilidad de trámites. Teniendo en cuenta los factores mencionados se decidió instalar la empresa en el distrito de San Isidro.

En el capítulo IV se dimensionó el servicio tomando variables como el mercado, recursos, tecnología y punto de equilibrio. Se obtuvo como factor determinante el 
mercado ya que técnicas más sofisticadas de recuperación y reutilización de relaves de los clientes conllevan a duplicar aproximadamente el periodo de duración de una relavera antes de iniciar su proceso de recrecimiento, lo cual frena la continuidad de servicios que se podría tener. Considerando ello se estima que al término del proyecto se podría alcanzar hasta un máximo de 2 equipos (10 especialistas) de seguridad y salud ocupacional.

En el capítulo V se detalla la tecnología a utilizar para el servicio, además se describe el proceso para la confirmación del servicio de la empresa, así como 3 procesos complementarios del servicio. Se determina el número y características de máquinas, equipos de seguridad y mano de obra que se requiere para la atención, para el 2025 se tendrán 2 equipos de especialistas trabajando en 3 proyectos al año cada uno. Finalmente, se muestra la disposición general y detallada de las áreas de la empresa, la oficina en Lima tendrá un área de $14.5 \mathrm{~m}$ x $12.4 \mathrm{~m}$.

La estructura organizacional del proyecto se establece en el capítulo VI, así como los requisitos del personal. Se iniciará con 4 áreas funcionales (administración, comercial, logística y operacional), para el 2025 se tendrá un total de 16 trabajadores incluyendo los equipos de especialistas.

En el capítulo VII se calcula la inversión necesaria para el proyecto, la cual asciende a $S / 255,466.97$, posteriormente se calcularon los costos totales que incluye materiales, servicios y mano de obra directa e indirecta; también se calcularon los ingresos por ventas y egresos como gastos administrativos y operativos para obtener los flujos económicos y financieros. En el capítulo VIII se analiza los principales indicadores económicos (VAN de S/41,293.53 y un TIR de 23.34\%) y financieros (VAN de S/82,378.40 y un TIR de 34.65\%), en ambos casos se tiene un valor actual neto positivo así como una rentabilidad mayor al costo de oportunidad, lo que convierte al proyecto en rentable superando las expectativas del inversionista. También se analizó la sensibilidad del proyecto considerando variaciones en los ingresos en un escenario optimista $(+3 \%)$ y pesimista $(-3 \%)$.

Por último, en el capítulo IX se evalúa el impacto social del proyecto en la zona de influencia. Se analiza indicadores como la densidad de capital e intensidad de capital y se obtiene impactos negativos mínimos, al contrario el mayor impacto positivo es 
fomentar una cultura de prevención de riesgos en las empresas, este cambio de mentalidad incluye desde la gerencia hasta los trabajadores.

Palabras clave: Servicio de tercerización / Administración del sistema de Gestión de Seguridad y Salud en el trabajo / Disposición de relaves mineros 


\section{EXECUTIVE SUMMARY}

This project focuses on the administration of an occupational safety and health system, which considers the implementation, monitoring and control, taking into account Law No. 29783 "Law on Occupational Safety and Health" and its amendment Law No. 30222, whose regulations are Supreme Decree No. 005-2012-TR and Supreme Decree No. 006-2014-TR respectively, which indicate the obligation to implement occupational health and safety systems to ensure the protection of the life, health and well-being of workers, but above all, to generate a culture of occupational risk prevention in companies and incorporate the concept of continuous improvement, which has a positive impact on their performance and productivity of the company.

In Chapter I shows the general aspects of the study as general and specific objectives, as well as the hypothesis. Despite the validity into force of law No. 29783 (Safety and Health at work law) from 2013, the statistics shows us that there are yet still accidents at companies therefore it is necessary to promote a proactive and responsible attitude to safety at all levels from the management participation to the staff participation, as well as the adoption of preventive and corrective measures for safety and occupational health. For this reason, the objective of the project complies the social, technical and economic justification.

Chapter II shows the market study detailing the main characteristics of the service and the area of influence, which is the city of Lima, and also analyzes the demand from mining contractors whose activity is the construction and growth of tailings deposits, for year 2025 the demand will be 6 companies, which was obtained through qualitative and quantitative studies.

Once the demand for the project is determined, the location of the service is determined in chapter III by means of the ranking method of factors, in which variables such as proximity to the offices of potential clients, citizen security, availability of office areas, cost per $\mathrm{m} 2$, ease of procedures was considered. Taking into account the factors mentioned above, it was decided to set up the company firm in the district of San Isidro. 
In Chapter IV the service was sized taking variables such as the mart, resources, technology and breakeven point. The mart was obtained as a determining factor since more sophisticated techniques of recovery and reuse of tailings lead to approximately double the duration of a tailings before starting its re-growth process, which slows the continuity of services that could be had. Considering this, it is estimated that up to 2 teams (10 specialists) of occupational health and safety could be reached at the end of the project.

Chapter $\mathrm{V}$ details the technology to be used for the service, and also describes the process for confirming the consultancy service, as well as complementary four service processes. The number of machines, equipment and manpower required for the care is determined, 2 teams of engineers working on 3 projects per year each shall be taken for the year 2025. Finally, the general and detailed layout of the service is shown.

The organizational structure of the project is set out in Chapter VI, as well as the staff requirements. It will start with 4 functional areas (Administration, commercial, logistics and operational), 2025 will have a total of 16 employee including the teams of engineers.

Chapter VII calculates the investment needed for the project, which amounts to $\mathrm{S} / 255,466.97$, to then see the total cost that includes materials, services and direct and indirect labor, it can also calculate income from sales and expenses as administrative and operating expenses to obtain economic and financial flows. Chapter VIII analyzes the main economic (NPV of S/41,293.53 and an IRR of 23.34\%) and financial (NPV of S/82,378.40 and an IRR of 34.65\%) indicators, in both cases you have a positive net present value as well as rising to the opportunity cost of profitability, making the project profitable exceeding the expectations of investors. Also it was analyzed the sensitivity of the project considering income variations in the optimistic $(+3 \%)$ and pessimistic $(-3 \%)$ view.

Finally, chapter IX assesses the social impact of the project in the area of influence. Analyze indicators such as capital density and capital intensity and obtain negative negative results, on the contrary the greatest positive impact is to foster a culture of risk prevention in companies, this change of mentality includes from management to workers. 
Keywords: Outsourcing service / Administration of the Occupational Health and Safety Management system / Mining tailings provision 


\section{INTRODUCCIÓN}

En la actualidad la competitividad es uno de los pilares que marca la permanencia de las empresas en el mercado, las mismas que se han enfocado en la importancia del aprovechamiento máximo de los recursos, entre ellos y más destacado el recurso humano como factor relevante para la producción de bienes y servicios. A nivel mundial el enfoque de riesgos en diferentes sectores de las industrias es un tema de gran importancia ya que de no cumplirse las condiciones adecuadas de trabajo de los colaboradores no solo peligran su vida y salud, sino también la sostenibilidad de sus familias.

La industria minera es una de las actividades más importantes y productivas del Perú con un aporte del $20 \%$ a los ingresos fiscales y $15 \%$ al PBI nacional, además contribuye con la generación de empleo y desarrollo del país; sin embargo, es también una de las actividades más riesgosas debido a la alta incidencia de accidentes de trabajo y enfermedades ocupaciones que afectan al personal, equipos y medio ambiente como consecuencia del proceso que sigue. La Ley N²9783 "Ley de Seguridad y Salud en el Trabajo" y su modificatoria Ley $N^{\circ} 30222$, cuyos reglamentos son Decreto Supremo $\mathrm{N}^{\circ} 005-2012-\mathrm{TR}$ y Decreto Supremo $\mathrm{N}^{\circ} 006-2014-\mathrm{TR}$ respectivamente indican la obligatoriedad de implementar sistemas de seguridad y salud en el trabajo para garantizar la protección de la vida, la salud y el bienestar de los trabajadores, pero sobretodo generar una cultura de prevención de riesgos laborales en las empresas e incorporar el concepto de mejoramiento continuo.

El presente proyecto se enfocará en la creación de una empresa que brinde el servicio de la administración del sistema de seguridad y salud en el trabajo, que considera la implementación, monitoreo y control, tomando en cuenta las leyes ya mencionadas, a fin de controlar los riesgos a los que están expuestos los trabajadores del rubro minero, lo cual impacta positivamente en su desempeño y productividad de las empresas mineras. 


\section{CAPITULO I: ASPECTOS GENERALES}

\subsection{Problemática}

Considerando que la industria minera en el Perú es una de las que tiene actividades con mayor riesgo se requiere de una disciplina operativa que permita fomentar una cultura preventiva, pero sobretodo implementar un sistema de gestión de seguridad y salud en el trabajo. Según estadísticas del Ministerio de Energía y Minas a mayo del 2019 se han registrado 13 accidentes mortales, de los cuales 6 pertenecen a empresas titulares mineras, 4 pertenecen a empresas contratistas mineras y 3 a empresas conexas. Ante esto, existe la necesidad de compromiso de las empresas sobre temas de seguridad y salud ocupacional de sus trabajadores y sistemas que revaloran el capital humano brindando un mejor lugar de trabajo.

La Ley $N^{\circ} 29783$ de Seguridad y Salud en el Trabajo promulgada en el año 2011 decreta la obligatoriedad de los sistemas de gestión de seguridad y salud en todas las empresas y directrices generales sobre su funcionamiento, además señala aspectos específicos que deben cumplir los sistemas de gestión, el Decreto Supremo N ${ }^{\circ} 005$ 2012-TR reglamento de la ley mencionada presenta guías para la implementación de los sistemas de gestión y la elaboración de reglamentos internos de seguridad y salud. La Ley de Seguridad y Salud en el Trabajo tiene como objetivo promover una cultura de prevención de riesgos laborales en el país; para ello, cuenta con el deber de prevención de los empleadores, el rol de fiscalización y control del Estado y la participación de los trabajadores y sus organizaciones sindicales, quienes, a través del diálogo social, velan por la promoción, difusión y cumplimiento de la normativa sobre la materia (Ley $\mathrm{N}^{\circ}$ 29783, 2011). 
Tabla 1.1

Accidentes mortales (2000-2019)

\begin{tabular}{|c|c|c|c|c|c|c|c|c|c|c|c|c|c|}
\hline ANo & ENE. & FEB. & MAR. & ABR. & MAY. & JUN & JUL. & AGO. & SEP. & OCT. & NOV. & DIC. & Total \\
\hline 2019 & 4 & 2 & 0 & 4 & 3 & & & & & & & & 13 \\
\hline 2018 & 2 & 1 & 2 & 5 & 3 & 2 & 1 & 3 & 2 & 2 & 3 & 1 & 27 \\
\hline 2017 & 5 & 5 & 3 & 2 & 6 & 1 & 3 & 4 & 2 & 8 & 0 & 2 & 41 \\
\hline 2016 & 4 & 3 & 3 & 1 & 6 & 2 & 2 & 3 & 4 & 1 & 2 & 3 & 34 \\
\hline 2015 & 5 & 2 & 7 & 2 & 0 & 2 & 1 & 2 & 2 & 3 & 3 & 0 & 29 \\
\hline 2014 & 6 & 1 & 1 & 1 & 1 & 3 & 7 & 2 & 2 & 0 & 1 & 7 & 32 \\
\hline 2013 & 4 & 6 & 5 & 6 & 1 & 4 & 4 & 4 & 5 & 2 & 4 & 2 & 47 \\
\hline 2012 & 2 & 6 & 8 & 2 & 4 & 2 & 5 & 5 & 3 & 8 & 4 & 4 & 53 \\
\hline 2011 & 4 & 8 & 2 & 5 & 6 & 5 & 4 & 5 & 4 & 5 & 1 & 3 & 52 \\
\hline 2010 & 5 & 13 & 1 & 6 & 5 & 9 & 6 & 4 & 3 & 4 & 4 & 6 & 66 \\
\hline 2009 & 4 & 14 & 6 & 2 & 3 & 8 & 6 & 4 & 2 & 1 & 4 & 2 & 56 \\
\hline 2008 & 12 & 5 & 7 & 6 & 3 & 5 & 6 & 6 & 5 & 3 & 3 & 3 & 64 \\
\hline 2007 & 5 & 6 & 7 & 3 & 7 & 6 & 4 & 6 & 5 & 6 & 5 & 2 & 62 \\
\hline 2006 & 6 & 7 & 6 & 3 & 6 & 5 & 6 & 5 & 4 & 9 & 4 & 4 & 65 \\
\hline 2005 & 3 & 8 & 6 & 6 & 6 & 3 & 5 & 3 & 7 & 5 & 8 & 9 & 69 \\
\hline 2004 & 2 & 9 & 8 & 5 & 2 & 9 & 1 & 3 & 4 & 7 & 5 & 1 & 56 \\
\hline 2003 & 4 & 8 & 5 & 7 & 5 & 3 & 4 & 5 & 3 & 3 & 4 & 3 & 54 \\
\hline 2002 & 20 & 2 & 4 & 6 & 5 & 5 & 4 & 6 & 4 & 8 & 8 & 1 & 73 \\
\hline 2001 & 2 & 9 & 5 & 5 & 8 & 3 & 8 & 8 & 4 & 5 & 4 & 5 & 66 \\
\hline 2000 & 6 & 4 & 2 & 3 & 3 & 6 & 8 & 0 & 0 & 7 & 8 & 7 & 54 \\
\hline Total & 105 & 119 & 88 & 80 & 83 & 83 & 85 & 78 & 65 & 87 & 75 & 65 & 1,013 \\
\hline
\end{tabular}

Fuente: Ministerio de Energía y Minas (2019)

En la tabla 1.1 se muestran las estadísticas de los accidentes mortales que hubo entre los años 2000 y mayo del 2019, se puede resaltar que desde que entró en vigencia la Ley $N^{\circ} 29783$ (Ley de Seguridad y Salud en el Trabajo) y con la creación de la Superintendencia Nacional de Fiscalización Laboral (SUNAFIL) a través de la Ley $\mathrm{N}^{\circ}$ 29981 en el año 2013 se empezó a reducir las cifras; sin embargo, aún falta lograr más, es necesario comenzar a fomentar una actitud proactiva y responsable hacia la seguridad en todos los niveles, contando con la participación del personal en las actividades preventivas; así como inversión de tiempo y esfuerzo para mantener la empresa activa en lo que refiere a análisis de riesgos, adopción de medidas preventivas y correctivas y aporte de ideas para la mejora continua en seguridad y salud ocupacional. La implementación de sistemas de Gestión de Seguridad y Salud en el trabajo representan una herramienta ideal para administrar los riesgos ya que otorgan una forma estructurada para que las empresas lo puedan realizar, pero también implica que la Dirección de la Empresa esté totalmente comprometida mediante una Política en definir objetivos que se deben conseguir firmemente.

La industria de la minería en el Perú abarca: empresas titulares mineras, empresas contratistas mineras y empresas conexas, ante el marco legal de seguridad y salud, la mayoría de empresas contratistas optan por contratar a Ingenieros de 
Seguridad para elaborar los planes de seguridad y salud de los proyectos que van a ejecutar pero no implementan adecuadamente un sistema de gestión de seguridad y salud, lo que conlleva a una mala práctica pues sin un sistema las empresas no pueden evaluar su rendimiento y mejora en la seguridad de sus operaciones, así como tampoco pueden fomentar una cultura de prevención en sus trabajadores; además de que la ley establece responsabilidad civil y penal para la alta dirección de las empresas.

\subsection{Objetivos de la investigación}

\section{Objetivo general}

Demostrar la viabilidad de mercado, técnica, económica y financiera para la creación de una empresa dedicada a brindar servicios de implementación, monitoreo y control de un sistema de gestión de seguridad y salud en el trabajo en la actividad de recrecimiento de depósitos de relave, realizado por empresas contratistas mineras.

\section{Objetivos específicos}

- Realizar un estudio de mercado que permita definir la viabilidad del proyecto y así poder identificar y analizar al público objetivo y la competencia.

- Evaluar la viabilidad técnica del proyecto evaluando la disponibilidad de herramientas y métodos, así como factor humano especializado.

- Determinar los procesos involucrados en el proyecto.

- Evaluar los costos asociados a la instalación de este proyecto para estudiar la viabilidad de la puesta en marcha del proyecto.

- Investigar sobre las Leyes Nacionales y Decretos Supremos vigentes en temas de seguridad y salud en el trabajo para asegurar su cumplimiento en el servicio que se brindará.

- Determinar si el proyecto es económica y financieramente viable.

\subsection{Justificación del tema}

\section{Justificación Técnica}

Este proyecto es técnicamente viable por la existencia de herramientas necesarias para realizar una implementación de Sistema de Gestión de Seguridad y Salud en el Trabajo 
(SGSST) explicadas en la Ley $\mathrm{N}^{\circ}$ 29783, DS $\mathrm{N}^{\circ}$ 005-2012-TR y modificatorias. La implementación se basa en el ciclo de mejora continua PHVA (Planear, hacer, verificar y actuar) popularizada por Edward Deming e involucra una serie de etapas (ver la figura 1.1) que se detallarán más adelante, hasta llegar a la plena operatividad.

Figura 1.1

Ciclo de Deming

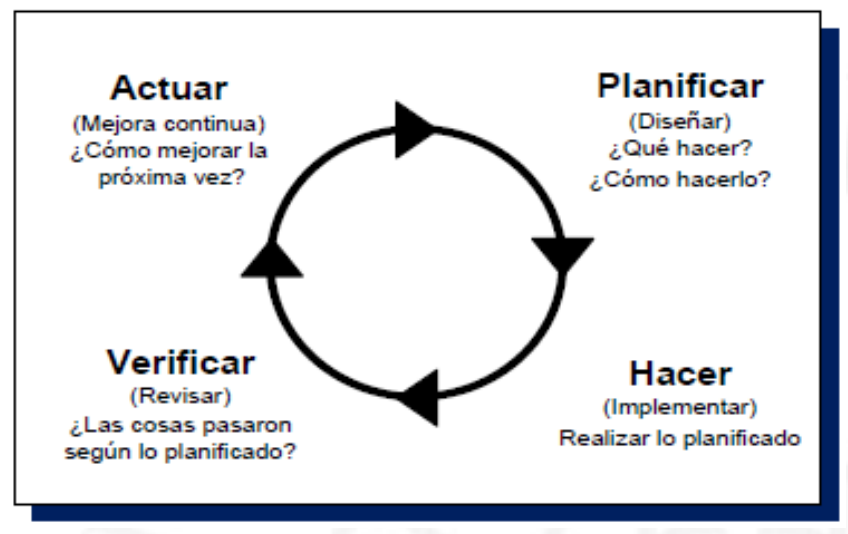

Fuente: Gestipolis (2005)

\section{Justificación Económica}

Se espera alcanzar resultados rentables ya que es necesario que todas las empresas cuenten con una implementación de gestión de seguridad y salud en el trabajo, además la mayoría de empresas contratistas mineras destinan sumas considerables en la gestión de seguridad para evitar pagar multas por incumplimiento de temas legales, indemnizaciones en caso de accidentes y mantener una buena imagen.

\section{Justificación Social}

Con el presente proyecto se pretende promover una cultura de prevención de riesgos laborales en el país, generar conciencia de lo esencial que es contar con un sistema de gestión de implementación de seguridad y salud por parte de las empresas a fin de evitar el aumento de accidente e incidentes, además de la generación de puestos de trabajo que beneficien a las familias peruanas.

\subsection{Hipótesis de trabajo}

La creación de una empresa que brinde servicios de implementación, monitoreo y control de un sistema de gestión de seguridad y salud en el trabajo en la actividad de recrecimiento de relavera realizada por una empresa contratista minera es factible, pues 
existe un mercado que va a aceptar el servicio y además es técnica, económica y financieramente viable.

\subsection{Marco referencial de la investigación}

Para realizar el análisis de la investigación se consultaron diferentes tesis, en las cuales se encontraron similitudes y diferencias con el proyecto planteado.

a) Adriana Barúa, Alejandra León - Gambetta. "Estudio de prefactibilidad para la instalación de una empresa consultora sobre salud ocupacional en plantas de manufactura". Lima, 2015.

La similitud de la tesis con el presente proyecto es acerca de los parámetros necesarios para implementar una empresa que brinda el servicio de gestionar un sistema de salud de los trabajadores. Sin embargo, se enfoca en temas relacionados a la salud ocupacional especializada en ergonomía para plantas de manufactura en Lima Metropolitana.

b) Miguel Quispe. "Sistema de gestión de seguridad y salud ocupacional para una empresa en la industria metalmecánica”. Lima, 2014.

La tesis hace referencia al igual que el proyecto en la implementación de un sistema de seguridad y salud en el trabajo basándose en la Ley $\mathrm{N}^{\circ} 29783$ y la norma OHSAS 18001. La diferencia es que la tesis está orientada a una empresa de manufactura perteneciente al sector metalmecánica.

c) Dennis Alejo. "Implementación de un sistema de gestión de seguridad y salud ocupacional en el rubro de construcción de carreteras”. Lima, 2012.

La tesis muestra la importancia de la implementación de un sistema de gestión de seguridad y salud ocupacional en el rubro de construcción de carreteras tomando como ejemplo la empresa EPROMING SRL y basándose en la Ley $\mathrm{N}^{\circ}$ 29783 y norma técnica G.050 “Seguridad Durante La Construcción”.

d) José Pérez. "Sistema de gestión en seguridad y salud ocupacional aplicado a empresas contratistas en el sector económico minero metalúrgico". Lima, 2007. La similitud entre la tesis y el presente proyecto es que ambas se centran en la industria de la minería y en el papel importante que cumplen las empresas contratistas mineras, la tesis se enfoca en poner al alcance de los interesados un 
Sistema de Seguridad y Salud Ocupacional para la evaluación y análisis de riesgos basado en especificaciones internacionales técnicas como es la OHSAS 18001, ya que en el año en que se realizó la tesis aún no era promulgada la Ley N²9783 "Ley de Seguridad y Salud en el Trabajo".

\subsection{Análisis del sector}

\section{- Riesgo de ingreso de competidores potenciales}

Se ha determinado que para este sector el ingreso de nuevos competidores representa un riesgo medio, esto se debe a lo siguiente:

- $\quad$ No existen barreras legales, según la Ley N² 29783 todas las empresas están en la obligación de tener un sistema de implementación de gestión de seguridad y salud en el trabajo, especialmente aquellas que representan un alto riesgo como lo es la actividad minera; por lo que el gobierno incentiva este tipo de servicios y se espera que en los próximos años se incrementen. Asimismo, el Decreto Supremo $\mathrm{N}^{\circ}$ 006-2014-TR reglamento de la Ley $\mathrm{N}^{\circ}$ 30222 menciona en el Artículo 26A la posibilidad de contratar una empresa especializada para la gestión, implementación, monitoreo y cumplimiento de las disposiciones legales y reglamentarias sobre seguridad y salud en el trabajo, pero sin liberar a la empresa principal de su obligación de acreditar ante la autoridad competente el cumplimiento de dichas obligaciones (Decreto Supremo Nº06, 2014)

- El requerimiento básico para brindar el servicio propuesto es la mano de obra calificada; según el Decreto Supremo Nº 024 esta tiene que cumplir una serie de requisitos para que un ingeniero de seguridad sea considerado apto.

\section{- Poder de negociación de proveedores}

En el presente proyecto los potenciales proveedores serán referidos a los vendedores de EPP's y señalizaciones; si bien es cierto, el volumen de compra de la empresa dependerá de la cantidad de trabajadores que laboren en la actividad de construcción de relavera por lo que en algún momento se tendrá que negociar cambios de precios con los proveedores, también se debe 
mencionar que existe en el mercado nacional una amplia gama de empresas que proveen dichos materiales como: Sekur Perú, 3M, MSA, entre otros. Debido a lo mencionado, este sector representa un poder de negociación medio.

\section{- Poder de negociación de compradores}

Este sector representa un poder medio, ya que debido a la Ley de Seguridad y Salud en el Trabajo vigente y la existencia de una entidad de fiscalización como la SUNAFIL que con las inspecciones multan y sancionan a las empresas, los clientes (empresas contratistas mineras) necesitarán buscar servicios como el que propone el presente proyecto.

\section{- Amenaza de productos sustitutos}

El único sustituto para el servicio que se ofrece es que las empresas contratistas mineras puedan disponer de sus propios especialistas, Ingenieros de Seguridad, para que implementen su sistema de gestión de seguridad y salud; sin embargo, su participación estará limitado por las jefaturas superiores de la empresa contratista priorizando en todo momento la producción sobre la seguridad (mala práctica), ya que según organigrama los ingenieros de seguridad están subordinados bajo la línea de mando operativo de la empresa contratista minera. Caso contrario con la tercerización se elimina la subordinación porque de por medio se encuentra el cumplimiento tajante de un contrato firmado por la gerencia de la empresa contratista.

Otro punto a favor para tener una empresa tercerizadora del sistema de gestión de seguridad y salud se refleja en la disminución de costo para la empresa contratista minera y una mayor eficiencia en el logro de objetivos, con ello la única preocupación de la empresa contratista es el cumplimiento de su programa operativo con la empresa titular minera.

\section{- Rivalidad entre firmas establecidas en el mercado}

Respecto a esta fuerza se ha determinado una rivalidad media, ya que en la actualidad existen empresas consultoras que brindan asesorías para la implementación de la Ley de seguridad y salud en el trabajo como: CASTEL MONTE ASOCIADOS, MCE CONSULTORES ASOCIADOS, SST Asesores SAC, SSMA Perú, AGS CONSULTING SAC y otros; sin embargo, el factor de 
diferenciación del presente proyecto es que nuestro servicio plantea una tercerización para la administración de ejecución de los sistemas de seguridad y salud en el trabajo.

Figura 1.2

Fuerzas de Porter

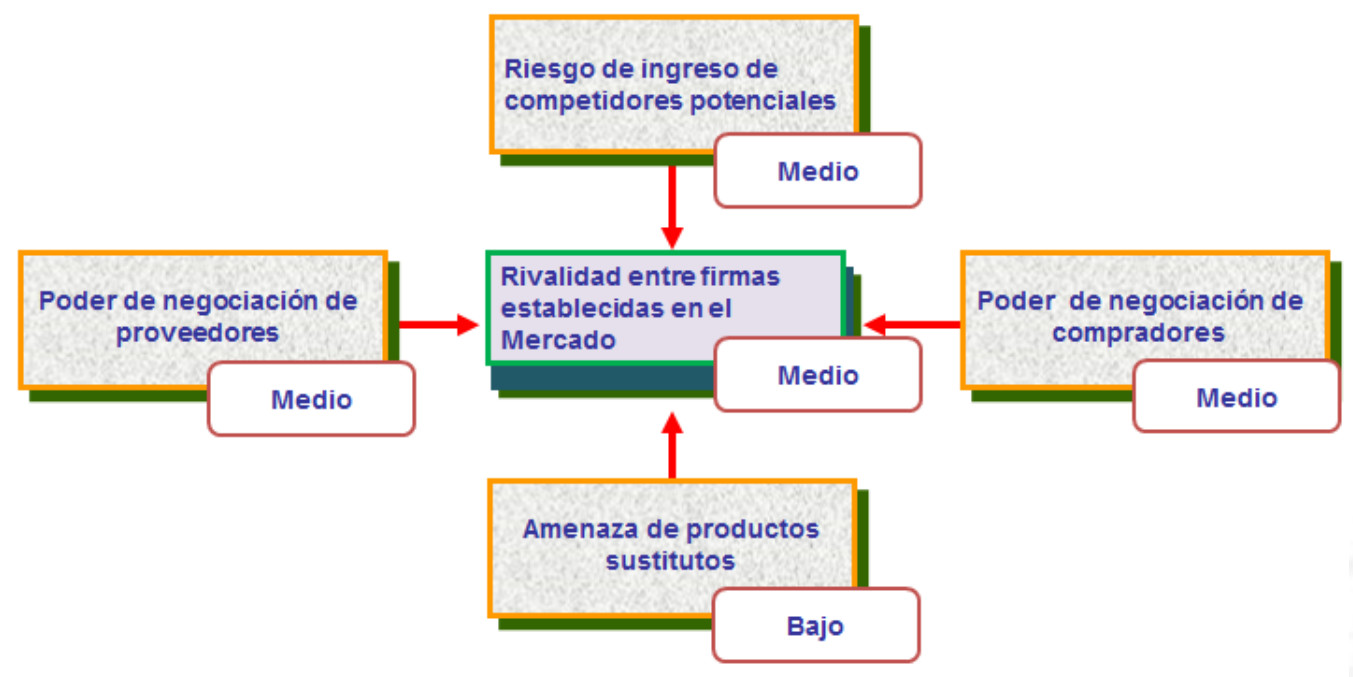

Elaboración propia 


\section{CAPITULO II: ESTUDIO DE MERCADO}

\subsection{Aspectos generales del estudio de mercado}

\subsubsection{Definición del servicio}

El presente trabajo se enfoca en la formación de una empresa que brinda el servicio de tercerización de la administración del sistema de Gestión de Seguridad y Salud en el Trabajo, que contempla la implementación, monitoreo y control en la actividad: Construcción y recrecimiento de depósitos de relave desde una cota de referencia realizada, generalmente, por empresas contratistas mineras.

Los depósitos o tranques de relaves se construye para contener en forma segura los relaves ${ }^{1}$ provenientes de una planta de beneficio de minerales. Está formado por un muro de contención, construido con la fracción gruesa del relave (o con material de préstamo proveniente de canteras). En el interior los sólidos finos sedimentan y en la superficie se forma una laguna de aguas clara, las cuales son recuperadas mayoritariamente y otra parte se evapora.

Figura 2.1

Depósito de relaves

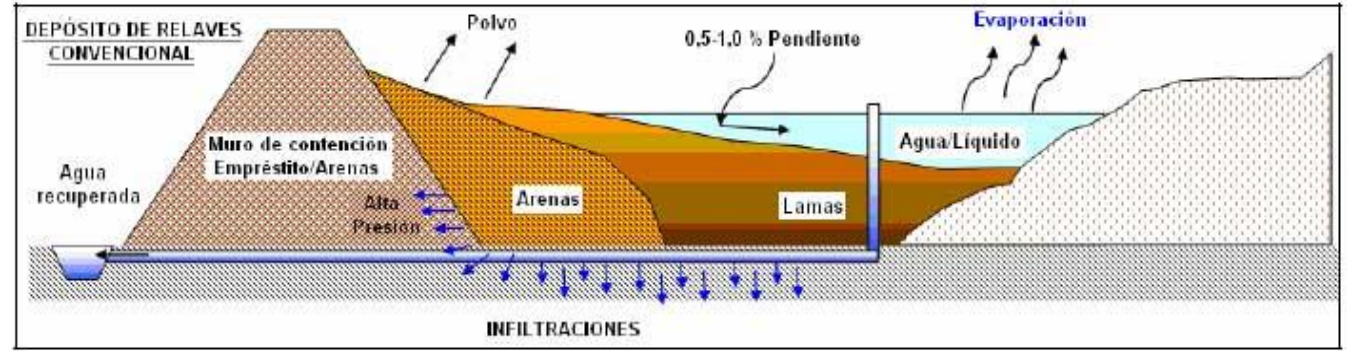

Fuente: Bligo (2016)

Se determinó la actividad mencionada porque la disposición de relaves es identificada como la más importante de los impactos ambientales en muchos proyectos mineros, pero también es una continua preocupación por mantener áreas apropiadas

\footnotetext{
${ }^{1}$ Conjunto de desechos tóxicos de la concentración de minerales, constituido por una mezcla de rocas molidas, agua y minerales de ganga (no usado), contienen altas concentraciones de químicos y elementos que alteran el medio ambiente (https://es.wikipedia.org/wiki/Relave).
} 
para su disposición, es por eso que la gran mayoría de empresas contratistas mineras realizan el recrecimiento de relaveras cada 2 años en promedio. Ante esto, se pretende generar un sistema de gestión eficaz para disminuir la cantidad de eventos ya sea accidentes o incidentes y enfermedades ocupacionales y al mismo tiempo que cumpla con la legislación que se exige a las empresas en prácticas proactivas y preventivas, mediante la identificación de peligros y evaluación de control de riesgos para brindar bienestar y seguridad a los trabajadores, y también fomentar una cultura de prevención de riesgos.

\subsubsection{Principales características del servicio}

\subsubsection{Clasificación CIUU}

El código CIIU clasifica las actividades económicas de acuerdo a 4 niveles: Sección, División, Grupo y Clase, con el objetivo de analizar estadísticamente las economías nacionales a nivel mundial.

De acuerdo a ello, para el trabajo de investigación se ha determinado los siguientes niveles:

- Sección: M

- División: 74

- $\quad$ Grupo: 749

- $\quad$ Clase: 7490

La sección M contiene actividades profesionales, científicas y técnicas, las cuales requieren un alto nivel de capacitación y ponen a disposición de los usuarios conocimientos y aptitudes especializadas. (Instituto Nacional de Estadística e Informática [INEI], 2010). Además, contiene a la División 74, la cual hace referencia a las actividades mencionadas anteriormente. El Grupo 749 incluye a la Clase 7490, la cual comprende una gran variedad de actividades de servicio, generalmente, a clientes comerciales según la información del INEI (2010). 


\subsubsection{Usos y características del servicio}

La implementación del SGSST se entregará en documentos físicos y digitales al cliente e incluirá, según la legislación vigente, lo siguiente:

1. Política y objetivos en materia de seguridad y salud en el trabajo.

2. Reglamento interno de seguridad y salud en el trabajo.

3. Identificación de peligros, evaluación y control de riesgos (matriz IPERC).

4. El mapa de riesgo.

5. La planificación de la actividad preventiva.

6. El Programa Anual de Seguridad y Salud en el Trabajo.

El servicio no se limitará a la entrega de la implementación física y digital del SGSST, sino que también se realizará el monitoreo y control de la implementación, además, se encargará de prevenir enfermedades ocupacionales para lo cual se realizarán monitoreos de agua, aire, ruido, iluminación. Con la matriz IPERC (Identificación de peligros, evaluación y control de riesgos) se podrá identificar las zonas y actividades laborales críticas de cada trabajador y se determinará los procedimientos para un trabajo seguro, así como la aplicación de acciones de control (preventivas y protección), la jerarquía de controles será tal como se puede ver en la figura 2.2. 
Figura 2.2

Prioridad en medidas de prevención y protección

Art. 21

PRIORIDAD EN MEDIDAS DE PREVENCIÓN Y PROTECCIÓN DEL SGSST

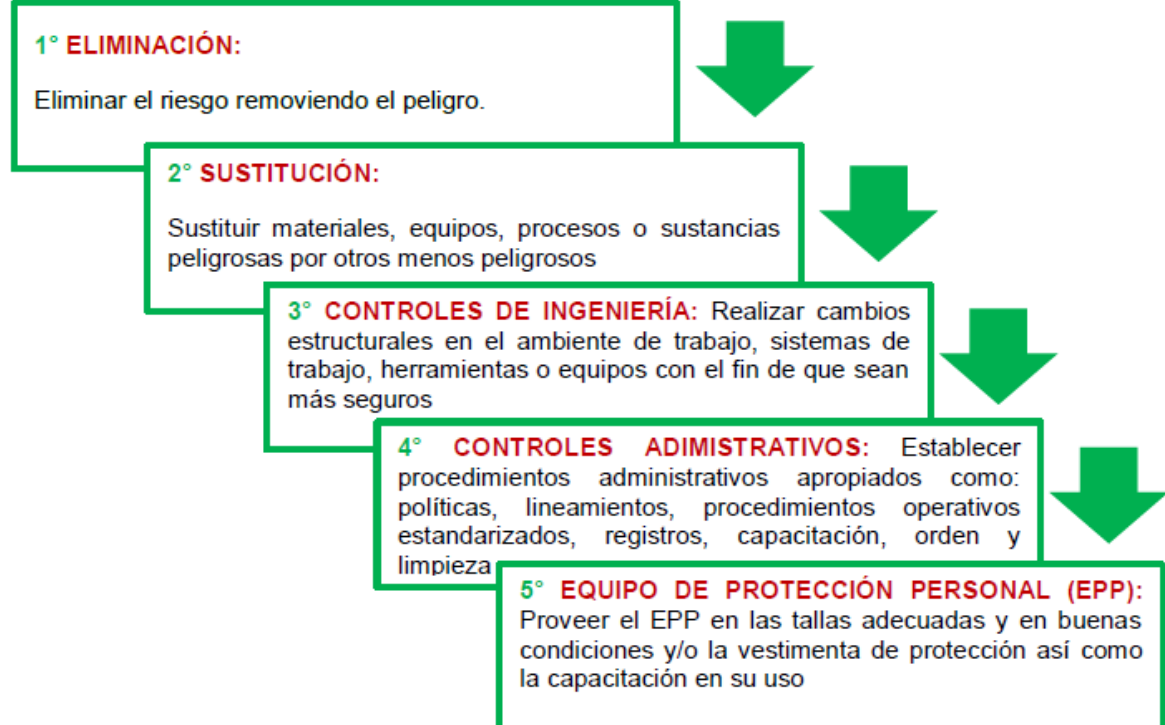

Fuente: Ley N 29783 "Ley de Seguridad y Salud en el Trabajo" (2016)

Elaboración propia

\subsubsection{Servicios sustitutos y complementarios}

Como servicio complementario la empresa entregará equipo de protección personal (EPP) a cada trabajador que labore en la actividad de construcción de relavera (que según estudios considera un promedio de 60 personas), actualmente existe en el mercado nacional una amplia gama de empresas que proveen dichos materiales de alta calidad como: Sekur Perú, 3M, MSA, entre otros. También, como parte del control administrativo se entregarán y ubicarán las señales de seguridad, según el mapa de riesgos, como: señales preventivas, prohibitivas e información, para esto se contará con el apoyo de Prosac, empresa peruana cuyos productos han sido elaborados bajo normas técnicas dictadas por Indecopi y cumplen con los requerimientos de Defensa Civil, además, se proveerá al cliente de sistemas visuales (proyectores, soluciones multimedia, ECRANS), productos eléctricos, reflectivos, radios de comunicación (motorolas), detectores de tormentas y todo aquello que garantice la protección de la vida y salud de los trabajadores 
La empresa también contará con el servicio de capacitaciones a los clientes sobre los temas de seguridad y salud en el trabajo, incluyendo los riesgos potenciales y complejidad de soluciones incorporadas. No se considerará servicios sustitutos.

\subsubsection{Definición del área de influencia del servicio}

El proyecto tiene el área de influencia a nivel nacional, dependiendo del lugar en donde se encuentre la mina del cliente, ya que al tratarse de una empresa tercerizadora de seguridad y salud la mayor parte del servicio no será en el local de las oficinas, sino que se deberá realizar en el área donde se encuentre la disposición del relave de la empresa contratista minera.

\subsubsection{Determinación de la metodología que se empleará en el estudio de mercado}

- Fuentes primarias: Como método cualitativo se realizará 1 entrevista al Gerente General de la empresa contratista minera "El Árabe S.A.”, de esta manera se podrá identificar y evaluar las necesidades y preferencias con respecto al servicio que se pretende brindar, también se entrevistará a un Ingeniero de Seguridad que cumple con los requisitos establecidos en la ley y que podrá brindar información acerca de los requerimientos para la implementación del Sistema de Gestión de Seguridad y Salud. Con respecto a las técnicas cuantitativas, se realizarán encuestas Ad-hoc vía internet a 18 personas entre gerentes generales de empresas contratistas mineras y responsables de seguridad en obra, en el cual la pregunta de interés será relacionado a su interés por adquirir el servicio que se propone, los resultados se podrán proyectar al total de empresas contratistas que hay hasta la fecha según el MINEM ${ }^{2}$ para determinar la demanda del proyecto.

- Fuentes secundarias: Se revisará información que tiene la biblioteca de la Universidad de Lima como tesis y revistas acerca de empresas tercerizadas de seguridad y salud en el trabajo, también se utilizará información de tesis de otras universidades e información de internet (páginas especializadas en el tema, Ministerio de Trabajo, Ministerio de Energía y Minas, etc), además de data secundaria que cuantifique a las empresas contratistas mineras.

${ }^{2}$ Ministerio de Energía y Minas 


\subsection{Análisis de la demanda}

\subsubsection{Cuantificación de los posibles mercados objetivo}

El mercado objetivo del estudio son las empresas contratistas mineras que realizan la actividad de construcción y recrecimiento de depósitos de relave desde una cota de referencia. En enfoque es directamente en las empresas contratistas porque las empresas mineras titulares dentro de sus programas anuales consideran la ejecución de este tipo de actividades a través de un contratista minero para evitar gastos en planilla de personal y adquisición de equipos pesados.

Según reporte del Ministerio de Energía y Minas del Perú actualizado a diciembre de 2018 hay 1719 empresas contratistas mineras las mismas que desarrollan trabajos de desarrollo, exploración, explotación, beneficio y actividades conexas, esta última representa aproximadamente el $5 \%$ del total e involucra el trabajo de construcción de tranques de relave. Para determinar la demanda objetivo del proyecto consideraremos una cuota creciente del mercado en cuanto a empresas contratistas mineras basándonos en el histórico, de esta forma evitamos el sesgo de vender el servicio al mismo cliente más de 1 vez.

En la tabla 2.1 se puede visualizar el mercado objetivo histórico desde el año 2013. Considerando el crecimiento de 143 empresas contratistas mineras para el año 2018 se obtiene un mercado objetivo de 7 empresas a quienes va dirigido el servicio propuesto.

Tabla 2.1

Mercado objetivo histórico

\begin{tabular}{|c|c|c|c|}
\hline Año & $\begin{array}{c}\text { Total de empresas } \\
\text { contratistas mineras }\end{array}$ & $\begin{array}{c}\text { Incremento anual de } \\
\text { empresas contratistas }\end{array}$ & $\begin{array}{c}\text { Actividad: Construccion y } \\
\text { recrecimiento de relavera } \\
\mathbf{5} \text { (empresas) }\end{array}$ \\
\hline 2013 & 1019 & 144 & 7 \\
\hline 2014 & 1172 & 153 & 8 \\
\hline 2015 & 1300 & 128 & 6 \\
\hline 2016 & 1445 & 145 & 7 \\
\hline 2017 & 1576 & 131 & 7 \\
\hline 2018 & 1719 & 143 & \\
\hline
\end{tabular}

Fuente: Ministerio de Energía y Minas (2019)

Elaboración propia 


\subsubsection{Demanda potencial}

\subsubsection{Patrones de consumo del servicio}

Los patrones de consumo del mercado objetivo están definidos por la Ley $\mathrm{N}^{\circ} 29783$, Decreto Supremo 005-2012-TR y sus respectivas modificatorias, las cuales exigen que toda empresa debe tener implementado su Sistema de Gestión de Seguridad y Salud en el Trabajo. Cabe resaltar que el 2014 la SUNAFIL inició con las actividades de inspección y cumplimiento de las normas legales y reglamentarias en todas las empresas, además de ejercer su facultad de ejecución coactiva respecto a las sanciones y multas que imponen.

Respecto al cliente se puede indicar que las empresas contratistas mineras realizan la gestión de recrecimiento de sus relaveras cada 2 años en promedio, ello dependerá de la capacidad de producción de la mina. El servicio propuesto se alinea a esta frecuencia para poder captar a los clientes.

El grado de tercerización que se plantea para el servicio es total, ya que contempla toda la administración del sistema de gestión de Gestión de Seguridad y Salud en el Trabajo (implementación, monitoreo y control). La Ley 30222 menciona en el Artículo 26A la posibilidad de contratar una empresa especializada para la gestión, implementación, monitoreo y cumplimiento de las disposiciones legales y reglamentarias sobre seguridad y salud en el trabajo

Es importante mencionar el caso de la empresa minera El Brocal S.A dedicada a la extracción, concentración y comercialización de diferentes minerales polimetálicos ya que existe información de la intención de tercerizar todo su sistema operativo de Seguridad y Salud en el Trabajo.

\subsubsection{Aplicación de estudios cualitativos y cuantitativos}

Los estudios cualitativos se realizaron a través de una entrevista al Gerente General de la empresa El Árabe S.A. Ing. Alexander Ronald Coronel Arimborgo, empresa dedicada a la ejecución de trabajos de construcción de presas y recrecimientos de relaveras, movimiento de tierras, construcción de carreteras, muros de contención y plataformas para perforación.

Se comenzó la entrevista preguntando su conocimiento sobre las leyes vigentes de Seguridad y Salud en el Trabajo a la que contestó acertadamente, posterior a ello se 
le preguntó cuánto de importancia se les da a estos temas en su empresa para ello le dio un puntaje de 8.5 (escala de 1 a 10, siendo 10 el más importante). Luego se le preguntó si utilizaría el servicio propuesto sobre seguridad y salud en el trabajo y respondió afirmativamente, como comentario final asevera que la tercerización del SGSST es una buena opción siempre y cuando esta sea llevada por profesionales competentes y experimentados y con precios competitivos.

De igual forma se realizó una entrevista al Ing. Héctor Huamancaja Padilla especialista en Seguridad y Salud en el Trabajo, de esta podemos destacar que mencionó que para realizar el servicio propuesto se requiere como mínimo un jefe de seguridad, 2 ingenieros de seguridad de guardia y 2 inspectores, además de que la empresa contratante debe cumplir obligatoriamente con las recomendaciones, el plan anual de seguridad y las exigencias del empleador.

Los estudios cuantitativos se realizaron a través de encuestas Ad-hoc (ver Anexo 8) vía internet a 18 personas entre gerentes generales de empresas contratistas mineras y responsables de seguridad en obra, los resultados serán explicados a continuación:

Figura 2.3

¿Cuántos trabajadores tiene su empresa?

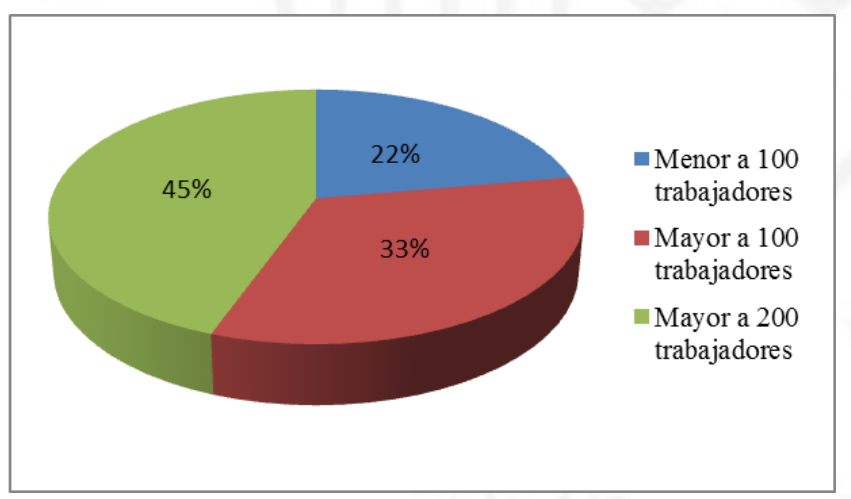

Fuente: Encuesta para el estudio de mercado (2019)

Elaboración propia

Los resultados de la pregunta 3 se pueden visualizar en la figura 2.3 y fue realizada para determinar un estimado de los costos en que se debe incurrir al proveer de EPP's a los trabajadores de la empresa, puesto que es uno de los servicios que ofrece la empresa. 
Figura 2.4

¿Qué tipo de accidente tuvieron en el último año?

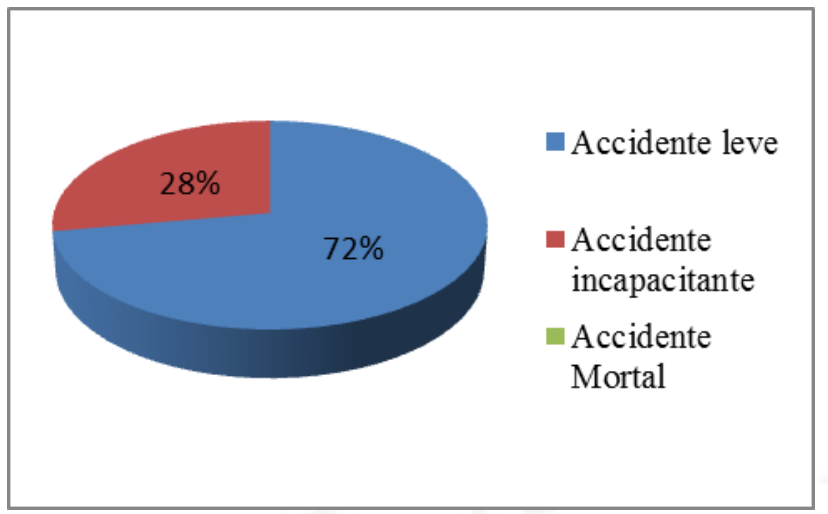

Fuente: Encuesta para el estudio de mercado (2019)

Elaboración propia

La pregunta 4 que se muestra en la figura 2.4 nos evidencia en casos reales la necesidad de una buena administración del sistema de seguridad y salud en el trabajo para evitar y eliminar la ocurrencia de accidentes en su totalidad, que es el enfoque del presente trabajo. Las 18 empresas encuestadas han presentado accidentes (en su mayoría leves) de sus trabajadores durante este año.

Figura 2.5

¿Tiene su empresa implementado un SGSST?

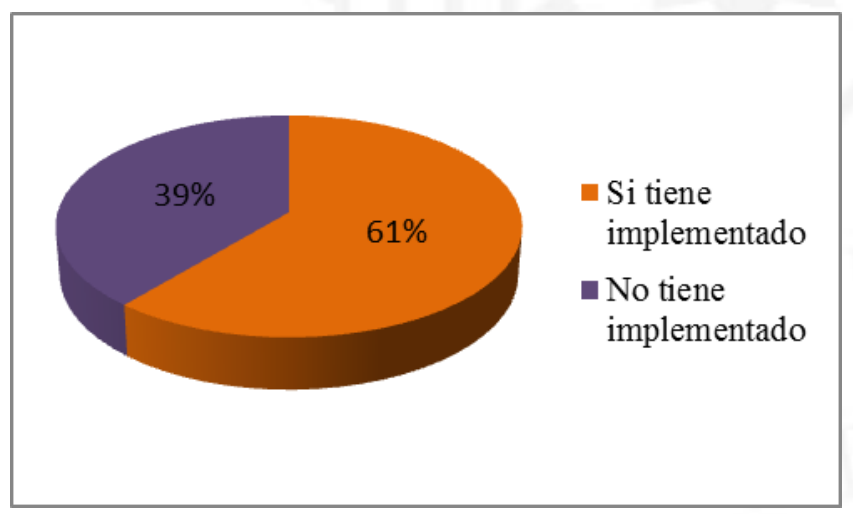

Fuente: Encuesta para el estudio de mercado (2019)

Elaboración propia

La figura 2.5 nos muestra que, de las 18 encuestas realizadas, 7 no tienen implementado un Sistema de Gestión de Seguridad y Salud, pero se encuentran en proceso de realizarlo y 11 empresas si tienen implementado el sistema según la normativa; sin embargo, comentaron que no se realiza el seguimiento respectivo de las medidas de control y prevención, lo dicho se puede evidenciar en la ocurrencia de 
accidentes (figura 2.4). Estos comentarios reflejan un gran problema existente en la actualidad, en la que muchas empresas implementan su SGSST solo para tenerlo en documentos físicos y evitar las multas por la normativa del Estado.

Figura 2.6

¿Estaría interesado en contratar los servicios para la Administración de su Sistema de Seguridad y Salud en el Trabajo?

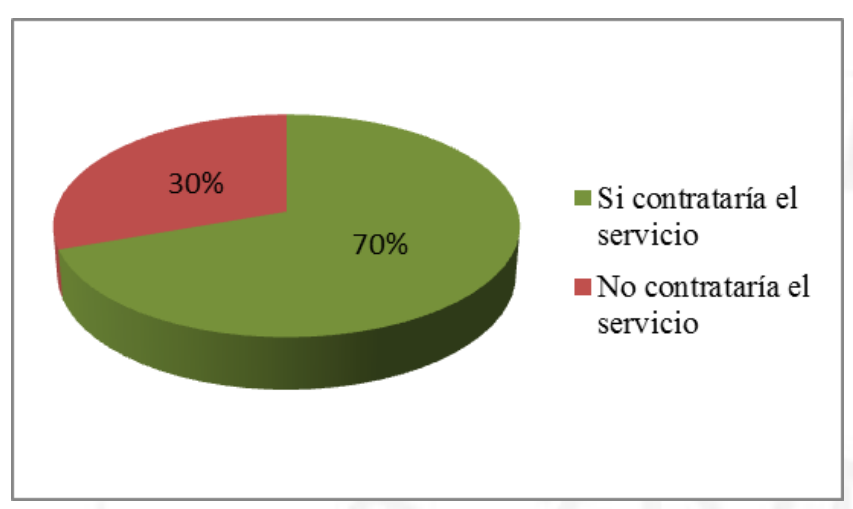

Fuente: Encuesta para el estudio de mercado (2019)

Elaboración propia

Los resultados de la pregunta 6 de la encuesta se puede visualizar en la figura 2.6, 13 de las 18 empresas encuestadas sí contratarían el servicio propuesto, incluso como comentarios se tuvo que la Administración del Sistema de Seguridad y Salud no solo se limite a la actividad de construcción y recrecimiento de relavera, sino también a actividades de desarrollo, explotación y exploración.

\subsubsection{Determinación de la demanda potencial}

La demanda potencial del proyecto está definida por una cuota creciente de las empresas contratistas mineras activas que hay en Perú a la actualidad y que realizan la actividad de construcción y recrecimiento de relaveras, debido a que es de carácter obligatorio el servicio propuesto según la Ley $\mathrm{N}^{\circ}$ 29783, DS 005-2012-TR y modificatorias y por las inspecciones de la SUNAFIL en cuanto al cumplimiento de las leyes y decretos, se abarcará el 100\% de la demanda potencial. Al año 2018 la demanda potencial es de 7 empresas. 


\subsubsection{Proyección de la demanda potencial y metodología de análisis}

Como se mencionó en el punto anterior la demanda potencial abarcará el $100 \%$ del mercado objetivo. Considerando la cantidad de empresas contratistas mineras desde el año 2013 al 2018 y tomando en cuenta el 5\% de ellas por la actividad a la cual se enfoca el servicio, se realizará la proyección a 7 años bajo el método de regresión lineal.

Con dicho método se determina la demanda en función del tiempo, además se tomó en cuenta la tendencia ascendente de los datos históricos. En la figura 2.7 se puede observar que la relación entre demanda y tiempo (correlación: $\mathrm{R}^{2}$ ) es muy fuerte y positiva porque es cercana a 1, lo cual indica que ambas variables son directamente proporcionales.

Figura 2.7

Demanda proyectada con el método de regresión lineal

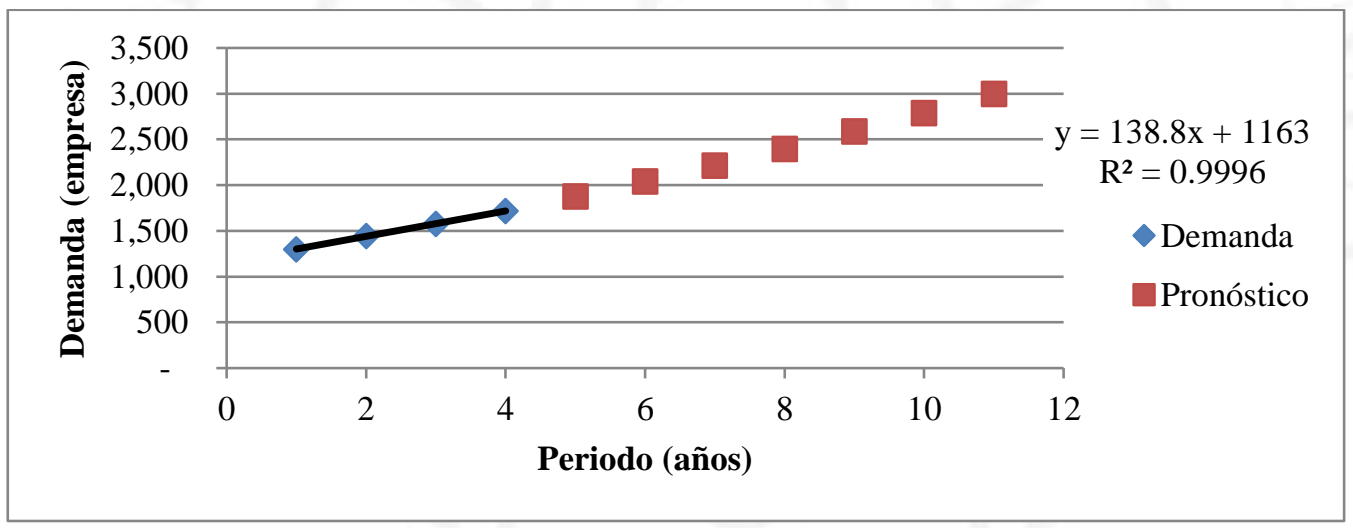

Nota: Considerando que los periodos representan a los años de análisis desde el 2013 hasta el año 2018.

Fuente: Ministerio de Energía y Minas (2019)

Elaboración propia

A continuación, se mostrará la demanda potencial para la empresa tercerizadora proyectada al año 2025.

Tabla 2.2

Proyección de la demanda potencial al 2025

\begin{tabular}{|c|c|c|c|}
\hline Año & $\begin{array}{c}\text { Total de empresas } \\
\text { contratistas mineras }\end{array}$ & $\begin{array}{c}\text { Incremento anual de } \\
\text { empresas contratistas }\end{array}$ & $\begin{array}{c}\text { Actividad: Construccion y } \\
\text { recrecimiento de relavera } \\
\mathbf{5 \%} \text { (empresas) }\end{array}$ \\
\hline 2025 & 2999 & 209 & 10 \\
\hline
\end{tabular}

Fuente: Ministerio de Energía y Minas (2019)

Elaboración propia 


\subsection{Análisis de la oferta}

\subsubsection{Análisis de la competencia. Número de operadores y ubicaciones}

En la actualidad no existe información sobre empresas tercerizadoras de la administración y gestión de riesgos a empresas contratistas mineras; sin embargo, existen empresas consultoras que brindan asesorías de cómo implementar la Ley de seguridad y salud en el trabajo como: CESEL INGENIEROS, Buenaventura Ingenieros S.A. (BISA), SESMA CONSULTORES, CASTEL MONTE ASOCIADOS, MCE CONSULTORES ASOCIADOS, SST Asesores SAC, SSMA Perú, AGS CONSULTING SAC y otros. Tomaremos como referencia a las 2 primeras empresas.

CESEL INGENIEROS: Es una empresa consultora en ingeniería con múltiples disciplinas integradas en proyectos portuarios, de industria pesada, diseños civiles y estructurales, industria minera e hidrocarburos. Su oficina principal está ubicada en Av. José Gálvez Barrenechea Nº46. San Isidro - Lima y su operación abarca todo el Perú.

Buenaventura Ingenieros S.A. (BISA): Es una empresa filial de la compañía de Minas Buenaventura, se dedica a la prestación de servicios de consultoría, ingeniería y construcción para el desarrollo de proyectos mineros y energéticos. Su sede principal se encuentra en Av. Carlos Villarán $N^{\circ} 790$, Urb. Santa Catalina - Lima.

\subsubsection{Descripción de las características del servicio ofertado por los principales competidores}

- CESEL INGENIEROS: Suministra servicios de consultoría en: obras viales, energía eléctrica, hidráulica e irrigaciones, medio ambiente, metros y ferrocarriles, minería e industria, saneamiento, puertos, hidrocarburos y petroquímica, edificaciones y desarrollo urbano, salud, aeropuertos, topografía y geomática. Sus equipos de proyecto están conformados por especialistas en su rubro. Se encargaron de asesorar la administración del sistema de gestión de riegos del proyecto Carhuacoto.

- Buenaventura Ingenieros S.A. (BISA): La empresa cuenta con 2 modalidades de negocio: consultoría y construcción, en el ámbito de consultoría se enfoca en realizar la implementación del Sistema de Gestión de Seguridad y Salud de la empresa Minas Buenaventura y otras que se encuentran en la región centro. 


\subsection{Demanda para el proyecto}

\subsubsection{Segmentación del mercado}

Para el presente trabajo solo se realizará una segmentación para encajar el perfil de la empresa cliente y poder medir mejor la demanda, está será:

Segmentación Sectorial: Se debe restringir el mercado meta por el giro de negocio de minería y actividad: construcción y crecimiento de depósitos de relave, que representa el 5\% del total de empresas contratistas mineras.

A nivel localización se considerará la siguiente segmentación:

Segmentación Geográfica: El proyecto abarcará todo el Perú, dependiendo el lugar en donde se encuentre la mina y por ende el tranque de relaves producto del proceso metalúrgico del mineral.

\subsubsection{Selección del mercado meta}

El mercado meta al cual está enfocado el servicio propuesto es la cuota creciente de empresas contratistas mineras que se obtuvo de las estadísticas del MINEM a quienes se debe aplicar la segmentación sectorial mencionada en el anterior punto y además contemplar que estos números serán acotados de acuerdo a los resultados de las encuestas, en el cual la pregunta 6 (¿Estaría interesado en contratar los servicios de una empresa para la Administración de su Sistema de Seguridad y Salud en el Trabajo, tomando en cuenta que esta contempla la implementación, monitoreo y control del sistema?) estimará la participación de mercado de la empresa, tal como se puede observar en la figura 2.6, el 70\% de los encuestados contratarían el servicio, esta última consideración se dará por estrategia empresarial que buscará satisfacer a los clientes con un servicio de calidad. A continuación, se mostrarán los datos obtenidos desde el año 2013 hasta 2018. 
Tabla 2.3

Datos históricos para determinar el mercado meta

\begin{tabular}{|c|c|c|c|}
\hline Año & $\begin{array}{c}\text { Histórico de empresas } \\
\text { contratistas mineras }\end{array}$ & $\begin{array}{c}\text { Incremento anual de } \\
\text { empresas contratistas }\end{array}$ & $\begin{array}{c}\text { Actividad: Construccion } \\
\text { y recrecimiento de } \\
\text { relavera 5\% (empresas) }\end{array}$ \\
\hline 2013 & 1019 & 144 & 7 \\
\hline 2014 & 1172 & 153 & 8 \\
\hline 2015 & 1300 & 128 & 6 \\
\hline 2016 & 1445 & 145 & 7 \\
\hline 2017 & 1576 & 131 & 7 \\
\hline 2018 & 1719 & 143 & 7 \\
\hline
\end{tabular}

Fuente: Ministerio de Energía y Minas (2019)

Elaboración propia

Esto permitirá proyectar la demanda del servicio hasta el año 2025 y obtener el mercado objetivo del proyecto.

Tabla 2.4

Mercado meta del proyecto (en número de empresas)

\begin{tabular}{|c|c|c|c|c|c|}
\hline Año & $\begin{array}{c}\text { Total de empresas } \\
\text { contratistas mineras }\end{array}$ & $\begin{array}{c}\text { Incremento anual de } \\
\text { empresas contratistas }\end{array}$ & $\begin{array}{c}\text { Actividad: Construccion y } \\
\text { recrecimiento de relavera } \\
\mathbf{4} \% \text { (empresas) }\end{array}$ & $\begin{array}{c}\text { Encuestas } \\
\text { (empresas) } \\
\mathbf{7 0 \%}\end{array}$ & $\begin{array}{c}\text { Mercado } \\
\text { Meta } \\
\text { (empresas) }\end{array}$ \\
\hline 2019 & 1876 & 157 & 8 & 5.5 & 6 \\
\hline 2020 & 2042 & 166 & 8 & 5.8 & 6 \\
\hline 2021 & 2216 & 174 & 9 & 6.1 & 7 \\
\hline 2022 & 2399 & 183 & 9 & 6.4 & 7 \\
\hline 2023 & 2590 & 191 & 10 & 6.7 & 7 \\
\hline 2024 & 2790 & 200 & 10 & 7.0 & 7 \\
\hline 2025 & 2999 & 209 & 10 & 7.3 & 8 \\
\hline
\end{tabular}

Fuente: Ministerio de Energía y Minas (2019)

Elaboración propia

\subsubsection{Determinación de la demanda para el proyecto}

Para obtener la demanda final del proyecto se debe considerar la capacidad de atención de la empresa, la cual se detalla en el punto 4.1, con ello el primer año se estaría atendiendo a 3 empresas.

A continuación, se mostrará la demanda final del proyecto hasta el año 2025. 
Tabla 2.5

Demanda del proyecto (en número de empresas)

\begin{tabular}{|c|c|c|c|c|c|c|}
\hline Año & $\begin{array}{c}\text { Total de empresas } \\
\text { contratistas mineras }\end{array}$ & $\begin{array}{c}\text { Incremento anual de } \\
\text { empresas contratis tas }\end{array}$ & $\begin{array}{c}\text { Actividad: Construccion y } \\
\text { recrecimiento de relavera } \\
\mathbf{4 \%} \text { (empresas) }\end{array}$ & $\begin{array}{c}\text { Encuestas } \\
\text { (empresas) } \\
\mathbf{7 0 \%}\end{array}$ & $\begin{array}{c}\text { Mercado } \\
\text { Meta } \\
\text { (empresas) }\end{array}$ & $\begin{array}{c}\text { Demanda del } \\
\text { proyecto } \\
\text { (empresas) }\end{array}$ \\
\hline 2019 & 1876 & 157 & 8 & 5.5 & 6 & 3 \\
\hline 2020 & 2042 & 166 & 8 & 5.8 & 6 & 3 \\
\hline 2021 & 2216 & 174 & 9 & 6.1 & 7 & 4 \\
\hline 2022 & 2399 & 183 & 9 & 6.4 & 7 & 4 \\
\hline 2023 & 2590 & 191 & 10 & 6.7 & 7 & 6 \\
\hline 2024 & 2790 & 200 & 10 & 7.0 & 7 & 6 \\
\hline 2025 & 2999 & 209 & 10 & 7.3 & 8 & 6 \\
\hline
\end{tabular}

Fuente: Ministerio de Energía y Minas (2019)

Elaboración propia

\subsection{Venta del servicio}

\subsubsection{Políticas de venta del servicio}

El jefe comercial, en la mayoría de casos, deberá atraer a los clientes contactándose con miembros del directorio de las empresas contratistas mineras y solicitando una reunión con ellos, en el cual se mostrará el servicio que se ofrece y los resultados que se pretende lograr con su aplicación. En esta reunión se debe enfocar la calidad de los resultados, además de un seguimiento constante de la implementación y control de medidas de prevención y protección. En la actualidad existe también el interés de las empresas contratistas para tercerizar actividades específicas como: topografía, transporte, seguridad, entre otros. Cabe resaltar que al ser una empresa de servicios pequeña, la gestión en la captación de los clientes no se limita únicamente al jefe comercial, es decir hasta el gerente de la empresa puede estar involucrado en la captura de clientes potenciales.

Al terminar la gestión del jefe comercial para identificar a un potencial cliente, el equipo de especialistas de seguridad inicia los procedimientos para conocer y ver la situación actual de la empresa contratista minera, si después de ello el cliente se encuentra interesado se define un contrato de venta indicando los antecedentes, objeto, monto contractual, forma de pago, adelanto directo, plazo de ejecución de obra, garantías, penalidades, resolución de contrato y responsabilidades de las partes involucradas.

Antes de iniciar el proyecto se solicitará un adelanto del $20 \%$ y el plazo de entrega del mismo, al momento de entrega del adelanto se proporcionará la garantía 
acompañada del comprobante de pago al cliente. La amortización del adelanto se realizará mediante descuentos proporcionales en cada uno de los pagos mensuales por la ejecución del servicio. Los pagos mensuales se realizarán mediante valorización según tarifas, que son pagos a cuenta de un contrato según trabajos realizados en el lapso de un mes.

La duración del servicio es como mínimo 4 meses, este dato se estimó con proyectos reales de recrecimiento de relaveras realizados, sin embargo va a depender de las dimensiones de base que tendrá la relavera con lo cual se podría ampliar hasta 1 año de trabajo.

\subsubsection{Análisis de precios}

\subsubsection{Tendencia histórica de los precios}

Al ser un negocio emergente y ya que no se encontraron competencias directas para el servicio no se tiene un histórico de precios; sin embargo, es importante mencionar que debido a la actual coyuntura de la exigencia de la Ley de Seguridad y Salud, la demanda de este servicio va en aumento al igual que el precio.

\subsubsection{Precios actuales y niveles del servicio}

Dado a que este servicio es una propuesta nueva no se encontró información que pueda ayudar a las comparaciones en precio para el servicio

Tomando en cuenta que muchos de los procesos que exige la norma, como la Matriz de Riesgos y Peligros, no puede ser realizado por el personal de la empresa, sino por empresas especializadas, las empresas encuentran más rentable tercerizar esta área a cambio de costos como: atención a la persona afectada, reparación del daño, deterioro de la imagen de la organización y el monto de las multas impuestas por la Sunafil.

El precio del servicio se determinará en función al costo, la información de análisis de costos se realizará en el capítulo VII "Presupuestos y Evaluación de Proyectos". 


\subsection{Marketing del servicio}

\subsubsection{Características principales del servicio}

A los días de la firma del contrato, previa visita al área de trabajo, la supervisión de seguridad (Jefe de seguridad, supervisores de seguridad) en coordinación con la jefatura de operaciones (residente y jefe de producción de la empresa contratista minera) elaborará el cronograma de trabajo para todo el proyecto e iniciará con la documentación de cumplimiento legal de la Ley $\mathrm{N}^{\circ} 29783$ y su modificatoria Ley $\mathrm{N}^{\circ}$ 30222 (Plan de Seguridad, Reglamento Interno de Seguridad, Reglamento Interno de Tránsito, entre otros). Paralelo a esto, se realizará el reclutamiento de personal, exámenes médicos, inducciones y compra de los materiales de requerimiento de seguridad (EPP, señalizaciones, etc).

\subsubsection{Publicidad y promoción}

Las estrategias de publicidad deben ganar reconocimiento en el mundo empresarial, mediante promociones en revistas en el rubro de minería como: Seguridad Minera, Minería, Business Negocios en el Perú, Mundo Empresarial y G. de Gestión. La empresa también contará con 2 plataformas digitales, las cuales serán: una página web vinculada a la página de Facebook y espacios publicitarios que se contratarán en páginas web relacionadas a la seguridad y salud en el trabajo (Colegio de Ingenieros, Ministerio de Energía y Minas, Ministerio de Trabajo y Promoción del Empleo y Ministerio de Salud)

Pero lo principal será la publicidad personal que tendrá la empresa con los clientes y se medirá con el rango de satisfacción de los resultados del servicio. 


\section{CAPÍTULO III. LOCALIZACIÓN DEL SERVICIO}

\subsection{Análisis de los factores de localización}

Para determinar la macrolocalización de la empresa se usará el método cualitativo: Factor dominante, en este caso la cercanía a los clientes, al buscar información sobre las empresas contratistas mineras se encontró que la gran mayoría tiene su oficina principal en el departamento de Lima, es por eso que la empresa se ubicará en el departamento de Lima. Es importante recalcar que el servicio se realizará en el centro de trabajo de la empresa contratista minera, pero es importante tener una oficina para informes y reuniones.

Una vez determinada la macrolocalización: Lima, se determinará el distrito (microlocalización) en el que se ubicará la empresa mediante el análisis de diversos factores. Para poder elegir la mejor alternativa de ubicación de la empresa primero se analizará el factor más importante: cercanía a las oficinas de las empresas contratistas mineras, puesto que son los clientes y en base a los resultados, se compararán los otros factores considerados:

\section{a. Cercanía a las oficinas de los clientes potenciales}

El servicio del presente trabajo está dirigido a empresas contratistas mineras, por tal motivo se considera como factor importante que la empresa se encuentre en una zona cercana a las oficinas de los clientes potenciales, de esta manera se evitará incomodidad y contratiempos en el traslado y aumentará la accesibilidad para solicitar el servicio. A continuación, se presenta un cuadro en el cual se muestran los tres primeros distritos de Lima que tienen mayor cantidad de oficinas de empresas contratistas mineras.

\section{Tabla 3.1}

Cantidad de empresas contratistas mineras por distrito

\begin{tabular}{|c|c|}
\hline Distrito & $\begin{array}{c}\text { Empresas Contratistas } \\
\text { Mineras }\end{array}$ \\
\hline San Borja & 40 \\
\hline San Isidro & 34 \\
\hline Santiago de Surco & 31 \\
\hline
\end{tabular}

Fuente: Ministerio de Energía y Minas (2019) 
En base a los distritos de San Borja, San Isidro y Santiago de Surco se analizarán los siguientes factores para determinar la mejor ubicación de la oficina.

b. Seguridad ciudadana

La percepción de la seguridad ciudadana es un factor importante para las personas, ya que la falta de este, actualmente, es considerado la primera problemática nacional que afecta la calidad de vida de la población. La Encuesta de Victimización en el Perú (2015) considera: "La percepción de inseguridad es la sensación de la población de ser víctima de algún hecho delictivo o evento que pueda atentar contra su seguridad, integridad física o moral, vulnere sus derechos y la conlleve al peligro, daño o riesgo" (p.145). A continuación, se detallarán los distritos que obtuvieron, según la investigación, menor porcentaje de percepción de inseguridad ciudadana y, por ende, se consideran las más seguras con menor cantidad de robos, secuestros, intimidaciones, amenazas y maltrato.

Tabla 3.2

Percepción de inseguridad ciudadana (\%) por distrito

\begin{tabular}{|c|c|}
\hline Distrito & $\begin{array}{c}\text { Percepción de } \\
\text { inseguridad ciudadana }\end{array}$ \\
\hline San Isidro & $21.40 \%$ \\
\hline San Borja & $32.80 \%$ \\
\hline Santiago de Surco & $43.00 \%$ \\
\hline
\end{tabular}

Fuente: Encuesta de Victimización en el Perú (2015)

\section{c. Evaluación de los serenazgos y policías}

El buen trabajo de serenazgos y policías incrementan la confianza ciudadana en ellos, los distritos analizados constantemente están implementando campañas para resguardar la seguridad de las familias.

Todos los distritos en mención cuentan con un serenazgo moderno, eficaz y cercano, todos capacitados y con recursos tecnológicos como: cámaras de video vigilancia, sistemas de comunicación directa, descentralización en sus funciones, instalación de módulos en diversas partes del distrito.

San Isidro recientemente creó una aplicación SOS Alto al Crimen que permite denunciar en forma rápida y anónima desde el Smartphone, también ofrece la opción de botón de pánico. Surco también tiene una aplicación Alerta Surco que 
permite enviar alertas de emergencia al serenazgo o reportar otros problemas desde un Smartphone. San Borja, por otro lado, cuenta una central de emergencia de Seguridad Ciudadana y múltiples sistema policiales y serenazgos como: Patrulleros de San Borja, Central 105, Águilas Negras, Empresas de seguridad Orus, Boxer, Emergencia Sur 1.

Según la Encuesta de Victimización 2015 los resultados de la evaluación favorable de los serenazgos por distrito son:

Tabla 3.3

Evaluación se serenazgos y policías

\begin{tabular}{|c|c|}
\hline Dis trito & $\begin{array}{c}\text { Evaluación favorable de } \\
\text { serenargo y policía }\end{array}$ \\
\hline San Isidro & $88.3 \%$ \\
\hline San Borja & $77.0 \%$ \\
\hline Santiago de Surco & $75.0 \%$ \\
\hline
\end{tabular}

Fuente: Encuesta de Victimización en el Perú (2015)

\section{d. Disponibilidad de áreas de oficina}

La disponibilidad para alquilar o comprar oficinas es considerada un factor importante, para analizarla se tomó en cuenta el reporte inmobiliario del segundo trimestre del 2016 realizado por Binswanger Perú que considera 2 clases de oficinas diferenciadas por su calidad física, ubicación y nivel de renta.

- Case Prime: Hace referencia a edificios que se ubican frente a vías principales, sus acabados y áreas comunes son de alta calidad, está enfocado a corporaciones, principalmente, que necesitan áreas grandes.

- Clase B: Hace referencia a edificios de fácil acceso, la calidad de sus acabados es estándar y cumple con la normativa de construcción, y suelen ofrecer áreas menores que los edificios prime.

Como se mencionó anteriormente, la mayor parte del trabajo de la empresa será en la ubicación de la mina del cliente; sin embargo, se debe tener en Lima una oficina que brinde informes y donde se realicen reuniones importantes, por esta razón se determinó la búsqueda de oficinas de clase B y que cuente con una buena accesibilidad. 
A continuación se mostrará la vacancia ${ }^{3}\left(\mathrm{~m}^{2}\right)$ de oficinas clase B en cada uno de los distritos con los que se está trabajando, cabe resaltar que la tasa de vacancia se incrementó respecto al trimestre anterior por la inversión en construcción de edificios comercializados.

Tabla 3.4

Vacancia $\left(\mathrm{m}^{2}\right)$ por distrito

\begin{tabular}{|c|c|}
\hline Distrito & Vacancia $(\mathrm{m} 2)$ \\
\hline San Isidro Financiero & $12,602.00$ \\
\hline San Isidro Empresarial & $6,386.00$ \\
\hline Santiago de Surco & $12,610.00$ \\
\hline San Borja & $1,024.00$ \\
\hline
\end{tabular}

Fuente: Reporte Inmobiliario Binswanger 2do Trimestre (2016)

Como se puede observar en la tabla 3.4 San Isidro posee 2 ejes corporativos consolidados debido a la dinámica inmobiliaria de su ubicación al igual que Surco, por otro lado, San Borja es considerado como un eje corporativo en desarrollo.

\section{e. Costo por metro cuadrado}

Para este factor se consideró el precio de alquiler $\left(\$ / \mathrm{m}^{2}\right)$, dato que se obtuvo del reporte inmobiliario del segundo trimestre del 2016 realizado por Binswanger Perú. Según el reporte, el precio promedio de alquiler de oficinas cayó respecto al trimestre anterior como consecuencia de la creciente vacancia. A continuación, se mostrará el precio de alquiler en cada uno de los distritos con los que se está trabajando.

Tabla 3.5

Precio de alquiler $\left(\$ / \mathrm{m}^{2}\right)$ por distrito

\begin{tabular}{|c|c|}
\hline Distrito & $\begin{array}{c}\text { Precio de } \\
\text { alquiler }(\$ / \mathrm{m} 2)\end{array}$ \\
\hline San Isidro Financiero & 17.07 \\
\hline San Isidro Empres arial & 18.56 \\
\hline Santiago de Surco & 15.66 \\
\hline San Borja & 17.00 \\
\hline
\end{tabular}

Fuente: Reporte Inmobiliario Binswanger 2do Trimestre (2016)

\footnotetext{
${ }^{3}$ Total de espacio disponible para ocupación inmediata.
} 


\section{f. Disponibilidad de estacionamientos}

Este factor es considerado importante tomando en cuenta que Lima presenta un déficit de al menos 45 mil espacios para estacionar debido al crecimiento diario del parque automotor. Para determinar la disponibilidad de estacionamientos en cada distrito trabajado se utilizó información de: Los Portales Estacionamientos y Central Parking System, que lideran este mercado en Lima y además otorgan un servicio integral para satisfacción de los clientes.

Tabla 3.6

Cantidad de estacionamientos por distrito

\begin{tabular}{|c|c|}
\hline Distrito & $\begin{array}{c}\mathbf{N}^{\circ} \text { de } \\
\text { estacionamientos }\end{array}$ \\
\hline San Borja & 6 \\
\hline San Isidro & 39 \\
\hline Santiago de Surco & 16 \\
\hline
\end{tabular}

Fuente: Los Portales Estacionamientos - Central Parking System (2016)

En la tabla 3.6 se menciona la cantidad de playas de estacionamientos por cada distrito ubicados en: principales avenidas, centros comerciales y retails, cada uno de estos abarca desde 100 hasta 1000 unidades.

\section{g. Tarifa de parqueos de estacionamientos}

Para la información de precios de estacionamiento se tomó en cuenta el estudio de Mapcity (ver anexo 7) realizado en el 2015 que considera que los estacionamientos ubicados en zonas financieras como: San Isidro o Surco tienen los costos más elevados de la ciudad. A continuación, se mostrará en cada distrito el precio en que oscilan los estacionamientos por hora.

Tabla 3.7

Rango de precios del estacionamiento por distrito

\begin{tabular}{|c|c|}
\hline Distrito & $\begin{array}{c}\text { Oscilación del precio del } \\
\text { estaciomaniento (S/.por hora) }\end{array}$ \\
\hline San Borja & $3.00-15.00$ \\
\hline San Isidro & $10.00-15.00$ \\
\hline Santiago de Surco & $3.00-15.00$ \\
\hline
\end{tabular}

Fuente: Estudio de Mapcity (2015) 


\section{h. Facilidad de trámites:}

Este factor es importante de analizar, ya que son de mucha ayuda las facilidades que brindan las municipalidades de cada distrito para la entrega de documentos al iniciar la empresa y también para las actividades del día a día. Los pasos para crear una empresa en Lima Metropolitana son similares y con las mismas entidades, la variación en este caso son el tiempo y la complejidad del trámite para la obtención de la licencia de funcionamiento por la municipalidad distrital. La mayoría de distritos pide principalmente 2 requisitos: formulario de solicitud para la obtención de la licencia de funcionamiento y la declaración jurada de condiciones básicas de seguridad.

Para el análisis de este factor se tomó en cuenta el Texto Único de Procedimiento Administrativo (TUPA ${ }^{4}$ ) de cada distrito que varía en el tiempo de entrega y costo de la licencia de funcionamiento. A continuación se detallará lo mencionado.

Tabla 3.8

Tiempo de entrega y precios de licencia de funcionamiento por distrito

\begin{tabular}{|c|c|c|c|}
\hline Distrito & Tiempo de entrega & Area de la oficina & Precios \\
\hline \multirow{2}{*}{ San Borja } & \multirow{2}{*}{10 dias hábiles $(*)$} & Hasta $100 \mathrm{~m}^{2}$ & S/. 693.51 \\
\cline { 3 - 4 } & & De 100.01 a $500 \mathrm{~m}^{2}$ & S/. 816.74 \\
\hline \multirow{2}{*}{ Santiago de Surco } & \multirow{2}{*}{15 dias hábiles $(*)$} & Hasta $100 \mathrm{~m}^{2}$ & S/. 42.80 \\
\cline { 3 - 4 } & & De 100.01 a $500 \mathrm{~m}^{2}$ & S/. 147.30 \\
\hline \multirow{2}{*}{ San Isidro } & \multirow{2}{*}{15 dias hábiles $(*)$} & Hasta $100 \mathrm{~m}^{2}$ & S/. 76.50 \\
\cline { 3 - 4 } & & De 100.01 a $500 \mathrm{~m}^{2}$ & S/. 370.20 \\
\hline
\end{tabular}

Nota: (*) A partir del día siguiente de la presentación del expediente

Fuente: Municipalidad de San Borja (2016), Municipalidad de Santiago de Surco (2016) y Municipalidad de San Isidro (2016)

\subsection{Posibles ubicaciones de acuerdo a factores predominantes}

\subsubsection{Cercanía al mercado}

Como se mencionó en el punto anterior, para determinar la ubicación de la oficina se tomó en cuenta 3 distritos que cumplen con el factor considerado como el más

\footnotetext{
${ }^{4}$ Documento de gestión que contiene toda la información realizada a la tramitación de procedimiento que los administrados realizan ante sus distintas dependencias (Superintendencia Nacional de Control de Servicios de Seguridad, Armas, Municiones y Explosivos de uso civil [SUCAMEC], 2016).
} 
importante: cercanía a los clientes potenciales. Es así que las tres opciones a considerar fueron:

\section{San Borja:}

Es uno de los 43 distritos de la provincia de Lima en el Perú creada el 1 de junio de 1983, está limitado por el norte con los distritos de San Luis, La Victoria y Ate, al oeste con el distrito de Santiago de Surco, al sur con el distrito de Surquillo y al este con el distrito de San Isidro. Su extensión es de $9.96 \mathrm{~km}^{2}$. Entre los principales destinos turísticos que tiene están: El Museo de la Nación, Biblioteca Nacional del Perú, Gran Teatro del Perú, Huaca San Borja, Paseo de Aguas, entre otras. Además es también sede del Ministerio de Energía y Minas, Ministerio de Cultura y Ministerio de Educación.

San Borja fue premiado como distrito ecológico y saludable, y considerado como distrito residencial que tiene una gran variedad de centros comerciales. Además según la Encuesta de Victimización (2015) con respecto a los distritos de Lima, San Borja es considerado como el distrito más seguro con un rápido accionar de los serenazgos y de la Policía y con mejor percepción de las personas. Además, recientemente está implementando el programa "Viaja en bici" y también programas de deportes, talleres y cultura.

Figura 3.1

Museo de la Nación

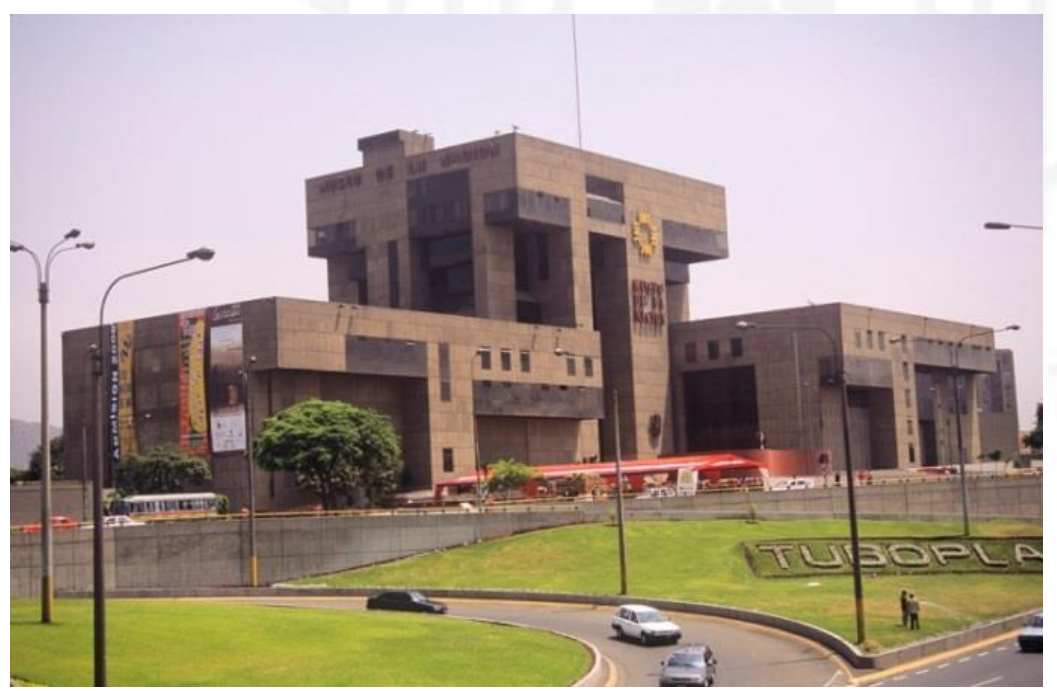

Fuente: Top 10 lugares en Lima (2016) 
Figura 3.2

Gran Teatro del Perú

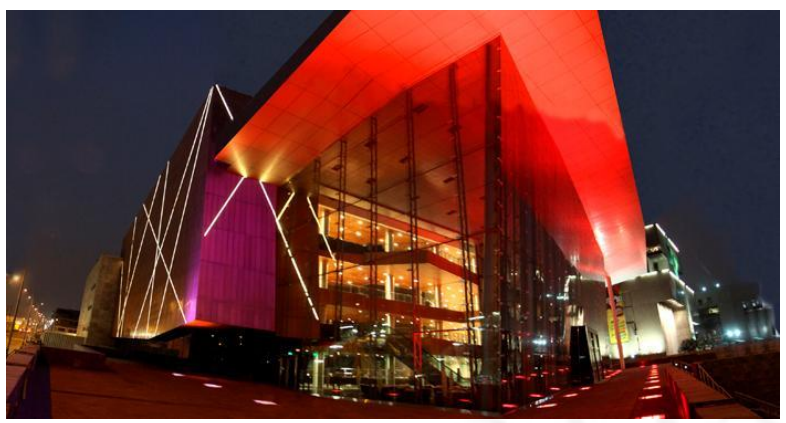

Fuente: Infoartes (2016)

\section{$\underline{\text { San Isidro: }}$}

Es considerado el centro financiero de Lima debido a su alta actividad económica en comercio y servicio. Limita al norte con los distritos de Lince, la Victoria y Jesús María, al este con el distrito de San Borja, al sur con Surquillo y Miraflores y al oeste con el distrito de Magdalena del Mar. Tiene un área total de $11.1 \mathrm{~km}^{2}$ que incluye gran cantidad de áreas verdes como: El Bosque El Olivar declarado como Monumento Nacional y que presenta varias hectáreas sembradas de olivos.

San Isidro tiene 2 principales ejes corporativos: San Isidro Financiero y Empresarial, por esta razón es sede de empresas nacionales y transnacionales, también de la mayoría de bancos del país como: Banco de Crédito del Perú, Interbank, Banco de la Nación, Banco Continental, Banco del Comercio, Scotiabank, Banco Financiero; de igual forma es sede de las mayores compañías aseguradoras: Rímac Seguros, Pacífico Seguros, La Positiva y otras grandes empresas que tienen su sede principal en este distrito como: Entel, Claro, Saga Falabella, 3M, PriceWaterhouseCooper, etc. Posee una gran actividad cultural reflejada en la cantidad de teatros, librerías, galerías de arte y casas de cultura, además de importantes hoteles, clubes sociales peruanos y centros de convenciones como: Country Club Lima Hotel, Royal Park Hotel, Hotel Westin Libertador, Lima Golf Club, Real Club de Lima, Club de la Banca y Comercio, entre otros. San Isidro es también sede de 38 residencias de embajadas y consulados. Entre sus atractivos turísticos se tiene 2 huacas: Huallamarca y Santa Cruz.

San Isidro está enfocándose en ser un distrito sostenible con programas como: San Isidro Recicla y Cultura Libre, que agrupan acciones institucionales y microacciones (cada persona) así se genera un mayor impacto en contribuir con el 
cuidado del medio ambiente. Ocupa el segundo lugar en la Encuesta de Victimización (2015, Lima) como uno de los distritos con mejor percepción de las personas en seguridad, la encuesta abarcó diversos temas: victimización por hogares, evaluación favorable de los serenazgos, evaluación favorable de la Policía y percepción de inseguridad.

Figura 3.3

\section{Bosque El Olivar}

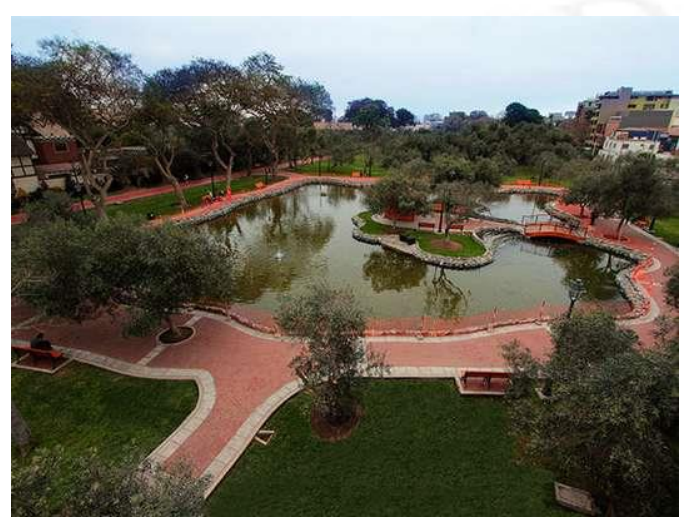

Fuente: Municipalidad de San Isidro (2016)

Figura 3.4

San Isidro Financiero

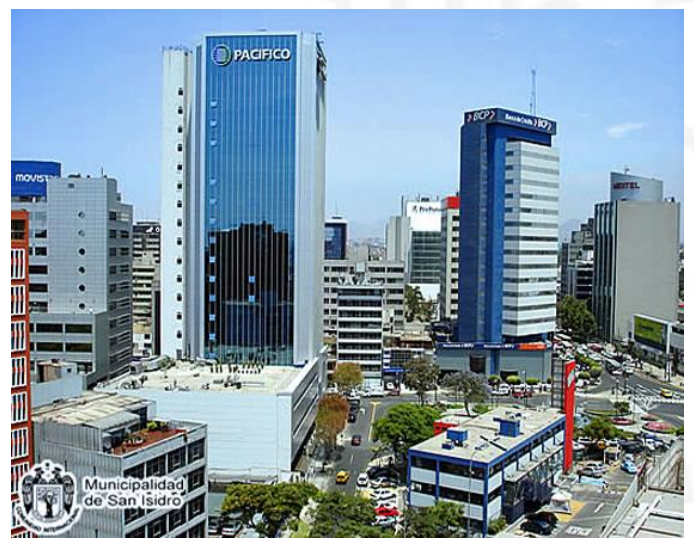

Fuente: Municipalidad de San Isidro (2016)

\section{$\underline{\text { Santiago de Surco: }}$}

Considerado como un distrito turístico, ecológico y tecnológico. Limita al noroeste con Ate Vitarte y San Borja, al este con La Molina, Villa María del Triunfo y San Juan de Miraflores, al oeste con los distritos de Chorrillos, Surquillo, Miraflores y Barranco. Tiene una superficie total de $52.00 \mathrm{~km} 2$. Como ya se mencionó, es el primer Distrito 
Turístico Ecológico de la Región Metropolitana (Lima) por sus parques y lomas como: Parque de la Amistad "María Graña Ottone" (considerado también como primer parque de inclusión social) y Plaza Mayor. Tambien es considera una zona comercial porque es sede de diversos centros comerciales: Jockey Plaza Shopping Center, Boulevard Caminos del Inca, Centro Comercial Chacarilla y Centro Comercial El Polo, además de clubes sociales peruanos: Los Inkas Golf Club, Jockey Club del Perú, entre otras.

Surco está apostando por un ritmo de vida sana mediante deportes, campañas de vacunación y evaluación dental, además de incentivar una tenencia responsable de las mascotas. Ocupa el cuarto lugar en la Encuesta de Victimización (2015, Lima) como uno de los distritos con mejor percepción de las personas en seguridad, la encuesta abarcó diversos temas: victimización por hogares, evaluación favorable de los serenazgos, evaluación favorable de la Policía y percepción de inseguridad.

Figura 3.5

Parque de la Amistad "María Graña Ottone"

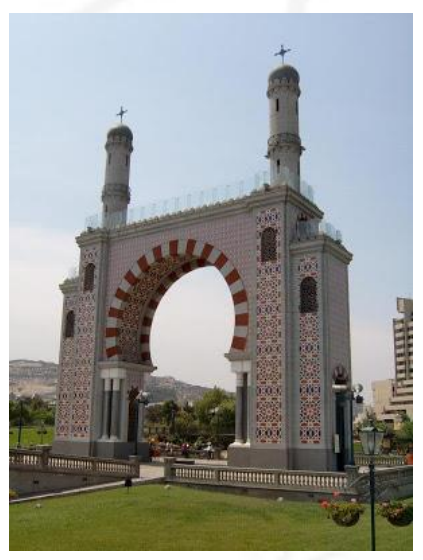

Fuente: Municipalidad de Santiago de Surco (2016)

\subsubsection{Requerimientos de infraestructura y condiciones socio-económicas}

La ubicación de la empresa será en una oficina ubicada de preferencia en el primer piso para que los clientes tengan una mayor accesibilidad, además deberá tener un estacionamiento interno propio. Deberá incluir, a parte de las oficinas administrativas, los servicios higiénicos, kitchenette, almacén de materiales y sala de reuniones.

La infraestructura del edificio deberá ser contra incendios y anti-sísmico, además deberá contar con suficientes salidas de emergencia. En cuanto a la conexión de 
equipos, la oficina deberá tener un adecuado cableado eléctrico que cumpla con todas las condiciones de seguridad.

\subsection{Evaluación y selección de la localización del servicio}

Una vez definidos los factores y alternativas de microlocalización procedemos a realizar el método Ranking de Factores para escoger el distrito que mejor califique para el servicio. Para facilitar el análisis se enumeraron los factores:

Tabla 3.9

Factores de Microlocalización

\begin{tabular}{|c|c|}
\hline Código & Factor \\
\hline F1 & Cercanía a las oficinas de los clientes potenciales \\
\hline F2 & Seguridad ciudadana \\
\hline F3 & Evaluación de los serenazgos y policías \\
\hline F4 & Disponibilidad de áreas de oficina \\
\hline F5 & Costo por metro cuadrado \\
\hline F6 & Disponibilidad de estacionamientos \\
\hline F7 & Tarifa de parqueos de estacionamientos \\
\hline F8 & Facilidad de trámites \\
\hline
\end{tabular}

Elaboración propia

Enumerados los factores se procederá a realizar una tabla de enfrentamiento para determinar la importancia de los mismos y después se analizará la importancia de los factores en relación a cada distrito tomando en cuenta la siguiente escala de calificación.

Tabla 3.10

Escala de calificación

\begin{tabular}{|c|c|}
\hline Excelente & 10 \\
\hline Muy bueno & 8 \\
\hline Bueno & 6 \\
\hline Regular & 4 \\
\hline Deficiente & 2 \\
\hline
\end{tabular}

Elaboración propia

Para el factor 1 se considera a San Borja con la máxima calificación (10) puesto que es el distrito con mayor cantidad de oficinas de empresa contratistas mineras, San Isidro y Surco tienen el mismo puntaje ya que ambas tienen una cantidad similar de oficinas de clientes menor a San Isidro. Respecto al factor 2, la calificación que se asignó a los distritos es proporcional al dato de percepción de inseguridad ciudadana, 
San Isidro tiene una menor percepción de inseguridad por ello tiene el mayor puntaje. La evaluación de serenazgos y policías (factor 3) califica a los distritos proporcionalmente a estos valores, San Isidro tiene un $88.30 \%$ como resultado favorable de la evaluación del serenazgo por ello tiene una calificación de 8, San Borja y Surco tienen un resultado similar pero menor a San Isidro por ellos ambos tienen el mismo puntaje. Al revisar la disponibilidad de áreas de oficina San Isidro tiene mayor espacio $\left(\mathrm{m}^{2}\right)$ de áreas de oficina para ocupación inmediata por eso tiene la máxima calificación (10), le siguen Surco y San Borja cuyas calificaciones son proporcionales al valor de vacancia $\left(\mathrm{m}^{2}\right)$ que tienen. Para calificar al factor 5 se consideró que Surco tiene un menor precio de alquiler por $\mathrm{m}^{2}$ respecto a los otros distritos por eso tiene la mejor calificación (10), San Borja y San Isidro tienen un precio de alquilar similar por ello se les asigna el mismo puntaje. La disponibilidad de estacionamientos (factor 6) le da un mayor puntaje a San Isidro porque tiene 39 estacionamientos (calificación 10) comparado a Surco con 16 estacionamientos (calificación 8) y San Borja con 6 estacionamientos (calificación 6), respecto a la tarifa de estacionamientos (factor 7) San Borja y Surco tiene una tarifa similar y menor a San Isidro por ello tienen una puntuación de 8 respecto a la calificación 6 de San Isidro con una tarifa mucho mayor. Por último el factor 8, facilidad de trámites, da una mayor puntuación a Surco (10) por tener los precios más accesibles respecto a San Isidro (calificación 6) y San Borja (calificación 4) que tiene los precios para gestionar la licencia de funcionamiento más elevados.

Tabla 3.11

Ponderación porcentual de los factores

\begin{tabular}{|c|c|c|c|c|c|c|c|c|c|c|}
\hline Factores & F1 & F2 & F3 & F4 & F5 & F6 & F7 & F8 & Conteo & $\begin{array}{c}\text { Ponderación } \\
(\%)\end{array}$ \\
\hline F1 & & 1 & 1 & 1 & 1 & 1 & 1 & 1 & 7 & $22.58 \%$ \\
\hline F2 & 0 & & 1 & 0 & 0 & 1 & 1 & 1 & 4 & $12.90 \%$ \\
\hline F3 & 0 & 1 & & 0 & 0 & 1 & 1 & 1 & 4 & $12.90 \%$ \\
\hline F4 & 0 & 1 & 1 & & 1 & 1 & 1 & 1 & 6 & $19.35 \%$ \\
\hline F5 & 0 & 1 & 1 & 1 & & 1 & 1 & 1 & 6 & $19.35 \%$ \\
\hline F6 & 0 & 0 & 0 & 0 & 0 & & 1 & 0 & 1 & $3.23 \%$ \\
\hline F7 & 0 & 0 & 0 & 0 & 0 & 1 & & 0 & 1 & $3.23 \%$ \\
\hline F8 & 0 & 0 & 0 & 0 & 0 & 1 & 1 & & 2 & $6.45 \%$ \\
\hline
\end{tabular}


Tabla 3.12

Ranking de factores - Microlocalización

\begin{tabular}{|c|c|c|c|c|c|c|c|}
\cline { 3 - 8 } \multicolumn{2}{c|}{} & \multicolumn{2}{c|}{ San Borja } & \multicolumn{2}{c|}{ San Isidro } & \multicolumn{2}{c|}{ Santiago de Surco } \\
\hline Factor & Peso & Calificación & Puntaje & Calificación & Puntaje & Calificación & Puntaje \\
\hline F1 & $22.58 \%$ & 10 & 2.258 & 8 & 1.8064 & 8 & 1.8064 \\
\hline F2 & $12.90 \%$ & 6 & 0.774 & 8 & 1.032 & 4 & 0.516 \\
\hline F3 & $12.90 \%$ & 6 & 0.774 & 8 & 1.032 & 6 & 0.774 \\
\hline F4 & $19.35 \%$ & 4 & 0.774 & 10 & 1.935 & 6 & 1.161 \\
\hline F5 & $19.35 \%$ & 8 & 1.548 & 8 & 1.548 & 10 & 1.935 \\
\hline F6 & $3.23 \%$ & 6 & 0.1938 & 10 & 0.323 & 8 & 0.2584 \\
\hline F7 & $3.23 \%$ & 8 & 0.2584 & 6 & 0.1938 & 8 & 0.2584 \\
\hline F8 & $6.45 \%$ & 4 & 0.258 & 6 & 0.387 & 10 & 0.645 \\
\hline
\end{tabular}

Elaboración propia

Conclusión: Con los resultados obtenidos en la tabla, San Isidro es el distrito más adecuado para ubicar la empresa de servicio propuesto, ya que este obtuvo el mayor puntaje entre los tres distritos. 


\section{CAPÍTULO IV. DIMENSIONAMIENTO DEL SERVICIO}

\subsection{Relación tamaño - mercado}

Para hallar el tamaño del servicio según el mercado se considerará como base la cuota creciente de empresas contratistas mineras, en base a ello se obtiene el mercado meta que engloba a las empresas contratistas mineras que realizan la actividad de Construcción y recrecimiento de relavera (5\% del total) y que tienen una alta probabilidad de aceptar el servicio propuesto (70\% del total), según las encuestas de aceptación del servicio, por último para determinar la demanda proyectada se toma en cuenta la mejora tecnológica que se da en las empresas, se explica a continuación:

Para la disposición de relaves se emplean equipos llamados hidrociclones que separan el material grueso (relave) del material fino (agua y relave), el material grueso puede ser utilizado para la misma construcción de la relavera o para usarlo como el relleno de labores subterráneas (relleno hidráulico o pasta cementada), lo cual duplica aproximadamente el periodo de duración de relavera por estar reutilizándose el material grueso del relave, es importante mencionar que este proceso está mejorando con el tiempo, por lo que estamos considerando este impacto en la proyección de demanda del proyecto. Por tanto, la demanda del primer año del proyecto consideraría el $50 \%$ (inversamente proporcional al periodo de duración de una relavera) del mercado meta, es decir 3 servicios. De esta forma el mercado se consideraría como factor limitante del tamaño del servicio.

Tabla 4.1

Proyección tamaño - mercado

\begin{tabular}{|c|c|c|c|c|c|c|c|}
\hline Año & 2019 & 2020 & 2021 & 2022 & 2023 & 2024 & 2025 \\
\hline $\begin{array}{c}\text { Incremento anual de } \\
\text { empresas contratistas } \\
\text { (en empresas) }\end{array}$ & 157 & 166 & 174 & 183 & 191 & 200 & 209 \\
\hline $\begin{array}{c}\text { Mercado Meta del } \\
\text { proyecto (en } \\
\text { empresas) }\end{array}$ & 6 & 6 & 7 & 7 & 7 & 7 & 8 \\
\hline $\begin{array}{c}\text { Demanda del proyecto } \\
\text { (empresas) }\end{array}$ & 3 & 3 & 4 & 4 & 6 & 6 & 6 \\
\hline
\end{tabular}

Elaboración propia 


\subsection{Relación tamaño - recursos}

Los recursos productivos que se considerarán para el siguiente servicio serán:

- Mano de obra: La oficina principal de la empresa en Lima estará conformada por el Gerente de la empresa, 1 secretaria, el área de Logística, Ventas y Administración contará con 1 trabajador cada uno. Por otro lado, se contarán con profesionales que llevarán a cabo el trabajo en la ubicación de la empresa contratista minera, ellos conformarán el área de Operaciones, se necesitará: 1 Gerente de Operaciones, 1 Jefe de Seguridad, 2 ingenieros de seguridad, 1 facilitador de obra y 1 administrador de obra. Tomando en cuenta que el ingeniero de seguridad para trabajos de minería puede ser un ingeniero de minas, metalurgista o geólogo, o en el caso de la actividad de recrecimiento de relavera al ser una construcción puede ser un ingeniero civil; se analizó la cantidad de egresados anuales de estas carreras según la Encuesta Nacional de Egresados Universitarios y Universidades del año 2014 realizada por la INEI.

En la tabla 4.2 se puede observar la cantidad de egresados en el año 2014 de carreras: Ingeniería Industrial y Producción u Ingeniería de la Construcción, Sanitaria y Arquitectura, que engloban a la ingeniería de minas, ingeniería metalurgista, geología o ingeniería civil.

Tabla 4.2

Cantidad de egresados de carreras profesionales

\begin{tabular}{lcr}
\hline \multirow{2}{*}{ Carrera más demandadas } & Nacional & \\
\cline { 2 - 3 } & Abs. & $\%$ \\
\hline Total & 196240 & 100,0 \\
Ciencias Administrativas y Comerciales & 32657 & 16,6 \\
\hline Ciencias de la Salud & 26202 & 13,4 \\
Ciencias Económicas y Contables & 22961 & 11,7 \\
Ingenieria Industrial y Producción & 20732 & 10,6 \\
Derecho, Ciencias Politicas y Juridicas & 17766 & 9,1 \\
Ingenieria de Sistemas y Telecomunicaciones & 11680 & 6,0 \\
Ingenieria de la Construcción, Sanitaria y Arquitectus & 11130 & 5,7 \\
Ciencias de la Comunicación & $B 656$ & 4,4 \\
\hline Ciencias Sociales y del Comportamiento & 7722 & 3,9 \\
Educación Inicial y Primaria & 6149 & 3,1 \\
\hline Otros & 30586 & 15,6 \\
\hline
\end{tabular}

Fuente: Encuesta Nacional de Egresados Universitarios y Universidades (2014) 
Además, los ingenieros de seguridad deberán cumplir ciertos requisitos de acuerdo a las leyes vigentes en el Perú para trabajos de minería como tener una capacitación o estudios de especialización en temas de seguridad y salud ocupacional con una duración mínima de 120 horas. Según el Decreto Supremo 024-2016- MEM, el Ingeniero de Seguridad debe tener un mínimo de 3 años de experiencia en la actividad seguridad y salud ocupacional.

A fin de cuantificar este factor, tomamos una muestra a través de una convocatoria en la plataforma Linkedin para un ingeniero de seguridad y salud ocupacional con la especialización requerida, del cual se obtuvo el siguiente detalle.

Tabla 4.3

Cantidad de CV que cumplen requisitos

\begin{tabular}{|c|c|c|}
\hline Día & $\begin{array}{r}\mathbf{N}^{\circ} \mathbf{C V} \\
\text { recibido }\end{array}$ & $\begin{array}{r}\text { ¿Cumplen con requisitos de } \\
\text { espcialización? }\end{array}$ \\
\hline 1 & 16 & 3 \\
\hline 2 & 19 & 4 \\
\hline 3 & 14 & 3 \\
\hline 4 & 10 & 2 \\
\hline 5 & 12 & 4 \\
\hline
\end{tabular}

Elaboración propia

En promedio, el $50 \%$ de los $\mathrm{CV}$ recibidos cumplen con los requisitos de ley para ser un ingeniero de seguridad y salud ocupacional; sin embargo solo el $20 \%$ tiene la especialización y experiencia en la actividad de construcción y recrecimiento de depósitos de relave solicitada.

Con ello se estima que el primer año se podría alcanzar hasta 3 equipos (15 especialistas) de seguridad y salud ocupacional que brinden 9 servicios (cada servicio con una duración aproximada de 4 meses). Este dato permite saber que el factor de mano de obra no limita el tamaño del servicio pues estamos estimando que para el primer año se necesitaría solo 1 equipo de especialistas.

- Materiales: Este factor considerará las diversas herramientas necesarias para el control y monitoreo del cumplimiento de las leyes de seguridad de la empresa. La empresa brindará EPP's a cada trabajador que labore en la actividad de recrecimiento de relavera, además de señales de seguridad (preventivas, prohibitivas e informativas), herramientas de sistemas visuales 
(proyectores, soluciones multimedia, ECRANS) y toda herramienta necesaria para salvaguardar la seguridad de los trabajadores. Hay una amplia gama de empresas que pueden proveer estos materiales como Sekur Perú, 3M, MSA, entre otros, por lo cual no es limitante para el tamaño de servicio.

A continuación se mencionarán algunos equipos de protección personal para los trabajadores:

- Protección para la cabeza: Como cascos, los cuales “están diseñados para resistir el impacto de un objeto de 4 kilos desde una altura de 1.5 m." (José Pérez, 2007, pág. 98). Según la norma ANSI (American National Standard Institute) hay 2 clases de cascos: los de alas completas que brindan protección a la cabeza, cara y nuca, y los que poseen una visera dotados de agarraderas para otros accesorios.

- Protección auditiva: El factor más importante para un buen protector de los oídos es su capacidad para reducir el nivel de exposición del ruido, según el Ministerio de Salud un trabajador puede soportar hasta un máximo de 85 decibeles durante un periodo de 8 horas. Los instrumentos de protección auditivas son: tapones auditivos y orejeras.

- Protección facial y visual: Para evitar la proyección de partículas se usan equipos como: anteojos de protección, lentes panorámicos y protectores faciales.

- Protección respiratoria: Para disminuir la inhalación de partículas tóxicas y aire contaminado.

- Protección contra caídas: Está compuesto por anclajes de acero o concreto, conector de anclaje, línea de vida absorvedora de impacto, arnés de cuerpo completo.

- Protección a los pies: Incluye calzado con puntera de seguridad y/o botas de protección para proteger los pies contra los peligros comunes como objetos que caen o ruedan, cortaduras y pinchaduras.

- Protección a las manos: Como guantes de vinilo, caucho y neopropeno

- Vestimentas: Incluye la protección del cuerpo de polvos, vapores y temperaturas extremas, además estas deben incluir franjas que se visualicen en la oscuridad como un método de visibilidad. 


\subsection{Relación tamaño - tecnología}

La tecnología necesaria para brindar el servicio de gestión de SSO implica el uso de personal altamente calificado en el tema, los mismos que aplican el proceso de prestación de acuerdo a lo indicado en el punto 5.2.2 y diagrama de flujo de la figura 5.8. Considerando que cada proceso de tercerización durará aproximadamente 4 meses y de acuerdo a lo obtenido en el punto 4.2 (3 equipos de especialistas) se puede llegar a atender hasta 9 servicios al año. Por lo tanto, el factor tecnología no limita el tamaño de servicio.

\subsection{Relación tamaño - punto de equilibrio}

Este factor es importante para determinar la cantidad mínima de empresas contratistas mineras a las cuales se debe brindar el servicio para cubrir los costos y garantizar la rentabilidad de la empresa.

Para hallar el punto de equilibrio utilizaremos la fórmula básica que incluye costos variables y fijos anuales que guardan relación con la prestación del servicio. Los costos variables hacen referencia a los costos del material (costo de EPP's, señalizaciones y otros) y mano de obra directa, y los costos fijos hacen referencia a los costos del servicio y mano de obra indirecta.

$$
\text { Servicios mínimos anuales }=\frac{\text { Costos fijos anuales }}{\text { Valor de venta unitario-Costo variable unitario }}
$$

Tabla 4.4

Costos y precios aproximados del servicio

\begin{tabular}{|c|c|}
\hline Costo fijo aproximado anual & S/. $947,740.26$ \\
\hline Costo variable aproximado unitario & S/. 211,386.57 \\
\hline Valor de venta aproximado unitario & S/. $548,281.13$ \\
\hline
\end{tabular}

Elaboración propia

Reemplazando los datos aproximados en la formula mencionada: 


$$
\text { Servicios mínimos anuales }=\frac{947,740.26}{548,281.13-211,386.57}=2.8 \text { proyectos }
$$

Se observa que el número mínimo de servicios que se puede brindar el primer año es de 3 servicios.

\subsection{Selección de la dimensión del servicio}

Como se mencionó, el mercado es limitante para el servicio puesto que la técnica de reutilización de los relaves conlleva a duplicar aproximadamente el periodo de duración de la relavera antes de iniciar un recrecimiento. Con respecto a los recursos, la mano de obra y los materiales no son limitantes porque hay ingenieros que cumplen con las especializaciones que se requiera y una gran cantidad de proveedores de los materiales necesarios y de calidad. Por otro lado, la tecnología tampoco será un limitante del servicio, ya que los especialistas realizarán el proceso de prestación de servicio en base al flujo respectivo durante aproximadamente 4 meses.

A continuación, se planteará un cuadro comparativo de los factores y sus enfoques. 


\section{Tabla 4.5}

Cuadro comparativo de las dimensiones del servicio

\begin{tabular}{|c|l|c|}
\hline $\begin{array}{c}\text { Relación } \\
\text { Tamaño }\end{array}$ & \multicolumn{1}{|c|}{ Enfoque } & ¿Es limitante del tamaño de servicio? \\
\hline Mercado & $\begin{array}{l}\text { Las técnicas de reutilización de relaves (cada vez más eficientes) conllevan a duplicar el periodo de } \\
\text { duración de una relavera, lo cual impacta inversamente proporcional en la demanda (considerando } \\
\text { aproximandamente la mitad del mercado meta). }\end{array}$ & $\begin{array}{l}\text { Si es limitante. La demanda del proyecto consideraría aproximandamente el 50\% } \\
\text { de la demanda proyectada para el primer año, es decir 3 servicios. }\end{array}$ \\
\hline Recursos & $\begin{array}{l}\text { Mano de obra:La especializacion, según ley, en temas de seguridad y salud en el trabajo de los ingenieros } \\
\text { de seguridad serán requisitos indispensables en la empresa. } \\
\text { Materiales: La consultoría brindará EPP’s a cada trabajador y materiales para brindar el servicio. }\end{array}$ & $\begin{array}{l}\text { No es limitante, según la toma de muestra de mano de obra especializada se podría } \\
\text { alcanza } 3 \text { equipos de 5 especialistas para realizar 9 servicios el primer año. }\end{array}$ \\
\hline Tecnología & $\begin{array}{l}\text { La pretación del servicio por parte del personal calificado seguirá un determinado flujo que abarcará 4 } \\
\text { meses aproximandamente. }\end{array}$ & $\begin{array}{l}\text { No es limitante, porque se podría realizar el proceso de prestar 9 servicios de } \\
\text { recursos. }\end{array}$ \\
\hline $\begin{array}{c}\text { Punto de } \\
\text { equilibrio }\end{array}$ & $\begin{array}{l}\text { Se utilizó la fórmula básica para hallar de equilibrio del servicio, se concluyó que se deben realizar 3 } 3 \\
\text { servicios anuales como mínimo para cubrir los costos y garantizar la rentabilidad de la consultoría. }\end{array}$ & No es limitante, se deberá realizar 3 servicios al año. \\
\hline
\end{tabular}

Elaboración propia 


\section{CAPÍTULO V. INGENIERÍA DEL PROYECTO}

\subsection{Definición del servicio basada en sus características de operación}

\subsubsection{Especificaciones técnicas del servicio}

El servicio se rige bajo la Ley $\mathrm{N}^{\circ} 29783$ de Seguridad y Salud en el Trabajo promulgada en el año 2011, el cual decreta la obligatoriedad de los sistemas de gestión de seguridad y salud en todas las empresas y directrices generales sobre su funcionamiento, además señala aspectos específicos que deben cumplir los sistemas de gestión, el Decreto Supremo $\mathrm{N}^{\circ}$ 005-2012-TR reglamento de la ley mencionada presenta guías para la implementación de los sistemas de gestión y la elaboración de reglamentos internos de seguridad y salud.

La Ley de Seguridad y Salud en el Trabajo tiene como objetivo promover una cultura de prevención de riesgos laborales en el país; para ello, cuenta con el deber de prevención de los empleadores, el rol de fiscalización y control del Estado y la participación de los trabajadores y sus organizaciones sindicales, quienes, a través del diálogo social, velan por la promoción, difusión y cumplimiento de la normativa sobre la materia (Ley $\left.\mathrm{N}^{\circ} 29783,2011\right)$.

Cabe resaltar que también se toma en cuenta la modificatoria la Ley $\mathrm{N}^{\circ} 30222$ (modificatoria de la Ley 29783) y su respectivo reglamento Decreto Supremo N0062014-TR, además del reglamento de seguridad y salud ocupacional en minería "Decreto Supremo N 024-2016-MEM" promulgada el 28 de agosto del 2016 para salvaguardar la salud de los trabajadores que se encuentran en la mina.

\subsection{Tecnología existente y proceso de realización del servicio}

\subsubsection{Naturaleza de la tecnología requerida}

\subsubsection{Descripción de la tecnología existente}

El presente servicio debe contar con tecnología referente al manejo de información de los clientes e informática, por ejemplo: 
- Acceso continuo a internet: La función principal de la empresa será llevada a cabo en los tranques de relave de las empresas contratistas mineras. Al estar alejados de la ciudad es necesario que los ingenieros de seguridad se estén comunicando continuamente con personal que se encontrará en la oficina en Lima, sobre todo con el área de logística para proveer de las herramientas necesarias para salvaguardar la seguridad de los trabajadores, además de la comunicación constante, el internet también es una fuente necesaria de investigación y conectividad. Por ello, tanto en la oficina como en la unidad minera contarán con una conexión inalámbrica a internet, el cual contará a su vez con firewall ${ }^{5}$, antispyware y antivirus que aseguran la confidencialidad de la información con la que se trabaja.

- Servidores de correos: Para una comunicación eficaz es necesario contar con servidores de correo seguros como Microsoft Outlook, el cual tiene como objetivo enviar, recibir y gestionar mensajes a través de redes de transmisión.

- Servidores de datos: La empresa manejará una gran cantidad de información confidencial de la empresa contratista minera para poder realizar la matriz IPERC, mapa de riesgos, Reglamento interno de seguridad y salud en el trabajo y la Política y objetivos. Cabe resaltar que estos servidores también estarán protegidos.

- Programa de Sistemas de Gestión de Seguridad: El formato estará realizado con macros En MS. Excel, permitirá el fácil ingreso de los datos y semanalmente presentará un informe automático, así también se podrá visualizar y compartir la información con otros trabajadores.

Además, es importante mencionar que el servicio, como parte de la administración del sistema de seguridad y salud, contará con herramientas y equipos sofisticados en la detección de situaciones que podrían poner en riesgo la seguridad y salud de los trabajadores como:

- Radio portátil: Equipo liviano y compacto que permite organizar los equipos en grupos de conversación, además de brindar sinergias de las comunicaciones.

\footnotetext{
5 También llamado cortafuegos, es un sistema diseñado para bloquear el acceso no autorizado en una red de ordenadores.
} 
- Detector de tormentas: Equipo que tiene un sistema aislado capaz de detectar la formación de la nube de tormenta desde fases tempranas, además genera alarmas cuando la tormenta se acerca de forma peligrosa. La información de rayos se puede almacenar en la base de datos especificando fecha, hora, latitud, longitud, polaridad, corriente, tipo de rayo (nube-tierra o intra-nube) y altura (en el caso de intra-nube)

- Equipo de monitoreo de monóxido: Posee un sistema electrónico con un sensor que genera una alerta cuando la concentración del monóxido de carbono alcanza un nivel sospechoso y dañino para la salud de las personas.

- Luxómetro: Instrumento de medición de la iluminancia real de un ambiente, convierte la luz en impulsos fotoeléctricos, los cuales son interpretados por el equipo. Permite determinar la posibilidad de ocurrencia de una enfermedad ocupacional por deficiencias lumínicas.

- Sonómetro: Instrumento de medida de los niveles del ruido en un lugar y momento determinado.

\subsubsection{Selección de la tecnología}

Para la selección de la tecnología hay una amplia gama de empresas que proveen equipos de alta calidad como: Sekur Perú, 3M, MSA, entre otros. Incluso, también serán consideradas para la compra de EPP's que la empresa entregará a cada trabajador del cliente como parte del servicio.

En la zona de trabajo de la empresa contratista minera se contarán con los siguientes equipos:

Figura 5.1

Sonómetro

\begin{tabular}{|l|}
\hline \multicolumn{2}{|c|}{ EQUIPO: SONOMETRO } \\
Características: Es un instrumento de \\
medida que sirve para medir niveles \\
de presión sonora en un determinado \\
lugar y momento. La unidad con la que \\
trabaja el sonómetro es el decibelio. \\
Precio: S/.250.00
\end{tabular}

Fuente: 3M (2016) 
Figura 5.5

Monitoreo de monóxido

\begin{tabular}{|l}
\hline \multicolumn{1}{|c|}{ EQUIPO: MONITOREO DE MONÓXIDO } \\
Características: \\
- Posee una carcasa revestida de \\
goma que lo hace resistente a \\
golpes y sustancias corrosivas. \\
- Vida útil: 2 años \\
Precio: S/. 1000.00
\end{tabular}

Fuente: 3M (2016)

Figura 5.6

Extintor PQS

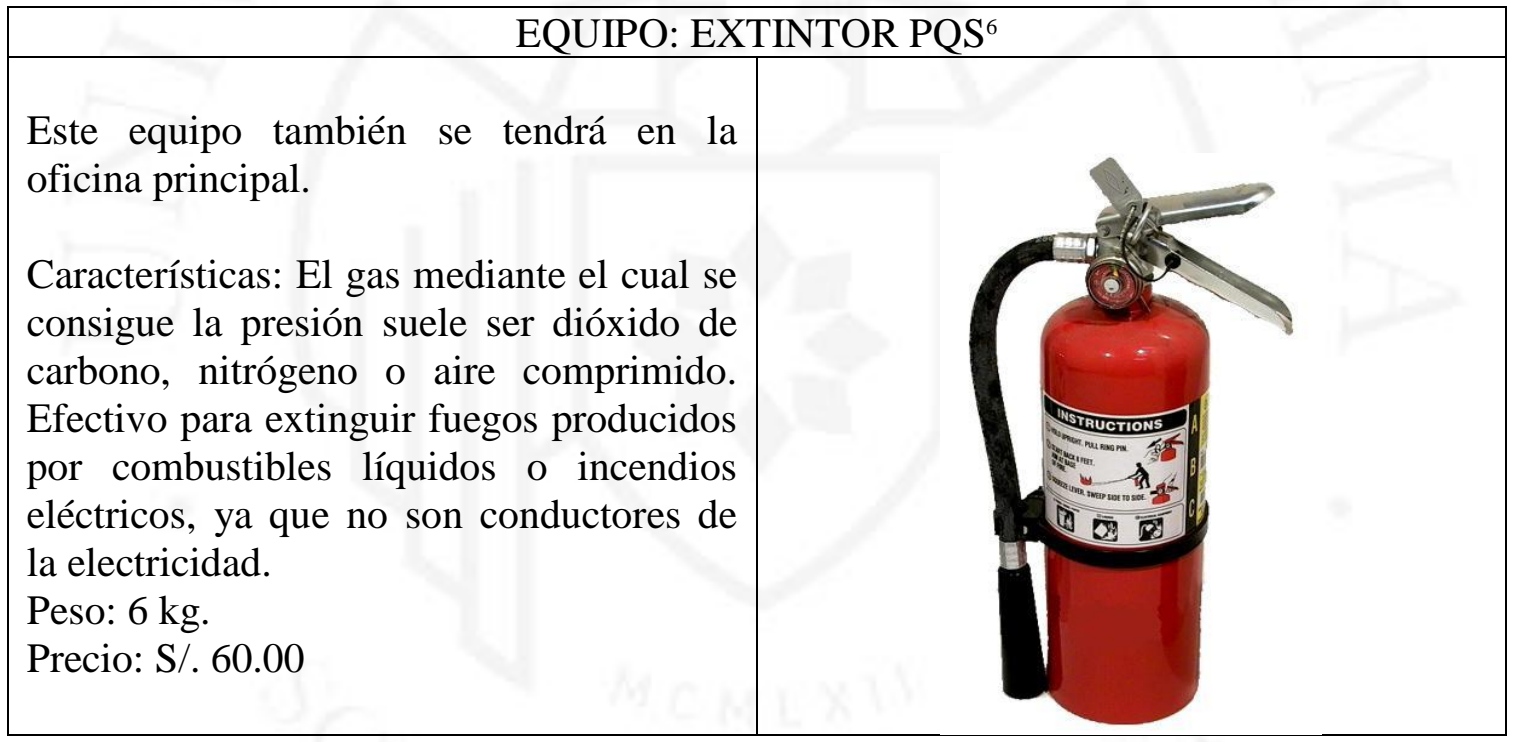

Fuente: 3M (2016)

\subsubsection{Proceso de realización del servicio}

\subsubsection{Descripción del proceso del servicio}

El servicio inicia cuando la empresa tercerizadora cita a una reunión a un posible cliente potencial, en este caso Gerente de la empresa contratista minera, en ella se les explica todo el proceso que involucra la administración del sistema de Gestión de Seguridad y Salud en el Trabajo que contempla la implementación, monitoreo y control en la

${ }^{6}$ Polvo químico seco, apropiado para extinguir tipos de fuego A, B, C 
actividad: Construcción y recrecimiento de depósitos de relave desde una cota de referencia en su empresa, previamente a ello la empresa tendrá mapeada a todos los clientes realicen dicha actividad. También se les informará de los resultados que se obtendrán y se fijará una visita programada a la zona de trabajo para determinar el nivel del proyecto y sobretodo fijar precios unitarios, además en dicha visita se realizará también un mapeo de los riesgos asociados a cada actividad (puntos críticos)

Después de la visita programada, nuevamente se realiza una reunión en la oficina ubicada en Lima para explicar al cliente la forma del desarrollo del servicio y se define el contrato indicando los antecedentes, objeto, monto contractual, forma de pago, adelanto directo, plazo de ejecución de obra, garantías, penalidades, resolución de contrato y responsabilidades de las partes involucradas. Si el cliente no está convencido con el servicio y/o contrato se buscará realizar acuerdos a fin de lograr la aceptación del cliente (en caso no acepte se concluye el proceso) y finaliza con la firma de contrato.

Posteriormente el equipo de especialistas entrega el Programa de Seguridad al cliente en el que se detalla fechas de capacitaciones, simulacros, inducciones, exámenes médicos, auditorías, inspecciones, implementación del SGSST y revisión del IPERC. Antes de iniciar el proyecto se solicitará un adelanto del $20 \%$ y el plazo de entrega del mismo, al momento de entrega del adelanto se proporcionará la garantía acompañada del comprobante de pago al cliente. La amortización del adelanto se realizará mediante descuentos proporcionales en cada uno de los pagos mensuales por la ejecución del servicio. Los pagos mensuales se realizarán mediante valorización según tarifas, que son pagos a cuenta de un contrato según trabajos realizados en el lapso de un mes.

La parte operativa inicia cuando el grupo operativo conformado por el Gerente de seguridad, jefe de seguridad y los supervisores viajará al lugar donde desarrollarán las actividades y en coordinación con el residente de obra y jefaturas operacionales de la empresa contratista minera primero se realizará el Plan de Seguridad, el cual contempla:

- Objetivos generales y específicos

- Metas: Indicadores reactivos (frecuencia, severidad, accidentabilidad) y proactivos de seguridad y salud ocupacional.

- Identificación de Peligros, Evaluación y Control de Riesgos (IPERC) de línea base

- Gestión del incidente 
- Estructura y responsabilidades

- Enumeración de actividades a desarrollar

- Estándares y procedimientos para cada actividad a desarrollar

- Inspecciones planeadas y no planeadas, reuniones, simulacros y entrenamientos.

- Procedimiento en caso de ocurrencia de accidentes

- Programa de capacitación de seguridad

- Preparación para respuesta a emergencias.

Luego de ello, se procede a elaborar el Reglamento Interno de Seguridad, Reglamento Interno de Tránsito, Plan de Emergencia, Mapa de Riesgos del proyecto; las cuales serán difundidos y mediante copias serán entregados a los trabajadores, cabe resaltar que en el panel informativo del área de trabajo se exhibirán los procedimientos, IPERC de línea base, Mapa de Riesgo, Estándares y Plan de Emergencia según la actividad que desarrollen. El Programa Anual y Reglamento Interno será aprobado por el comité de seguridad, la misma que será de conformación paritaria (50\% de los trabajadores y $50 \%$ de la parte del empleador). La Política de Seguridad y Salud en el Trabajo no será realizada por la empresa ya que esta es elaborada por el directorio del cliente, la misma que será considerada en el Plan de Seguridad.

Considerando que para trabajos en mina el reclutamiento de personal es progresivo llegando para la actividad mencionada a 120 trabajadores en su punto más alto y considerando, incluso, doble turno de trabajo, los EPP's serán adquiridas por el área de logística de la empresa y puesta en obra disponible para el personal que es asignado a las tareas. El seguimiento y capacitación para el ingreso del personal nuevo a la obra se realizará según los anexos 4 y 5 del Decreto Supremo 024-2016-MEM concerniente a la inducción y orientación básica y programa de capacitación específica en el área de trabajo respectivamente. La duración de la inducción y orientación básica (anexo 4) será no menor a 8 horas y la capacitación específica teórico practica (anexo 5) será durante 2 días si es actividad de menor riesgo y 4 días si las actividades son de alto riesgo, considerando cada día no menor a 8 horas. Al término de las inducciones el personal será puesto a disposición del residente.

Las actividades diarias que realizará el área de seguridad serán las siguientes:

- En la mañana se asiste a la reunión programada por el área de seguridad de la empresa titular minera. Luego, se realizará la charla de seguridad de 5 minutos a los trabajadores y en ella se indica el reporte de incidencias, medidas 
correctivas, entre otras. Posteriormente, se realizará una reunión con el residente quien brinda la información de las actividades a desarrollarse durante el día.

- Al saber las actividades del día se planeará la ruta de inspección de los supervisores de seguridad priorizando los trabajos de alto riesgo, en cada área de trabajo se solicitará: orden de trabajo, IPERC continuo, lista de equipos o herramientas para la verificación, correcciones y firma de los documentos.

Respecto a las señalizaciones, estas se realizarán de manera continua para prevención y restricción. Para casos de emergencia como tormenta eléctrica, incendios, inundaciones, entre otros, se actuará de acuerdo al plan de emergencia.

Los informes de seguridad serán entregadas al titular de la actividad minera y a la gerencia de le empresa contratista mensualmente y con ello medir el cumplimiento del Programa de Seguridad.

\subsubsection{Diagrama de flujo del servicio}


Figura 5.7

Flujograma de la confirmación del servicio de tercerización

FLUJOGRAMA DE LA CONFIRMACIÓN DEL SERVICIO DE TERCERIZACIÓN SOBRE SEGURIDAD Y SALUD EN EL TRABAJO A EMPRESAS CONTRATISTAS MINERAS

JEFE COMERCIAL

SECRETARIA

EQUIPO DE ESPECIALISTAS

CLIENTE
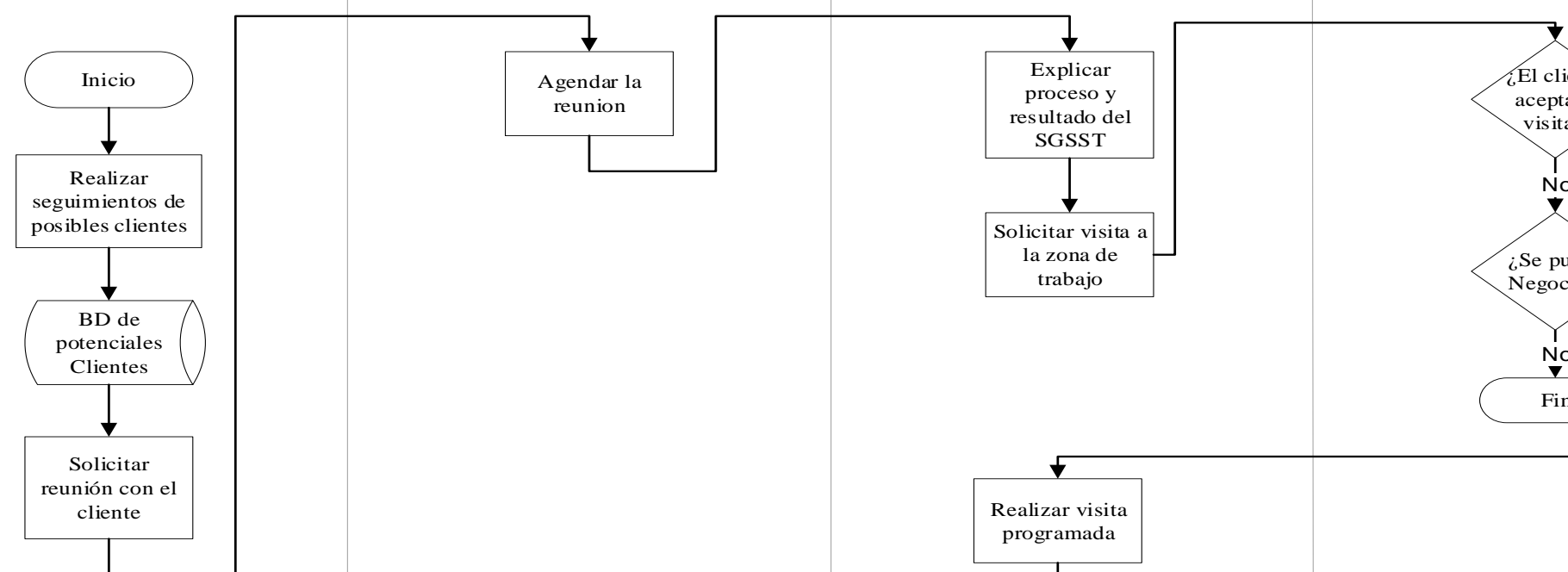

El cliente

acepta la

visita?

Solicitar visi

trabajo

No

¿Se puede - Sít

$\begin{aligned} & \text { ¿Se puede } \\ & \text { Negociar? }\end{aligned}-\mathrm{Si} \rightarrow$

Negociar

Fi

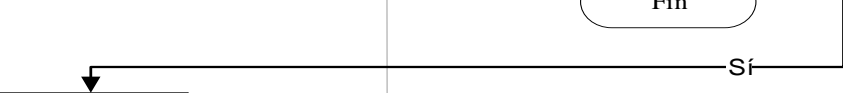

Realizar visita

programada

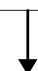

D de puntos

criticos

Agendar la
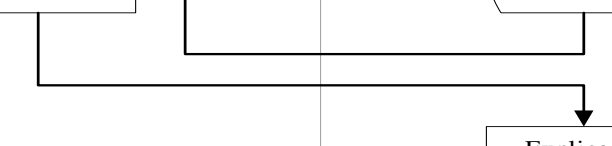

Explicar la

$\downarrow$

A

(Continúa) 
(Continuación)

FLUJOGRAMA DE LA CONFIRMACIÓN DEL SERVICIO DE TERCERIZACIÓN SOBRE SEGURIDAD Y SALUD EN EL TRABAJO A EMPRESAS CONTRATISTAS MINERAS

JEFE COMERCIAI

SECRETARIA
EQUIPO DE ESPECIALISTAS
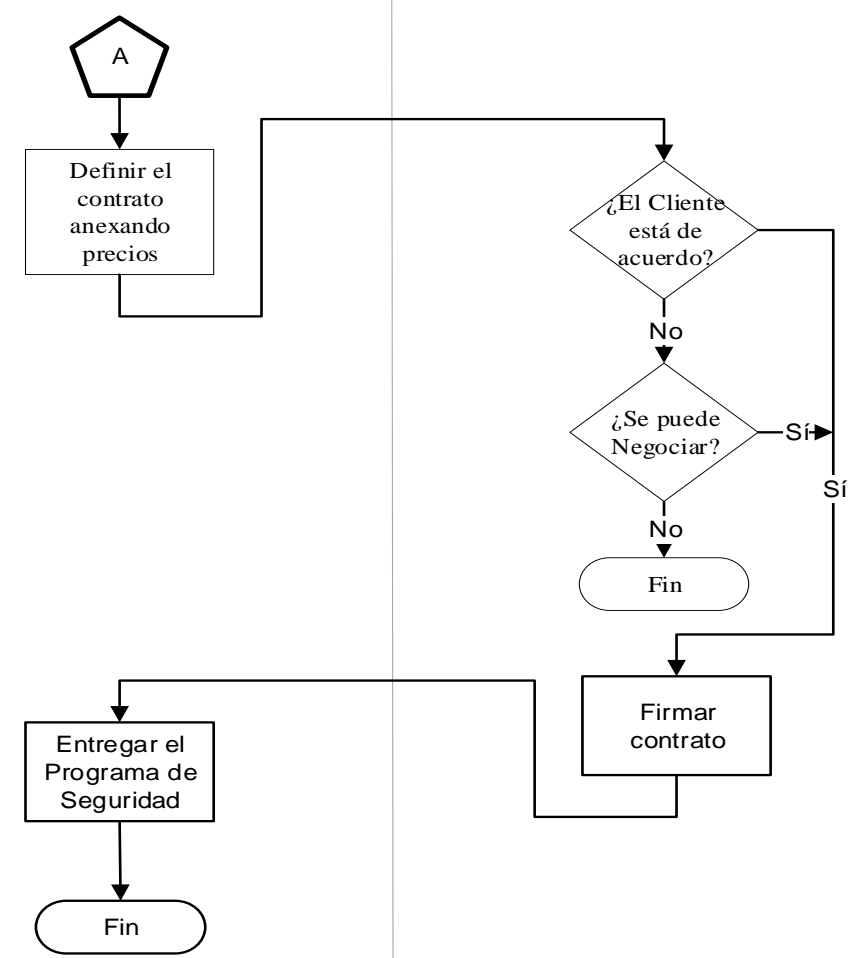

CLIENTE

\section{Elaboración propia}


Figura 5.8

Flujograma de la implementación del Sistema de Gestión de Seguridad y Salud en el Trabajo

FLUJOGRAMA DE LA IMPLEMENTACIÓN DEL SISTEMA DE GESTIÓN DE SEGURIDAD Y SALUD EN EL TRABAJO AL CLIENTE

EQUIPO DE ESPECIALISTAS

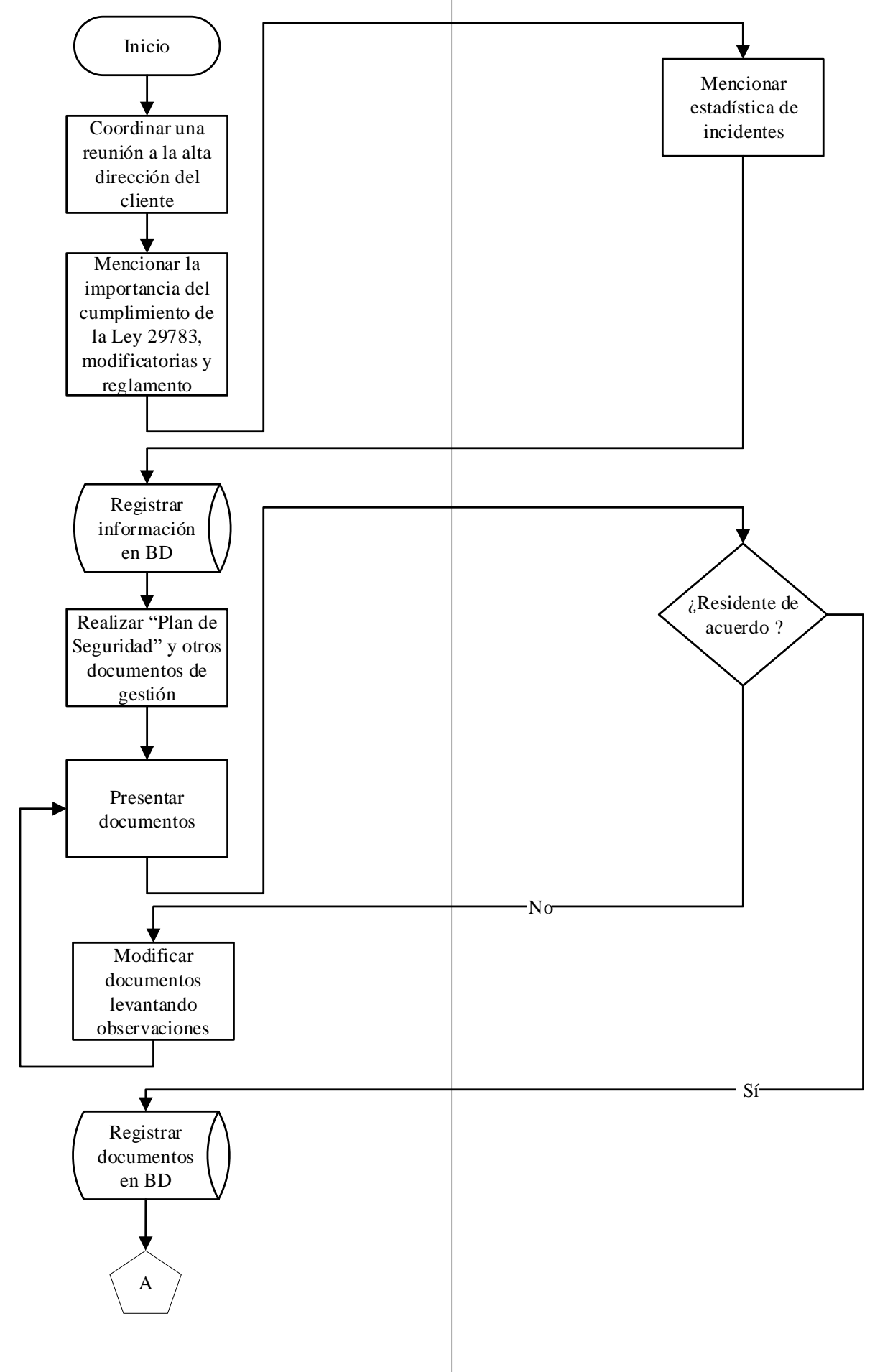

RESIDENTE DEL CLIENTE

(Continúa) 
(Continuación)

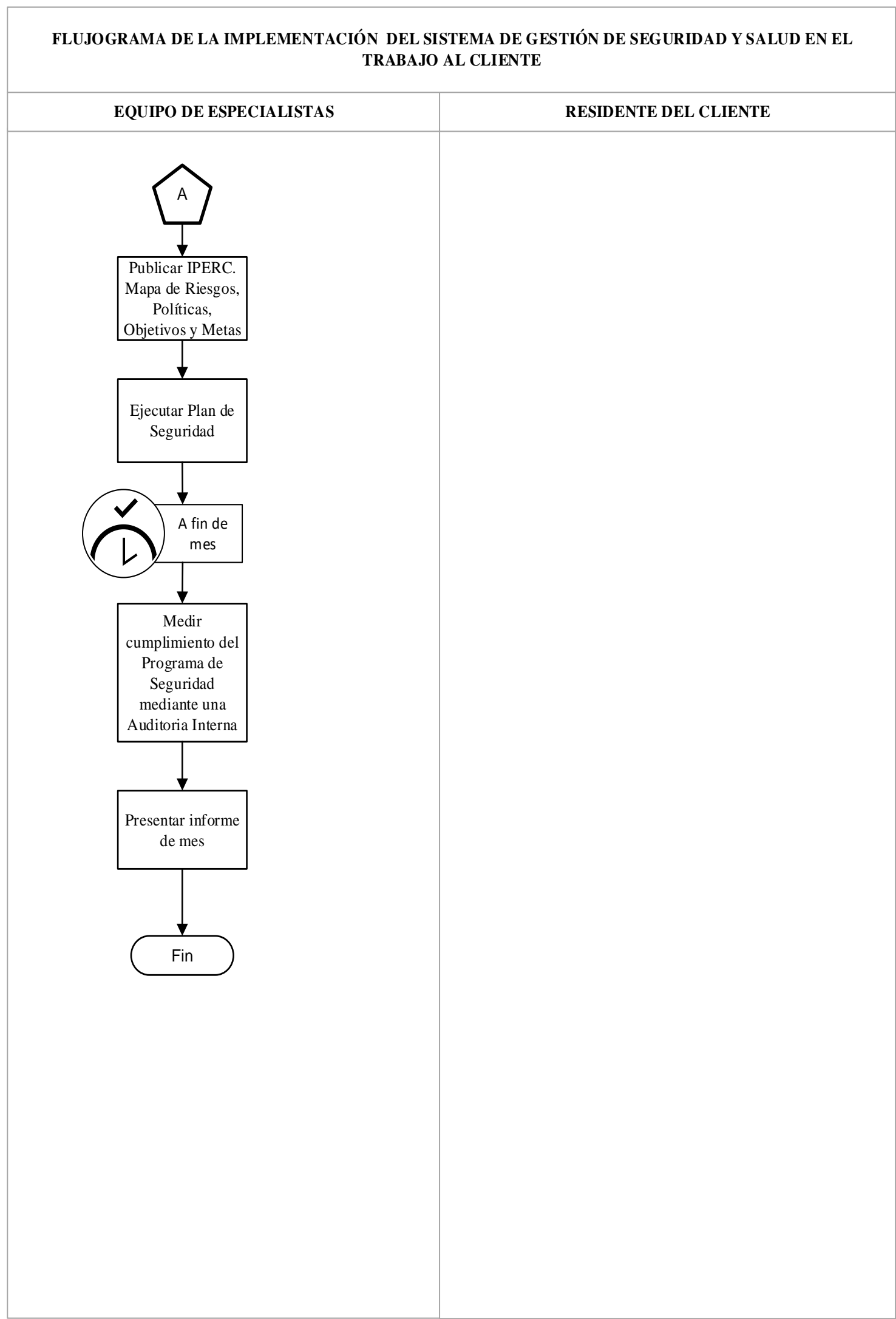

Elaboración propia 
Figura 5.9

Flujograma de las actividades diarias realizadas por el equipo de especialistas

FLUJOGRAMA DE LAS ACTIVIDADES DIARIAS REALIZADAS POR LA EMPRESA EN LA ZONA DE TRABAJO
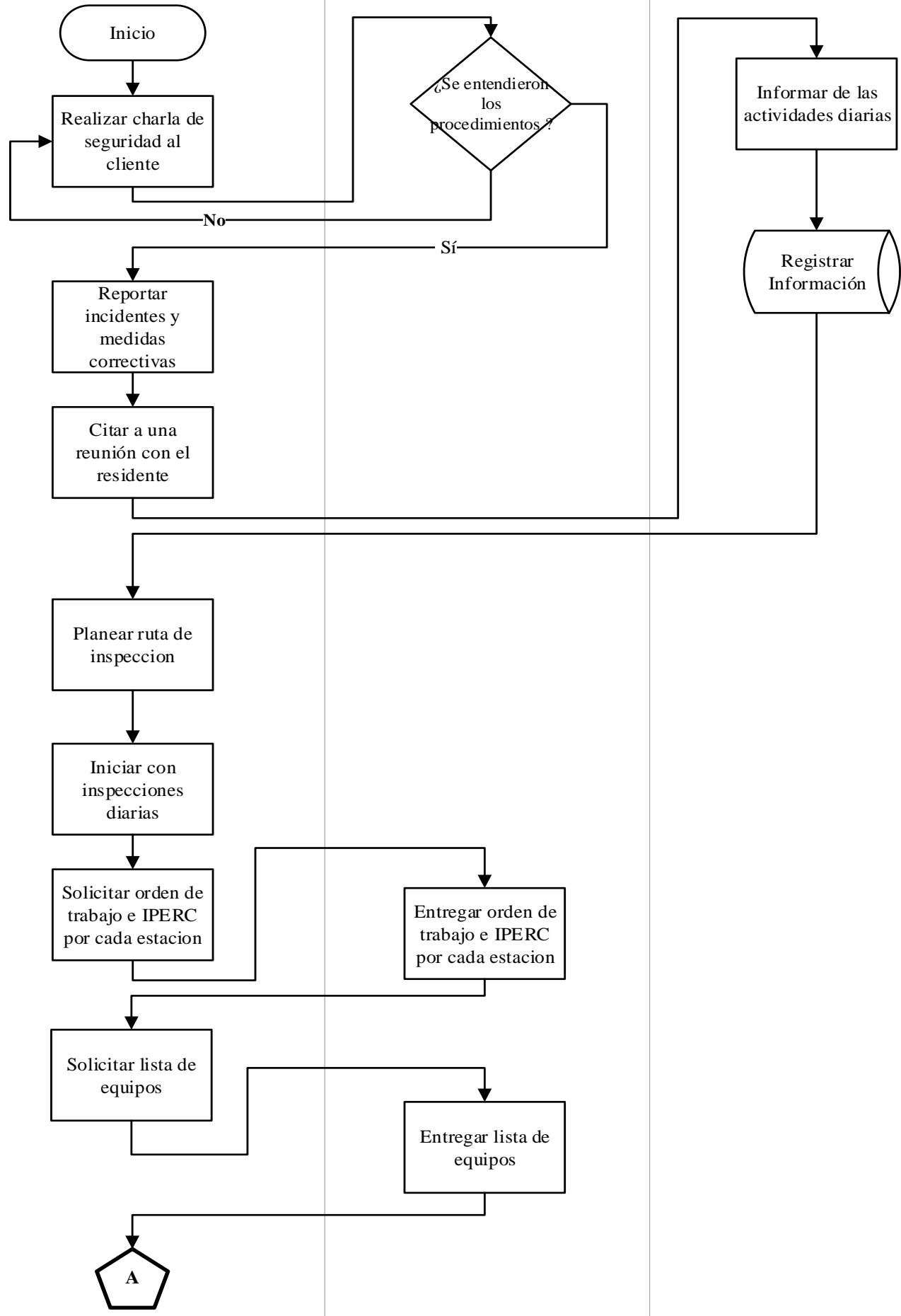

(Continúa) 
(Continuación)

FLUJOGRAMA DE LAS ACTIVIDADES DIARIAS REALIZADAS POR LA EMPRESA EN LA ZONA DE TRABAJO

\section{EQUIPO DE ESPECIALISTAS}

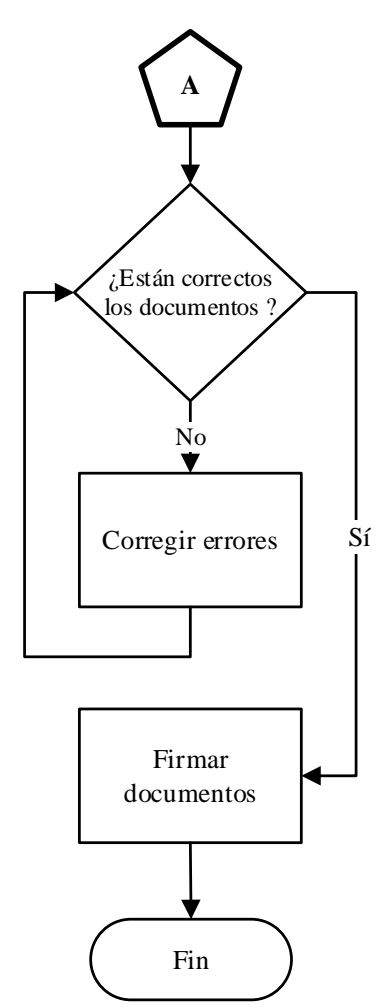

TRABAJADORES DEL CLIENTE

RESIDENTE DEL CLIENTE

Elaboración propia 
Figura 5.10

Flujograma para la solicitud de EPP'S al área logística de la empresa

FLU JOGRAMA PARA LA SOLICITUD DE EPP'S AL ÁREA DE LOGÍSTICA DE LA EMPRESA

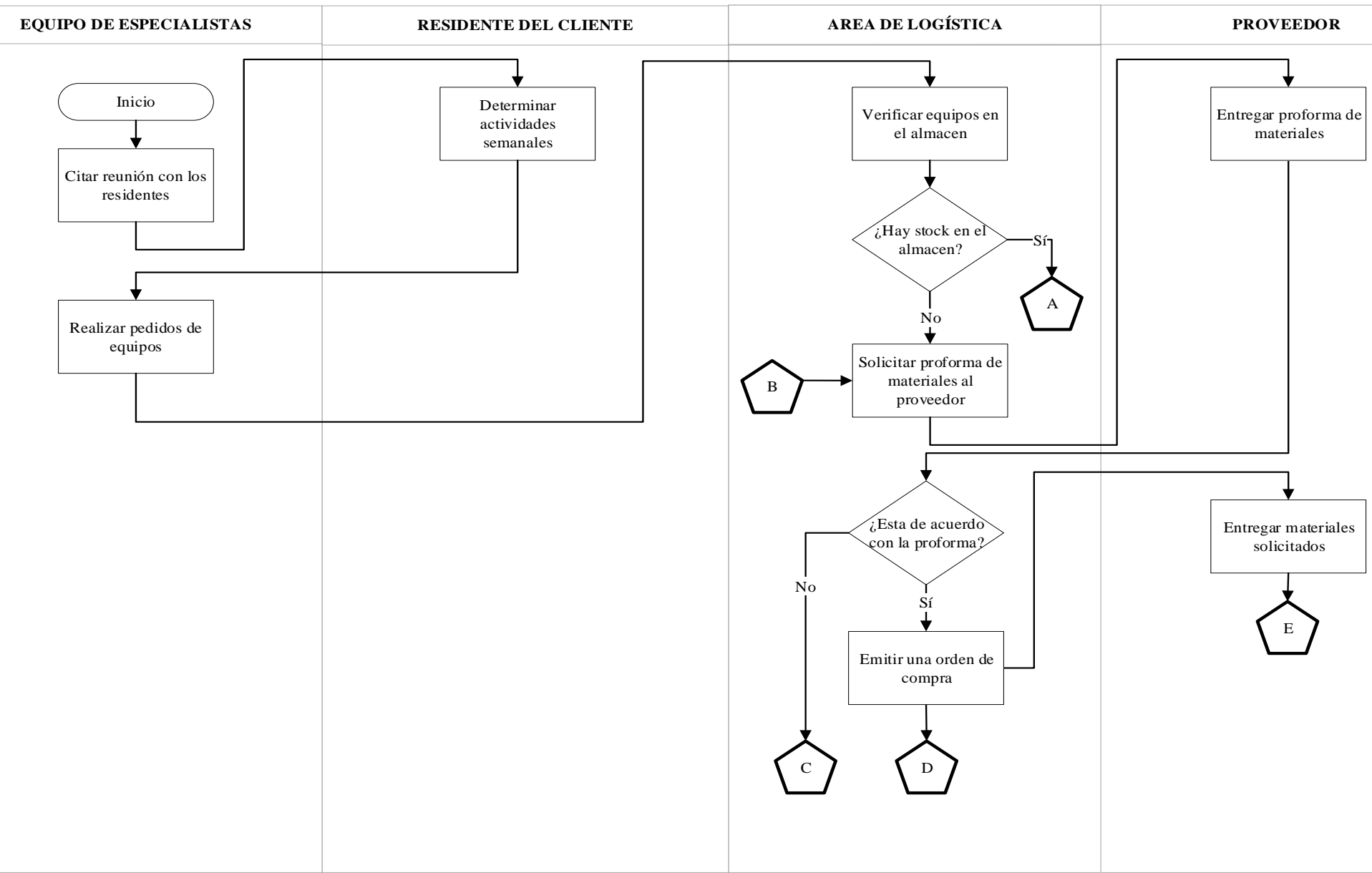


(Continuación)

FLUJOGRAMA PARA LA SOLICITUD DE EPP'S AL ÁREA DE LOGíSTICA DE LA EMPRESA

EQUIPO DE ESPECIALISTAS

D DES

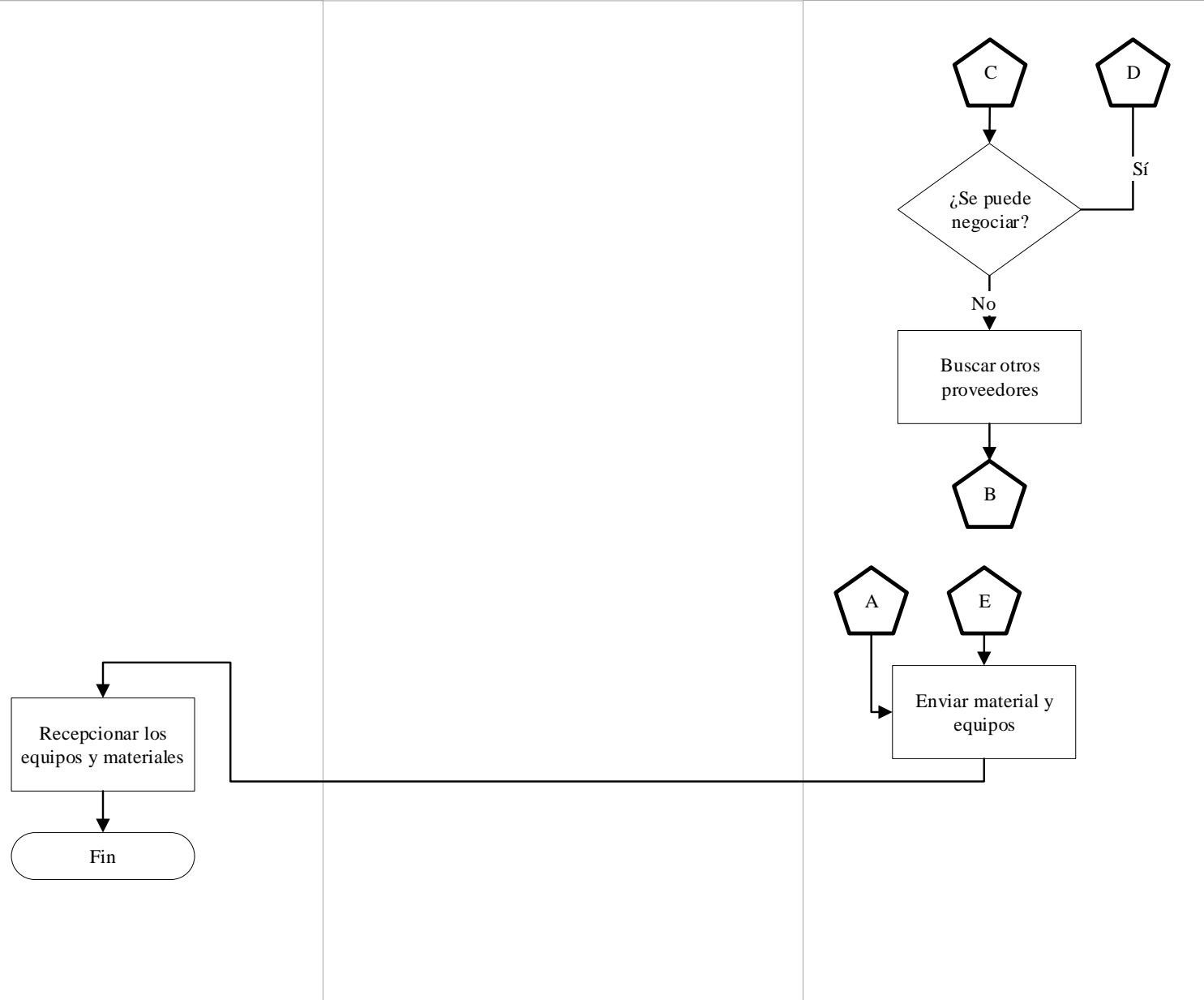

PROVEEDOR

Elaboración propia 


\subsection{Características de las instalaciones y equipo}

\subsubsection{Selección de las instalaciones y equipo}

Para iniciar la instalación de las laptops, impresora, proyector digital, aire acondicionado se debe verificar que la oficina que se alquilará para el servicio cuente con una buena implementación del cableado eléctrico, así como puestas a tierra de los equipos, lo cual garantiza la seguridad de los trabajadores. Otro punto a tomar en cuenta para el alquiler es que la oficina cuente con una gran cantidad de tomacorrientes para que no haya problemas con el uso de dichos equipos.

Por parte de la empresa se implementará puntos red para acceder a los sistemas de la empresa, en caso haya problemas con la conexión inalámbrica. De esta forma se tendrá acceso a los servidores del correo y datos, así como el acceso continuo a internet. Para la identificación de equipos tanto en oficina como en la zona de trabajo se consideró las necesidades básicas para llevar a cabo un buen servicio. Las laptops serán de la marca HP, las impresoras serán de la marca Epson, el proyector digital será de la marca ViewSonic, el equipo de aire acondicionado pertenecerá a la marca Mabe. Los EPP's que entregará la empresa serán de la marca Sekur Perú, 3M y MSA.

\subsubsection{Especificaciones de las instalaciones y equipo}

Será necesario contar con equipos de trabajo en las oficinas y en la zona de trabajo del cliente, como:

- Laptops: La empresa entregará laptops a todos los trabajadores para la realización de informes e investigaciones, ya que al estar siempre en constante movimiento se optó por una laptop y no una computadora fija a un lugar. Cabe resaltar, que la oficina tendrá conexión inalámbrica a internet el cual contará a su vez con antispyware y antivirus que aseguran la confidencialidad de la información con la que se trabaja. Además, las laptops estarán implementados con servidores de correos como Microsoft Outolook y servidores de datos. 
Figura 5.11

Laptop

\begin{tabular}{|l}
\hline \multicolumn{2}{|c|}{ EQUIPO: LAPTOP } \\
Características: \\
- Windows 10 \\
- Disco duro: $1 \mathrm{~TB}$ \\
- Pantalla LED \\
$\quad$ Tamaño de pantalla: 15.6 pulgadas \\
Precio: S/. 1599.00
\end{tabular}

Fuente: HP (2016)

- Impresora: Las oficinas (tanto en Lima como en la zona de trabajo) contarán con una impresora para todo el personal, se buscará que sea rápida para evitar demoras en los procesos, además deberá ser multifuncional y realizar otras funciones como escaneo de documentos y fotocopiadora.

Figura 5.12

Impresora

\section{EQUIPO: IMPRESORA}

Características:

- Impresora multifunción

- Velocidad de impresión: 21 p.p.m

- Resolución: 600 x 1200 dpi

Precio: S/. 799.00

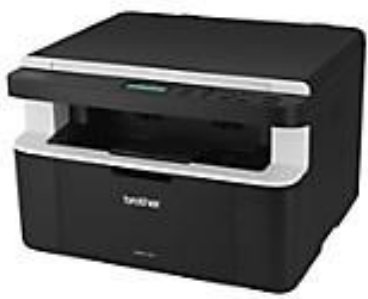

Fuente: Epson (2016)

- Proyector digital: La empresa tendrá con una sala de reuniones, la cual contará con un proyector para realizar la presentación del servicio a los clientes, así como la visualización de resultados e informes al final del servicio. Reflejar los documentos a través del proyector mejorará su visualización. 
Figura 5.13

Proyector Digital

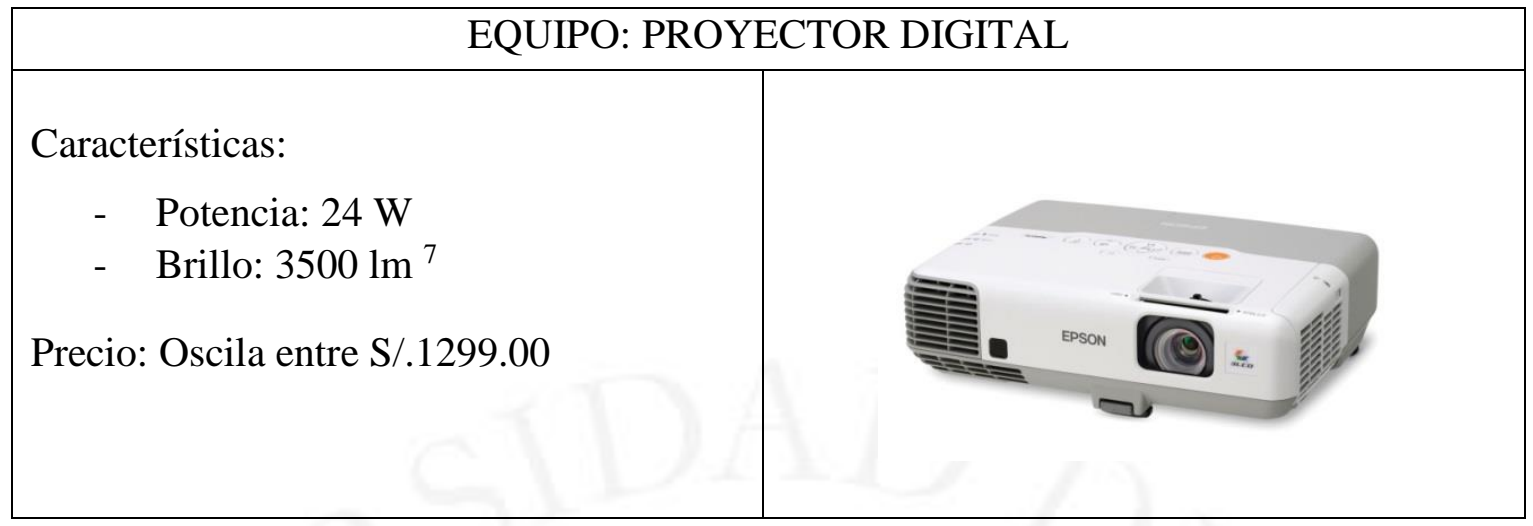

Fuente: ViewSonic (2016)

- Aire acondicionado: Algunas áreas de la oficina de la empresa contarán con aire acondicionado, sobre todo para mejorar el ambiente de trabajo de los colaboradores.

Figura 5.14

Aire Acondicionado

EQUIPO: AIRE ACONDICIONADO

Características:

- Pantalla digital LCD y control remoto.

- Sensor de temperatura de ambiente.

Precio: S/. 769.00

Fuente: Mabe (2016)

- Teléfonos y celulares: Los teléfonos contarán con anexos y serán instalados en todas las áreas de la oficina en donde se encuentren los trabajadores para mejorar la comunicación entre ellos. Además, se les entregará un celular a cada uno de ellos, en los cuales tendrán acceso a los servidores de correo de la empresa cuando sea necesario responder correos electrónicos urgentes. Los

\footnotetext{
${ }^{7}$ Lumen, unidad del Sistema Internacional de Medidas para medir el flujo luminoso emitido por una fuente.
} 
ingenieros que se encuentren en la zona de trabajo del cliente también contarán con celulares.

También se detalla las especificaciones técnicas de los materiales y herramientas importantes para el desarrollo del servicio como equipos de protección personal (EPP) con los que trabajará la empresa como las características, dimensiones, precios, entre otros.

Figura 5.15

Casco Tipo Jockey

\section{EQUIPO: CASCO TIPO JOCKEY}

Material: Estructura de polietileno y un tafilete de suspensión diseñado para mantener el armazón del casco estable en la cabeza

Resistencia: Cumplen con estándares de penetración e impactos verticales. Protege contra impactos y penetración de objetos que caen o vuelan

Precio: S/. 54.00

Fuente: 3M (2016)

Figura 5.16

Botas de jebe con puntera de acero

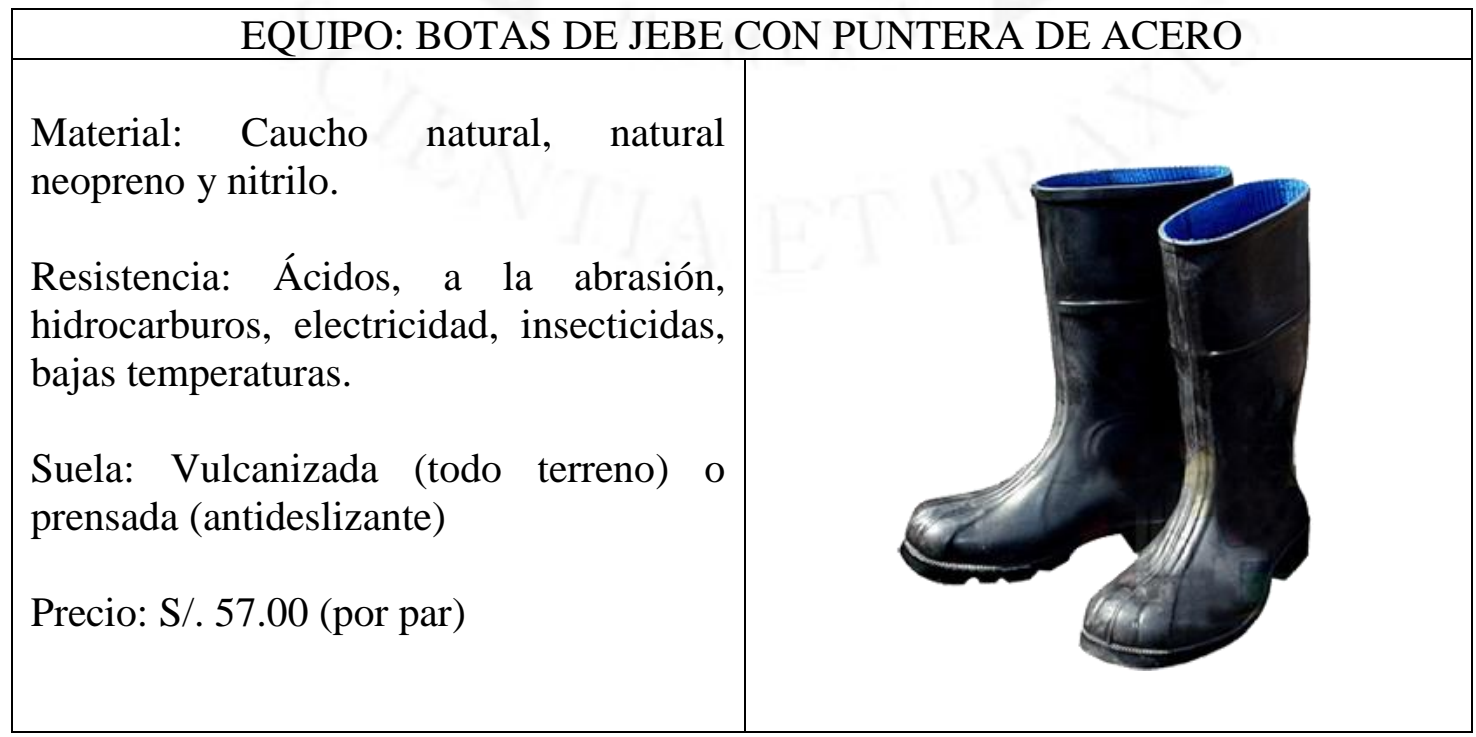

Fuente: MSA (2016) 
Figura 5.17

Tafilete suspensión para casco

EQUIPO: TAFILETE SUSPENSIÓN PARA CASCO
Material: Suspensión plástica inyectada
con anillo central de apoyo en la cabeza.
Banda frontal en tela sintética perforada
para absorción de transpiración.
Se considera como material de repuesto,
ya que el casco tipo jockey ya incluye su
propio sistema de suspensión.
Precio: S/. 15.00

Fuente: 3M (2016)

Figura 5.18

Respirador 7200

\section{EQUIPO: RESPIRADOR 7200}

Material: La pieza facial está hecha de silicón y las bandas elásticas de elastómeros.

Resistencia: Polvos, humos, neblinas, vapores orgánicos, entre otros químicos.

Precio: S/. 71.50

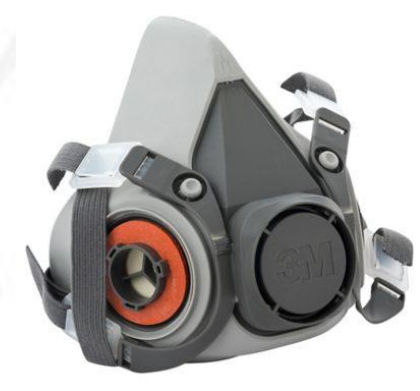

Fuente: 3M (2016) 
Figura 5.19

Guantes de cuero tipo mosquetero

\begin{tabular}{|l|}
\hline \multicolumn{2}{|c|}{ EQUIPO: GUANTES DE CUERO TIPO MOSQUETERO } \\
Características: Flexible y suave, guantes \\
exclusivos para personal de piso que \\
realizan tareas de retiro de materiales. \\
Material: Cuero \\
Resistencia: A rotura y desgarros. \\
Precio: S/. 11.50
\end{tabular}

Fuente: MSA (2016)

Figura 5.20

Mameluco naranja con cinta reflectiva

\section{EQUIPO: MAMELUCO NARANJA CON CINTA REFLECTIVA}

Material: Mameluco de trabajo manga ranglan confeccionado 35\% de algodón y $65 \%$ polyester.

Características: Conjunto slack gabardina con dos bolsillos delanteros y con cintas reflectantes especialmente pensado para poder ser visto a gran distancia.

Precio: s/. 80.00

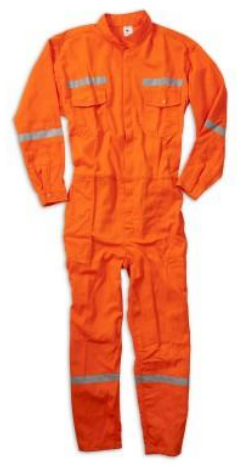

Fuente: MSA (2016) 
Figura 5.21

Tapones para oídos

\begin{tabular}{l}
\hline EQUIPO: TAPONES PARA OIDOS \\
Material: Su forma cónica y su superficie \\
perfectamente lisa han sido \\
específicamente diseñadas para adaptarse \\
cómodamente a la mayoría de los canales \\
auditivos. \\
Resistencia: Efectiva e higiénica \\
protección a los trabajadores que se \\
desempeñan en áreas donde los niveles de \\
ruido superan los $85 \mathrm{~dB}(\mathrm{~A})$. \\
Precio: S/. 5.00
\end{tabular}

Fuente: 3M (2016)

Figura 5.22

Arnés completo para respirador

\section{EQUIPO: ARNÉS COMPLETO PARA RESPIRADOR}

Material: Usado como parte de repuestos para respiradores de media cara.

Precio: S/. 84.00

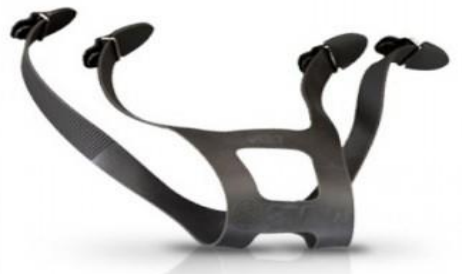

Fuente: 3M (2016) 
Figura 5.23

Lentes de seguridad

\begin{tabular}{l}
\hline \multicolumn{1}{|c|}{ EQUIPO: LENTES DE SEGURIDAD } \\
Material: Sus lunas panorámicas de \\
policarbonato ofrecen un 99\% de \\
protección contra los rayos UV y contra \\
empañaduras. El diseño de estos lentes \\
incrementa su comodidad, debido a los \\
marcos hechos de plástico ligero, \\
fácilmente ajustables. \\
Resistencia: Estos lentes están diseñados \\
para la protección contra salpicaduras, \\
impacto y radiación. \\
Precio: S/. 10.00
\end{tabular}

Fuente: 3M (2016)

Figura 5.24

Guantes de Neoprene

\section{EQUIPO: GUANTES DE NEOPRENE}

Material: Fabricados en hule de neopreno.

Resistencia: A químicos como ácidos, álcalis, ésteres, poseen además resistencia mecánica, resistente a la flama y no conductiva.

Precio: S/. 12.50

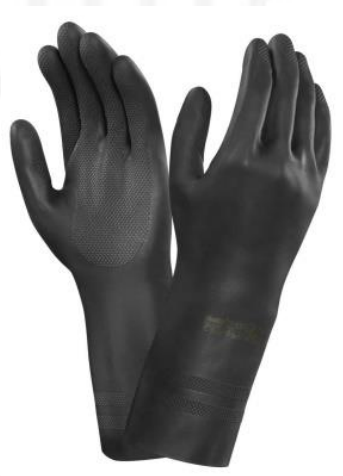

Fuente: MSA (2016) 
Figura 5.25

Filtro de alta eficiencia contra polvos

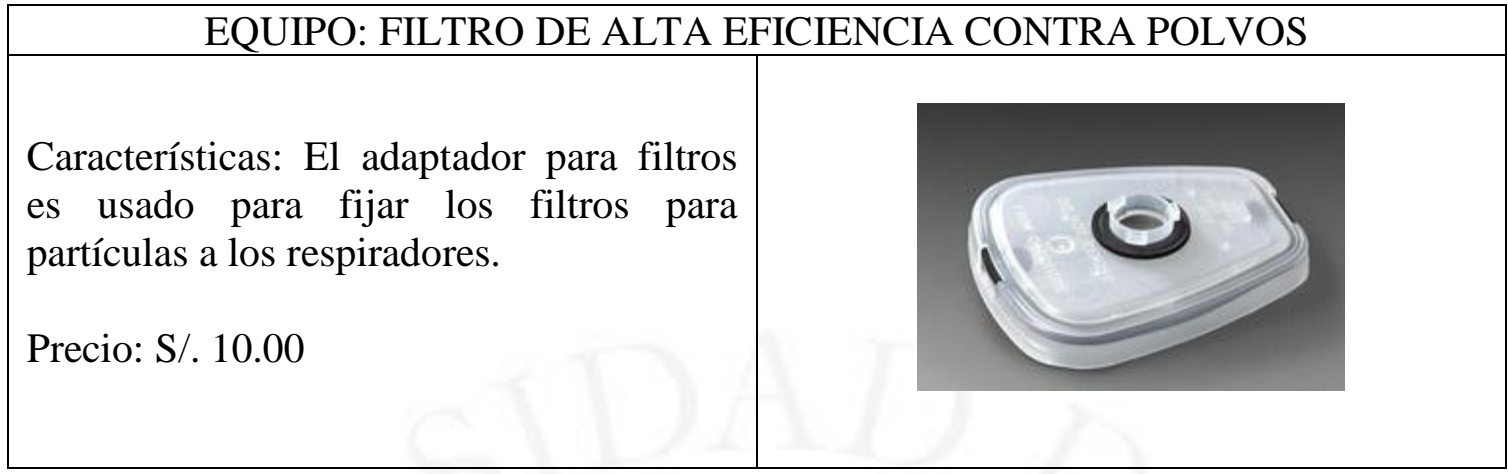

Fuente: Sekur Perú (2016)

Figura 5.26

Guantes de soldador

\section{EQUIPO: GUANTES DE SOLDADOR}

Material: Cuero serraje crupón o de palma en flor vacuno dependiendo del tipo de soldadura, forrado con tejido de algodón

Características: Proteger de las proyecciones que podrían saltar del material que se esté soldando así como proteger las manos y los brazos del calor convectivo de la máquina de soldar.

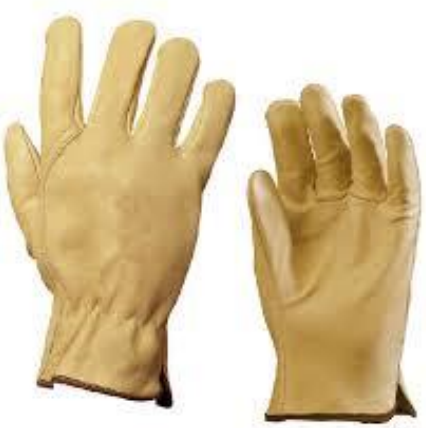

Precio: S/. 24.00

Fuente: 3M (2016) 
Figura 5.27

Correa de seguridad portalámparas de cuero

\begin{tabular}{l}
\hline EQUIPO: CORREA DE SEGURIDAD PORTALÁMPARAS DE CUERO \\
Características: Fabricada en cuero, \\
cinturón de 2 pulgadas y protector lumbar \\
de cuero acolchado de 4 pulgadas, \\
equipada con hebilla, 02 anillos tipo "D" \\
de alto impacto, línea de vida de $1.80 \mathrm{mts}$. \\
con gancho doble seguro probado a 5,000 \\
lbs., y con portaherramientas, accesorios \\
metálicos importados. \\
Precio: S/. 25.00
\end{tabular}

Fuente: 3M (2016)

Figura 5.28

Zapatos con puntera de acero

\section{EQUIPO: ZAPATOS CON PUNTERA DE ACERO}

Material: Tobillera acolchada con espuma de alta resistencia para comodidad del calzado. El forro del calzado debe ser fabricado en cuero flor y descarne (antimicótico natural). Puntera de acero ergonométrica.

Resistencia: Aislación térmica thinsulate (fibra para mantener el calor corporal), para mantener el pie en condiciones óptimas de temperatura y humedad.

Precio: S/. 72.00

Fuente: 3M (2016)

Figura 5.29

Silbato de policía

\section{EQUIPO: SILBATO DE POLICIA}

Material: Silbato de PVC color negro con bola de corcho en el interior. Lleva argolla para poner en el cordón.

Precio: S/. 5.00

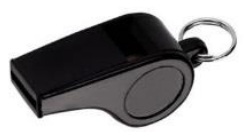

Fuente: 3M (2016) 
Figura 5.30

Luna clara para máscara de soldar

\begin{tabular}{l}
\hline EQUIPO: LUNA CLARA PARA MASCARA DE SOLDAR \\
Material: Confeccionada en Nylon \\
termoplástico de alta resistencia al calor, \\
brinda comodidad por su diseño \\
ergonómico. Liviana y fresca. \\
Características: Protege los ojos y la cara \\
de polvo, virutas, chispas, calor, \\
salpicaduras químicas y otras sustancias \\
que puedan afectar el rostro del \\
trabajador. \\
Precio: S/. 25.00
\end{tabular}

Fuente: MSA (2016)

Figura 5.31

Cintas reflectivas

\section{EQUIPO: CINTAS REFLECTIVAS}

Material: Es una lámina reflectiva autoadhesiva de color amarillo haciéndola más visibles de noche. También aplica para diversos trabajos de señalización.

Fuente: 3M (2016) 
Figura 5.32

Trajes Keyguard

\begin{tabular}{|l|l|}
\hline \multicolumn{3}{|c|}{ EQUIPO: TRAJES KEYGUARD } \\
\hline Material: Pantalón drill & 100\% Algodón \\
al costado de las piernas con tapa y botón & \\
con cinta reflectiva color plata & \\
en las piernas. & \\
Precio: S/. 69.90
\end{tabular}

Fuente: 3M (2016)

Figura 5.33

Capotines

\section{EQUIPO: CAPOTINES}

Material: Fabricado en PVC y Poliéster. Espesor del material $0.10 \mathrm{~mm}, 0.32 \mathrm{~mm}$ y $0.42 \mathrm{~mm}$.

Características: Poncho impermeable con capucha para la protección de área de la cabeza.

Precio: S/. 19.90

Fuente: 3M (2016)

Figura 5.34

Cortavientos

\section{EQUIPO: CORTAVIENTOS}

Material: Fabricado en tela drill.

Características: Proteger cuello y cara del sol.

Precio: S/. 9.90

\section{ANTाए}

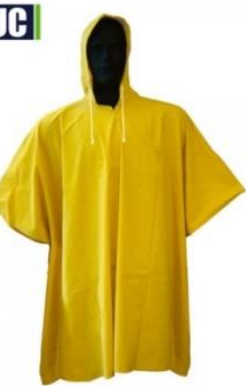

Fuente: 3M (2016) 
Figura 5.35

Chalecos de seguridad

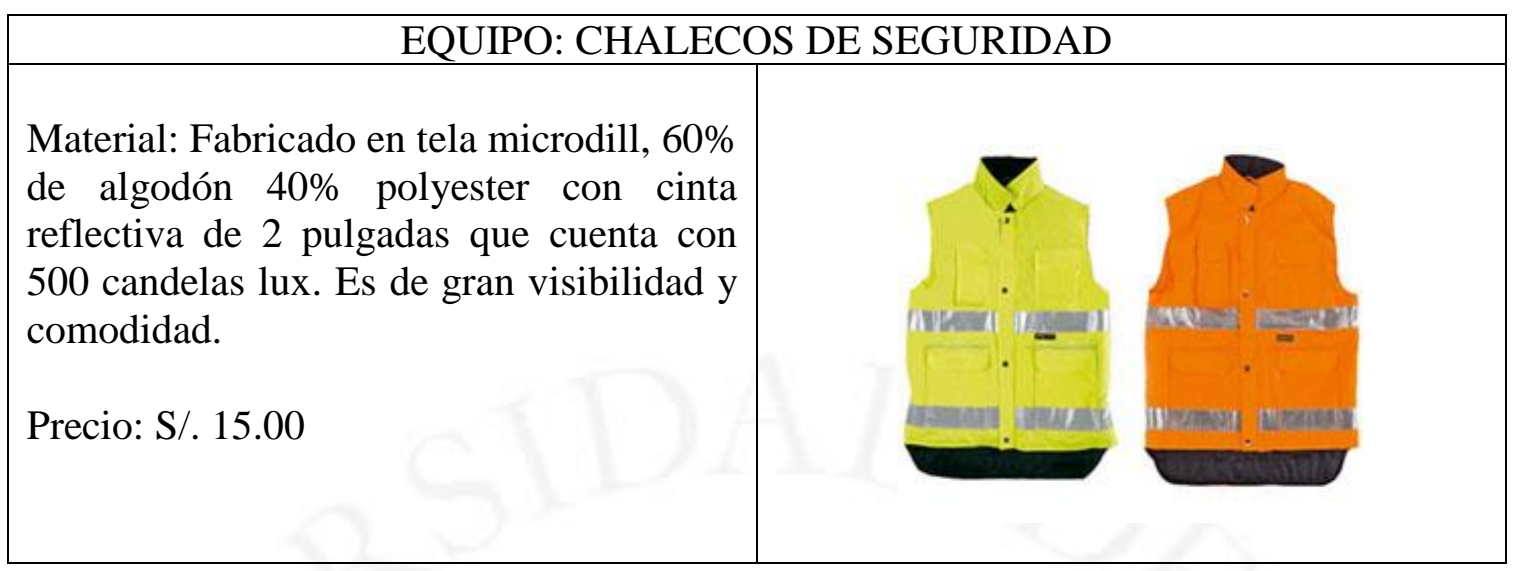

Fuente: 3M (2016)

\subsection{Capacidad instalada}

\subsubsection{Cálculo de la capacidad instalada para el servicio}

El factor limitante del servicio está determinado por el mercado, como se mencionó en el Capítulo IV en el punto Tamaño - Mercado, ya que técnicas más eficientes para la reutilización de relaves podrían duplicar el periodo de duración de una relavera, por ello consideraremos como capacidad instalada 3 servicios para el primer año, lo cual representa el 50\% de la demanda del proyecto.

Además, los 3 servicios definidos para el primer año se alinean al tiempo de duración mínimo para cada proyecto que es de 4 meses y al punto de equilibrio que se obtiene en el punto 4.4, en el que se menciona que la cantidad mínima de empresas contratistas mineras a las cuales se debe brindar el servicio para cubrir los costos y garantizar la rentabilidad son 3 empresas.

En la tabla $\mathrm{N}^{\circ} 5.1$ se muestra la cantidad proyectada de especialistas que tendrá la empresa, tomando en cuenta que se tendrá un mejor posicionamiento, lo cual aumentará la capacidad de manejo de proyectos. 


\section{Tabla 5.1}

$\mathrm{N}^{\circ}$ de equipos, especialistas y empresas abarcadas proyectadas

\begin{tabular}{|c|c|c|c|c|c|c|c|}
\hline Año & 2019 & $\mathbf{2 0 2 0}$ & $\mathbf{2 0 2 1}$ & $\mathbf{2 0 2 2}$ & $\mathbf{2 0 2 3}$ & $\mathbf{2 0 2 4}$ & $\mathbf{2 0 2 5}$ \\
\hline Demanda (empresas) del proyecto & 6 & 6 & 7 & 7 & 7 & 7 & 8 \\
\hline $\mathrm{N}^{\circ}$ de consultores & 5 & 5 & 10 & 10 & 10 & 10 & 10 \\
\hline Equipo de consultores en zona de trabajo * & 1 & 1 & 2 & 2 & 2 & 2 & 2 \\
\hline Proyectos abarcados ** & 3 & 3 & 4 & 4 & 6 & 6 & 6 \\
\hline
\end{tabular}

Nota: *Considerando que 1 equipo está conformado por 5 miembros

**Considerando que la duración promedio de un proyecto es de 4 meses.

Elaboración propia

Se debe tomar en cuenta también que el equipo en la zona de trabajo seguirá un sistema de trabajo atípico de 14 días trabajados y descansarán 7 días, que es el mismo sistema usado por empresas contratistas en minería.

Tabla 5.2

Capacidad de atención de la empresa

\begin{tabular}{|c|c|c|c|c|c|c|c|}
\hline Año & 2019 & 2020 & 2021 & 2022 & 2023 & 2024 & 2025 \\
\hline Demanda (empresas) del proyecto & 6 & 6 & 7 & 7 & 7 & 7 & 8 \\
\hline Capacidad de atención (empresas) & 3 & 3 & 4 & 4 & 6 & 6 & 6 \\
\hline
\end{tabular}

Elaboración propia

\subsubsection{Cálculo detallado del número de recursos para el servicio}

La cantidad de los materiales usados para el servicio va a depender de la cantidad de equipos de especialistas que estarán trabajando en forma paralela en las zonas de trabajo, ya que el aumento de esta variable es directamente proporcional a los proyectos que abarcará la empresa.

En la tabla 5.3 se muestra la cantidad de los principales materiales que involucra el servicio para cada año proyectado.

Se debe considerar:

- Los EPP's entregados dependerán de la cantidad de trabajadores de la empresa contratista minera en cada proyecto.

- Los equipos como laptop y celulares se entregarán a cada trabajador de la empresa.

- Se considerarán 1 impresora y 1 proyector digital que se encontrarán en la oficina de la empresa, además cada equipo de especialistas tendrá un proyector digital y una impresora adicional en la zona de trabajo pues es necesario para las capacitaciones e inducciones. 
- Los teléfonos con anexos y aire acondicionado estarán en cada área de trabajo en la oficina de la empresa.

- El luxómetro, sonómetro, detector de tormentas, equipo de monitoreo de monóxido y radios Motorola serán considerados por cada proyecto.

Tabla 5.3

$\mathrm{N}^{\circ}$ de materiales necesarios proyectado

\begin{tabular}{|l|c|c|c|c|c|c|c|}
\hline \multicolumn{1}{|c|}{ Añ̃o } & $\mathbf{2 0 1 9}$ & $\mathbf{2 0 2 0}$ & $\mathbf{2 0 2 1}$ & $\mathbf{2 0 2 2}$ & $\mathbf{2 0 2 3}$ & $\mathbf{2 0 2 4}$ & $\mathbf{2 0 2 5}$ \\
\hline $\mathrm{N}^{\circ}$ de especialistas & 5 & 5 & 10 & 10 & 10 & 10 & 10 \\
\hline Equipo de especialistas en zona de trabajo & 1 & 1 & 2 & 2 & 2 & 2 & 2 \\
\hline Proyectos abarcados & 3 & 3 & 4 & 4 & 6 & 6 & 6 \\
\hline Personal de cada proyecto *** & 60 & 60 & 60 & 60 & 60 & 60 & 60 \\
\hline Equipo: Laptop & 11 & 11 & 16 & 16 & 16 & 16 & 16 \\
\hline Equipo: Impresora & 2 & 2 & 3 & 3 & 3 & 3 & 3 \\
\hline Equipo: Proyector digital & 2 & 2 & 3 & 3 & 3 & 3 & 3 \\
\hline Equipo: Aire acondicionado & 3 & 3 & 3 & 3 & 3 & 3 & 3 \\
\hline Equipo: Telefonos & 7 & 7 & 7 & 7 & 7 & 7 & 7 \\
\hline Equipo: Celulares & 11 & 11 & 16 & 16 & 16 & 16 & 16 \\
\hline Equipo: Luxómetro & 1 & 1 & 2 & 2 & 2 & 2 & 2 \\
\hline Equipo: Sonómetro & 1 & 1 & 2 & 2 & 2 & 2 & 2 \\
\hline Equipo: Detector de tormentas & 1 & 1 & 2 & 2 & 2 & 2 & 2 \\
\hline Equipo: Monitoreo de Monóxido & 1 & 1 & 2 & 2 & 2 & 2 & 2 \\
\hline Equipo: Radio Motorola & 4 & 4 & 8 & 8 & 8 & 8 & 8 \\
\hline
\end{tabular}

Nota: *** Considerando que la cantidad de trabajadores mínimo para un recrecimiento de relave es de 60 trabajadores

Elaboración propia

\subsection{Resguardo de la calidad}

\subsubsection{Calidad del proceso y del servicio}

La calidad del servicio se medirá en base al cumplimiento de los objetivos y metas planteados en el Programa de Seguridad, por ejemplo:

- $100 \%$ de los exámenes médicos de ingreso y retiro de los trabajadores.

- Capacitación al $100 \%$ de lo programado.

- Revisión de los procedimientos escritos de trabajo seguro según el programa establecido.

- Cumplimiento de simulacros, inspecciones, entre otros programados en base al programa de Seguridad.

Las cuales redundarán en el resultado de seguridad: cero (0) accidentes y cero (0) registros de trabajadores con enfermedades ocupacionales. 
A futuro, para complementar todas las mediciones de calidad durante el proceso, la empresa buscará obtener la certificación de calidad en los servicios ISO 9001:2015. Esta certificación garantizará la implementación de un sistema de gestión de calidad basado en el proceso. Para la obtención de esta certificación, la empresa deberá evaluar el sistema actual de calidad, agregar sistemas y procesos para satisfacer los requisitos y documentar los procesos con un "Manual de calidad, Procedimiento e instrucciones de Trabajo". También se buscará obtener la certificación internacional ISO 45001:2018 para la implementación de un SGSST, de esta manera se buscará la mejora continua en el desempeño y cumplimiento de objetivos del sistema para prevenir lesiones y enfermedades relacionadas con el trabajo proporcionando ambientes laborales seguros y saludables, es importante resaltar que la estructura de esta norma permite integrarse con diferentes Sistemas de Gestión ISO.

\subsubsection{Niveles de satisfacción del cliente}

Para poder medir la satisfacción del cliente se tomará en cuenta de lo siguiente:

- La entrega del Certificado de Imagen del desempeño hacia la Seguridad y Salud Ocupacional otorgada por la empresa titular minera al final del proyecto.

- Los resultados de los índices de seguridad (índice de frecuencia, severidad y accidentabilidad) igual a cero (0) durante la ejecución del proyecto, cabe resaltar que este resultado son estándares para empresas titulares mineras tanto a nivel nacional como internacional, además para la contratación de las empresas contratistas mineras es requisito fundamental tener los resultados de los índices de seguridad igual a cero en los últimos 2 proyectos.

Indice de Frecuencia de Accidentes (IF): Número de accidentes mortales e incapacitantes por cada millón de horas-hombre trabajadas.

Indice de Severidad de Accidentes (IS): Número de días perdidos por cada millón de horas-hombre trabajadas.

Indice de Accidentabilidad: Combina el índice de frecuencia de lesiones con tiempo perdido (IF) y el índice de severidad de lesiones (IS), como un medio de clasificar a las empresas mineras.

El resultado objetivo se logrará con la aplicación de acciones de control (preventivas y protección) y un adecuado cumplimiento del proceso del servicio, 
haciendo mayor énfasis en las capacitaciones y charlas diarias que debe recibir el personal de la empresa contratista minera, de esta forma se generará una cultura de prevención de riesgos laborales en todos los niveles, iniciando de la gerencia, la cual es la base para gestión propuesta.

- Encuestas a la gerencia y línea de mando (residente) de la empresa contratista minera, una vez que termine todo el proyecto, se le preguntará al cliente si quedó satisfecho con el servicio y que cree que pudo ser mejor durante el proceso (lo mencionado servirá para el mejoramiento continuo).

\subsubsection{Medidas de resguardo de la calidad}

Se realizará en base a la gestión documental, cuyas evidencias y registros serán resguardadas en archivos digitales y físicos.

\section{6 Impacto ambiental}

La empresa con el interés y compromiso con el medio ambiente implementará acciones simples en la oficina principal para poder reducir los riesgos para el medio ambiente, a continuación, se mencionarán las siguientes acciones:

- Ahorro y uso eficiente del agua: Se buscará administrar de la mejor manera el consumo del agua, se utilizará en los servicios higiénicos sistemas como inodoros ahorradores y caños con sensores de movimiento.

Figura 5.36

Caño con sensor

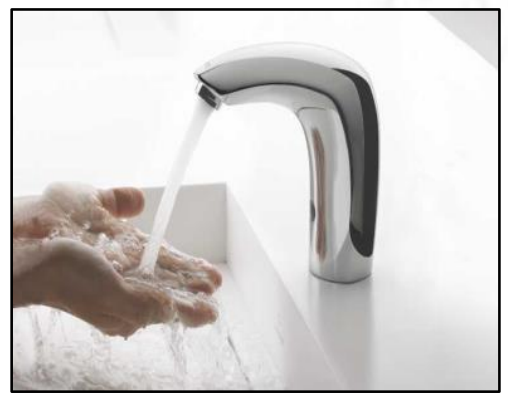

Fuente: Reformas y cocinas (2016)

- Ahorro y uso eficiente de la energía: Se realizarán campañas de información y formación entre para promover el ahorro energético, se utilizarán equipos con 
sistemas de ahorro energético, se promoverá a apagar y desenchufar los equipos que no vayan a ser usados (fotocopiadoras, impresoras, etc), sustituir bombillas por fluorescentes (se reduce el consumo hasta una quinta parte) y por último se tendrá que hacer un mantenimiento a los filtros del aire acondicionado para mejorar la salida del aire.

- Manejo integral de residuos, se promoverá el reaprovechamiento y reciclaje de materiales. Se buscará separar los residuos de acuerdo a sus características (orgánicos, papel, plásticos) y además los residuos que puedan contaminar más o que sean diferentes a los antes mencionados (pilas, vidrios, baterías) tendrán un despacho diferente.

\section{Figura 5.37}

Tachos diferenciadores de sólidos

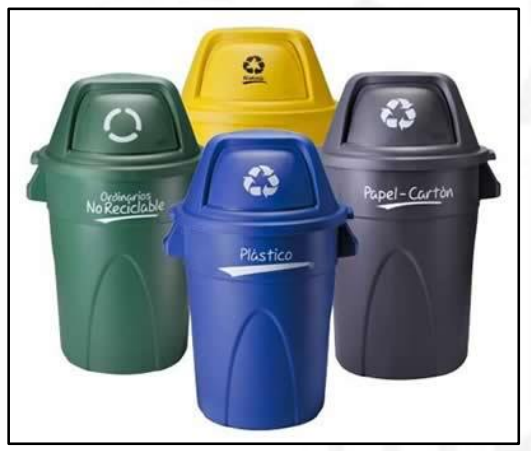

Fuente: Vida más verde (2016)

\section{Tabla 5.4}

Impacto ambiental de la oficina principal

\begin{tabular}{|c|c|c|c|c|}
\hline $\begin{array}{l}\text { Procesos dentro } \\
\text { del servicio }\end{array}$ & Salidas & $\begin{array}{c}\text { Aspecto } \\
\text { Ambiental } \\
\end{array}$ & $\begin{array}{c}\text { Impacto } \\
\text { Ambiental } \\
\end{array}$ & Medidas Correctoras \\
\hline $\begin{array}{l}\text { Aire } \\
\text { acondicionado }\end{array}$ & $\begin{array}{l}\text { Ruido,vibración, } \\
\text { efluentes }\end{array}$ & $\begin{array}{l}\text { Fuga de Gases } \\
\text { refrigerantes }\end{array}$ & $\begin{array}{l}\text { Alteración de la } \\
\text { calidad del aire }\end{array}$ & $\begin{array}{l}\text { Cambio de los equipos a otros que usen gases } \\
\text { refrigerantes amigables, aquellos que no tienen } \\
\text { efectos sobre la capa de ozono, tal como el caso del } \\
\text { gas refrigerante R410A. }\end{array}$ \\
\hline $\begin{array}{c}\text { Tareas } \\
\text { Adminis trativas }\end{array}$ & $\begin{array}{c}\text { Residuos } \\
\text { sólidos,orgánicos } \\
\text { e inorgánicos }\end{array}$ & $\begin{array}{c}\text { Acumulación } \\
\text { de desechos y } \\
\text { contaminacion } \\
\text { del agua } \\
\end{array}$ & $\begin{array}{l}\text { Daño al medio } \\
\text { ambiente }\end{array}$ & $\begin{array}{l}\text { Colocar basureros especiales para separar los } \\
\text { desechos y motivar a los trabajadores al reciclaje. }\end{array}$ \\
\hline $\begin{array}{l}\text { Tintas de } \\
\text { impresoras }\end{array}$ & $\begin{array}{c}\text { Residuos sólidos } \\
\text { y gases } \\
\text { contaminantes }\end{array}$ & $\begin{array}{l}\text { Liberación de } \\
\text { gases }\end{array}$ & $\begin{array}{c}\text { lteración de la } \\
\text { calidad del aire y } \\
\text { tierra. }\end{array}$ & Mantenimiento preventivo del equipo. \\
\hline
\end{tabular}

Elaboración propia

A continuación, se detalla el impacto ambiental del equipo de especialistas en la zona de trabajo y sus respectivas medidas de control. 
Tabla 5.5

Impacto ambiental en la zona de trabajo

\begin{tabular}{|c|l|}
\hline IMPACTO AMIBIDNTAL & \multicolumn{1}{|c|}{ MIDDIDAS PROTECTORAS } \\
\hline Alteración de la calidad del suelo y agua & $\begin{array}{l}\text { Mantenimiento y limpieza de baño por la empresa autorizada coordinada con la empresa } \\
\text { contratista minera. }\end{array}$ \\
\hline Disminución del recurso agua & Sensibilización en el consumo del agua mensual \\
\hline $\begin{array}{c}\text { Disminución de energía disponible para } \\
\text { otros usos }\end{array}$ & $\begin{array}{l}\text { Colocar señalizacion en los interruptores de apagar luces y equipos cuando no se utilicen. } \\
\text { Capacitación referente al uso de adecuado de recursos (trimestral). } \\
\text { Se apaga las fuentes de energía y equipos que no se utilizan o cuando están fuera de trabajo. }\end{array}$ \\
\hline $\begin{array}{c}\text { Disminución de la energía disponible } \\
\text { para otros usos. }\end{array}$ & $\begin{array}{l}\text { Apagar el motor del vehículo una vez llegado a su destino. } \\
\text { Mantenimiento de los equipos de acuerdo a programación. } \\
\text { Capacitación al personal en uso adecuado de recursos trimestralmente. }\end{array}$ \\
\hline Disminución del recurso forestal & $\begin{array}{l}\text { Reciclaje de papeles y cartones. } \\
\text { Capacitación referente al uso de adecuado de recursos (trimestral). }\end{array}$ \\
\hline Alteración de la calidad del aire & $\begin{array}{l}\text { Mantenimiento preventivo de vehículos mensual } \\
\text { Revisión técnica mensual. }\end{array}$ \\
\hline
\end{tabular}

Elaboración propia

Además, se coordinará con la gerencia de la empresa contratista los controles aplicables para minimizar y evitar los impactos ambientales producto de las actividades del proyecto, sobretodo enfocado en los relaves mineros que son altamente tóxicos y podrían provocar un impacto peligroso en el medio ambiente.

\section{Tabla 5.6}

Control del impacto ambiental por la actividad de recrecimiento de relaveras

\begin{tabular}{|c|c|l|}
\hline ASPECTO AMIBIENTAL & IMPACTO AMIB IDNTAL & \multicolumn{1}{c|}{ MIDDIDAS PROTECTORAS } \\
\hline Emisión de polvo & Alteración de la calidad del aire & $\begin{array}{l}\text { - Riego de las vías en las zonas de tránsito vehícular. } \\
\text { - Control de consumo de agua de acuerdo a formato establecido. }\end{array}$ \\
\hline $\begin{array}{c}\text { Generación de Desmonte } \\
\text { (movimiento de desmonte) }\end{array}$ & Alteración de la calidad del suelo & $\begin{array}{l}\text { - El desmonte resultante de las actividades de recrecimiento de la presa de } \\
\text { relaves serán dispuestos lugares autorizados. } \\
\text { - Se capacitará a todo el personal sobre el manejo de des monte trimestralmente. }\end{array}$ \\
\hline $\begin{array}{c}\text { Potencial derrame de } \\
\text { hidrocarburos y derivados }\end{array}$ & Alteración de la calidad del suelo & $\begin{array}{l}\text { - Capacitación en respuesta a emergencias ambientales trimestralmente. } \\
\text { - Kit de respuesta a emergencias ( paños absorventes, sacos, escoba, bolsas, } \\
\text { lampa, pico, bandejas, cinta de señalización en cada vehículo y equipo pesado). } \\
\text { - Revisión técnica, mantenimiento de los equipos de acuerdo a programación y } \\
\text { check list diario. } \\
\text { - El mantenimiento de los equipos deberán ser en los lugares autorizados por el } \\
\text { titular de la actividad minera. } \\
\text { - Contención secundaria para el almacenamiento de todos los hidrocarburos y/o } \\
\text { sus derivados. }\end{array}$ \\
\hline $\begin{array}{c}\text { Residuos sólidos } \\
\text { peligrosos }\end{array}$ & Alteración de la calidad suelo y agua & $\begin{array}{l}\text { - Capacitación en el estándar de Gestión Integral de Residuos trimestralmente. } \\
\text { - Cilindros para disposición de Residuos. }\end{array}$ \\
\hline
\end{tabular}

Elaboración propia 
Tabla 5.7

Matriz Leopold del impacto ambiental en la zona de trabajo

\begin{tabular}{|c|c|c|c|c|c|c|c|c|c|}
\hline & & 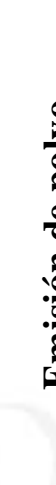 & & & & & 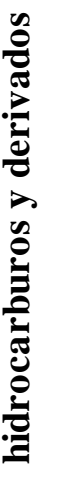 & 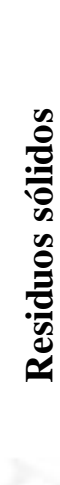 & 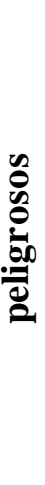 \\
\hline & cciones Propuestas & $\mathbf{M}$ & $\mathbf{I}$ & $\mathbf{M}$ & $\mathbf{I}$ & $\mathbf{M}$ & I & $\mathbf{M}$ & $\mathbf{I}$ \\
\hline$\Delta \mathrm{im}$ & Contaminación & -8 & 8 & -4 & 5 & -8 & 8 & -5 & 5 \\
\hline หй & Calidad & -8 & 8 & -4 & 5 & -8 & 8 & -5 & 5 \\
\hline Agua & Calidad & -7 & 7 & -4 & 5 & -8 & 8 & -8 & 8 \\
\hline Flora & Arboles y arbustos & -2 & 5 & -6 & 8 & -9 & 10 & -6 & 7 \\
\hline Suelo & Contaminación & -3 & 7 & -6 & 8 & -10 & 10 & -8 & 8 \\
\hline Sucto & Fertilidad de suelos & -5 & 5 & -6 & 7 & -10 & 10 & -8 & 8 \\
\hline Reactivos & Zona de baño y limpieza & 1 & 1 & 1 & 1 & 1 & 1 & 1 & 1 \\
\hline Salud & Empleo & -5 & 5 & 1 & 1 & -7 & 7 & -7 & 7 \\
\hline & Salud y Seguridad & -8 & 8 & -5 & 5 & -6 & 6 & -6 & 6 \\
\hline & & -45 & & -33 & & -65 & & -52 & \\
\hline
\end{tabular}

\subsection{Seguridad y salud ocupacional}

La empresa hace un gran énfasis en el cumplimiento de la seguridad y salud ocupacional. Está completamente alineada a la Ley № 29783 "Ley de Seguridad y Salud en el Trabajo" y su modificatoria Ley $\mathrm{N}^{\circ}$ 30222, y sus respectivos reglamentos Decreto Supremo Nº05-2012-TR y Decreto Supremo N006-2014-TR, además del reglamento de seguridad y salud ocupacional en minería "Decreto Supremo N 0242016-MEM” promulgada el 28 de agosto del 2016.

Las oficinas de la empresa en Lima y el área de trabajo en donde se encontrarán los trabajadores en el campamento minero de la empresa contratista tendrán un ambiente de trabajo adecuado y condiciones necesarias de clima, iluminación, ruido, entre otros. El ambiente estará diseñado bajo un formato ergonómico para que se ajusten a las capacidades de los trabajadores y cumplirá con 9 guías de trabajo:

- Guía 1: Determinar que las herramientas y materiales deben ser alcanzados y usados por el trabajador. 
- Guía 2: Todos los movimientos de los trabajadores se deben restringir dentro de su "área normal de trabajo", la cual se encuentra frente a él/ella y que se alcanza hasta rotar los brazos, usando los codos como puntos de rotación.

Figura 5.38

Movimientos en el área de trabajo

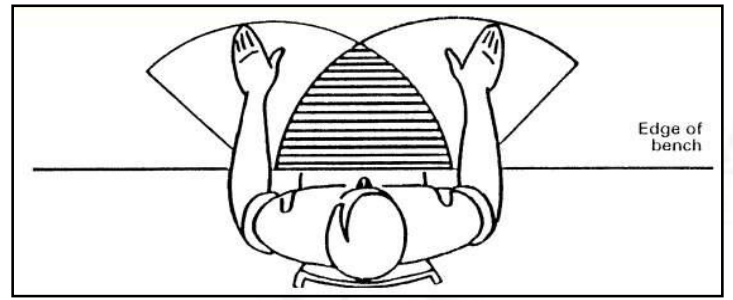

Fuente: Métodos y tiempos (2016)

- Guía 3: Cada trabajador tendrá un sitio fijo y definido

- Guía 4: Se debe mantener el área de trabajo limpia y libre de objetos.

- Guía 5: La altura de la superficie de trabajo debe ser la más cómoda y productiva posible.

- Guía 6: Proveer de una silla ajustable y cómoda. las cuales deben tener un asiento acojinado y solo debe ceder $25 \mathrm{~mm}$ para mantener el balance de tuberosidades isquiáticas (huesos situados en la pelvis), el borde debe ser redondeado y se deben evitar los adornos, además debe estar forrado de tela porque reduce el deslizamiento del cuerpo. El asiento debe estar ligeramente inclinado hacia atrás $\left(1^{\circ}-5^{\circ}\right)$ para evitar que el cuerpo se deslice hacia el frente y propiciar el uso de espaldar, la inclinación del espaldar no debe ser mayor a $30^{\circ}$. También es recomendable el uso de descansa pies.

Figura 5.39

Sillas ergonómicas

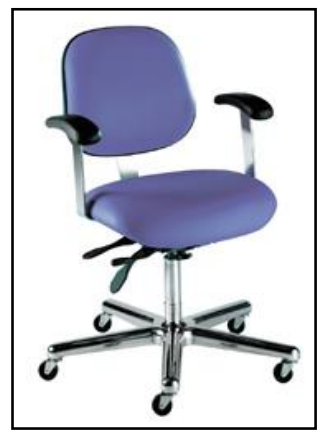

Fuente: Ergonomía Perú (2016) 
- Guía 9: Proveer de condiciones ambientales agradables respecto a la iluminación, control de ruido, temperatura, ventilación, orden y limpieza.

Se contarán con estaciones de VDT (Video Display Terminal), que son todas aquellas estaciones que cuentan con un monitor. Según la Resolución Ministerial $N^{\circ}$ 375-2008-TR establece que la pantalla debe ser ubicada de tal forma que la parte superior de ésta se encuentre a la misma altura de los ojos, dado que es óptimo mirar hacia abajo y no hacia arriba. Además, ya que todos los trabajadores de la empresa trabajarán con una laptop se tomarán en cuenta las medidas ergonómicas como:

- Uso de un teclado y mouse independiente para poder controlar las distancias y tener la movilidad que permita al operador adaptarse a las tareas a realizar.

\section{Figura 5.40}

Uso de mouse y teclado independiente

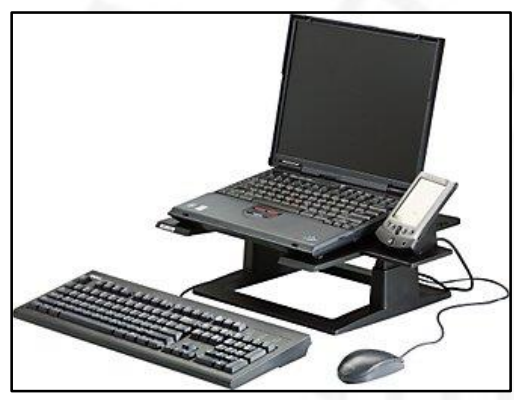

Fuente: Ergonomía Perú (2016)

- La base donde se apoya el teclado debe ser ajustable para permitir que las manos y el antebrazo estén en posición recta.

Figura 5.41

Base de apoyo para el teclado

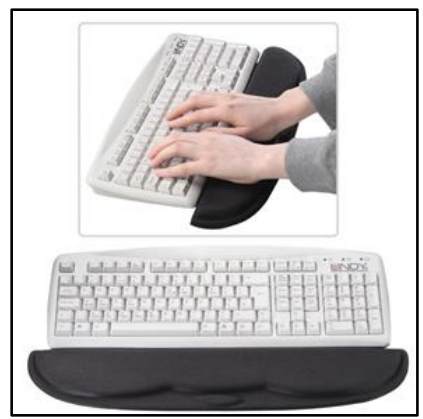

Fuente: Ergonomía Perú (2016) 
- Uso de superficies que ayudan a la ventilación de la laptop y brinda una inclinación cómoda.

Figura 5.42

Postura adecuada durante el manejo de la laptop
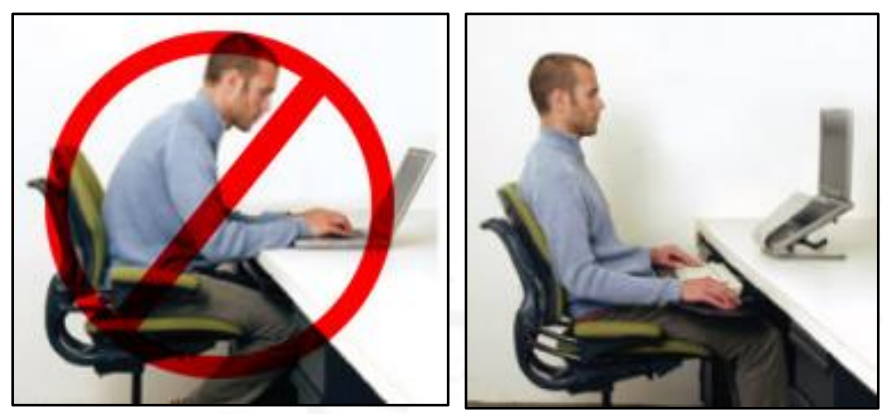

Fuente: Ergonomía Perú (2016)

En el anexo 9 se podrá encontrar un ejemplo de la Matriz de Identificación de Peligros y Evaluación de Riesgos (IPER) de las actividades de la empresa en la zona de trabajo.

\subsection{Sistema de mantenimiento}

Se deberá contar con un sistema de mantenimiento que se encargará del óptimo estado del funcionamiento de la infraestructura de las oficinas de la empresa, los sistemas de información utilizados dentro como fuera de las oficinas y los equipos utilizados durante las evaluaciones en las empresas contratistas mineras.

a. Mantenimiento de Infraestructura y equipos propios:

Se deberá contar con procesos establecidos dentro de la política de la empresa para aplicar dos tipos de mantenimientos: Planificados y no planificados a las instalaciones, es decir a las oficinas, y a los equipos propios dentro de estas tales como teléfonos, computadoras, impresoras, proyectores, entre otros. Se debe realizar revisiones y limpiezas del equipo dentro de las instalaciones como parte del mantenimiento planificado y preventivo, así también como revisiones de puertas, sensores y dispositivos de iluminación. Para el mantenimiento planificado se contratará un servicio de limpieza quienes estarán a cargo de limpiar y ordenar las oficinas diariamente; por otro lado, la empresa contará con un técnico especializado para el mantenimiento no planificado es decir en caso 
de averías o paradas de las maquinas se tendrá una persona encargada de poder solucionar los problemas.

b. Mantenimiento al sistema de información y tecnología

Este mantenimiento de forma similar debe contar con un programa de mantenimiento planificado y no planificado. Por el lado del planificado, el equipo de soporte debe realizar evaluaciones rutinarias tanto de funcionabilidad y de seguridad en el hardware y software de la empresa. Además, deberá realizar pruebas y verificar que las copias de seguridad están activas y funcionales. Este mantenimiento deberá hacer hincapié en verificar el funcionamiento adecuado de los firewalls, antivirus y otros software y hardware usados para garantizar la seguridad de la información de la empresa.

c. Mantenimiento de Equipo de Protección Personal:

Nuestra empresa brindará una serie equipos de protección a cada uno de los trabajadores de la empresa cliente, por lo cual estos equipos necesitan revisiones periódicas para asegurar que estén en excelentes condiciones, ya que es de vital importancia que estas herramientas estén en buen estado, en caso de encontrar algún equipo con alguna falla inmediatamente se tendrá que reemplazar por otro ofreciendo así equipos de alta calidad.

Para asegurarse de que los tres mantenimientos mencionados se estén llevando a cabo la empresa debe contar con un cronograma de mantenimiento en el cual se programará un mantenimiento preventivo para los equipos cada cuatro meses. Esto se hace con el fin de aumentar la disponibilidad de los equipos, planificar mejor los recursos y dar una mayor seguridad y confiabilidad al proceso. Sin embargo, no siempre se pueden controlar todos los imprevistos, por lo que también se aplicarán mantenimientos no planificados, en este caso será el mantenimiento correctivo en el caso que algunas máquinas presenten fallas o no rindan lo adecuado para el proceso. 


\subsection{Programa de operaciones del servicio}

\subsubsection{Consideraciones sobre la vida útil del proyecto}

El proyecto se evaluará para un periodo de 7 años desde la planificación de la demanda hasta la proyección de los flujos de fondo económico y financiero.

\subsubsection{Programa de operaciones del servicio durante la vida útil del proyecto}

Como se mencionó anteriormente el tiempo promedio para un proyecto de construcción y crecimiento de relavera es de 4 meses como mínimo en promedio y se determinó que para el año 1 y 2 la empresa tendrá 1 solo equipo de especialistas que en promedio realizará 3 proyectos asignados cada año, para el año 3 y 4 se plantea tener a 2 equipos de especialistas trabajando en paralelo diferentes proyectos, este incremento está alineado al crecimiento de la demanda y se estimó, según demanda histórica, que en dichos años se tendrá la incursión de nuevas empresas contratistas mineras que iniciarán el proceso de construcción de relaveras desde cero, no solo el recrecimiento desde un punto de referencia, por eso proyecta que cada servicio durará en promedio 6 meses y que cada equipo realizaría 2 servicios anuales. En el año 5, 6 y 7 se mantiene a los 2 equipos de especialistas pero considerando que cada uno preste el servicio a 3 clientes por año.

A continuación se presenta el programa de la cantidad de equipos que se necesitarán en los 7 años de proyección para satisfacer la demanda. 


\section{Tabla 5.8}

Programa de Operaciones del servicio durante la vida útil

$$
\text { Año } 1
$$$$
\text { Año } 2
$$$$
\text { Año } 3
$$

Año 4

Año 5

Año 6

Año 7

1er Cuat.2do Cuat. 3er Cuat. 1er Cuat.2do Cuat. 3er Cuat. 1er Sem. 2do Sem 1 1er Sem. 2do Sem 1 er Cuat. 2do Cuat. 3er Cuat. 1er Cuat. 2do Cuat. 3er Cuat. 1er Cuat.2do Cuat. 3er Cuat.

\begin{tabular}{|l|l|l|l|l|l|l|l|l|l|l|l|l|l|l|l|l|l|l|l}
\hline Equipo 1 & Equipo 1 & Equipo 1 & Equipo 1 & Equipo 1 & Equipo 1 & Equipo 1 & Equipo 1 & Equipo 1 & Equipo 1 & Equipo 1 & Equipo 1 & Equipo 1 & Equipo 1 & Equipo 1 & Equipo 1 & Equipo 1 & Equipo 1 & Equipo 1 \\
\hline
\end{tabular}

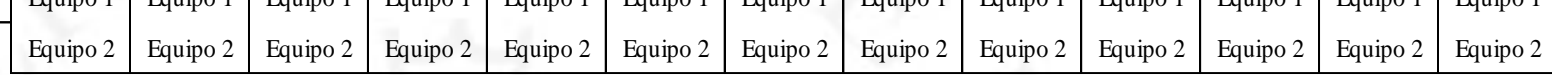

Elaboración propia 


\subsection{Requerimiento de materiales, personal y servicios}

\subsubsection{Materiales para el servicio}

Los materiales que la empresa necesita para brindar el servicio se pueden dividir en 3 grandes grupos:

- Materiales enfocados al cliente: Incluye equipos de protección personal que la empresa entregará a los trabajadores de la empresa contratista minera como parte del Sistema de Gestión de Seguridad y Salud Ocupacional. También incluye avisos, señalizaciones de advertencia, prevención de peligro, cintas, entre otros. Estos materiales ya fueron explicados anteriormente en el punto 5.3.

- Equipos de oficina: Para garantizar un buen servicio es necesario contar en la oficina tanto en Lima como en el área de trabajo con todos los recursos necesarios. Es necesario herramientas de sistemas visuales (proyectores digitales, soluciones multimedia y ecrans), impresoras, aire acondicionado, así como la entrega de laptops y celulares a todos los trabajadores.

- Equipos tecnológicos: Estas herramientas sofisticadas serán usadas en el área de trabajo para la detección de situaciones que podrían poner en riesgo la seguridad y salud de los trabajadores, como: luxómetro, sonómetro, detector de tormentas, equipo de monitoreo de monóxido.

\subsubsection{Determinación del requerimiento de personal de atención al cliente}

El servicio contará con el equipo de especialistas que se encontrarán en la zona de trabajo de la empresa contratista minera. A continuación, se determinará los requerimientos de la empresa para quienes realizarán la parte operativa de la empresa. 


\begin{tabular}{|l|}
\hline \multicolumn{2}{|c|}{ GERENTE DE SEGURIDAD Y SALUD OCUPACIONAL } \\
\hline Vacante: 1 \\
Requisitos: \\
- Ingeniero de Minas, Ingeniero Geólogo o Metalurgista titulado, colegiado y \\
habilitado. \\
- Experiencia de 8 años en el área de Seguridad y Salud Ocupacional en la \\
minería, de los cuales 5 años en trabajos similares (relacionado a relavera). \\
- Maestría en Administración y Diplomado en Sistemas de Gestión en Seguridad \\
- y Salud Ocupacional, Medio Ambiente y Calidad. \\
- Dapacidad para trabajar en lugares a gran altitud. \\
\end{tabular}

\begin{tabular}{|l|}
\hline \multicolumn{2}{|c|}{ JEFE DE SEGURIDAD Y SALUD OCUPACIONAL } \\
\hline Vacante: 1 \\
Requisitos: \\
- $\quad$ Ingeniero de Minas, Ingeniero Geólogo o Metalurgista titulado, colegiado y \\
habilitado. \\
- $\quad$ Experiencia de 5 años en el área de Seguridad y Salud Ocupacional, de los \\
cuales 3 años deben ser en trabajos similares. \\
- Maestría en Administración y Diplomado en Sistemas de Gestión en Seguridad \\
y Salud Ocupacional, Medio Ambiente y Calidad.
\end{tabular}

\begin{tabular}{|l|}
\hline \multicolumn{2}{|c|}{ INGENIERO DE SEGURIDAD Y SALUD OCUPACIONAL } \\
\hline Vacantes: 2 \\
Requisitos: \\
- Ingeniero de Minas, Ingeniero Geólogo o Metalurgista titulado, colegiado y \\
habilitado. \\
- Experiencia de 3 años en el área de Seguridad y Salud Ocupacional, de los \\
cuales 2 años deben ser en trabajos similares. \\
- Maestría en Administración y Diplomado en Sistemas de Gestión en Seguridad \\
y Salud Ocupacional, Medio Ambiente y Calidad.
\end{tabular}




\section{FACILITADOR DE OBRA}

Vacante: 1

Requisitos:

- Ingeniero de Minas, Ingeniero Geólogo, Metalurgista o carreras afines.

- Experiencia de 1 año en el área de Seguridad y Salud Ocupacional

- Conocimiento avanzado del MS. Office,

\begin{tabular}{|l|}
\hline \multicolumn{1}{|c|}{ ADMINISTRADOR } \\
\hline Vacante: 1 \\
Requisitos: \\
- Tener estudios en Administración o técnico en administración. \\
- Experiencia de 1 año en el área de Seguridad y Salud Ocupacional \\
- Conocimiento intermedio del MS. Office. \\
\hline
\end{tabular}

\subsubsection{Servicios de terceros}

Entre los servicios de terceros con los que contará la empresa se encuentran:

a. Servicio de limpieza

Se encargará de la limpieza y manteamiento de inmuebles que se encuentren en la oficina y de servicios higiénicos. Además de ordenar y trasladar los desperdicios y desechos a los lugares correctos para su eliminación. También mantendrán limpio y seco el suelo y pasillos. Este servicio se realizará todos los días al término de la jornada laboral.

b. Servicio de mantenimiento:

Se contará con el servicio de mantenimiento planificado y no planificado de infraestructura y equipos propios, sistemas de información y tecnologías, y equipos de protección personal. Se encargarán de la acción inmediata antes situaciones imprevistas y situaciones programadas. 


\section{c. Servicio médico}

Según Artículo 1 de la Resolución Ministerial (RM) N 571-2014, la presencia del médico ocupacional para la vigilancia de la salud de los trabajadores en las empresas y/o ambientes de trabajo, debe regirse de acuerdo a lo siguiente:

a. Con más de 500 trabajadores, se deberá garantizar la permanencia del médico ocupacional por 6 horas diarias por 5 días a la semana

b. Con menos de 500 trabajadores, el desarrollo de la actividad de vigilancia de salud estará a cargo del médico ocupacional, sin la exigencia de un mínimo de horas presenciales, lo cual se verificará con la presentación y cumplimiento de los siguientes documentos:

$>$ Plan Anual de Salud Ocupacional

$>$ Programa de Vigilancia de la Salud de los Trabajadores

El cumplimiento de los documentos señalados es responsabilidad del empleador sin la exigencia de un mínimo de horas presenciales del médico ocupacional.

Ya que la empresa contratista minera tiene en promedio 60 trabajadores y en su tope máximo 120 trabajadores, se encuentra inmerso al punto (b) del Artículo mencionado, por ello el medico ocupacional será considerado dentro del programa para realizar el Plan Anual de Salud Ocupacional y Programa de Vigilancia de la Salud de los Trabajadores, así como el resguardo total del examen médico de los trabajadores de la empresa.

\section{d. Servicio de movilidad}

Se contará con una camioneta en cada proyecto a cargo de una empresa tercerizada, la misma que será usada por la supervisión de seguridad, entre ellos la movilización del personal en la zona de trabajo, ya que la actividad diaria de los especialistas detalla que deben seguir una ruta por todas las estaciones laborales para solicitar ordenes de trabajo, IPERC, entre otros documentos.

e. Servicio de asesoría legal

Se contará con la participación de un abogado cuando hay documentos de revisión y algún tipo de denuncia por atender. 


\subsubsection{Otros: energía eléctrica, agua, transportes, etc.}

En este punto se analizarán los factores que afectan a la oficina de la empresa en Lima.

a. Energía eléctrica: Luz del Sur será la empresa encargada de proveer de energía eléctrica a la empresa, este servicio es indispensable para el funcionamiento de laptops, impresoras, proyectora y la recarga de energía de algunos equipos, además de iluminación a las oficinas. La tarifa de Luz del Sur por el servicio es de S/. 0.66 por KW.

En el anexo 14 se mostrará el costo promedio por la energía eléctrica de la oficina por año, la potencia de los artefactos se obtuvo según el Organismo Supervisor de la Inversión en Energía y Minería (Osinergmin) y se está considerando un adicional en "otros" para artefactos con una potencia promedio.

b. Agua: Este servicio será brindado por la empresa Sedapal. Según una investigación de Sedapal a febrero del 2017, se determinó que el distrito de San Isidro ocupa el ler puesto en mayor consumo promedio de agua por cada habitante en un día: 364 litros de agua potable. Debido a ello nuestra empresa tendrá un énfasis en el ahorro y buen aprovechamiento del agua, sobre todo para actividades de aseo y alimentación. En el anexo 15 se puede ver el costo total de la empresa por año en agua.

c. Telefonía Fija y móvil: Se contará con teléfonos individuales en los escritorios con anexos independientes en todas las oficinas, por otro lado, todos los trabajadores contarán con un celular móvil ya que por este medio se contactarán por temas urgentes. Se deberá cotizar con las empresas líderes del mercado en este rubro: Telefónica, Claro o Entel, para poder tomar la mejor propuesta de estas empresas y brindarles un buen servicio a nuestros trabajadores.

\subsection{Soporte físico del servicio}

\subsubsection{Factor edificio}

Como se determinó en el Capítulo III, la oficina de la empresa en Lima estará ubicada en el distrito de San Isidro después del análisis de diversos factores de ubicación. Se buscará una oficina de $180 \mathrm{~m}^{2}$ en el primer piso de un edificio que cuente con un estacionamiento interno, esto para brindar mayor seguridad a los clientes. Tendrá áreas de oficinas, servicios higiénicos, kitchenette, almacén de equipos y materiales, y sala de 
reuniones. El edificio escogido deberá tener la infraestructura adecuada contra incendios y anti-sísmico, además de salidas fácilmente ubicables ante cualquier emergencia.

La oficina tendrá un precio aproximado de \$3,072.6 considerando el precio promedio por metro cuadrado de la zona elegida (\$17.07).

Además, el edificio deberá contar con suficientes salidas de emergencia estratégicamente ubicadas. Es importante cumplir con la ley en lo relacionado y tener corredores de $1.2 \mathrm{~m}$ de ancho o más. Por último, también deberá contar con conexiones a tierra y las medidas necesarias para garantizar la integridad del edificio y la salud del personal.

\subsubsection{El ambiente del servicio}

El factor servicio del proyecto se puede dividir en los siguientes tres rubros:

a) Relacionado al personal:

Todos los trabajadores tendrán una oficina que brinde la mayor comodidad posible con aire acondicionado y anexos telefónicos, estos ambientes estarán libres de ruido e interferencias. Además, la oficina contará con una kitchenette, en el cual los trabajadores podrán servirse una variedad de bebidas, así como hacer uso del microondas para el calentamiento de los almuerzos si deciden almorzar en la oficina, puesto que también esta área contará con sillas y mesas para su comodidad.

La empresa contará con una sala de reuniones amplia en el cual se llevarán a cabo los encuentros con los altos directivos de la empresa contratista minera, es importante mencionar que esta sala será usada por el equipo de especialistas cuando no se encuentren en la zona de trabajo (mina), sino que se encuentren en Lima para poder exponer sus avances de los proyectos en gestión. Este espacio estará provisto de un proyector digital y aire acondicionado para brindar un mejor servicio.

Para comodidad del personal también se contará con estacionamientos internos, el cual aumenta la seguridad. 
Figura 5.43

\section{Oficinas}

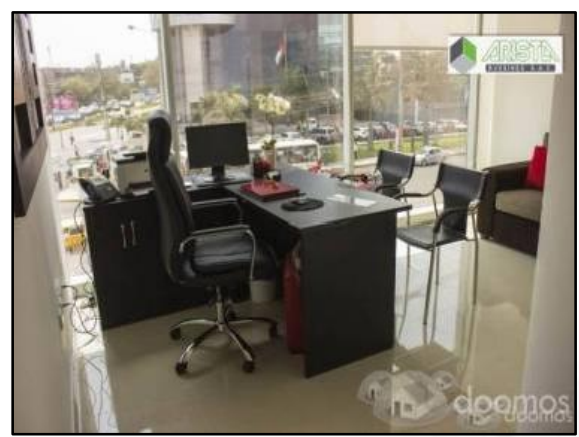

Fuente: Mitula (2016)

Figura 5.44

Kitchenette

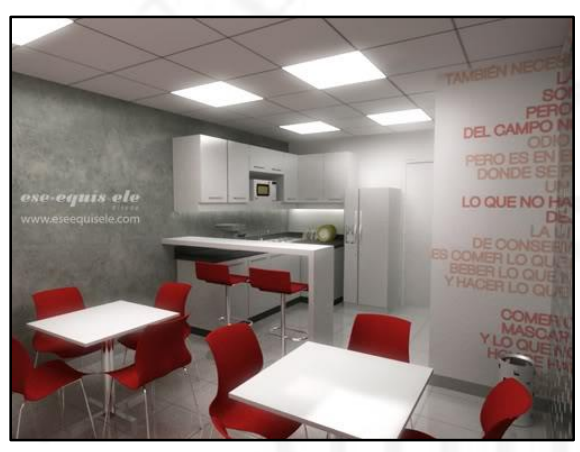

Fuente: SXL (2016)

Figura 5.45

Sala de reuniones

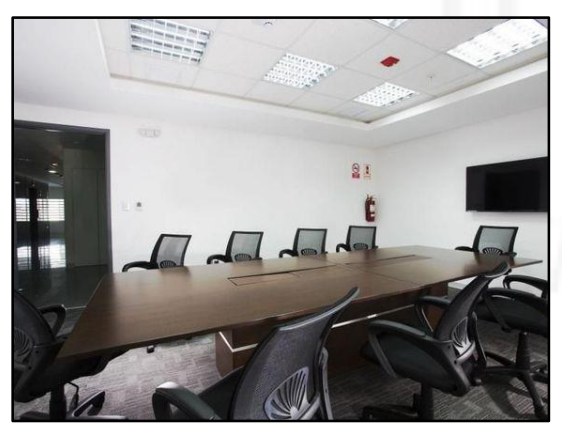

Fuente: Properati (2016)

b) Relacionado a los equipos

El almacén de equipos y materiales tendrá un stock de seguridad con respecto a los EPP's, por ello es importante que se encuentre cerca al área de Logística para agilizar los inventarios. 
El almacén deberá tener las condiciones apropiadas tanto de temperatura y de humedad para los materiales que se encuentren en él.

Figura 5.46

Almacén de EPP 's

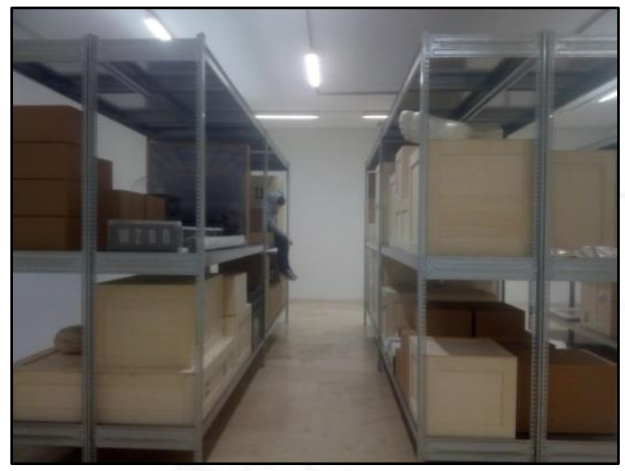

Fuente: República (2016)

c) Relacionado al Edificio

El factor edificio contará con las señalizaciones de obligación, peligro, auxilio y prohibición, también con señales de seguridad como rutas de escape y evacuación ante cualquier emergencia. Además de implementos de seguridad necesarios: botiquín completamente equipado y extintor.

Figura 5.47

Señal de evacuación

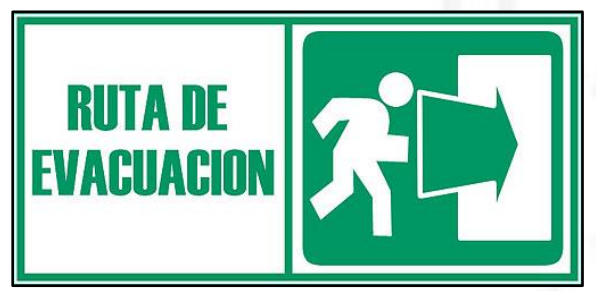

Fuente: Seguridad SOS (2016)

d) Relacionado al cliente

Para brindar un mejor servicio al cliente, la empresa contará con un estacionamiento interno del edificio en donde se encuentre la oficina. Así mismo, los servicios higiénicos serán amplios para varones y mujeres separados con 2 cubículos cada uno. 
Figura 5.48

Estacionamientos internos

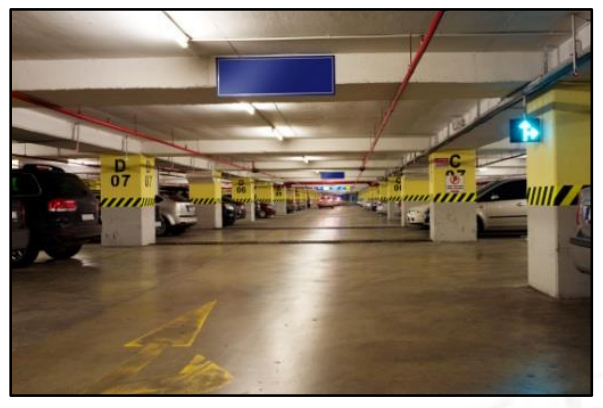

Fuente: Gante Estacionamiento (2016)

\subsection{Disposición de la instalación del servicio}

\subsubsection{Disposición general}

Como se ha mencionado, las oficinas contarán con áreas apropiadas para el personal, servicios higiénicos, kitchenette, almacén de materiales, así también con una sala de reuniones, una recepción y estacionamientos propios del edificio.

Para el área de oficinas, se seguirán los parámetros propuestos en el texto "Disposición de Planta" que indica que el área de oficinas puede oscilar entre $4.5 \mathrm{~m}^{2} \mathrm{a}$ $9 \mathrm{~m}^{2}$. En la tabla 5.9 se detallarán las áreas de las zonas de trabajo en la oficina.

Tabla 5.9

Áreas de las zonas de trabajo

\begin{tabular}{|c|c|}
\hline Zona de trabajo & Área de trabajo $\left(\mathbf{m}^{2}\right)$ \\
\hline Recepción & 12.19 \\
\hline Oficina Gerente General & 18.33 \\
\hline Sala de reuniones & 25.88 \\
\hline Kitchenette & 8.34 \\
\hline Oficina Gerente de Seguridad & 8.34 \\
\hline Área de administración y finanzas & 8.34 \\
\hline SSHH Damas & 5.60 \\
\hline SSHH Varones & 5.60 \\
\hline Área de ventas & 8.34 \\
\hline Área de logística & 8.68 \\
\hline Almacén & 8.34 \\
\hline SSHH Gerencia General & 4.00 \\
\hline
\end{tabular}

Elaboración propia 
Con respecto a los servicios higiénicos se consideró 2 baños, uno para varones y otros para mujeres, y en cada uno de ellos habrá 2 cubículos. Se tomó esta medida para dar una mayor facilidad a los clientes cuando haya reuniones. Para la disposición general se debe considerar lo siguiente:

- Es importante que el almacén se encuentre cerca al área de logística para evitar demoras en los inventarios, así mismo debe estar cerca a la recepción para que los traslados de materiales sean más rápidos.

- Todas las oficinas deben tener un rápido acceso a la sala de reuniones, así como también cercanía al kitchenette y los servicios higiénicos por comodidad.

- Las oficinas tienen que ser cercanas entre sí para crear sinergias y sobre todo para que la información fluya más rápido.

Cabe resaltar, que la figura mostrada a continuación refleja una oficina en San Isidro que visitamos, por ello se consideró dicho plano. 
Figura 5.49

Plano de la oficina

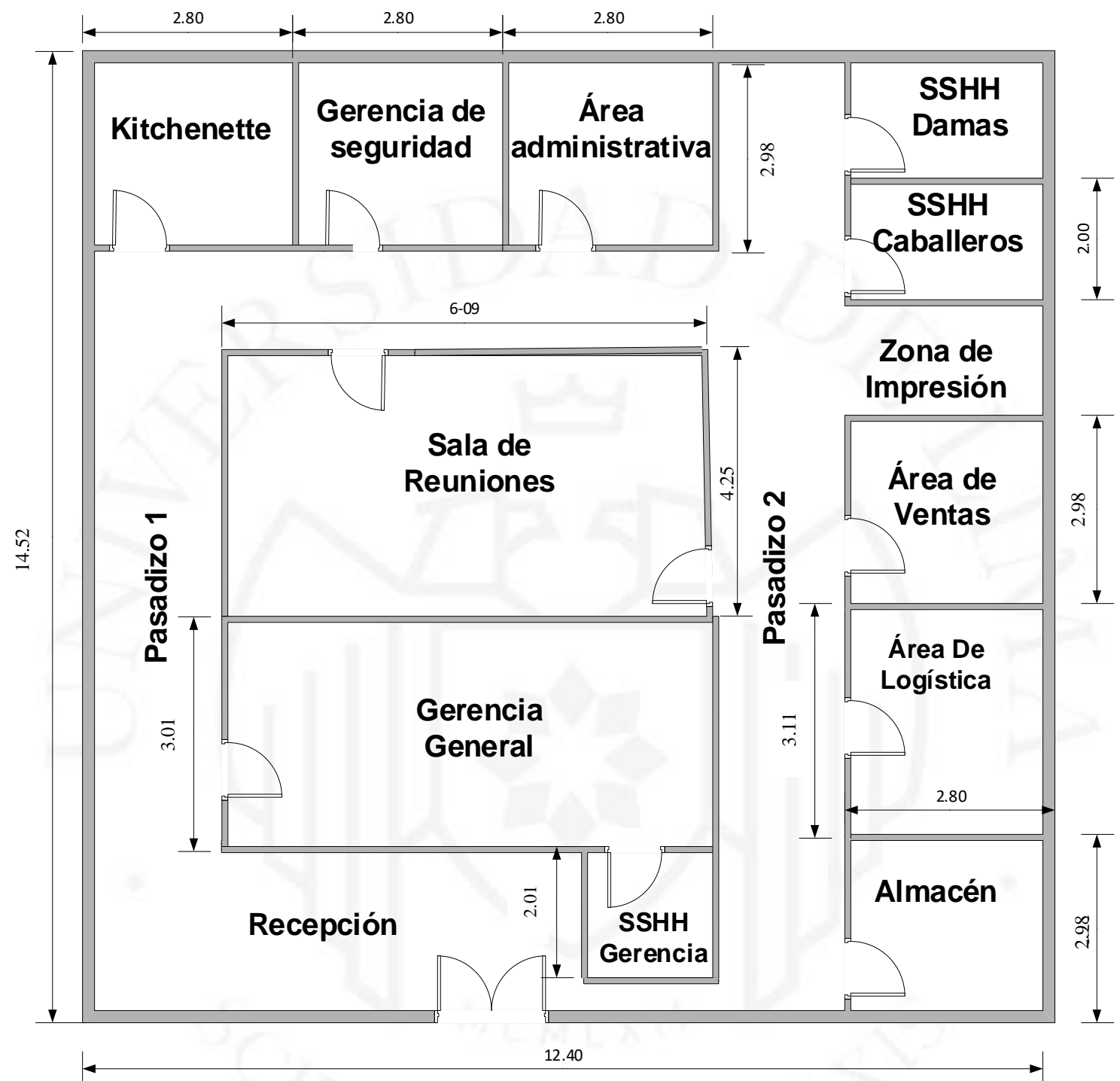

Elaboración propia

\subsubsection{Disposición de detalle}

La disposición a detalle se obtendrá del diagrama relacional de actividades, la cual mostrará la distribución de las áreas de trabajo.

Primero, se realizará la lista de motivos o razones para determinar si las áreas de trabajo deben estar cercanas o alejadas. 
Tabla 5.10

Listado de motivos

\begin{tabular}{|c|c|}
\hline CÓDIGO & LISTA DE MOTIVOS \\
\hline 1 & Comodidad del personal \\
\hline 2 & No hay una relación directa \\
\hline 3 & Olores indeseados desprendidos \\
\hline 4 & Conveniencia \\
\hline 5 & Necesidad de información \\
\hline 6 & Comodidad del cliente \\
\hline 7 & Imagen y limpieza \\
\hline
\end{tabular}

Elaboración propia

Se utilizó los códigos de proximidades para determinar la importancia que tienen las distancias entre las áreas.

Tabla 5.11

Novel de proximidad de las áreas

\begin{tabular}{|c|c|}
\hline CÓDIGO & PROXIMIDAD \\
\hline A & Absolutamente necesario \\
\hline E & Especialmente necesario \\
\hline I & Importante \\
\hline O & Normal \\
\hline U & Sin importancia \\
\hline X & No deseable \\
\hline XX & Altamente no deseable \\
\hline
\end{tabular}

Elaboración propia

Utilizando la información de los cuadros 5.10 y 5.11 se realizó la tabla relacional, que permite ubicar la proximidad e importancia de la proximidad entre las áreas de trabajo. 
Figura 5.50

Tabla relacional para la disposición de las áreas

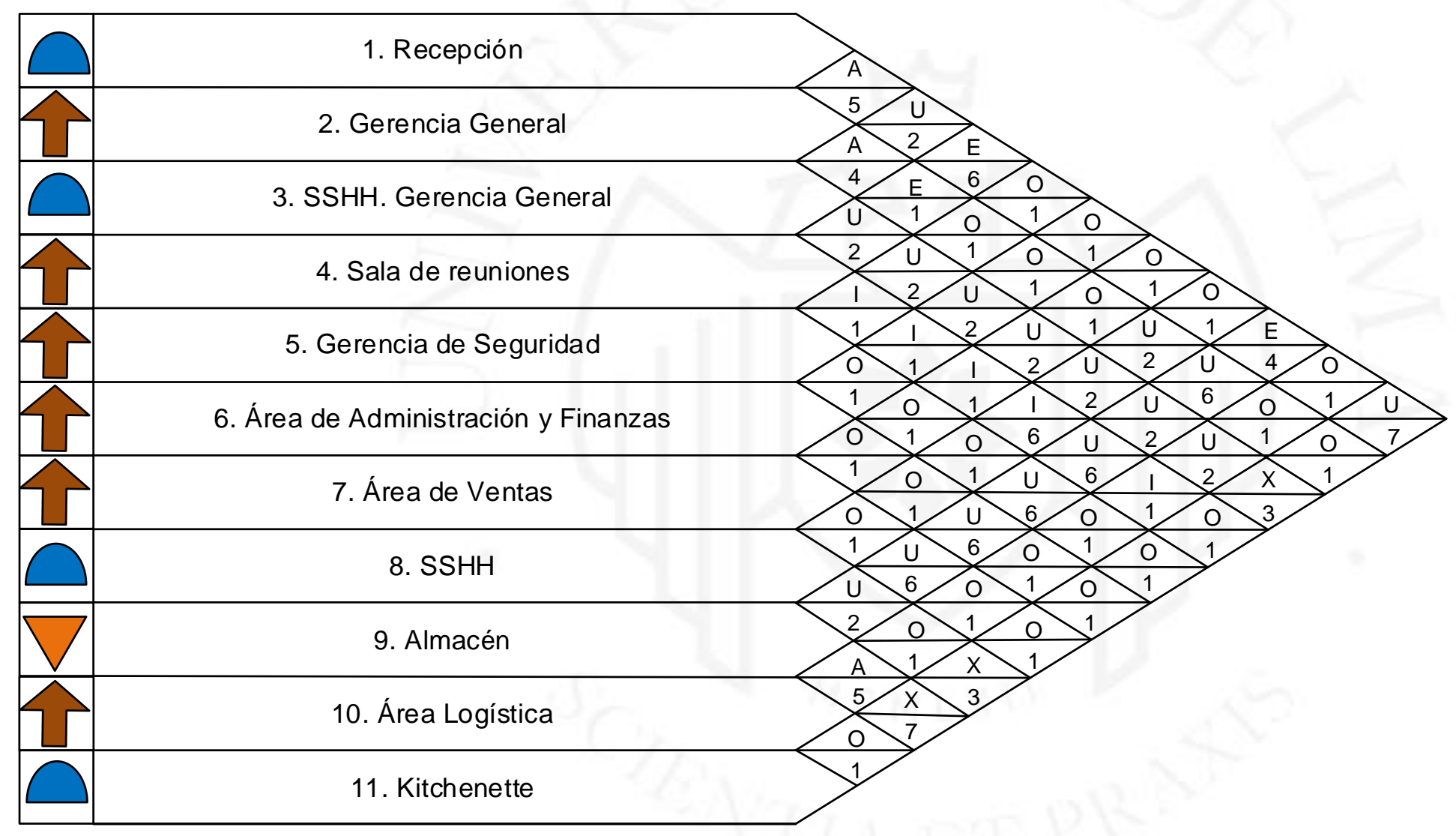

Elaboración propia 
Después de obtener dicha información se realizará el diagrama relacional tomando en cuenta el cuadro 5.12 para la selección de las líneas de unión.

Tabla 5.12

Color de líneas para el diagrama relacional

\begin{tabular}{|c|c|c|c|}
\hline CÓDIGO & PROXIMIDAD & COLOR & $N^{\circ}$ DE LINEAS \\
\hline A & Absolutamente necesario & Rojo & 4 rectas \\
\hline E & Especialmente necesario & Amarillo & 3 rectas \\
\hline I & Importante & Verde & 2 rectas \\
\hline O & Normal & Azul & 1 recta \\
\hline$U$ & Sin importancia & - & no se traza \\
\hline$X$ & No deseable & Plomo & 1 zigzag \\
\hline XX & Altamente no deseable & Negro & 2 zigzag \\
\hline
\end{tabular}

Elaboración propia

Figura 5.51

Diagrama relacional para la disposición de áreas

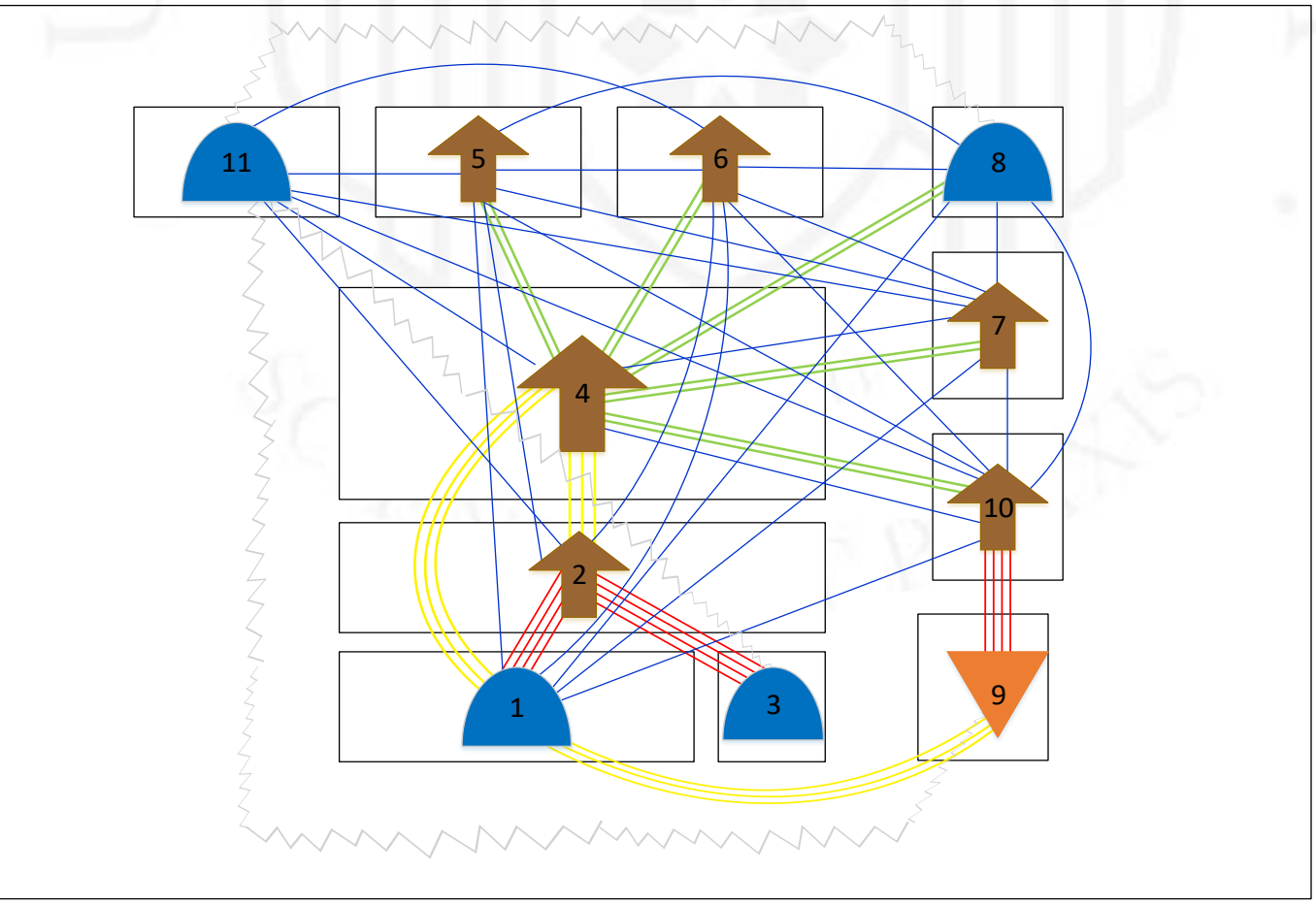

Elaboración propia 
Figura 5.52

Plano de las oficinas de la empresa

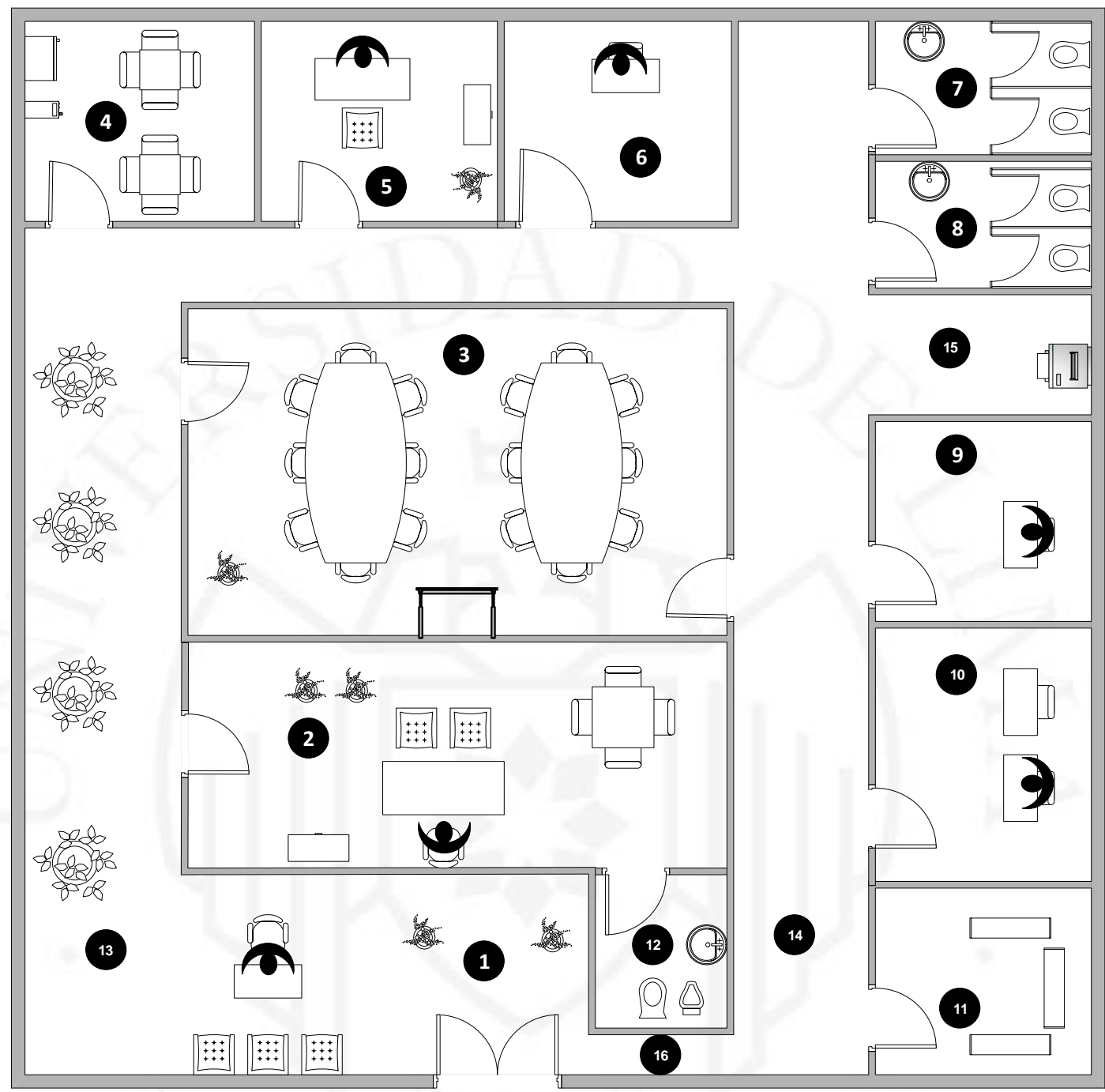

\section{Leyenda :}

1. Recepción

2. Gerencia General

3. Sala de reuniones

4. Kitchenette

5. Gerencia de Seguridad

6. Area administrativa y de finanzas

7. SSHH. de Damas

8. SSHH. de Varones

9. Área de Ventas

10. Área de Logística

11. Almacén

12. SSHH. Gerencia General

13. Pasadizo 1

14. Pasadizo 2

15. Zona de Impresión

16. Pasadizo 3

\begin{tabular}{|c|c|c|c|}
\hline \multicolumn{2}{|c|}{$\begin{array}{c}\text { Universidad de Lima } \\
\text { Escuela Universitaria de } \\
\text { Ingeniería } \\
\text { Facultad de Ingeniería } \\
\text { Industrial }\end{array}$} & $\begin{array}{c}\text { Plano de la oficina de una } \\
\text { "Empresa dedicada la tercerización } \\
\text { de la administración del sistema de } \\
\text { seguridad y salud en el trabajo al } \\
\text { rubro de servicios mineros" }\end{array}$ \\
\hline ESCALA & FECHA & ÁREA & INTEGRANTE \\
\hline $1: 100$ & $02-06-2019$ & $14.5 \mathrm{~m} \times 12.4 \mathrm{~m}$ & $\begin{array}{l}\text { Diana Vera } \\
\text { Veliz }\end{array}$ \\
\hline
\end{tabular}

Elaboración propia 


\subsection{Cronograma de implementación del proyecto}

A continuación, se presentan las fechas estimadas para la implementación del proyecto.

Tabla 5.13

Actividades de implementación

\begin{tabular}{|l|c|c|c|}
\hline \multicolumn{1}{|c|}{ Actividad } & Duración & Inicio & Fin \\
\hline Constituir la empresa & 60 & $01 / 08 / 2018$ & $30 / 09 / 2018$ \\
\hline Buscar y Alquilar local & 30 & $01 / 10 / 2018$ & $31 / 10 / 2018$ \\
\hline Buscar y Contratar Empleados & 45 & $01 / 10 / 2018$ & $15 / 11 / 2018$ \\
\hline Comprar Mobiliario & 21 & $01 / 11 / 2018$ & $22 / 11 / 2018$ \\
\hline Acondicionamiento del servicio & 28 & $23 / 11 / 2018$ & $21 / 12 / 2018$ \\
\hline Inicio del Servicio & 14 & $22 / 12 / 2018$ & $05 / 01 / 2019$ \\
\hline
\end{tabular}

Elaboración propia

Figura 5.53

Cronograma de implementación

\begin{tabular}{|c|c|c|c|c|}
\hline $01 / 08 / 2018$ & $22 / 09 / 2018$ & $14 / 11 / 2018$ & 06/01/2019 & \multirow{7}{*}{$\begin{array}{l}\text { Inicio } \\
\text { Duración }\end{array}$} \\
\hline Constituir la empresa & & & & \\
\hline Buscar y Alquilar local & & & & \\
\hline Buscar y Contratar Empleados & & & & \\
\hline Comprar Mobiliria & & & & \\
\hline Acondicionamiento del Local & & & & \\
\hline Inicio del Servicio & & & & \\
\hline
\end{tabular}

Elaboración propia 


\section{CAPÍTULO VI. ORGANIZACIÓN ADMINISTRATIVA}

\subsection{Organización empresarial}

Al ser una empresa pequeña, se plantea que en un inicio solo tenga 4 áreas funcionales, cada una de ellas con tareas específicas a desarrollar y todas deberán estar alineadas con los mismos objetivos estratégicos para asegurar el éxito y el crecimiento de la empresa. La comunicación y el trabajo en equipo entre las áreas son fundamentales para que todos tengan los objetivos claros y bajo una visión común o compartida. Esto se debe realizar desde los líderes hasta los trabajadores para poder formar una organización con sinergia.

Las áreas principales consideradas son:

- Gerencia general: Imprescindible, será el representante de la empresa frente al público y clientes. Dirigirá con liderazgo a las otras áreas funcionales para que la empresa tenga un adecuado manejo y poder cumplir con éxitos las metas trazadas.

- Área de administración: El jefe administrativo se encargará en el negocio desde las contrataciones, capacitaciones hasta pagos al personal. También se encargará del registro contable teniendo en cuenta todos los movimientos de dinero, ya que no se tendrá un contador.

- Área comercial: Plantea las estrategias que la empresa seguirá en el área de marketing y ventas, para poder desarrollar la imagen de la empresa y que el servicio brindado sea óptimo. El jefe comercial será el encargado de cerrar los contratos con las empresas contratistas mineras y contactar a futuros clientes.

- Área de logística: El jefe de logística se encargará de la compra, distribución y verificación de los materiales según la cantidad de personal que tenga la empresa cliente para poder entregarle a cada uno de sus trabajadores los EPP's necesarios según el contrato establecido y poder brindar un servicio de alta calidad.

- Área de operaciones: Es considerada la principal área en la empresa, ya que son los encargados directos de realizar el servicio que brinda la empresa, dentro de esta área se tendrá un gerente de operaciones con el objetivo de 
planificar los objetivos principales que se necesita para cumplir con lo establecido en el contrato, también se contará con un jefe de seguridad el cual tendrá a su cargo a dos ingenieros especializados en seguridad, además de un facilitador de obra y administrador de obra todos ellos tendrán la misión de que todo lo establecido se lleve a cabo y cumplir con las metas y objetivos de la empresa cliente.

\subsection{Requerimientos del personal directivo, administrativo y de soporte interno del servicio}

GERENTE GENERAL (Vacante: 1)

Requisitos:

- Ingeniero de Minas, Ingeniero Geólogo o Metalurgista titulado, colegiado y habilitado.

- Experiencia de 5 años en el área de Seguridad y Salud Ocupacional en la minería, de los cuales 3 años en trabajos similares (relacionado a relavera).

- Maestría en Administración y Diplomado en Sistemas de Gestión en Seguridad y Salud Ocupacional, Medio Ambiente y Calidad.

- Computación, administración, finanzas, contabilidad, comercialización y ventas.

- Capacidad de liderazgo y manejo de personal, así como toma de decisiones estratégicas de la empresa.

- Desarrollo de metas y objetivos a corto y largo plazo.

- Dominio del idioma inglés.

\section{SECRETARIA (Vacante: 1)}

Requisitos:

- Conocimiento avanzado del MS. Office.

- Facilidad de palabra y buen trato con las personas, habilidades de redacción y capacidad de trabajo en equipo

- Apoyo a las otras áreas en lo que requieren. 


\section{JEFE ADMINISTRATIVO (Vacante: 1 )}

Requisitos:

- Título profesional de Administrador(a) o carreras afines.

- Deseable que el (la) postulante tenga capacitación o estudios de post título en el control de recursos financieros (presupuestos, facturación).

- Manejo de herramientas MS. Office nivel avanzado.

- Conocimiento en evaluación de los flujos de efectivo para la administración de la contabilidad y tesorería de la empresa, así como la asignación eficiente para las diferentes actividades de la empresa. Conocimiento sobre liquidaciones, AFP, trámites en Essalud y elaboración de contratos.

\section{JEFE DE VENTAS (Vacante: 1)}

Requisitos:

- Ingeniero industrial con experiencia mínima de 2 años en el área comercial.

- Disponibilidad para viajar al interior del país y capacidad para establecer estrategias para una mayor captura de clientes.

- Encargado del marketing de la empresa a través de todas las plataformas que se manejan y dar seguimiento continuo a los clientes en todas las etapas del servicio brindado.

JEFE DE LOGISTICA (Vacante: 1)

Requisitos:

- Carreras universitarias de Ingeniería Industrial o carreras afines

- Indispensable inglés avanzado.

- Conocimiento del software SAP

- Manejo de herramientas MS. Office nivel avanzado

- Experiencia mínima de 2 años en Jefatura de cadena de abastecimiento, logística, compras y trato con proveedores 
Requisitos:

- Ingeniero de Minas, Ingeniero Geólogo o Metalurgista titulado, colegiado y habilitado.

- Experiencia de 8 años en el área de Seguridad y Salud Ocupacional en la minería.

- Maestría en Administración y Diplomado en Sistemas de Gestión en Seguridad y Salud Ocupacional, Medio Ambiente y Calidad.

- Capacidad para trabajar en lugares a gran altitud.

JEFE DE SEGURIDAD Y SALUD OCUPACIONAL (Vacante: 1)

Requisitos:

- Ingeniero de Minas, Ingeniero Geólogo o Metalurgista titulado, colegiado y habilitado.

- Experiencia de 5 años en el área de Seguridad y Salud Ocupacional, de los cuales 3 años deben ser en trabajos similares.

- Maestría en Administración y Diplomado en Sistemas de Gestión en Seguridad y Salud Ocupacional, Medio Ambiente y Calidad.

INGENIERO DE SEGURIDAD Y SALUD OCUPACIONAL (Vacantes: 2)

Requisitos:

- Ingeniero de Minas, Ingeniero Geólogo o Metalurgista titulado, colegiado y habilitado.

- Experiencia de 3 años en el área de Seguridad y Salud Ocupacional, de los cuales 2 años deben ser en trabajos similares.

- Maestría en Administración y Diplomado en Sistemas de Gestión en Seguridad y Salud Ocupacional, Medio Ambiente y Calidad.

\section{FACILITADOR DE OBRA (Vacante: 1 )}

- Ingeniero de Minas, Ingeniero Geólogo, Metalurgista o carreras afines.

- Experiencia de 2 años en el área de Seguridad y Salud Ocupacional

- Conocimiento avanzado del MS. Office. 


\subsection{Estructura organizacional}

Al establecer la estructura organizacional de la empresa y hacerla visible a todos los cargos se tendrá una mejor visualización de los puestos ocupados por cada uno de ellos, permitiendo que se sepa a quién está conectado jerárquicamente el empleador. Utilizado de manera estratégica, puede facilitar los procesos y sinergias dentro de la empresa.

Figura 6.1

Organigrama de la empresa

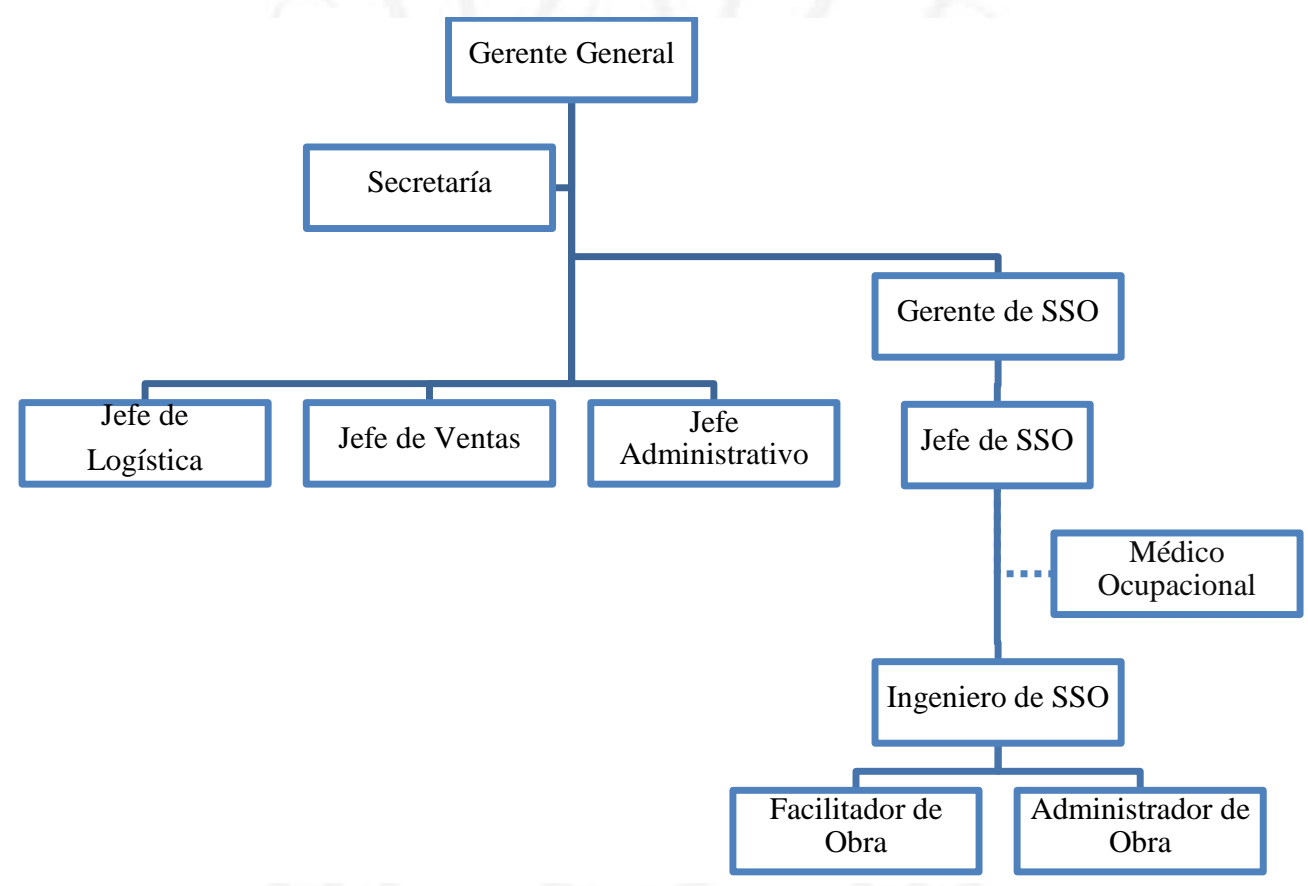

Elaboración propia

A continuación, se presentará la cantidad de personal durante los primeros 7 años, ya que el número de personas se incrementará para poder mantener un servicio de calidad a medida que la demanda se incrementará en los próximos años. 
Tabla 6.1

Cantidad de trabajadores por año

\begin{tabular}{|c|c|c|c|c|c|c|c|}
\hline Áreas y Cargos & $\mathbf{2 0 1 9}$ & $\mathbf{2 0 2 0}$ & $\mathbf{2 0 2 1}$ & $\mathbf{2 0 2 2}$ & $\mathbf{2 0 2 3}$ & $\mathbf{2 0 2 4}$ & $\mathbf{2 0 2 5}$ \\
\hline Gerencia General & 2 & 2 & 2 & 2 & 2 & 2 & 2 \\
\hline Gerente General & 1 & 1 & 1 & 1 & 1 & 1 & 1 \\
\hline Secretaria & 1 & 1 & 1 & 1 & 1 & 1 & 1 \\
\hline Área de Logística & 1 & 1 & 1 & 1 & 1 & 1 & 1 \\
\hline Jefe de Logística & 1 & 1 & 1 & 1 & 1 & 1 & 1 \\
\hline Área Comercial & 1 & 1 & 1 & 1 & 1 & 1 & 1 \\
\hline Jefe Comercial & 1 & 1 & 1 & 1 & 1 & 1 & 1 \\
\hline Área Administrativa & 1 & 1 & 1 & 1 & 1 & 1 & 1 \\
\hline Jefe Administrativo & 1 & 1 & 1 & 1 & 1 & 1 & 1 \\
\hline Área Operaciones & 6 & 6 & 11 & 11 & 11 & 11 & 11 \\
\hline Gerente de Seguridad y Salud Ocupacional & 1 & 1 & 1 & 1 & 1 & 1 & 1 \\
\hline Jefe de Seguridad y Salud Ocupacional & 1 & 1 & 2 & 2 & 2 & 2 & 2 \\
\hline Ingenierio de Seguridad y Salud Ocupacional & 2 & 2 & 4 & 4 & 4 & 4 & 4 \\
\hline Facilitador de Obra & 1 & 1 & 2 & 2 & 2 & 2 & 2 \\
\hline Administrador de Obra & 1 & 1 & 2 & 2 & 2 & 2 & 2 \\
\hline Total & $\mathbf{1 1}$ & $\mathbf{1 1}$ & $\mathbf{1 6}$ & $\mathbf{1 6}$ & $\mathbf{1 6}$ & $\mathbf{1 6}$ & $\mathbf{1 6}$ \\
\hline
\end{tabular}

Elaboración propia 


\section{CAPÍTULO VII. ASPECTOS ECONÓMICOS}

\subsection{Inversiones}

En el presente capítulo se detallarán las inversiones que serán necesarias hasta la puesta en marcha del servicio, para ello consideraremos la suma de activos tangibles, activos intangibles y capital de trabajo.

\subsubsection{Inversión en la infraestructura para el servicio}

Inversión fija intangible: Son inversiones que no tienen forma física ni existencia material, pero representa un valor por los derechos que le otorga al propietario la constitución de la organización.

- Inversión en trámites de constitución: De la tabla 7.1 se enfatiza, principalmente en el software de Microsoft Office, el cual será instalado en todas las laptops de los trabajadores, ello tiene un precio de $\$ 65.00$ cada uno. El monto total a invertir en activos fijos intangibles es de S/. 3,050.15.

Tabla 7.1

Inversión en trámites de constitución

\begin{tabular}{|l|c|}
\hline \multicolumn{1}{|c|}{ Descripción } & $\begin{array}{c}\text { Valor de venta } \\
\text { (S/.) }\end{array}$ \\
\hline Trámite de la licencia de funcionamiento & 303.56 \\
\hline Búsqueda y res erva nombre SUNARP & 73.80 \\
\hline Asesoría legal & 410.00 \\
\hline Creación de la página web & 328.00 \\
\hline Microsoft Office & $1,934.79$ \\
\hline \multicolumn{1}{|c|}{ TOTAL } & S/. $3,050.15$ \\
\hline
\end{tabular}

Elaboración propia

- Inversión en garantía de alquiler: Se ha determinado que se buscará una oficina de $180 \mathrm{~m}^{2}$ en un edificio empresarial ubicado en el distrito de San Isidro. Según el capítulo III del presente trabajo el precio promedio de alquiler por metro cuadrado en la zona elegida es de $\$ 17.07$, lo cual tendrá un precio aproximado de \$3,072.6 mensual, este será considerado como gasto administrativo. Sin 
embargo, la garantía que incluye el alquiler de las oficinas será de 2 meses, lo cual equivale a 2 cuotas mensuales que serán consideradas como inversión en garantía de alquiler. Tipo de cambio de S/.3.30 por dólar, de acuerdo a la fecha.

Tabla 7.2

Inversión en garantía de alquiler

\begin{tabular}{|c|c|}
\hline Descripción & $\begin{array}{c}\text { Valor de venta } \\
\text { (S/.) }\end{array}$ \\
\hline Garantía de alquiler & $16,628.91$ \\
\hline TOTAL & S/. 16,628.91 \\
\hline
\end{tabular}

Elaboración propia

La inversión en activos fijos intangibles es de S/. 19,679.07.

Tabla 7.3

Inversión fija intangible

\begin{tabular}{|c|c|}
\hline \multicolumn{1}{|c|}{ Activos fijos intangibles } & Total (S/.) \\
\hline Trámites de constitución & $3,050.15$ \\
\hline Garantía de alquiler & $16,628.91$ \\
\hline TOTAL & S/. 19,679.07 \\
\hline
\end{tabular}

Elaboración propia

Inversión fija tangible: Está compuesta por bienes con forma física o existencia material que conforma los activos tangibles, cabe resaltar que el acondicionamiento físico no forma parte de la inversión, ya que se buscará un ambiente de trabajo completamente equipado para realizar labores de oficina. La inversión comprende:

- Inversión en maquinaria y equipos: Comprende la primera compra de equipos tecnológicos que serán usados para la prestación del servicio.

Tabla 7.4

Inversión en maquinaria y equipos

\begin{tabular}{|l|c|c|c|c|}
\hline \multicolumn{1}{|c|}{ Equipo } & Cantidad & Precio unitario (S/.) & $\begin{array}{c}\text { Valor de venta } \\
\text { unitario (S/.) }\end{array}$ & $\begin{array}{c}\text { Valor de venta } \\
\text { total (S/.) }\end{array}$ \\
\hline Luxometro & 1 & $1,450.00$ & $1,189.00$ & $1,189.00$ \\
\hline Sonometro & 1 & 250.00 & 205.00 & 205.00 \\
\hline Detector de tormentas & 1 & 245.99 & 201.71 & 201.71 \\
\hline Radio motorola & 4 & 400.00 & 328.00 & $1,312.00$ \\
\hline Monitoreo de monoxido & 1 & $1,000.00$ & 820.00 & 820.00 \\
\hline \multicolumn{4}{|c|}{ TOTAL } & S/. 3,727.71 \\
\hline
\end{tabular}

Elaboración propia 
- Inversión en equipos de oficina: Incluye equipos de uso administrativo como: impresora, proyector digital y aire acondicionado.

\section{Tabla 7.5}

Inversión en equipos de oficina

\begin{tabular}{|l|c|c|c|c|}
\hline \multicolumn{1}{|c|}{ Equipo } & Cantidad & Precio unitario (S/.) & $\begin{array}{c}\text { Valor de venta } \\
\text { unitario (S/.) }\end{array}$ & $\begin{array}{c}\text { Valor de venta } \\
\text { total (S/.) }\end{array}$ \\
\hline Impresora principal & 1 & 799.00 & 655.18 & 655.18 \\
\hline Impresora pequeña & 1 & 599.00 & 491.18 & 491.18 \\
\hline Proyector digital & 2 & $1,299.00$ & $1,065.18$ & $2,130.36$ \\
\hline Aire acondicionado & 3 & 769.00 & 630.58 & $1,891.74$ \\
\hline Ecrans & 2 & 340.00 & 278.80 & 557.60 \\
\hline Laptops & 11 & $1,599.00$ & $1,311.18$ & $14,422.98$ \\
\hline
\end{tabular}

Elaboración propia

- Muebles y enseres: Incluye la relación total de mobiliario y enseres que se necesitará en la oficina. Los muebles y enseres en la zona de trabajo mencionado en el cuadro 7.5 se encuentra detallado en el anexo 10.

Tabla 7.6

\section{Inversión en muebles y enseres}

\begin{tabular}{|l|c|c|c|c|}
\hline \multicolumn{1}{|c|}{ Descripcion } & Cantidad & Precio unitario (S/.) & $\begin{array}{c}\text { Valor de venta } \\
\text { unitario (S/.) }\end{array}$ & $\begin{array}{c}\text { Valor de venta } \\
\text { total (S/.) }\end{array}$ \\
\hline Pizarra & 1 & 74.90 & 61.42 & 61.42 \\
\hline Escritorio para secretaria & 1 & 700.00 & 574.00 & 574.00 \\
\hline Escritorios para trabajadores & 5 & 500.00 & 410.00 & $2,050.00$ \\
\hline Mesa de reuniones & 1 & $1,000.00$ & 820.00 & 820.00 \\
\hline Juego de muebles de espera & 1 & 300.00 & 246.00 & 246.00 \\
\hline Sillas ergonómicas para trabajadores & 6 & 220.00 & 180.40 & $1,082.40$ \\
\hline Sillas ergonómicas para sala de reunión & 8 & 260.00 & 213.20 & $1,705.60$ \\
\hline Mueble archivador & 2 & 300.00 & 246.00 & 492.00 \\
\hline Estante de almacén & 2 & 375.00 & 307.50 & 615.00 \\
\hline Extintor PQS & 2 & 60.00 & 49.20 & 98.40 \\
\hline Microondas & 1 & 379.00 & 310.78 & 310.78 \\
\hline Cafetera & 1 & 224.90 & 184.42 & 184.42 \\
\hline Sillas para el kitchenette & 6 & 60.00 & 49.20 & 295.20 \\
\hline Mesas para el kitchenette & 2 & 90.00 & 73.80 & 147.60 \\
\hline Útiles de oficina & 1 & 500.00 & 410.00 & 410.00 \\
\hline Tachos de basura & 7 & 70.00 & 57.40 & 401.80 \\
\hline Muebles y enseres en zona de trabajo & 1 & $3,284.90$ & $2,693.62$ & $2,693.62$ \\
\hline & TOTAL & & S/. 12,188.23 \\
\hline
\end{tabular}

Elaboración propia

La inversión en activos fijos tangibles es de S/. 36,064.99. 
Tabla 7.7

Inversión fija tangible

\begin{tabular}{|c|c|}
\hline Activos fijos tangibles & Total (S/.) \\
\hline Maquinaria y equipos & $3,727.71$ \\
\hline Equipos de oficina & $20,149.04$ \\
\hline Muebles y enseres & $12,188.23$ \\
\hline TOTAL & S/. 36,064.99 \\
\hline
\end{tabular}

Elaboración propia

\subsubsection{Capital de trabajo}

El capital de trabajo es necesario para poner en marcha el proyecto y para que la empresa opere en el corto plazo, ya que se requiere pago de remuneraciones al personal y cubrir los principales servicios como lo energía eléctrica, agua, alquiler de local y teléfono/internet. El detalle para la obtención de los sueldos de los trabajadores se explicará en el punto 7.2.3. Se está considerando un capital de trabajo para 60 días pues en esta clase de servicio (tercerización) el flujo de captación del cliente desde la realización de la visita programada hasta la firma del contrato durará aproximadamente 1 mes (tomando en cuenta que somos una empresa nueva), una vez iniciadas las actividades con el cliente se manejará un ciclo de caja de 30 días (es decir, un mes adicional) con pagos mensuales a fin de mes por la ejecución del proyecto.

Tabla 7.8

Capital de trabajo para cubrir sueldos

\begin{tabular}{|c|c|c|c|c|}
\hline Cargo & Cantidad & $\begin{array}{c}\text { Sueldo mensual } \\
\text { (S/.) }\end{array}$ & Núm. de meses & Total (S/.) \\
\hline Gerente general & 1 & $18,903.64$ & 2 & $37,807.27$ \\
\hline Secretaria & 1 & $3,089.91$ & 2 & $6,179.81$ \\
\hline Jefe de logística & 1 & $7,088.86$ & 2 & $14,177.73$ \\
\hline Jefe Comercial & 1 & $5,407.34$ & 2 & $10,814.67$ \\
\hline Jefe administrativo & 1 & $6,952.29$ & 2 & $13,904.58$ \\
\hline Gerente de operaciones & 1 & $14,965.38$ & 2 & $29,930.76$ \\
\hline Jefe de seguridad & 1 & $11,027.12$ & 2 & $22,054.24$ \\
\hline Ingeniero de seguridad & 2 & $8,664.17$ & 2 & $17,328.33$ \\
\hline Facilitador de obra & 1 & $4,725.91$ & 2 & $9,451.82$ \\
\hline Administrador de obra & 1 & $4,725.91$ & 2 & $9,451.82$ \\
\hline Abogado & 1 & 500.00 & 2 & $1,000.00$ \\
\hline Médico Ocupacional & 1 & $3,000.00$ & 2 & $6,000.00$ \\
\hline \multicolumn{4}{|c|}{ TOTAL } & S/. 178,101.02 \\
\hline
\end{tabular}

Elaboración propia 
Tabla 7.9

Capital de trabajo para cubrir servicios

\begin{tabular}{|l|c|c|c|}
\hline \multicolumn{1}{|c|}{ Servicio } & Costo (S/.)/ mes & Núm. de meses & Total (S/.) \\
\hline Energia eléctrica & 748.23 & 2 & $1,496.47$ \\
\hline Agua & 186.37 & 2 & 372.73 \\
\hline Alquiler de local & $8,314.46$ & 2 & $16,628.91$ \\
\hline Celulares & 712.58 & 2 & $1,425.16$ \\
\hline Teléfono & 129.31 & 2 & 258.63 \\
\hline Servicio de limpieza & 720.00 & 2 & $1,440.00$ \\
\hline & TOTAL & S/. 21,621.90 \\
\hline
\end{tabular}

Elaboración propia

Tabla 7.10

Total de capital de trabajo

\begin{tabular}{|c|c|}
\hline \multicolumn{1}{|c|}{ Descripción } & Capital de trabajo \\
\hline Sueldos a cubrir & $178,101.02$ \\
\hline Servicios a cubrir & $21,621.90$ \\
\hline TOTAL & S/. $199,722.92$ \\
\hline
\end{tabular}

Elaboración propia

Por lo tanto, considerando tanto activo fijo tangible, intangible y capital de trabajo se tiene como inversión total para el proyecto: S/. 255,466.97.

Tabla 7.11

Inversión total del proyecto

\begin{tabular}{|l|c|}
\hline \multicolumn{1}{|c|}{ Descripción } & Inversión del proyecto \\
\hline Inv. Tangible & $36,064.99$ \\
\hline Inv. Intangible & $19,679.07$ \\
\hline Capital de trabajo & $199,722.92$ \\
\hline \multicolumn{1}{|c|}{ TOTAL } & S/.255,466.97 \\
\hline
\end{tabular}

Elaboración propia

\subsection{Costos de las operaciones del servicio}

\subsubsection{Costos de materiales del servicio}

A continuación, se presentará los detalles de materiales necesarios para el servicio proyectado para los próximos 7 años. Se consideran los EPP's que se entregarán a los 
trabajadores de las empresas contratistas y señalizaciones, para ello se tomará en cuenta que la cantidad promedio de trabajadores de la empresa contratista minera es de 60 personas en la actividad de recrecimiento de relavera, se usará ese valor para obtener los costos. Sin embargo, se debe indicar que este dato es un referencial, ya que las empresas contratistas mineras pueden tener más trabajadores dependiendo de la cobertura de la obra.

También se debe tomar en cuenta que la entrega de EPP's será por cada proyecto y estos no podrán ser reutilizados para otros proyectos, por normativa de calidad de la empresa y puesto que son equipos personales.

Tabla 7.12

Costo total de entrega de EPP's

\begin{tabular}{|c|c|c|c|c|c|c|c|}
\hline Descripción & $\mathbf{2 0 1 9}$ & $\mathbf{2 0 2 0}$ & $\mathbf{2 0 2 1}$ & $\mathbf{2 0 2 2}$ & $\mathbf{2 0 2 3}$ & $\mathbf{2 0 2 4}$ & $\mathbf{2 0 2 5}$ \\
\hline Cantidad de proyectos abarcados & 3 & 3 & 4 & 4 & 6 & 6 & 6 \\
\hline Costo de entrega de EPP's por proyecto & $26,097.48$ & $26,097.48$ & $26,097.48$ & $26,097.48$ & $26,097.48$ & $26,097.48$ & $26,097.48$ \\
\hline Costo total de entrega de EPP's & S/. $78,292.45$ & S/. $78,292.45$ & S/. 104,389.94 & S/. 104,389.94 & S/. 156,584.90 & S/. 156,584.90 & S/. 156,584.90 \\
\hline
\end{tabular}

Elaboración propia

En el anexo 11 se detallan los equipos de protección personal utilizados durante la actividad de recrecimiento de relavera para un promedio de 60 trabajadores. Es importante mencionar que algunos equipos son para una actividad y cantidad de trabajadores específica como los guantes de soldador.

Otro de los materiales que la empresa provee como parte del servicio son las señalizaciones de advertencia, prevención de peligro, cintas, entre otros, los cuales también se requerirá por proyecto como se puede observar en el cuadro 7.12. La comisión de venta para el área comercial (jefe comercial) es de S/1,000.00 por cada servicio aceptado, este monto representa aproximadamente el $22 \%$ del sueldo total (fijo y variable) que debería recibir el jefe comercial.

Con respecto a los viáticos y transporte se considera que por el traslado de cada especialista a la mina se tiene un costo de $\mathrm{S} / .200 .00$ y se realizarán 2 viajes por mes (entrada y salida de la mina) por cada equipo de trabajo, además de los viáticos de ventas y la gasolina de la camioneta para el transporte en mina. La alimentación de los especialistas será en el comedor del titular minero (zona de trabajo) y tendrá un costo de S/.35.00 por persona al día, considerando 21 días de trabajo al mes, por el sistema de trabajo en la mina (tal como se mencionó en el punto 5.4.1.) 
Tabla 7.13

Costo total de avisos, comisiones y otros

\begin{tabular}{|l|c|c|c|c|c|c|c|}
\hline \multicolumn{1}{|c|}{ Descripción } & $\mathbf{2 0 1 9}$ & $\mathbf{2 0 2 0}$ & $\mathbf{2 0 2 1}$ & $\mathbf{2 0 2 2}$ & $\mathbf{2 0 2 3}$ & $\mathbf{2 0 2 4}$ & $\mathbf{2 0 2 5}$ \\
\hline Costo de señalizaciones & $3,000.00$ & $3,000.00$ & $4,000.00$ & $4,000.00$ & $6,000.00$ & $6,000.00$ & $6,000.00$ \\
\hline Comisiones de Ventas & $3,000.00$ & $3,000.00$ & $4,000.00$ & $4,000.00$ & $6,000.00$ & $6,000.00$ & $6,000.00$ \\
\hline Otros (viaticos, transporte) & $52,080.00$ & $52,080.00$ & $104,160.00$ & $104,160.00$ & $104,160.00$ & $104,160.00$ & $104,160.00$ \\
\hline Otros (alimentación) & $44,100.00$ & $44,100.00$ & $88,200.00$ & $88,200.00$ & $88,200.00$ & $88,200.00$ & $88,200.00$ \\
\hline Costo total de avisos, comisiones y otros & S/. 102,180.00 & S/. 102,180.00 & S/. 200,360.00 & S/.200,360.00 & S/. 204,360.00 & S/.204,360.00 & S/.204,360.00 \\
\hline
\end{tabular}

Elaboración propia

En cuadro 7.14 se muestra el costo total de materiales del servicio

Tabla 7.14

Costo total de materiales del servicio

\begin{tabular}{|l|c|c|c|c|c|c|c|}
\hline \multicolumn{1}{|c|}{ Descripción } & $\mathbf{2 0 1 9}$ & $\mathbf{2 0 2 0}$ & $\mathbf{2 0 2 1}$ & $\mathbf{2 0 2 2}$ & $\mathbf{2 0 2 3}$ & $\mathbf{2 0 2 4}$ & $\mathbf{2 0 2 5}$ \\
\hline Costo total de entrega de EPP's & $\mathbf{7 8 , 2 9 2 . 4 5}$ & $\mathbf{7 8 , 2 9 2 . 4 5}$ & $104,389.94$ & $104,389.94$ & $156,584.90$ & $156,584.90$ & $156,584.90$ \\
\hline Costo total de avisos, comisiones y otros & $102,180.00$ & $102,180.00$ & $200,360.00$ & $200,360.00$ & $204,360.00$ & $204,360.00$ & $204,360.00$ \\
\hline Costo total de materiales del servicio & $\mathrm{S} / .180,472.45$ & $\mathrm{~S} / .180,472.45$ & $\mathrm{~S} / .304,749.94$ & $\mathrm{~S} / .304,749.94$ & $\mathrm{~S} / .360,944.90$ & $\mathrm{~S} / .360,944.90$ & $\mathrm{~S} / .360,944.90$ \\
\hline
\end{tabular}

Elaboración propia

\subsubsection{Costo de los servicios (energía eléctrica, agua, transporte, etc)}

A continuación, se detallan los costos del servicio:

a. Servicios de telefonía

Se consideran los celulares que se entregarán a los trabajadores de la empresa que conforman la mano de obra directa e indirecta, es decir aquellos que tiene una relación directa o parcial con el servicio. El plan elegido tiene un precio de S/. 79.00 por mes obtenido de Entel, el celular es un Smartphone marca LG con memoria interna de 8 GB y sistema operativo Android 6. Como se mencionó anteriormente, a través de este medio se pretende tener mayor conexión entre los especialistas y los trabajadores en oficina.

En el anexo 12 se detallarán los servicios de telefonía considerados costos por cada año, se considera que aumenta en cada año ya que el Área de Operaciones incrementa.

Tabla 7.15

Costo de los servicios de telefonía

\begin{tabular}{|c|c|c|c|c|c|c|c|}
\hline Servicios telefónicos & $\mathbf{2 0 1 9}$ & $\mathbf{2 0 2 0}$ & $\mathbf{2 0 2 1}$ & $\mathbf{2 0 2 2}$ & $\mathbf{2 0 2 3}$ & $\mathbf{2 0 2 4}$ & $\mathbf{2 0 2 5}$ \\
\hline Teléfonos Móviles & $\mathbf{6 , 2 1 8 . 8 8}$ & $\mathbf{6 , 2 1 8 . 8 8}$ & $\mathbf{1 0 , 1 0 5 . 6 8}$ & $10,105.68$ & $10,105.68$ & $10,105.68$ & $10,105.68$ \\
\hline TOTAL & S/. 6,218.88 & S/. 6,218.88 & S/. 10,105.68 & S/. 10,105.68 & S/. 10,105.68 & S/. 10,105.68 & S/. 10,105.68 \\
\hline
\end{tabular}

Elaboración propia 
b. Servicio de terceros

Considera el servicio de mantenimiento planificado y no planificado de infraestructura y equipos propios y tecnológicos. La movilidad en la zona de trabajo también será un servicio tercerizado, pues se solicitará una camioneta por proyecto durante todo el mes para el traslado de los ingenieros durante las inspecciones diarias a diferentes puntos de trabajo, el alquiler de una camioneta es de S/.190.00 por día.

El servicio de abogados será necesario en caso se presenten documentos para revisión o algún tipo de denuncia, su pago será a través de recibos por honorario S/.500.00 mensual. El servicio médico contará con un médico ocupacional cuyo pago también será a través de recibos por honorarios S/.3,000.00 mensuales, de acuerdo a lo definido en el Capítulo 5 (punto 5.10.3).

Tabla 7.16

Costo de los servicios de terceros

\begin{tabular}{|l|c|c|c|c|c|c|c|}
\hline \multicolumn{1}{|c|}{ Servicios de terceros } & $\mathbf{2 0 1 9}$ & $\mathbf{2 0 2 0}$ & $\mathbf{2 0 2 1}$ & $\mathbf{2 0 2 2}$ & $\mathbf{2 0 2 3}$ & $\mathbf{2 0 2 4}$ & $\mathbf{2 0 2 5}$ \\
\hline Mantenimiento & $12,000.00$ & $12,000.00$ & $12,000.00$ & $12,000.00$ & $12,000.00$ & $12,000.00$ & $12,000.00$ \\
\hline Movilidad & $68,400.00$ & $68,400.00$ & $136,800.00$ & $136,800.00$ & $136,800.00$ & $136,800.00$ & $136,800.00$ \\
\hline Servicio médico & $36,000.00$ & $36,000.00$ & $36,000.00$ & $36,000.00$ & $36,000.00$ & $36,000.00$ & $36,000.00$ \\
\hline Servicio de abogado & $6,000.00$ & $6,000.00$ & $6,000.00$ & $6,000.00$ & $6,000.00$ & $6,000.00$ & $6,000.00$ \\
\hline \multicolumn{1}{|c|}{ TOTAL } & S/. 122,400.00 & S/. 122,400.00 & S/. 190,800.00 & S/. 190,800.00 & S/. 190,800.00 & S/. 190,800.00 & S/. 190,800.00 \\
\hline
\end{tabular}

Elaboración propia

A continuación, se muestra el total de costos de servicios para el proyecto.

Tabla 7.17

Costo total de servicios

\begin{tabular}{|l|c|c|c|c|c|c|c|}
\hline \multicolumn{1}{|c|}{ Descripción } & $\mathbf{2 0 1 9}$ & $\mathbf{2 0 2 0}$ & $\mathbf{2 0 2 1}$ & $\mathbf{2 0 2 2}$ & $\mathbf{2 0 2 3}$ & $\mathbf{2 0 2 4}$ & $\mathbf{2 0 2 5}$ \\
\hline Servicios telefónicos & $6,218.88$ & $6,218.88$ & $10,105.68$ & $10,105.68$ & $10,105.68$ & $10,105.68$ & $10,105.68$ \\
\hline Servicios de terceros & $122,400.00$ & $122,400.00$ & $190,800.00$ & $190,800.00$ & $190,800.00$ & $190,800.00$ & $190,800.00$ \\
\hline TOTAL & S/. $128,618.88$ & S/. $128,618.88$ & S/. 200,905.68 & S/.200,905.68 & S/.200,905.68 & S/. 200,905.68 & S/.200,905.68 \\
\hline
\end{tabular}

Elaboración propia

\subsubsection{Costo del personal}

\subsubsection{Personal de atención al cliente}

La mano de obra directa de la empresa está conformada por el grupo de especialistas (1 Jefe de Seguridad, 2 ingenieros de seguridad, 1 facilitador de obra y 1 administrador) que se encontrarán en la zona de trabajo de la empresa contratista minera, ya que son 
ellos quienes están en contacto directo con los clientes y sus necesidades. Se considera que todos los beneficios que por ley le corresponde al trabajador tiene un porcentaje de $57.53 \%$ sobre el sueldo mensual, en el anexo 13 se detalla lo mencionado.

Entre los beneficios están EsSalud, AFP Jubilación Anticipada, Vida ley y el Seguro Complementario de Trabajo de Riesgo (SCTR), este último es importante ya que la minería y construcción son consideradas actividades riesgosas, por lo que el Estado remarca la obligatoriedad de estos seguros. El SCTR cubre prótesis y aparatos ortopédicos, prevención en Seguridad y Salud Ocupacional, cobertura total en accidentes laborales y rehabilitación y readaptación laboral.

A partir del año 3 se realizará un incremento del $10 \%$ en el sueldo de los colaboradores tanto del personal de soporte al cliente como del soporte interno del servicio, el cual se va a mantener durante los siguientes 2 años.

Tabla 7.18

Sueldos mano de obra directa

\begin{tabular}{|l|c|c|c|}
\hline \multicolumn{1}{|c|}{ Colaborador } & Sueldo mensual (S/.) & $\begin{array}{c}\text { Sueldo real mensual } \\
(\mathbf{S} / .)\end{array}$ & Sueldo real anual (S/.) \\
\hline Jefe de SSO & $7,000.00$ & $11,027.12$ & S/. 132,325.45 \\
\hline Ingeniero de SSO & $5,500.00$ & $8,664.17$ & S/. 103,970.00 \\
\hline Facilitador de obra & $3,000.00$ & $4,725.91$ & S/. 56,710.91 \\
\hline Administrador de obra & $3,000.00$ & $4,725.91$ & S/. 56,710.91 \\
\hline
\end{tabular}

Elaboración propia

\subsubsection{Personal de soporte interno del servicio}

La mano de obra indirecta está conformada por el personal involucrado en brindar el servicio y que se encuentra en la oficina de la empresa en Lima. Se considera el gerente general y de operaciones, ya que ellos también viajarán a las zonas de trabajo para realizar verificaciones, y el área de logística porque en ello recae la responsabilidad sobre los materiales necesarios para el servicio. El porcentaje de beneficios por ley al igual que el punto anterior es de $57.53 \%$. 
Tabla 7.19

Sueldos mano de obra indirecta

\begin{tabular}{|l|c|c|c|}
\hline \multicolumn{1}{|c|}{ Colaborador } & Sueldo mensual (S/.) & $\begin{array}{c}\text { Sueldo real } \\
\text { mensual }\end{array}$ & Sueldo real anual \\
\hline Gerente General & $12,000.00$ & $18,903.64$ & $226,843.63$ \\
\hline Jefe de Logística & $4,500.00$ & $7,088.86$ & $85,066.36$ \\
\hline Gerente de SSO & $9,500.00$ & $14,965.38$ & $179,584.54$ \\
\hline
\end{tabular}

Elaboración propia

A continuación, se mostrará los costos de mano de obra directa e indirecta del proyecto por cada año del horizonte del proyecto. 
Tabla 7.20

Costos de la mano de obra directa e indirecta

\begin{tabular}{|c|c|c|c|c|c|c|c|c|c|c|c|c|c|c|c|}
\hline \multirow{2}{*}{ Colaborador } & \multirow{2}{*}{$\begin{array}{c}\text { Sueldo } \\
\text { total } \\
\text { anual (S/.) }\end{array}$} & \multicolumn{2}{|r|}{2019} & \multicolumn{2}{|r|}{2020} & \multicolumn{2}{|r|}{2021} & \multicolumn{2}{|r|}{2022} & \multicolumn{2}{|r|}{2023} & \multicolumn{2}{|r|}{2024} & \multicolumn{2}{|r|}{2025} \\
\hline & & Q & Total (S/.) & Q & Total (S/.) & $\mathrm{Q}$ & Total (S/.) & $\mathrm{Q}$ & Total (S/.) & $\mathrm{Q}$ & Total (S/.) & $\mathrm{Q}$ & Total (S/.) & $\mathrm{Q}$ & Total (S/.) \\
\hline Jefe de SSO & $132,325.45$ & 1 & $132,325.45$ & 1 & $132,325.45$ & 2 & $291,115.99$ & 2 & $291,115.99$ & 2 & $317,581.08$ & 2 & $317,581.08$ & 2 & $344,046.17$ \\
\hline $\begin{array}{l}\text { Ingeniero de } \\
\text { SSO }\end{array}$ & $103,970.00$ & 2 & $207,939.99$ & 2 & $207,939.99$ & 4 & $457,467.98$ & 4 & $457,467.98$ & 4 & $499,055.98$ & 4 & $499,055.98$ & 4 & $540,643.97$ \\
\hline $\begin{array}{l}\text { Facilitador de } \\
\text { obra }\end{array}$ & $56,710.91$ & 1 & $56,710.91$ & 1 & $56,710.91$ & 2 & $124,763.99$ & 2 & $124,763.99$ & 2 & $136,106.18$ & 2 & $136,106.18$ & 2 & $147,448.36$ \\
\hline $\begin{array}{l}\text { Administrador } \\
\text { de obra }\end{array}$ & $56,710.91$ & 1 & $56,710.91$ & 1 & $56,710.91$ & 2 & $124,763.99$ & 2 & $124,763.99$ & 2 & $136,106.18$ & 2 & $136,106.18$ & 2 & $147,448.36$ \\
\hline \multicolumn{2}{|c|}{ TOTAL } & 5 & $\begin{array}{c}\mathrm{S} / . \\
453,687.25 \\
\end{array}$ & 5 & \begin{tabular}{|c|}
$\mathrm{S} /$. \\
$453,687.25$ \\
\end{tabular} & 10 & $\begin{array}{c}\mathrm{S} / . \\
998,111.95\end{array}$ & 10 & $\begin{array}{c}\mathrm{S} / . \\
998,111.95\end{array}$ & 10 & $\begin{array}{c}\mathrm{S} / . \\
1,088,849.40\end{array}$ & 10 & $\begin{array}{c}\mathrm{S} / . \\
1,088,849.40\end{array}$ & 10 & $\begin{array}{c}\mathrm{S} / . \\
1,179,586.85\end{array}$ \\
\hline
\end{tabular}

\begin{tabular}{|c|c|c|c|c|c|c|c|c|c|c|c|c|c|c|c|}
\hline \multirow{2}{*}{ Colaborador } & \multirow{2}{*}{$\begin{array}{c}\text { Sueldo } \\
\text { total } \\
\text { anual }(\mathrm{S} / .)\end{array}$} & \multicolumn{2}{|r|}{2019} & \multicolumn{2}{|r|}{2020} & \multicolumn{2}{|r|}{2021} & \multicolumn{2}{|r|}{2022} & \multicolumn{2}{|r|}{2023} & \multicolumn{2}{|r|}{2024} & \multicolumn{2}{|r|}{2025} \\
\hline & & $\mathbf{Q}$ & Total (S/.) & $\mathbf{Q}$ & Total (S/.) & $\mathbf{Q}$ & Total (S/.) & $\mathbf{Q}$ & Total (S/.) & $\mathbf{Q}$ & Total (S/.) & $\mathbf{Q}$ & Total (S/.) & $\mathbf{Q}$ & Total (S/.) \\
\hline $\begin{array}{l}\text { Gerente } \\
\text { General }\end{array}$ & $226,843.63$ & 1 & $226,843.63$ & 1 & $226,843.63$ & 1 & $249,527.99$ & 1 & $249,527.99$ & 1 & $272,212.35$ & 1 & $272,212.35$ & 1 & $294,896.71$ \\
\hline $\begin{array}{l}\text { Jefe de } \\
\text { Logística }\end{array}$ & $85,066.36$ & 1 & $85,066.36$ & 1 & $85,066.36$ & 1 & $93,573.00$ & 1 & $93,573.00$ & 1 & $102,079.63$ & 1 & $102,079.63$ & 1 & $110,586.27$ \\
\hline $\begin{array}{l}\text { Gerente de } \\
\text { SSO }\end{array}$ & $179,584.54$ & 1 & $179,584.54$ & 1 & $179,584.54$ & 1 & $197,542.99$ & 1 & $197,542.99$ & 1 & $215,501.44$ & 1 & $215,501.44$ & 1 & $233,459.90$ \\
\hline \multicolumn{2}{|c|}{ TOTAL } & 3 & $\begin{array}{c}\mathrm{S} / . \\
491,494.52\end{array}$ & 3 & $\begin{array}{c}\text { S/. } \\
491,494.52\end{array}$ & 3 & $\begin{array}{c}\mathrm{S} / . \\
540,643.97 \\
\end{array}$ & 3 & $\begin{array}{c}\text { S/. } \\
540,643.97\end{array}$ & 3 & $\begin{array}{c}\mathrm{S} / . \\
589,793.43\end{array}$ & 3 & $\begin{array}{c}\mathrm{S} / . \\
589,793.43\end{array}$ & 3 & $\begin{array}{c}\text { S/. } \\
638,942.88\end{array}$ \\
\hline
\end{tabular}

Nota: Cantidad de colaboradores (Q)

Elaboración propia 


\subsection{Presupuesto de ingresos y egresos}

\subsubsection{Presupuesto de ingreso por ventas}

Para obtener los ingresos de la empresa por año se tomará en cuenta un $4 \%$ de margen de ganancia en promedio respecto a la suma de todos los egresos involucrados en el proyecto: costos (costo de EPP's, señalizaciones y otros, costo de servicios, mano de obra directa e indirecta), gastos, depreciación y amortización en el primer año al año 7 del proyecto la ganancia será de $5 \%$.

Tabla 7.21

Presupuesto de ingresos por ventas

\begin{tabular}{|l|c|c|c|c|c|c|c|}
\hline \multicolumn{1}{|c|}{ Descripción } & $\mathbf{2 0 1 9}$ & $\mathbf{2 0 2 0}$ & $\mathbf{2 0 2 1}$ & $\mathbf{2 0 2 2}$ & $\mathbf{2 0 2 3}$ & $\mathbf{2 0 2 4}$ & $\mathbf{2 0 2 5}$ \\
\hline Total de egresos & S/. 1,586,155.63 & S/. 1,586,155.63 & S/.2,377,572.16 & S/. 2,377,572.16 & S/. 2,573,654.03 & S/.2,577,381.74 & S/.2,713,540.93 \\
\hline Total de ingresos sin IGV & S/. 1,644,843.39 & S/. 1,644,843.39 & S/.2,467,919.90 & S/.2,472,675.05 & S/. 2,676,600.19 & S/.2,684,343.09 & S/.2,835,650.28 \\
\hline
\end{tabular}

Elaboración propia

\subsubsection{Presupuesto operativo de costos}

Incluye todos los costos que se generan en el proyecto, como: costos de los materiales, costos de los servicios, costos por mano de obra directa e indirecta, la depreciación de activos tangibles y amortización de activos intangibles. El detalle de la depreciación y amortización se puede observar en la tabla 7.23. Es importante mencionar que en la depreciación de los activos tangibles, puesto que la maquinaria y equipos tienen una vida útil de 5 años, en el año 2024 se considerará la adquisición de estos como un gasto administrativo.

Tabla 7.22

Presupuesto de costos del servicio

\begin{tabular}{|l|c|c|c|c|c|c|c|}
\hline \multicolumn{1}{|c|}{ Descripción } & $\mathbf{2 0 1 9}$ & $\mathbf{2 0 2 0}$ & $\mathbf{2 0 2 1}$ & $\mathbf{2 0 2 2}$ & $\mathbf{2 0 2 3}$ & $\mathbf{2 0 2 4}$ & $\mathbf{2 0 2 5}$ \\
\hline Costo de EPP's, señalizaciones y otros & $180,472.45$ & $180,472.45$ & $304,749.94$ & $304,749.94$ & $360,944.90$ & $360,944.90$ & $360,944.90$ \\
\hline Costo de servicios & $128,618.88$ & $128,618.88$ & $200,905.68$ & $200,905.68$ & $200,905.68$ & $200,905.68$ & $200,905.68$ \\
\hline Mano de obra directa & $453,687.25$ & $453,687.25$ & $998,111.95$ & $998,111.95$ & $1,088,849.40$ & $1,088,849.40$ & $1,179,586.85$ \\
\hline Mano de obra indirecta & $491,494.52$ & $491,494.52$ & $540,643.97$ & $540,643.97$ & $589,793.43$ & $589,793.43$ & $638,942.88$ \\
\hline Depreciación activos tangibles & $3,979.27$ & $3,979.27$ & $3,979.27$ & $3,979.27$ & $3,979.27$ & $3,979.27$ & $3,979.27$ \\
\hline Amorización activos intangibles & 276.40 & 276.40 & 276.40 & 276.40 & 276.40 & 276.40 & 276.40 \\
\hline \multicolumn{1}{|c|}{ TOTAL } & S/ $1,258,528.77$ & S/. 1,258,528.77 & S/.2,048,667.21 & S/. 2,048,667.21 & S/.2,244,749.08 & S/.2,244,749.08 & S/.2,384,635.98 \\
\hline
\end{tabular}

Elaboración propia 
Tabla 7.23

Depreciación de activos tangibles y amortización de activos intangibles

\begin{tabular}{|c|c|c|c|c|c|c|c|c|c|c|}
\hline Descripción & Inversión & Depreciación ${ }^{8}$ & 2019 & 2020 & 2021 & 2022 & 2023 & 2024 & 2025 & $\begin{array}{l}\text { Valor en } \\
\text { libros }\end{array}$ \\
\hline Maquinaria y equipos & $3,727.71$ & $20 \%$ & 745.54 & 745.54 & 745.54 & 745.54 & 745.54 & 745.54 & 745.54 & $2,236.63$ \\
\hline Equipos de oficina & $20,149.04$ & $10 \%$ & $2,014.90$ & $2,014.90$ & $2,014.90$ & $2,014.90$ & $2,014.90$ & $2,014.90$ & $2,014.90$ & $16,119.23$ \\
\hline Muebles y enseres & $12,188.23$ & $10 \%$ & $1,218.82$ & $1,218.82$ & $1,218.82$ & $1,218.82$ & $1,218.82$ & $1,218.82$ & $1,218.82$ & $3,656.47$ \\
\hline \multicolumn{3}{|c|}{ Total de depreciación activos tangibles } & $\begin{array}{c}\mathrm{S} / . \\
3,979.27\end{array}$ & $\begin{array}{c}\mathrm{S} / . \\
3,979.27 \\
\end{array}$ & $\begin{array}{c}\mathrm{S} / . \\
3,979.27 \\
\end{array}$ & $\begin{array}{c}\mathrm{S} / \\
3,979.27 \\
\end{array}$ & $\begin{array}{c}\mathrm{S} / . \\
3,979.27\end{array}$ & $\begin{array}{c}\mathrm{S} / . \\
3,979.27\end{array}$ & $\begin{array}{c}\mathrm{S} / \\
3,979.27\end{array}$ & $\begin{array}{c}\mathrm{S} / . \\
22,012.33 \\
\end{array}$ \\
\hline
\end{tabular}

\begin{tabular}{|c|c|c|c|c|c|c|c|c|c|c|}
\hline Descripción & Inversión & Vida útil & 2019 & 2020 & 2021 & 2022 & 2023 & 2024 & 2025 & $\begin{array}{c}\text { Valor en } \\
\text { libros }\end{array}$ \\
\hline Microsoft Office & $1,934.79$ & 7 años & 276.40 & 276.40 & 276.40 & 276.40 & 276.40 & 276.40 & 276.40 & 0.00 \\
\hline \multicolumn{3}{|c|}{ Total de amortización activos intangibles } & S/. 276.40 & S/. 276.40 & S/. 276.40 & S/. 276.40 & S/. 276.40 & S/. 276.40 & S/. 276.40 & S/. 0.00 \\
\hline
\end{tabular}

Elaboración propia

心 ${ }^{8}$ Según la Superintendencia Nacional de Aduanas y de Administración Tributaria (SUNAT) 


\subsubsection{Presupuesto operativo de gastos administrativos y ventas}

Los gastos operativos incluyen los gastos administrativos y gastos de ventas. Los gastos administrativos hacen referencia al pago mensual del alquiler de la oficina de la empresa (como se explicó anteriormente la oficina será alquilada), sueldos del área administrativa de la empresa y servicios de la empresa. Entre los gastos de ventas están considerados los gastos de publicidad y marketing como las publicaciones que se realizarán en revistas en el rubro de minería como: Seguridad Minera, Minería, Business Negocios en el Perú, Mundo Empresarial y G. de Gestión, además de publicaciones en espacios publicitarios que se contratarán en páginas web relacionadas a la seguridad y salud en el trabajo (Colegio de Ingenieros, Ministerio de Energía y Minas, Ministerio de Trabajo y Promoción del Empleo y Ministerio de Salud).

- Servicios administrativos

Incluye gastos por servicios básicos como energía eléctrica y agua, en el anexo 14 y 15 se muestran los detallen de cómo se hallaron estos valores por cada año. Los servicios telefónicos incluyen a los teléfonos fijos (anexos) que se encontrarán en la oficina, se tomará el plan de S/.157.70 que ofrece Movistar por una central Intelbras Impacta 16 con 2 líneas análogas y 6 anexos analógicos, además de un identificador de llamadas y operadora automática, en el anexo 18 se muestra detalle. Respecto a los teléfonos móviles, estos serán para los trabajadores del área administrativa de la empresa, en el anexo 17 se detalla. El servicio de terceros contempla el servicio de limpieza de la oficina, el cual tiene un costo de S/.30.00 por hora, se determinó que la limpieza será de lunes a viernes al cierre del día laboral y durante 1 hora, con excepción del lunes que se está considerando una duración de 2 horas, ya que la limpieza será con mayor profundidad.

Tabla 7.24

Gastos por servicios básicos administrativos

\begin{tabular}{|c|c|c|c|c|c|c|c|}
\hline $\begin{array}{c}\text { Servicios básicos } \\
\text { administrativos }\end{array}$ & $\mathbf{2 0 1 9}$ & $\mathbf{2 0 2 0}$ & $\mathbf{2 0 2 1}$ & $\mathbf{2 0 2 2}$ & $\mathbf{2 0 2 3}$ & $\mathbf{2 0 2 4}$ & $\mathbf{2 0 2 5}$ \\
\hline Energía Eléctrica & $8,978.79$ & $8,978.79$ & $10,256.89$ & $10,256.89$ & $10,256.89$ & $10,256.89$ & $10,256.89$ \\
\hline Agua & $2,236.39$ & $2,236.39$ & $2,236.39$ & $2,236.39$ & $2,236.39$ & $2,236.39$ & $2,236.39$ \\
\hline \multicolumn{1}{|c|}{ TOTAL } & S/. $11,215.18$ & S/. $11,215.18$ & S/. 12,493.28 & S/. 12,493.28 & S/. 12,493.28 & S/. 12,493.28 & S/.12,493.28 \\
\hline
\end{tabular}

Fuente: Sedapal, Luz del Sur (2017)

Elaboración propia 
Tabla 7.25

Gastos por servicios telefónicos

\begin{tabular}{|l|c|c|c|c|c|c|c|}
\hline Servicios telefónicos & $\mathbf{2 0 1 9}$ & $\mathbf{2 0 2 0}$ & $\mathbf{2 0 2 1}$ & $\mathbf{2 0 2 2}$ & $\mathbf{2 0 2 3}$ & $\mathbf{2 0 2 4}$ & $\mathbf{2 0 2 5}$ \\
\hline Telefonos Móviles & $2,332.08$ & $2,332.08$ & $2,332.08$ & $2,332.08$ & $2,332.08$ & $2,332.08$ & $2,332.08$ \\
\hline Telefonos Fijos & $1,551.77$ & $1,551.77$ & $1,551.77$ & $1,551.77$ & $1,551.77$ & $1,551.77$ & $1,551.77$ \\
\hline TOTAL & S/.3,883.85 & S/.3,883.85 & S/.3,883.85 & S/.3,883.85 & S/. $3,883.85$ & S/.3,883.85 & S/.3,883.85 \\
\hline
\end{tabular}

Fuente: Movistar (2017)

Elaboración propia

Tabla 7.26

Gastos por servicios de terceros

\begin{tabular}{|c|c|c|c|c|c|c|c|}
\hline Servicios de terceros & $\mathbf{2 0 1 9}$ & $\mathbf{2 0 2 0}$ & $\mathbf{2 0 2 1}$ & $\mathbf{2 0 2 2}$ & $\mathbf{2 0 2 3}$ & $\mathbf{2 0 2 4}$ & $\mathbf{2 0 2 5}$ \\
\hline Limpieza & $9,360.00$ & $9,360.00$ & $9,360.00$ & $9,360.00$ & $9,360.00$ & $9,360.00$ & $9,360.00$ \\
\hline TOTAL & S/. $9,360.00$ & S/. $9,360.00$ & S/. $9,360.00$ & S/. $9,360.00$ & S/. $9,360.00$ & S/. $9,360.00$ & S/. $9,360.00$ \\
\hline
\end{tabular}

Elaboración propia

Tabla 7.27

Gastos totales por servicios

\begin{tabular}{|l|c|c|c|c|c|c|c|}
\hline \multicolumn{1}{|c|}{ Descripción } & $\mathbf{2 0 1 9}$ & $\mathbf{2 0 2 0}$ & $\mathbf{2 0 2 1}$ & $\mathbf{2 0 2 2}$ & $\mathbf{2 0 2 3}$ & $\mathbf{2 0 2 4}$ & $\mathbf{2 0 2 5}$ \\
\hline Servicios básicos & $11,215.18$ & $11,215.18$ & $12,493.28$ & $12,493.28$ & $12,493.28$ & $12,493.28$ & $12,493.28$ \\
\hline Servicios telefónicos & $3,883.85$ & $3,883.85$ & $3,883.85$ & $3,883.85$ & $3,883.85$ & $3,883.85$ & $3,883.85$ \\
\hline Servicios terceros & $9,360.00$ & $9,360.00$ & $9,360.00$ & $9,360.00$ & $9,360.00$ & $9,360.00$ & $9,360.00$ \\
\hline \multicolumn{1}{|c|}{ TOTAL } & S/. $24,459.03$ & S/.24,459.03 & S/.25,737.13 & S/. 25,737.13 & S/. 25,737.13 & S/.25,737.13 & S/.25,737.13 \\
\hline
\end{tabular}

Elaboración propia

- Sueldos administrativos:

Corresponden a los sueldos del personal administrativo de la empresa. Se considera que todos los beneficios que por ley corresponde tiene un porcentaje de $54.50 \%$ sobre el sueldo mensual, en el anexo 18 se detalla lo mencionado. A diferencia de los sueldos de mano de obra directa e indirecta, en este caso ya no se considera el Seguro Complementario de Trabajo de Riesgo (SCTR) porque la labor en oficina no representa una actividad de alto riesgo como lo es la actividad minera o de construcción. 
Tabla 7.28

Sueldos área administrativa

\begin{tabular}{|l|c|c|c|}
\hline \multicolumn{1}{|c|}{ Colaborador } & $\begin{array}{c}\text { Sueldo mensual } \\
(\mathbf{S} / .)\end{array}$ & $\begin{array}{c}\text { Sueldo real } \\
\text { mensual (S/.) }\end{array}$ & $\begin{array}{c}\text { Sueldo real } \\
\text { anual (S/.) }\end{array}$ \\
\hline Secretaria & $2,000.00$ & $3,089.91$ & $37,078.87$ \\
\hline Jefe Comercial & $3,500.00$ & $5,407.34$ & $64,888.02$ \\
\hline Jefe Administrativo & $4,500.00$ & $6,952.29$ & $83,427.46$ \\
\hline
\end{tabular}

Elaboración propia 
Tabla 7.29

Gastos por sueldos administrativos

\begin{tabular}{|c|c|c|c|c|c|c|c|c|c|c|c|c|c|c|c|}
\hline \multirow{2}{*}{ Colaborador } & \multirow{2}{*}{$\begin{array}{c}\text { Sueldo } \\
\text { total } \\
\text { anual } \\
(\mathrm{S} / .)\end{array}$} & \multicolumn{2}{|r|}{2019} & \multicolumn{2}{|r|}{2020} & \multicolumn{2}{|r|}{2021} & \multicolumn{2}{|r|}{2022} & \multicolumn{2}{|r|}{2023} & \multicolumn{2}{|r|}{2024} & \multicolumn{2}{|r|}{2025} \\
\hline & & $\mathbf{Q}$ & Total (S/.) & $\mathbf{Q}$ & Total (S/.) & $\mathbf{Q}$ & Total (S/.) & $\mathbf{Q}$ & Total (S/.) & $\mathbf{Q}$ & Total (S/.) & $\mathbf{Q}$ & Total (S/.) & $\mathbf{Q}$ & Total (S/.) \\
\hline Secretaria & $37,078.87$ & 1 & $37,078.87$ & 1 & $37,078.87$ & 1 & $37,078.87$ & 1 & $37,078.87$ & 1 & $37,078.87$ & 1 & $37,078.87$ & 1 & $37,078.87$ \\
\hline $\begin{array}{c}\text { Jefe } \\
\text { Comercial }\end{array}$ & $64,888.02$ & 1 & $64,888.02$ & 1 & $64,888.02$ & 1 & $64,888.02$ & 1 & $64,888.02$ & 1 & $64,888.02$ & 1 & $64,888.02$ & 1 & $64,888.02$ \\
\hline $\begin{array}{c}\text { Jefe } \\
\text { administrativo }\end{array}$ & $83,427.46$ & 1 & $83,427.46$ & 1 & $83,427.46$ & 1 & $83,427.46$ & 1 & $83,427.46$ & 1 & $83,427.46$ & 1 & $83,427.46$ & 1 & $83,427.46$ \\
\hline \multicolumn{2}{|c|}{ TOTAL } & 3 & $\begin{array}{c}\text { S/. } \\
185,394.35\end{array}$ & 3 & $\begin{array}{c}\mathrm{S} / . \\
185,394.35\end{array}$ & 3 & $\begin{array}{c}\text { S/. } \\
185,394.35\end{array}$ & 3 & $\begin{array}{c}\text { S/. } \\
185,394.35\end{array}$ & 3 & $\begin{array}{c}\text { S/. } \\
185,394.35\end{array}$ & 3 & $\begin{array}{c}\text { S/. } \\
185,394.35\end{array}$ & 3 & $\begin{array}{c}\text { S/. } \\
185,394.35\end{array}$ \\
\hline
\end{tabular}

Nota: Cantidad de colaboradores (Q)

Elaboración propia 
A continuación, se muestra el presupuesto de gastos operativos.

Tabla 7.30

Presupuesto de gastos operativos

\begin{tabular}{|l|c|c|c|c|c|c|c|}
\hline \multicolumn{1}{|c|}{ Descripción } & $\mathbf{2 0 1 9}$ & $\mathbf{2 0 2 0}$ & $\mathbf{2 0 2 1}$ & $\mathbf{2 0 2 2}$ & $\mathbf{2 0 2 3}$ & $\mathbf{2 0 2 4}$ & $\mathbf{2 0 2 5}$ \\
\hline Alquiler de oficina & $99,773.47$ & $99,773.47$ & $99,773.47$ & $99,773.47$ & $99,773.47$ & $99,773.47$ & $99,773.47$ \\
\hline Publicidad y marketing & $18,000.00$ & $18,000.00$ & $18,000.00$ & $18,000.00$ & $18,000.00$ & $18,000.00$ & $18,000.00$ \\
\hline Sueldos operativos & $185,394.35$ & $185,394.35$ & $185,394.35$ & $185,394.35$ & $185,394.35$ & $185,394.35$ & $185,394.35$ \\
\hline Servicios administrativos & $24,459.03$ & $24,459.03$ & $25,737.13$ & $25,737.13$ & $25,737.13$ & $25,737.13$ & $25,737.13$ \\
\hline \multicolumn{1}{|c|}{ TOTAL } & S/.327,626.85 & S/. 327,626.85 & S/.328,904.95 & S/. 328,904.95 & S/. 328,904.95 & S/. 328,904.95 & S/.328,904.95 \\
\hline
\end{tabular}

Elaboración propia

Para obtener el presupuesto de servicio a la deuda se trabajó con una tasa efectiva mensual y en base a cuotas constantes. En la tabla 7.31 Datos financieros se muestra la TEA ofrecida por el Banco Continental y su conversión a periodo mensual (TEM)

Tabla 7.31

Datos financieros

\begin{tabular}{|c|c|}
\hline COK & $19.20 \%$ \\
\hline TEA & $15.41 \%$ \\
\hline TEM & $1.20 \%$ \\
\hline CPPC & $14.20 \%$ \\
\hline
\end{tabular}

Elaboración propia

El COK fue hallado con la siguiente fórmula:

$$
C O K=R f+\beta *(R m-R f)+\text { Riesgo pais }
$$

Los valores que se tienen son:

- $\quad$ Rf: Tasa libre de riesgo (1.92\%)

- Rm: Prima de mercado (13.46\%)

- Riesgo país: $1.22 \%$

La $\beta$ que se considera en la fórmula es de tipo apalancado. Según la base de betas no apalancadas se obtuvo que la beta para el rubro de negocio y servicio es de 0.68 , este valor reemplazando en la fórmula de $\beta$ apalancada se obtiene como resultado 1.39 . 


$$
\beta=\beta_{U}\left[1+(1-T)\left(\frac{D}{E}\right)\right]
$$

B: Beta apalancada

Bu: Beta no apalancada

D: Deuda

E: Capital

Reemplazando en la fórmula:

$$
\beta=0.68 *\left[1+(1-0.295) *\left(\frac{0.6}{0.4}\right)\right]=1.39
$$

Reemplazando en la fórmula para hallar el COK:

$$
C O K=1.92 \%+1.39 *(13.46 \%-1.92 \%)+1.22 \%=19.2 \%
$$

La deuda será trabajada en cuotas constantes y bajo una tasa efectiva mensual de $1.20 \%$, en la tabla Servicio a la deuda se puede observar un consolidado de las cuotas en años.

Tabla 7.32

Presupuestos de servicio a la deuda

\begin{tabular}{|c|c|c|c|c|}
\hline Año & Prestamos & Amortización & Intereses & Pago \\
\hline 1 & S/. 153,280.18 & S/. 13,676.23 & S/. 21,219.57 & S/. 34,895.80 \\
\hline 2 & S/. 139,603.95 & S/. 15,783.74 & S/. 19,112.06 & S/. 34,895.80 \\
\hline 3 & S/. 123,820.22 & S/. 18,216.01 & S/. 16,679.79 & S/. 34,895.80 \\
\hline 4 & S/. 105,604.20 & S/.21,023.10 & S/. 13,872.70 & S/. 34,895.80 \\
\hline 5 & S/.84,581.11 & S/.24,262.76 & S/. 10,633.04 & S/. 34,895.80 \\
\hline 6 & S/.60,318.35 & S/.28,001.65 & S/.6,894.15 & S/. 34,895.80 \\
\hline 7 & S/.32,316.70 & S/.32,316.70 & S/.2,579.10 & S/. 34,895.80 \\
\hline
\end{tabular}

Elaboración propia

\subsection{Flujo de fondos netos}

\subsubsection{Flujo de fondos económicos}

A continuación, se mostrará el estado de resultados y el flujo de caja económico durante la vida útil del proyecto.

Cabe resaltar que según el Artículo 2 del Decreto Supremo N 009-98-TR, las empresas que cuenten con más de 20 trabajadores en planilla están obligadas a realizar el pago de utilidades, en este caso no se está considerando la participación de los 
trabajadores en las utilidades puesto que la empresa inicia con 11 trabajadores y finaliza con 16 trabajadores su proyección. 
Tabla 7.33

Estado de resultados 2019-2025 (expresado en S/.)

\begin{tabular}{|c|c|c|c|c|c|c|c|}
\hline & 2019 & 2020 & 2021 & 2022 & 2023 & 2024 & 2025 \\
\hline Ingresos & $1,644,843.39$ & $1,644,843.39$ & $2,467,919.90$ & $2,472,675.05$ & $2,676,600.19$ & $2,684,343.09$ & $2,835,650.28$ \\
\hline (-)Costo operativo & $1,258,528.77$ & $1,258,528.77$ & $2,048,667.21$ & $2,048,667.21$ & $2,244,749.08$ & $2,244,749.08$ & $2,384,635.98$ \\
\hline Utilidad bruta & $386,314.61$ & $386,314.61$ & $419,252.69$ & 424,007.84 & 431,851.11 & 439,594.01 & $451,014.29$ \\
\hline (-)Gastos operativos & $327,626.85$ & $327,626.85$ & $328,904.95$ & $328,904.95$ & $328,904.95$ & $332,632.66$ & $328,904.95$ \\
\hline (-)Gastos financieros & $21,219.57$ & $19,112.06$ & $16,679.79$ & $13,872.70$ & $10,633.04$ & $6,894.15$ & $2,579.10$ \\
\hline Utilidad antes de impues to & $37,468.19$ & $39,575.69$ & $73,667.95$ & $81,230.18$ & $92,313.12$ & $100,067.19$ & 119,530.24 \\
\hline (-)Impuesto a la renta (29.5\%) & $11,053.12$ & $11,674.83$ & $21,732.05$ & $23,962.90$ & $27,232.37$ & $29,519.82$ & $35,261.42$ \\
\hline Utilidad neta & $26,415.07$ & $27,900.86$ & $51,935.91$ & $57,267.28$ & $65,080.75$ & $\mathbf{7 0 , 5 4 7 . 3 7}$ & $84,268.82$ \\
\hline
\end{tabular}

Elaboración propia

Tabla 7.34

Flujo de fondos económicos (expresado en S/.)

\begin{tabular}{|c|c|c|c|c|c|c|c|c|}
\hline & Año 0 & 2019 & 2020 & 2021 & 2022 & 2023 & 2024 & 2025 \\
\hline Inversión total & $255,466.97$ & & & & & & & \\
\hline Utilidad Neta & & $26,415.07$ & $27,900.86$ & $51,935.91$ & $57,267.28$ & $65,080.75$ & $70,547.37$ & $84,268.82$ \\
\hline Depreciación & 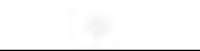 & $3,979.27$ & $3,979.27$ & $3,979.27$ & $3,979.27$ & $3,979.27$ & $3,979.27$ & $3,979.27$ \\
\hline Amortización Intangibles & & 276.40 & 276.40 & 276.40 & 276.40 & 276.40 & 276.40 & 276.40 \\
\hline Gastos Financieros & & $14,959.80$ & $13,474.01$ & $11,759.25$ & $9,780.26$ & $7,496.30$ & $4,860.38$ & $1,818.27$ \\
\hline Capital de Trabajo & & & & & & 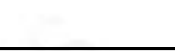 & & $199,722.92$ \\
\hline Valor residual & & & & & & & & $22,012.33$ \\
\hline Flujo de Fondo Económico & $-255,466.97$ & $45,630.54$ & $45,630.54$ & $67,950.83$ & $71,303.20$ & $76,832.71$ & $79,663.41$ & $312,078.00$ \\
\hline
\end{tabular}

Elaboración propia 


\subsubsection{Flujo de fondos financieros}

A continuación, se mostrará el estado de situación financiera al cierre del primer año de vida útil del proyecto y el flujo de caja financiero a lo largo de la vida útil del proyecto, para ello fue necesario calcular el presupuesto de servicio a la deuda del proyecto que se encuentra en la tabla 7.32.

Tabla 7.35

Balance general al 01.2020 (expresado en S/)

\begin{tabular}{|c|c|c|c|}
\hline ACTIVO TOTAL & $255,466.97$ & PASIVO TOTAL & $153,280.18$ \\
\hline$\underline{\text { Activo corriente }}$ & $199,722.92$ & $\underline{\text { Pasivo corriente }}$ & - \\
\hline Caja & $199,722.92$ & & \\
\hline$\underline{\text { Activo no corriente }}$ & $55,744.05$ & $\underline{\text { Pasivo no corriente }}$ & $153,280.18$ \\
\hline Act. Tangibles & $36,064.99$ & Deuda bancos & $153,280.18$ \\
\hline Act. Intangibles & $19,679.07$ & & \\
\hline & & PATRIMONIO & $102,186.79$ \\
\hline TOTAL ACTIVOS & $255,466.97$ & TOTAL PAS.+PAT. & $255,466.97$ \\
\hline
\end{tabular}

Elaboración propia 
Tabla 7.36

Flujo de fondos financieros (expresado en S/.)

\begin{tabular}{|l|c|c|c|c|c|c|c|c|}
\cline { 2 - 8 } \multicolumn{1}{c|}{} & Año 0 & $\mathbf{2 0 1 9}$ & $\mathbf{2 0 2 0}$ & $\mathbf{2 0 2 1}$ & $\mathbf{2 0 2 2}$ & $\mathbf{2 0 2 3}$ & $\mathbf{2 0 2 4}$ & $\mathbf{2 0 2 5}$ \\
\hline Capital Social & $102,186.79$ & & & & & & & \\
\hline Utilidad Neta & & $26,415.07$ & $27,900.86$ & $51,935.91$ & $57,267.28$ & $65,080.75$ & $70,547.37$ & $84,268.82$ \\
\hline Depreciación & & $\mathbf{3 , 9 7 9 . 2 7}$ & $\mathbf{3 , 9 7 9 . 2 7}$ & $\mathbf{3 , 9 7 9 . 2 7}$ & $\mathbf{3 , 9 7 9 . 2 7}$ & $\mathbf{3 , 9 7 9 . 2 7}$ & $\mathbf{3 , 9 7 9 . 2 7}$ & $\mathbf{3 , 9 7 9 . 2 7}$ \\
\hline Amortización Intangibles & & 276.40 & 276.40 & 276.40 & 276.40 & 276.40 & 276.40 & 276.40 \\
\hline Amortización del Préstamo & & $13,676.23$ & $15,783.74$ & $18,216.01$ & $21,023.10$ & $24,262.76$ & $28,001.65$ & $32,316.70$ \\
\hline Capital de Trabajo & & & & & & & & $199,722.92$ \\
\hline Valor residual & & & & & & & & $22,012.33$ \\
\hline Flujo de Fondo Financiero & $\mathbf{- 1 0 2 , 1 8 6 . 7 9}$ & $\mathbf{1 6 , 9 9 4 . 5 1}$ & $\mathbf{1 6 , 3 7 2 . 8 0}$ & $\mathbf{3 7 , 9 7 5 . 5 6}$ & $\mathbf{4 0 , 4 9 9 . 8 5}$ & $\mathbf{4 5 , 0 7 3 . 6 6}$ & $\mathbf{4 6 , 8 0 1 . 3 9}$ & $\mathbf{2 7 7 , 9 4 3 . 0 4}$ \\
\hline
\end{tabular}

Elaboración propia 


\section{CAPÍTULO VIII. EVALUACIÓN ECONÓMICAY Y FINANCIERA DEL PROYECTO}

\subsection{Evaluación económica: VAN, TIR, B/C, PR}

Para la evaluación económica se evalúa el proyecto de forma general sin distinguir las fuentes de financiamiento ni su estructura, considerando el COK de la empresa. A continuación, se presentan los indicadores económicos para determinar la viabilidad del proyecto.

Tabla 8.1

Indicadores económicos

\begin{tabular}{|c|c|}
\hline VAN & 41293.53 \\
\hline TIR & $23.34 \%$ \\
\hline B/C & 1.16 \\
\hline PR (años) & 6.14 \\
\hline
\end{tabular}

Elaboración propia

En la tabla 8.1 se puede apreciar que el Valor Actual Neto (VAN) del proyecto bajo el costo de oportunidad (COK) de $19.20 \%$ es de S/.41,293.53, ya que este valor es mayor a cero (positivo) y de monto razonable, se acepta el proyecto. Este indicador indica que se tiene S/.41,293.53 adicional en la empresa después de cubrir los gastos operativos y recuperar la inversión, así se genera valor para el accionista durante la vida útil del proyecto. Para análisis de la Tasa Interna de Retorno (TIR) que representa la rentabilidad generada por la inversión se obtiene un valor de $23.34 \%$, el cual es mayor al COK, por lo que se acepta el proyecto al ser rentable y superar las expectativas del inversionista. Con respecto a la relación beneficio-costo $(B / C)$, que expresa la rentabilidad por unidad monetaria invertida, se tiene un valor de 1.16 que indica que por cada sol invertido en el proyecto se gana 1.16 soles, lo cual supera al sol invertido. Por último, analizando el periodo de recupero (PR) en años se tiene un valor de 6.14 años, indica el tiempo que transcurre desde que el proyecto inicia hasta la recuperación total de la inversión, considerando ello el inversionista recuperará la inversión en el año 2025 .

Se concluye que los resultados son favorables por lo que el proyecto es rentable. 


\subsection{Evaluación financiera: VAN, TIR, B/C, PR}

Para la evaluación financiera se considera el presupuesto de servicio a la deuda. A continuación, se presentan los indicadores financieros para determinar la viabilidad del proyecto.

Tabla 8.2

Indicadores financieros

\begin{tabular}{|c|c|}
\hline VAN & 82378.40 \\
\hline TIR & $34.65 \%$ \\
\hline B/C & 1.81 \\
\hline PR (años) & 5.11 \\
\hline
\end{tabular}

Elaboración propia

En la tabla 8.2 se puede apreciar que el Valor Actual Neto (VAN) del proyecto bajo el costo de oportunidad (COK) de $19.20 \%$ es de S/.82,378.40, ya que este valor es mayor a cero (positivo) y de monto razonable, se acepta el proyecto. Este indicador indica que se tiene S/.82,378.40 adicional en la empresa después de cubrir los gastos operativos y recuperar la inversión, así se genera valor para el accionista durante la vida útil del proyecto. Para análisis de la Tasa Interna de Retorno (TIR) que representa la rentabilidad generada por la inversión se obtiene un valor de $34.65 \%$, el cual es mayor al COK, por lo que se acepta el proyecto al ser rentable y superar las expectativas del inversionista. Con respecto a la relación beneficio-costo $(B / C)$, que expresa la rentabilidad por unidad monetaria invertida, se tiene un valor de 1.81 que indica que por cada sol invertido en el proyecto se gana 1.81 soles, lo cual supera al sol invertido. Por último, analizando el periodo de recupero (PR) en años se tiene un valor de 5.11 años, indica el tiempo que transcurre desde que el proyecto inicia hasta la recuperación total de la inversión, considerando ello el inversionista recuperará la inversión en el año 2024.

Se concluye que los resultados son favorables por lo que el proyecto es rentable.

\subsection{Análisis de los resultados económicos y financieros del proyecto}

Los ratios de liquidez y endeudamiento fueron obtenidos del balance general al 01.2020 (tabla 7.35) y corresponde a los resultados presentados al finalizar el primer año de gestión. 
- $\quad$ Ratios de liquidez: Nos permiten determinar la capacidad de la empresa de generar efectivo a partir de sus activos.

\section{Capital de trabajo $=$ Act. Corriente - Pas. Corriente}

Se obtuvo un capital de trabajo de S/. 199,722.92 para que la empresa pueda operar en el corto plazo, además observando la tabla 7.33 se visualiza que los ingresos aumentan, por lo que el capital de trabajo también aumentará.

- $\quad$ Ratios de endeudamiento: Evalúa el grado de endeudamiento y la capacidad de pago de las obligaciones de la empresa

$$
\text { Razón deuda patrimonio }=\frac{\text { Pas. Total }}{\text { Patrimonio }}
$$

Se obtuvo una razón deuda patrimonio de 1.5 veces, es decir el pasivo total es

1.5 veces el valor del patrimonio

$$
\text { Razón endeudamiento }=\frac{\text { Pas. Total }}{\text { Act. Total }}
$$

Se obtuvo una razón endeudamiento de 0.6 veces, es decir es el $60 \%$ del activo total.

$$
\text { Razón deuda a largo plazo patrimonio }=\frac{\text { Pas. No Corriente }}{\text { Patrimonio }}
$$

Se obtuvo una razón deuda a largo plazo patrimonio de 1.5 veces, es decir el pasivo no corriente es 1.5 veces el valor del patrimonio.

- Ratios de rentabilidad: Evalúa la eficiencia operativa de la empresa mostrando la rentabilidad respecto a las ventas e inversión.

$$
\text { Rentabilidad neta }=\frac{\text { Utilidad Neta }}{\text { Ventas }}
$$


Tabla 8.3

Rentabilidad neta

\begin{tabular}{|c|c|c|c|c|c|c|}
\hline 2019 & 2020 & 2021 & 2022 & 2023 & 2024 & 2025 \\
\hline $1.61 \%$ & $1.70 \%$ & $2.10 \%$ & $2.32 \%$ & $2.43 \%$ & $2.63 \%$ & $2.97 \%$ \\
\hline
\end{tabular}

Elaboración propia

Se puede observar en la tabla 8.3 que la rentabilidad neta aumenta, es decir el porcentaje de las ventas que logran convertirse en utilidad disponible para los accionistas va aumentando con los años, lo cual es un buen indicador para ellos.

$$
R O A^{9}=\frac{\text { Utilidad Neta }}{\text { Activo Total }}
$$

Este indicador muestra la eficiencia de los activos totales durante un año, al cierre del primer año se obtuvo como ROA 10\%, es decir las ventas corresponden a $10 \%$ respecto a los activos totales

$$
\text { ROE }^{10}=\frac{\text { Utilidad Neta }}{\text { Patrimonio Total }}
$$

Se obtuvo un ROE de $26 \%$ para el primer año, esto implica que los socios obtuvieron un rendimiento sobre su inversión del $26 \%$.

$$
\text { EBITDA }{ }^{11}=\text { Utilidad antes de impuestos }- \text { Dep. }
$$

El propósito del indicador EBITDA es obtener una imagen fiel de lo que la empresa está ganando o perdiendo en el núcleo de su negocio.

Tabla 8.4

EBITDA

\begin{tabular}{|c|c|c|c|c|c|c|}
\hline 2019 & 2020 & 2021 & 2022 & 2023 & 2024 & 2025 \\
\hline $20,366.65$ & $22,403.73$ & $59,161.12$ & $63,666.06$ & $69,236.22$ & $81,060.72$ & $85,231.56$ \\
\hline
\end{tabular}

Elaboración propia

\footnotetext{
${ }^{9}$ Return on Assets (Retorno sobre los Activos)

${ }^{10}$ Return on Equity (Retorno sobre el Capital)

${ }^{11}$ Earnings Before Interests, Taxes, Depreciation and Amortization
} 


\subsection{Análisis de sensibilidad del proyecto}

Después de realizar la evaluación económica y financiera del proyecto se debe realizar un análisis de sensibilidad tomando en cuenta las variables más significativas que influyen en el servicio, en este caso ingresos. Se consideró una variación de +/-3\%, ya que según análisis de propuestas económicas para este tipo de servicio se considera un real de $3 \%$.

Tabla 8.5

Análisis de sensibilidad

\begin{tabular}{|c|c|c|}
\hline Indicador & Ingres os (+3 \% ) & Ingres os (-3\%) \\
\hline VAN & 212520.86 & -129933.80 \\
\hline TIR & $39.6 \%$ & $5.4 \%$ \\
\hline B/C & 1.83 & 0.49 \\
\hline PR (años) & 4.91 & 7.96 \\
\hline Var. VAN (veces) & 2.84 & -3.35 \\
\hline
\end{tabular}

Elaboración propia

De la tabla 8.5 se puede apreciar que con la variación de 3\% en los ingresos del proyecto manteniendo los otros datos fijos, varía el VAN, mencionado en la tabla 8.2, en +2.84 veces considerando un escenario optimista que refleja un crecimiento en la demanda del servicio por la experiencia ganada cada año, lo cual mejora la calidad del servicio entregado. Bajo un escenario pesimista, se tiene una variación de -3.35 veces en el VAN, lo cual refleja que no se está cumpliendo con la cantidad de clientes que se estimó en la proyección o puede implicar también la presencia de competencia reciente en la industria, en este escenario se obtiene el VAN negativo y TIR menor al costo de oportunidad (19.20\%), por lo que no es rentable.

La sensibilidad del proyecto radica principalmente en la demanda que se abarca, ya que en base a cada servicio realizado se obtiene un margen de ganancia, de esta forma y a fin de evitar el impacto sobre cambios en la demanda, se tendrá como alternativa la diversificación de la actividad en la cual se enfoca el proyecto, el cual es: Construcción y recrecimiento de depósitos de relave desde una cota de referencia. Una acción de mejora es ampliar el enfoque de la tercerización de la Gestión de Seguridad y Salud Ocupacional no solo a la actividad en mención sino también a actividades que van desde la exploración hasta la explotación de obras mineras, las cuales son realizadas también por empresas contratistas mineras. 


\section{CAPÍTULO IX. EVALUACIÓN SOCIAL DEL PROYECTO}

\subsection{Identificación de las zonas y comunidades de influencia del proyecto}

Al ser una empresa de servicios y considerando el alcance a nivel nacional, las zonas de influencia se subdividen en:

- Zona de influencia directa: Estará conformada por las comunidades aledañas en donde se desarrollará el servicio, ya que la actividad a la cual está enfocada el servicio se encuentra en diferentes zonas mineras del Perú.

- Zona de influencia indirecta: Estará conformada por Lima Metropolitana. Esto se debe a que la empresa tendrá sus oficinas ubicadas en esta zona.

\subsection{Impacto en la zona de influencia}

Los impactos negativos que genera una empresa de tercerización son mínimos ya que no tiene procesos de producción que genere residuos ni brinda un servicio que puede generar oposición por parte del mercado o de las zonas aledañas.

Los impactos positivos que se consideran en este tipo de proyectos son los ingresos adicionales de los pueblos aledaños por la fluidez de comercio y transporte de parte de los trabajadores.

\subsection{Impacto social del proyecto}

El impacto social del proyecto es amplio y trae muchos beneficios tanto para la sociedad como para los empleados de la empresa.

\section{- Empleabilidad}

La empresa buscará la generación de empleo y el reconocimiento justo tanto salarial como profesional, ya que nuestro proyecto tiene como finalidad poder incrementar la cantidad de ingenieros especializados en Seguridad y Salud Ocupacional a nivel nacional. Se analizó el siguiente indicador a fin de obtener la relación de la inversión del capital con el empleo generado por la empresa el primer año. 
- Ser agentes de cambio en mentalidad de peruanos

La empresa buscará generar un cambio en la cultura organizacional de las empresas y promover una cultura de prevención de riesgos laborales en el país. Considerando lo necesario que es tener un sistema de gestión de implementación de seguridad y salud en cada empresa no solo para evitar ser sancionados por la ley, sino con el fin de salvaguardar la seguridad y salud de sus empleados. Esto incorpora en la empresa el mejoramiento continuo.

- Mejores condiciones de vida de los trabajadores

La empresa busca ser no solo una empresa líder en el servicio de tercerización en seguridad y salud sino también en formación del personal. Es por eso que los trabajadores se encontrarán en continuas capacitaciones no solo sobre temas de seguridad y salud sino de liderazgo, emprendimiento y esto ayudara a formar personas trabajadoras, comprometidas y emprendedoras con su trabajo.

Adicionalmente, mostraremos una serie de indicadores que se miden desde el punto de vista social. Para determinar estos indicadores primero debemos obtener el valor agregado que genera el proyecto, el cual se detallará en la tabla 9.1.

Tabla 9.1

Valor agregado del proyecto

\begin{tabular}{|c|c|c|c|c|c|c|c|}
\hline Rubro & 2019 & 2020 & 2021 & 2022 & 2023 & 2024 & 2025 \\
\hline Gastos Operativos & $327,626.85$ & $327,626.85$ & $328,904.95$ & $328,904.95$ & $328,904.95$ & $332,632.66$ & $328,904.95$ \\
\hline Depreciación & $3,979.27$ & $3,979.27$ & $3,979.27$ & $3,979.27$ & $3,979.27$ & $3,979.27$ & $3,979.27$ \\
\hline Gastos Financieros & $21,219.57$ & $19,112.06$ & $16,679.79$ & $13,872.70$ & $10,633.04$ & $6,894.15$ & $2,579.10$ \\
\hline Utilidad Antes de Impuesto & $37,468.19$ & $39,575.69$ & $73,667.95$ & $81,230.18$ & $92,313.12$ & $100,067.19$ & $119,530.24$ \\
\hline Valor Agregado & $390,293.88$ & $390,293.88$ & $423,231.96$ & $427,987.11$ & $435,830.38$ & $443,573.28$ & $454,993.56$ \\
\hline WACC & $14.2 \%$ & & & & & & \\
\hline Valor agregado actual & $1,780,803.59$ & & & & & & \\
\hline
\end{tabular}

Elaboración propia

- Densidad de capital (D/C): Este indicador estima la inversión necesaria para crear un puesto de trabajo, en este caso se requiere de S/ 23,224.27 para crear un puesto de trabajo.

$$
\text { Densidad de capital }=\frac{\text { Inversión total }}{\# \text { de empleos }}
$$

Densidad de capital $=\frac{S / 255,466.97}{11}=23,224.27$ 
- Intensidad de capital del proyecto (I.C): Este indicador determinar la relación de la inversión total del proyecto respecto al valor agregado, cuando este indicador es menor que uno significa que la empresa está gastando menos de lo que beneficia, es decir tiene una intensidad de capital baja lo cual nos indica que es un proyecto rentable.

$$
\text { Intesidad de capital }=\frac{\text { Inversión total }}{\text { Valor agregado del proyecto }}
$$

$$
\text { Intensidad de capital }=\frac{S / 255,466.97}{S / 1,780,803.59}=14.3 \%
$$

- Relación producto capital (PK): Se entiende por este indicador que por cada sol invertido en el proyecto se genera 7.0 soles.

$$
\text { Relación producto capital }=\frac{\text { Valor agregado del proyecto }}{\text { Inversión total }}
$$

$$
\text { Relación producto capital }=\frac{S / 1,780,803.59}{S / 255,466.97}=6.97
$$

Adicionalmente, se recopiló información de 2 proyectos que brindan diferentes servicios a fin de comparar los resultados de indicadores sociales.

a) Delgado Marchena, Arelyn Lizeth. "Estudio de prefactibilidad para la instalación de un centro de inteligencia digestiva corporal y emocional para una salud integral”. Lima, 2015.

Este proyecto considera como Intensidad de Capital $38 \%$ vs $14.3 \%$, lo cual se obtiene del servicio de tercerización, diferenciando ambos resultados el servicio propuesto tiene una intensidad de capital menor y más lejana de la unidad, es decir un proyecto más rentable. Por el lado del indicador Relación Producto Capital se considera que por cada sol invertido se genera 2.63 soles (menor a los 6.97 soles del proyecto propuesto).

b) Patiño La Noire, Karina Lizbeth - Martinez. "Estudio de prefactibilidad para la instalación de un ecolodge mediante la utilización de servicios ecoeficientes en la zona sur del Perú”. Lima, 2014. 
La Intensidad de Capital de este proyecto es de $36 \%$ vs $14.3 \%$, que se obtiene del servicio de tercerización, este último presenta una mejor rentabilidad al estar más lejos de la unidad. En cuanto al indicador Relación producto capital se considera que por cada sol invertido se genera 2.78 soles, es decir un $60 \%$ menor a lo generado en el presente proyecto (6.97 soles). 


\section{CONCLUSIONES}

- Siendo la industria minera una de las actividades más productivas y riesgosas del Perú debido a la alta incidencia de accidentes de trabajo y enfermedades ocupaciones que afectan al personal, equipos y medio ambiente, todas las empresas titulares mineras, empresas contratistas mineras y empresas conexas tienen la obligatoriedad de cumplir con la Ley vigente N$^{\circ} 29783$ "Ley de Seguridad y Salud en el Trabajo" y su modificatoria Ley $\mathrm{N}^{\circ} 30222$ para implementar su sistema de seguridad y salud en el trabajo, lo cual garantiza la protección de la vida, salud y bienestar de los trabajadores.

- Se evidencia en el capítulo II de Estudio de Mercado la existencia de una oportunidad de negocio favorable, medido por el aumento de la demanda de las empresas contratistas mineras y una baja oferta, actualmente de este tipo de servicios, presentan un escenario óptimo para el proyecto.

- El servicio que se pretende ofrecer, en la actualidad, es novedoso por lo que se tendrá que explicar las bondades, los beneficios y sobre todo la seriedad de la empresa para poder captar clientes. Además, la calidad ofrecida en el servicio es primordial para satisfacer las necesidades del cliente y asegurar la fidelidad del mismo. Dentro de la evaluación que realizan las empresas titulares mineras para seleccionar a sus contratistas mineras que van a realizar la disposición de relaves se tiene como requisito indispensable solicitar su Sistema de Gestión de Seguridad y Salud en el Trabajo, y su performance de sus últimos trabajos. Además, es causal de recesión de contrato cuando existen sucesivos accidentes o incidentes de alto potencial.

- La localización estratégica de la oficina de la empresa fue hallada por el método de Ranking de Factores, así se eligió como mejor microlocalización el distrito de San Isidro.

- El factor limitante del servicio es respecto al mercado, implica que las técnicas de reutilización de los relaves por parte de las empresas mineras conlleva a duplicar aproximadamente el periodo de duración de una relavera antes de iniciar el proceso de recrecimiento. 
- La organización está formada por 4 áreas funcionales alineadas con los mismos objetivos estratégicos para asegurar su éxito y crecimiento. Será indispensable la comunicación y trabajo en equipo, así se formarán sinergias entre las áreas.

- Para determinar el financiamiento del proyecto se concluyó que la mejor estructura de capital es $40 \%$ capital propio y $60 \%$ financiamiento. El costo de oportunidad es de $19.20 \%$ y se escogió como tasa efectiva anual el $15.41 \%$ ofrecida por el Banco Continental.

- Puede observarse que el proyecto es favorable, el VAN económico y financiero ambos son mayores a 0 , de igual forma la TIR económica y financiera son mayores al costo de oportunidad y el ratio beneficio costo es mayor a 1. Se concluyó que el proyecto es financieramente viable de acuerdo a estos resultados obtenidos en el Capítulo VIII.

- La sensibilidad del VAN a las ventas se debe en parte a que el servicio propuesto al pertenecer a la actividad de minería es altamente dependiente de factores externos para su ejecución (factores políticos, económicos, sociales, entre otros), ante ello como empresa buscaremos formas de incorporar la Gestión de Seguridad y Salud Ocupacional no solo a la actividad de Recrecimiento de relaveras sino a otras actividad pertenecientes al sector de minería como el desarrollo, exploración y explotación de obras mineras.

- Comparando los resultados de indicadores sociales con otros servicios de diferentes proyectos se obtiene por el resultado de Intensidad de Capital que el presente proyecto es más rentable puesto que es menor que la unidad, es decir se está gastando mucho menos de lo que se beneficia. Respecto al indicador de Relación Producto Capital se obtiene una ganancia de 6.97 soles por cada sol invertido, este dato es mayor respecto a los otros proyectos revisados.

- Finalmente, se ha demostrado la viabilidad técnica, económica, financiera y de mercado para la instalación de una empresa dedicada a la administración de sistema de seguridad y salud en el trabajo a empresas de servicios mineros 


\section{RECOMENDACIONES}

- En el capítulo III de localización de planta es recomendable utilizar la herramienta "Ranking de Factores", ya que nos permite comparar cuantitativamente las opciones establecidas en fase a factores determinados.

- Para realizar el plano de la oficina realizamos una visita a las oficinas disponibles para alquiler en San Isidro y guiarnos de ello. Se recomienda el alquiler de una oficina que cumpla con todos los acondicionamientos posibles en el local, conexiones a internet, electricidad, tuberías, entre otros; de esta manera se genera un ahorro en los flujos de egresos.

- Es totalmente necesario contar con especialistas altamente calificados en temas de seguridad y salud ocupacional, es recomendable la búsqueda de aquellos ingenieros que tienen una mayor experiencia en control de incidentes en minería.

- Todos los niveles jerárquicos de la empresa contratista minera, así como los trabajadores deben estar comprometidos con el Sistema de Gestión de Seguridad y Salud en el Trabajo para cumplir con los objetivos establecidos por la empresa.

- Se recomienda realizar jornadas de sensibilización en las empresas mineras que se enfoquen en la importancia de implementar medidas de control que eviten accidentes laborales y enfermedades profesionales. Hay que recordar que la Ley de Seguridad y Salud en el Trabajo tiene como objetivo promover una cultura de prevención de riesgos laborales en el país; y ello se cumple con la participación conjunta de los empleadores, Estado y trabajadores.

- La empresa buscará obtener la certificación de calidad en los servicios ISO 9001:2015 y certificación internacional de seguridad y salud en el trabajo bajo la norma ISO 45001:2018. Para la obtención de la certificación de calidad, la empresa deberá evaluar el sistema actual de calidad, agregar sistemas y procesos para satisfacer los requisitos y documentar los procesos con un "Manual de calidad, Procedimiento e instrucciones de Trabajo". Con ambas acreditaciones se espera que el servicio brindado mejore, que el margen del servicio se incremente, obtener un reconocimiento externo, expandir el mercado y fidelizar a nuestros clientes.

- Por último, se recomienda a la empresa incursionar ofreciendo el mismo servicio a otras actividades más continuas de laboreo minero, como: sostenimiento en mina subterránea, desarrollos de galerías, rampas y transporte. 


\section{REFERENCIAS}

Alejo, D. (2012). Implementación de un sistema de gestión de seguridad y salud ocupacional en el rubro de construcción de carreteras.

Asesorías Perú. (2018). Recuperado de http://asesoriasperu.com

Barua, A. y León-Gambetta, A. (2015). Estudio de prefactibilidad para la instalación de una empresa consultora sobre salud ocupacional en plantas de manufactura.

Casas Ríos, F. C. (2013). Estudio de Pre Factibilidad para la implementación de un Centro de Idiomas en la ciudad de Chincha Alta. Lima.

Construirán edificio de 12 sótanos y 391 estacionamientos en San Isidro. (17 de Junio de 2016). Correo .

Decreto Supremo $\mathrm{N}^{\circ} 005,2008$

Decreto Supremo $N^{\circ} 006,2014$

Decreto Supremo N009,1998

Fandiño Soto, L. y Trujillo Peña, G. M. (2010). Plan de negocios para la creación de una empresa de asesorías y consultorías para las PYMES en el área Metropolitana de Bucaramanga. Bogotá.

García-Rada Benavides, S. y Samanez Gliksman, G. (2016). Estudio de prefactibilidad para la instalación de una empresa de servicios de asesoría para la comercialización de bonos de carbono, producido en territorio peruano, para empresas nacionales e internacionales. Lima.

Instituto Nacional de Estadística e Informática. (Enero de 2010). Clasificación Industrial Internacional Uniforme. Recuperado de https://www.inei.gob.pe

Ley $\mathrm{N}^{\circ} 29783,2011$

Lima: hay un déficit de al menos 45 mil espacios para estacionar, según estudio. (21 de Marzo de 2016). La República.

Ministerio de Economía y Finanzas. (2019). Anexo N 11: Parámetros de Evaluación Social. Recuperado de https://www.mef.gob.pe/contenidos/inv_publica/anexos/anexo11_directiva001_ 2019EF6301.pdf

Ministerio del Interior . (Enero de 2016). Texto Único de Procedimientos Administrativos TUPA . Recuperado de https://www.sucamec.gob.pe/web/index.php/descargas/finish/10-tupa/1500-eltexto-unico-de-procedimiento-administrativo-tupa

OSINERGMIN. (Junio de 2017). ¿Cómo ahorrar energía eléctrica? Recuperado de http://www.osinergmin.gob.pe/seccion/centro_documental/Folleteria/5\%20Quie res\%20saber\%20cuanto\%20consumen\%20tus\%20artefactos.pdf

Pérez, J. L. (2007). Sistema de gestión en seguridad y salud ocupacional aplicado a empresas contratistas mineras en el sector económico minero metalúrgico.

Quispe Huallparimachi, M. A. (2014). Sistema de gestión en seguridad y salud ocupacional para una empresa en la industria metalmecánica.

Resolución Ministerial N 571, 2014 - MINSA 


\section{BIBLIOGRAFÍA}

¿En qué zonas de Lima es más caro estacionar tu auto? (14 de Febrero de 2015). El Comercio.

Barabdiarán Villegas, L. B. (2014). Propuesta de un sistema de gestión de seguridady salud para una empresa constructora de edificaciones.

Barco. (Junio de 2017). Barco. Recuperado de /www.barco.com/

Barletta, F., Pereira, M., Robert, V. y Yoguel, G. (2013). Argentina: dinámica reciente del sector de software y servicios informáticos. Revista de la CEPAL(110), 137155. Recuperado de http://www.cepal.org/publicaciones/xml/1/50511/RVE110Yoqueletal.pdf

BINSWANGER PERÚ. (Noviembre de 2016). BINSWANGER PERÚ Consultores Inmobiliarios Internacionales. Recuperado de http://www.cbb.com.pe/

BISA . (Noviembre de 2016). Recuperado de http://www.bisa.com.pe/

Cadena Tellez, L. F. (2011). SISTEMA DE GESTIÓN DE SEGURIDAD Y SALUD OCUPACIONAL PARA CONSTRUCTORA HERALD LTDA. Bucaramanga.

Carrasco Gonzales, M. C. (2012). Propuesta de implementación de un sistema de gestiòn de seguridad y salud en el trabajo en el área de inyección de una empresa fabricante de productos plásticos. .

CASTELMONTE ASOCIADOS SAC. (2016). CENTRO CASTELMONTE. Recuperado de http://centrocastelmonte.com/route.php?err404.html

Central Parking System . (noviembre de 2016). Central Parking System . Recuperado de http://www.parking.com.pe/

CESEL INGENIEROS. (noviembre de 2016). CESEL INGENIEROS . Recuperado de HTTP://WWW.CESEL.COM.PE/

Chavarria Zavala, O. W. y Lara Quezada, C. L. (2006). Propuesta de diseño de un sistema de gestión en seguridad y salud ocupacional en la universidad de El Salvador basado en normas OHSAS18000. Ciudad Universitaria.

Choy, M. y Chang, G. (2014). Medidas macroprudenciales aplicadas en el Perú. Lima: Banco Central de Reserva del Perú. Recuperado de http://www.bcrp.gob.pe/docs/Publicaciones/Documentos-deTrabajo/2014/documento-de-trabajo-07-2014.pdf

Ciudad Nuestra. (2015). Encuesta Metropolitana de Victimización 2015 . Recuperado de http://www.limacomovamos.org/

Damodaran, A. (Junio de 2017). Betas by Sector (US). Recuperado de http://pages.stern.nyu.edu/ adamodar/New_Home_Page/datafile/Betas.html

Economipedia. (Agosto de 2019). Recuperado de https://economipedia.com/definiciones/tasa-descuento.html

Entel . (1 de Julio de 2017|). Recuperado de http://www.entel.pe

Flores Quispe, P. G. (2013). IMPLEMENTACIÓN DE UN SISTEMA DE SEGURIDAD Y SALUD OCUPACIONAL EN MINERIA SUBTERRANEA.

Ganoza, R. B. (13 de Noviembre de 2012). Conexion Esan . Recuperado de Los factores que ponen en riesgo el futuro de la minería peruana: http://www.esan.edu.pe/conexion/bloggers/el-blog-de-roque/2012/11/futuromineria-peruana/

García Nieto, J. P. (2013). Construye tu Web comercial: de la idea al negocio. Madrid: RA-MA.

Guzmán Cervantes, E. O. (2018). Aplicación práctica del sistema de seguridad y salud ocupacional para control de pérdidas en la cantera de rocas y planta de chancado Pariahuanca. Arequipa. 
Housekipp. (Junio de 2017). Housekipp. Recuperado de https://housekipp.com/site/limpieza/\#pricing

INEI. (Agosto de 2019). Anexo Metodológico $N^{\circ} 6$ Metedología para el Cálculo de Indicadores Económicos-Financieros. Recuperado de https://www.inei.gob.pe/media/MenuRecursivo/publicaciones_digitales/Est/Lib 0961/anexo06.pdf

Los Portales. (Noviembre de 2016). Los Portales Estacionamientos. Recuperado de HTTP://WWW.LOSPORTALES.COM.PE/ESTACIONAMIENTOS/

MCE Consultores Asociados. (2016). MCE Consultores Asociados. Recuperado de http://www.mceconsultoresasociados.com/home.htm

Mobi Office. (Junio de 2017). Mobi Office. Recuperado de http://mobioffice.website/muebles-de-oficina-para-sala-de-reuniones/83-uniformuebles-de-oficina-mdl-system-sala-de-reuniones.html

Movistar. (Junio de 2017). Movistar. Recuperado de http://www.movistar.com.pe/movil/postpago/planes

Movistar. (Junio de 2017). Movistar. Recuperado de http://www.movistar.com.pe/negocio/para-tu-oficina/intelbras-pack

Municipalidad de San Borja. (Noviembre de 2016). Recuperado de http://www.munisanborja.gob.pe/

Municipalidad de San Isidro. (Noviembre de 2016). Recuperado de http://msi.gob.pe/portal/

Municipalidad de Santiago de Surco . (Noviembre de 2016). Recuperado de http://www.munisurco.gob.pe/surco_portal/municipio/index.asp

Ofinobel. (Junio de 2017). Ofinobel muebles ergonómicos para oficina. Recuperado de http://www.ofinobel.com.mx/ofinobel/index.php?cPath=3_43

Pacífico. (1 de Julio de 2017). Pacífico. Recuperado de http://www.pacifico.com.pe/seguros/sctr

Perez Chavez, B. G. (2012). Implementación de un sistema de gestión y mejores prácticas de seguridad y salud ocupacional en los proyectos mineros de ampliaciòn.

PROSAC. (Noviembre de 2016). Recuperado de http://www.prosac.com.pe/categorias/microbiologia-y-seguridad-de-losalimento

RAMÍREZ, Á. G. (5 de Noviembre de 2013). ¿Qué opinan los laboralistas acerca de la ley de seguridad y salud? El Comercio .

Romero Rios, D. (2010). Implementación del sistema de gestión de seguridad y salud ocupacional en la compañía minera Casapalca S.A.

Sedapal. (16 de Enero de 2017). Sedapal. Recuperado de http://www.sedapal.com.pe/c/document_library

Sillas Comedor Industrial. (Junio de 2017). Sillas Comedor Empleados. Recuperado de http://www.sillascomedorempleados.com.mx/page3.php

SODIMAC. (Junio de 2017). Homecenter Constructor SODIMAC. Recuperado de http://www.sodimac.com.pe

Sunarp. (Junio de 2017). Superintendencia Nacional de los Registros Públicos. Recuperado de https://www.sunarp.gob.pe/sunarp-en-tu-pueblo.asp

Superintendencia de Banca, Seguros y AFP. (28 de Junio de 2017). Tasa de interés promedio del sistema bancario. Recuperado de http://www.sbs.gob.pe/app/pp/EstadisticasSAEEPortal/Paginas/TIActivaTipoCr editoEmpresa.aspx?tip=B 
Tecn-Ofic. (Junio de 2017). Tecn-Ofic Amoblamiento Integral. Recuperado de http://www.tecn-ofic.com.ar/web/index.php/sillas-y-sillones/sillones-recepción

Terán Pareja, I. S. (2012). Propuesta de implementación de un sistema de gestión de seguridad y salud ocupacional bajo la norma OHSAS 18001 en una empresa de capacitación técnica en la industria.

Urbania. (Noviembre de 2016). URBANIA. Recuperado de HTTP://URBANIA.PE/BLOG/MERCADO-INMOBILIARIO-2/OFICINASEN-LIMA-SITUACION-2016/

Valverde Montero, L. K. (2014). Propuesta de un sistema de seguridad industrial y salud ocupacional para áreas operativas y de almacenamientoen una empresa pocesadora de vaina de Tara.

Wikipedia. (Noviembre de 2016). Distrito de San Borja. Recuperado de https://es.wikipedia.org/wiki/Distrito_de_San_Borja

Wikipedia. (Noviembre de 2016). Distrito de San Isidro. Recuperado de https://es.wikipedia.org/wiki/Distrito_de_San_Isidro_(Lima)

Wikipedia. (Noviembre de 2016). Distrito de Santiago de Surco. Recuperado de https://es.wikipedia.org/wiki/Distrito_de_Santiago_de_Surco

Wittmann, R. (2006). ¿Hubo una revolución en la lectura a finales del siglo XVIII? En G. Cavallo, y R. Chartier, Historia de la lectura en el mundo occidental (págs. 435-472). México D.F.: Santillana. 
ANEXOS 


\section{Anexo 1: Depósito de relave vista 1}

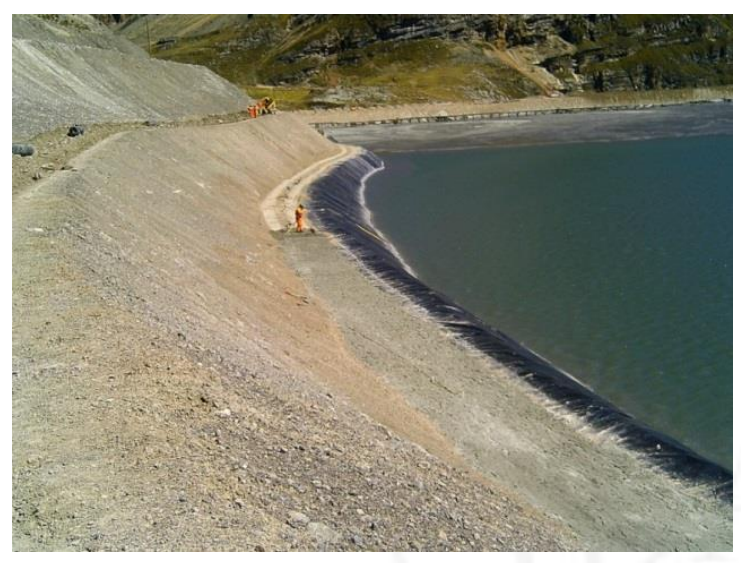

Fuente: Relavera San Cristobal (2016)

Anexo 2: Depósito de relave vista 2

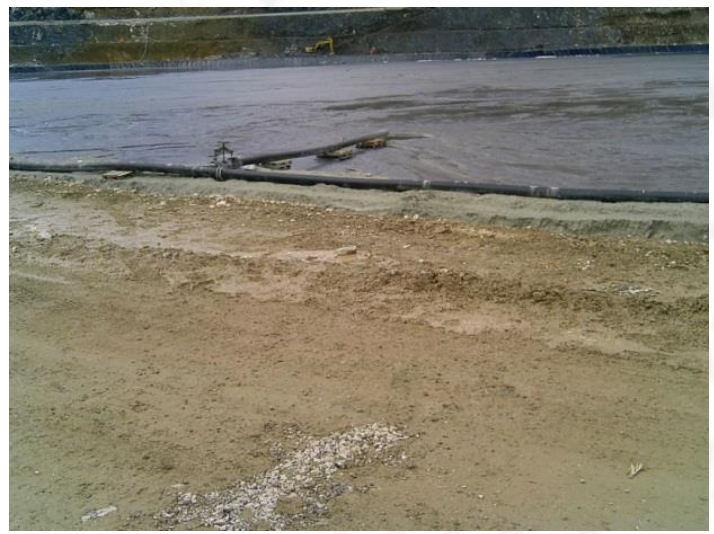

Fuente: Relavera San Cristobal (2016)

Anexo 3: Primera fase del proceso de recrecimiento de relavera

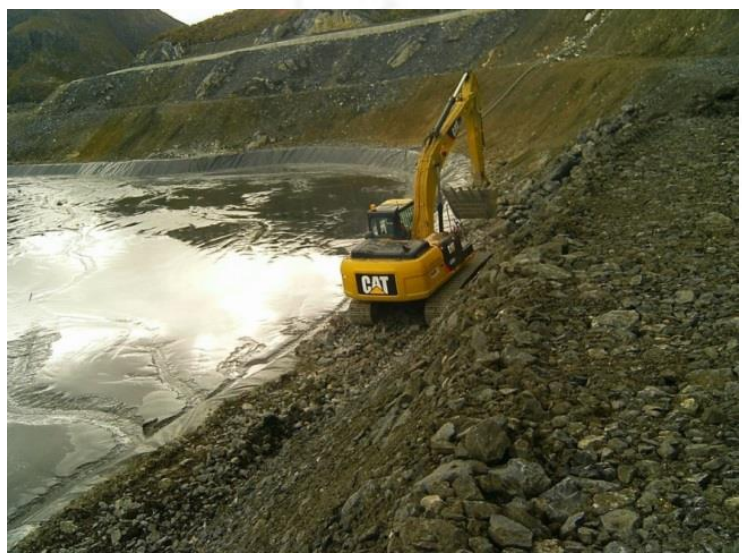

Fuente: Relavera San Cristóbal (2016) 


\section{Anexo 4: Segunda fase del proceso de recrecimiento de relavera}

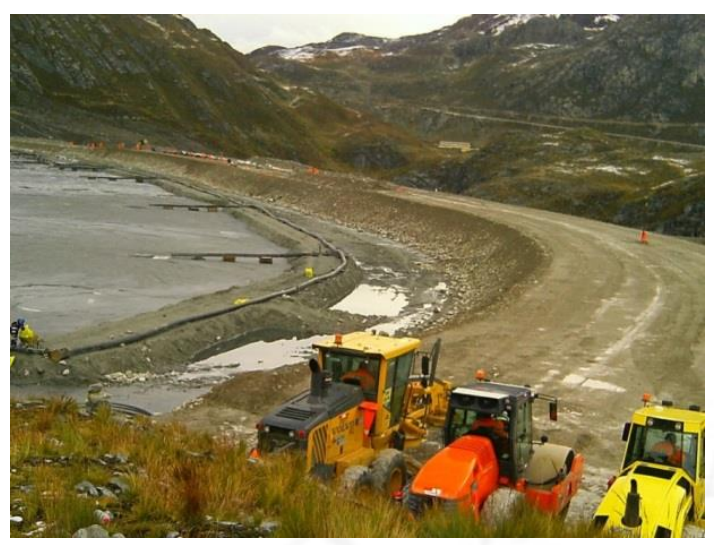

Fuente: Relavera San Cristóbal (2016)

\section{Anexo 5: Última fase del proceso de recrecimiento de relavera}

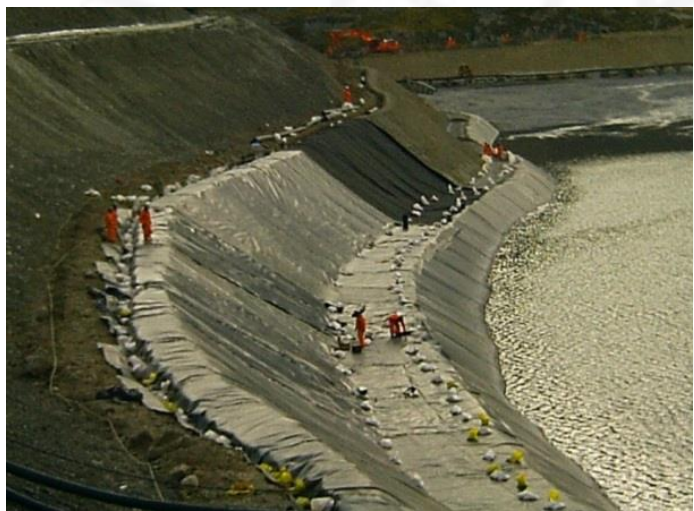

Fuente: Relavera San Cristóbal (2016)

Anexo 6: Precios de alquiler de oficinas $\left(\$ / \mathrm{m}^{2}\right)$

\begin{tabular}{|c|c|c|c|c|c|c|c|c|}
\hline Ejes consolidados & Stock & $\begin{array}{c}\text { Nuevas } \\
\text { entregas }\end{array}$ & Vacancia & $\begin{array}{l}\text { Tasa de } \\
\text { Vacancia }\end{array}$ & Absorción & $\begin{array}{c}\text { En } \\
\text { Construcción }\end{array}$ & $\begin{array}{l}\begin{array}{l}\text { Precio de } \\
\text { alquiler }^{1}\end{array} \\
\end{array}$ & $\begin{array}{l}\text { Precio de } \\
\text { venta }^{2}\end{array}$ \\
\hline 1. San Isidro Financiero & $140,933 \mathrm{~m}^{2}$ & $0 \mathrm{~m}^{2}$ & $12,602 \mathrm{~m}^{2}$ & $8.94 \%$ & $561 \mathrm{~m}^{2}$ & $1,813 \mathrm{~m}^{2}$ & $\$ 17.07 / \mathrm{m}^{2}$ & \\
\hline 2. San Isidro Empresarial & $101,994 \mathrm{~m}^{2}$ & $0 \mathrm{~m}^{2}$ & $6,386 \mathrm{~m}^{2}$ & $6.26 \%$ & $-1,789 m^{2}$ & $2,460 \mathrm{~m}^{2}$ & $\$ 18.56 / \mathrm{m}^{2}$ & \\
\hline 3. Miraflores & $154,357 \mathrm{~m}^{2}$ & $4,559 \mathrm{~m}^{2}$ & $23,417 \mathrm{~m}^{2}$ & $15.17 \%$ & $3,278 \mathrm{~m}^{2}$ & $45,000 \mathrm{~m}^{2}$ & $\$ 16.74 / \mathrm{m}^{2}$ & $\$ 2,198 / \mathrm{m}^{2}$ \\
\hline 4. Surco-La Molina & $95,307 \mathrm{~m}^{2}$ & $0 \mathrm{~m}^{2}$ & $12,610 \mathrm{~m}^{2}$ & $13.23 \%$ & $2,012 \mathrm{~m}^{2}$ & $19,154 \mathrm{~m}^{2}$ & $\$ 15.66 / \mathrm{m}^{2}$ & $\$ 2,027 / \mathrm{m}^{2}$ \\
\hline 5. Chacarilla & $73,852 \mathrm{~m}^{2}$ & $13,720 \mathrm{~m}^{2}$ & $12,061 \mathrm{~m}^{2}$ & $16.33 \%$ & $2,967 \mathrm{~m}^{2}$ & $8,400 \mathrm{~m}^{2}$ & $\$ 16.39 / \mathrm{m}^{2}$ & $\$ 2,300 / \mathrm{m}^{2}$ \\
\hline Ejes en desarrollo & Stock & $\begin{array}{c}\text { Nuevas } \\
\text { entregas }\end{array}$ & Vacancia & $\begin{array}{l}\text { Tasa de } \\
\text { Vacancia }\end{array}$ & Absorción & $\begin{array}{c}\text { En } \\
\text { Construcción }\end{array}$ & $\begin{array}{l}\text { Precio de } \\
\text { alquiler' }^{\prime}\end{array}$ & $\begin{array}{l}\text { Precio de } \\
\text { venta }^{2}\end{array}$ \\
\hline 6. San Borja & $25,530 \mathrm{~m}^{2}$ & $1,536 \mathrm{~m}^{2}$ & $1,024 \mathrm{~m}^{2}$ & $4.01 \%$ & $512 \mathrm{~m}^{2}$ & $2,795 \mathrm{~m}^{2}$ & & $\$ 2,298 / \mathrm{m}^{2}$ \\
\hline 7. Ejército Corporativo & $32,688 \mathrm{~m}^{2}$ & $0 \mathrm{~m}^{2}$ & $5,491 \mathrm{~m}^{2}$ & $16.80 \%$ & $868 \mathrm{~m}^{2}$ & $6,000 \mathrm{~m}^{2}$ & $\$ 17.75 / \mathrm{m}^{2}$ & \\
\hline 8. Magdalena & $37,976 \mathrm{~m}^{2}$ & $0 \mathrm{~m}^{2}$ & $28,671 \mathrm{~m}^{2}$ & $75.50 \%$ & $2,020 \mathrm{~m}^{2}$ & $0 \mathrm{~m}^{2}$ & $\$ 15.67 / \mathrm{m}^{2}$ & \\
\hline 9. Surquillo & $40,937 \mathrm{~m}^{2}$ & $12,321 \mathrm{~m}^{2}$ & $24,912 \mathrm{~m}^{2}$ & $60.85 \%$ & $2,094 \mathrm{~m}^{2}$ & $1,242 \mathrm{~m}^{2}$ & $\$ 14.85 / \mathrm{m}^{2}$ & \\
\hline 10. Lince & $5,188 \mathrm{~m}^{2}$ & $0 \mathrm{~m}^{2}$ & $1.729 \mathrm{~m}^{2}$ & $33.33 \%$ & $0 \mathrm{~m}^{2}$ & $11,080 \mathrm{~m}^{2}$ & $\$ 13.00 / \mathrm{m}^{2}$ & $\$ 1,705 / \mathrm{m}^{2}$ \\
\hline 11. La Victoria & $10,310 \mathrm{~m}^{2}$ & $0 \mathrm{~m}^{2}$ & $4,183 \mathrm{~m}^{2}$ & $40.57 \%$ & $604 \mathrm{~m}^{2}$ & $0 \mathrm{~m}^{2}$ & $\$ 14.00 / \mathrm{m}^{2}$ & \\
\hline 13. San Miguel & $15,376 \mathrm{~m}^{2}$ & $0 \mathrm{~m}^{2}$ & $4,658 \mathrm{~m}^{2}$ & $30.29 \%$ & $0 \mathrm{~m}^{2}$ & $0 \mathrm{~m}^{2}$ & $\$ 14.84 / \mathrm{m}^{2}$ & \\
\hline 14. Ate & $13,608 \mathrm{~m}^{2}$ & $0 \mathrm{~m}^{2}$ & $2,369 \mathrm{~m}^{2}$ & $17.41 \%$ & $0 \mathrm{~m}^{2}$ & $0 \mathrm{~m}^{2}$ & $\$ 12.00 / \mathrm{m}^{2}$ & \\
\hline 15. Callao & $18,200 \mathrm{~m}^{2}$ & $0 \mathrm{~m}^{2}$ & & & $0 \mathrm{~m}^{2}$ & $0 \mathrm{~m}^{2}$ & & \\
\hline
\end{tabular}

Fuente: Reporte Inmobiliario Binswanger 2do Trimestre (2016) 


\section{Anexo 7: Precios de estacionamiento}

\begin{tabular}{|c|c|c|c|c|c|}
\hline \multicolumn{6}{|c|}{ [Foto] ¿En qué zonas de Lima es más caro esta } \\
\hline \multicolumn{3}{|c|}{ PLAYAS DE ESTACIONAMIENTO MAS CARAS } & \multicolumn{3}{|c|}{ PLAYAS DE ESTACIONAMIENTO MASS BARATAS } \\
\hline Distrito & Cadena & Precio & Distrito & Cadena & Precio \\
\hline La Molina & Los Portales & $S / .15,00$ & Callao & Los Portales & $S / .1,50$ \\
\hline Miraflores & Los Portales & $S / .15,00$ & Jesús María & Los Portales & $S / 2,50$ \\
\hline \multirow{2}{*}{ San Borja } & \multirow{2}{*}{ Los Portales } & \multirow[b]{2}{*}{$S / .15,00$} & Ate & Central Parking & $5 / .3,00$ \\
\hline & & & La Victoria & Los Portales & $5 / .3,00$ \\
\hline San Isidro & Los Portales & $S / .15,00$ & San Borja & Los Portales & $S / .3,00$ \\
\hline Surco & Los Portales & $S / .15,00$ & Surco & Los Portales & $5 / .3,00$ \\
\hline \multirow{2}{*}{ Barranco } & \multirow{2}{*}{ Los Portales } & \multirow{2}{*}{$S / .12,00$} & Jesús Maria & Central Parking & $S / .4,00$ \\
\hline & & & La Molina & Central Parking & $S / .4,00$ \\
\hline Miraflores & Los Portales & $5 / .12,00$ & Lima & Central Parking & $S / .4,00$ \\
\hline Surco & Central Parking & $S / .10,00$ & Los Olivos & Central Parking & $5 / .4,00$ \\
\hline \multirow{2}{*}{ La Molina } & \multirow{2}{*}{ Central Parking } & \multirow{2}{*}{$S / .10,00$} & Chorrillos & Los Portales & $S / .4,00$ \\
\hline & & & La Victoria & Los Portales & $S / .4,00$ \\
\hline Lima & Central Parking & $S / .10,00$ & Lima & Los Portales & $S / .4,00$ \\
\hline Miraflores & Central Purking & $S / .10,00$ & Rimac & Los Portales & $S / .4,00$ \\
\hline \multirow{2}{*}{ San Isidro } & \multirow{2}{*}{ Central Parking } & \multirow{2}{*}{$S / .10,00$} & San Juan de Lurigancho & Los Portales & $5 / .4,00$ \\
\hline & & & San Juan de Miraflores & Los Portales & $5 / .4,00$ \\
\hline Surco & Central Parking & $S / .10,00$ & San Miguel & Los Portales & $S / .4,00$ \\
\hline
\end{tabular}

Fuente: El Comercio (2016) 


\section{Anexo 8: Formato de encuesta para el estudio de mercado}

1. Cargo actual

2. ¿Cuál es el nombre de su empresa?

3. ¿Cuál es el giro de negocio de su empresa?

( ) Minería

( ) Construcción

4. ¿Cuántos trabajadores tiene su empresa?

( ) Menos de 100 trabajadores

( ) Más de 100 trabajadores

( ) Más de 200 trabajadores

5. ¿Qué tipo de accidentes tuvieron en el último año?

( ) Accidentes Leves

( ) Accidentes Incapacitantes (Parcial /Total)

( ) Accidentes mortales

6. ¿Tiene su empresa implementado un Sistema de Gestión de Seguridad y Salud en el Trabajo? Si la respuesta es "SI" indicar cuál es el sistema que usa.
( ) $\mathrm{Si}$
( ) No

7. ¿Estaría interesado en contratar los servicios de una empresa para la Administración de su Sistema de Seguridad y Salud en el Trabajo, tomando en cuenta que esta contempla la implementación, monitoreo y control del sistema?
( ) $\mathrm{Si}$
( ) No

8. ¿Qué comentarios/propuestas realizaría hacia el servicio planteado según el interés que tiene? 
Anexo 9: Matriz de identificación de peligros y evaluación de riesgos (IPER) 


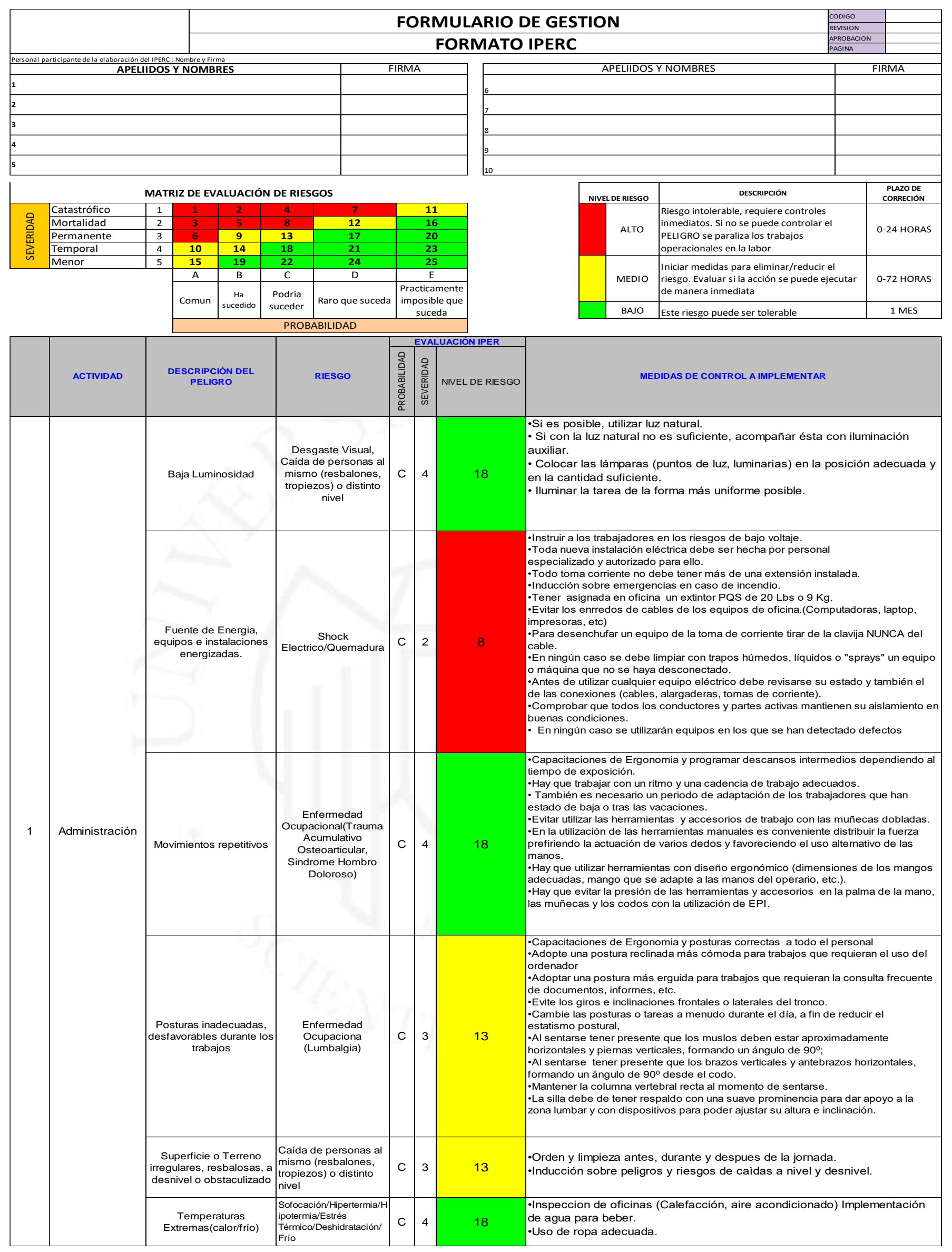




\section{Anexo 10: Muebles y enseres en la zona de trabajo}

\begin{tabular}{|l|c|c|c|c|}
\hline \multicolumn{1}{|c|}{ Descripcion } & Cantidad & $\begin{array}{c}\text { Precio unitario } \\
\text { (S/.) }\end{array}$ & $\begin{array}{c}\text { Valor de venta } \\
\text { unitario (S/.) }\end{array}$ & $\begin{array}{c}\text { Valor de venta } \\
\text { total (S/.) }\end{array}$ \\
\hline Camas* & 4 & 120.00 & 98.40 & 393.60 \\
\hline Cafetera & 1 & 224.90 & 184.42 & 184.42 \\
\hline Escritorio grande** & 1 & 600.00 & 492.00 & 492.00 \\
\hline Sillas ergonómicas* & 4 & 220.00 & 180.40 & 721.60 \\
\hline Utiles de escritorio & 1 & 300.00 & 246.00 & 246.00 \\
\hline Colchón* & 4 & 200.00 & 164.00 & 656.00 \\
\hline \multicolumn{4}{|c|}{ TOTAL } & S/.2,693.62 \\
\hline
\end{tabular}

Elaboración propia

*Las camas, colchones y sillas ergonómicas se contabilizan solo para 4 personas, ya que el sistema de trabajo de los especialistas será de 14 días trabajados y 7 días de descanso. Por ello en obra siempre habrá 4 personas.

** El escritorio grande será para las 4 personas que se encuentren en la zona de trabajo. Cabe resaltar que el espacio en los campamentos mineros es reducido, por ello se enfatizará en el ahorro de espacio personal.

\section{Anexo 11: Costo (S/) de EPP's por proyecto}

\begin{tabular}{|l|c|c|c|}
\hline \multicolumn{1}{|c|}{ Equipos de proteccion personal } & $\begin{array}{c}\text { Costo unitario } \\
(\mathbf{S} / .)\end{array}$ & Cantidad & Total (S/.) \\
\hline Botas de jebe con punta de acero & 46.74 & 20 & 934.80 \\
\hline Casco tipo Jockey & 44.28 & 60 & $2,656.80$ \\
\hline Tafilete Suspensión para Casco & 12.30 & 30 & 369.00 \\
\hline Respirador & 58.63 & 60 & $3,517.80$ \\
\hline Guantes de cuero tipo mosquetero & 9.43 & 60 & 565.80 \\
\hline Mameluco naranja con cinta reflectiva & 65.60 & 50 & $3,280.00$ \\
\hline Arnes completo para respirador & 68.88 & 30 & $2,066.40$ \\
\hline Lentes de seguridad & 8.20 & 60 & 492.00 \\
\hline Guantes de Neoprene & 10.25 & 30 & 307.50 \\
\hline Guantes de soldador & 19.68 & 6 & 118.08 \\
\hline Correa de seguridad & 20.50 & 4 & 82.00 \\
\hline Zapatos con puntera de acero & 59.04 & 40 & $2,361.60$ \\
\hline Filtro de alta eficiencia contra polvos & 8.20 & 60 & 492.00 \\
\hline Luna clara para mascara de soldar & 20.50 & 6 & 123.00 \\
\hline Mameluco en tela drill & 98.40 & 60 & $5,904.00$ \\
\hline Trajes keyguard & 57.32 & 8 & 458.54 \\
\hline Capotines & 16.32 & 60 & 979.08 \\
\hline Cortavientos & 8.12 & 60 & 487.08 \\
\hline Chalecos de seguridad & 12.30 & 50 & 615.00 \\
\hline Tapones para oidos & 4.10 & 60 & 246.00 \\
\hline Silbato de policia & 4.10 & 10 & 41.00 \\
\hline & & & S/.26,097.48 \\
\hline
\end{tabular}

Elaboración propia 


\section{Anexo 12: Costo (S/) de servicios de telefonía móvil}

Año $2019-2020$
\begin{tabular}{|c|c|c|c|c|c|}
\hline Descripcion & $\begin{array}{c}\text { Cantidad de } \\
\text { Trabajadores }\end{array}$ & Precio Mensual (S/.) & $\begin{array}{c}\text { Costo Mensual por } \\
\text { trabajador (S/.) }\end{array}$ & $\begin{array}{c}\text { Costo mensual total } \\
\text { (S/.) }\end{array}$ & Costo anual (S/.) \\
\hline Gerente General & 1 & 79.00 & 64.78 & 64.78 & 777.36 \\
\hline Área Logistica & 1 & 79.00 & 64.78 & 64.78 & 777.36 \\
\hline Área Operaciones & 6 & 79.00 & 64.78 & 388.68 & $4,664.16$ \\
\hline
\end{tabular}

Elaboración propia

Año 2021 - 2025

\begin{tabular}{|c|c|c|c|c|c|}
\hline Descripcion & $\begin{array}{c}\text { Cantidad de } \\
\text { Trabajadores }\end{array}$ & Precio Mensual (S/.) & $\begin{array}{c}\text { Costo Mensual por } \\
\text { trabajador (S/.) }\end{array}$ & $\begin{array}{c}\text { Costo mensual total } \\
(\mathbf{S} / .)\end{array}$ & Costo anual (S/.) \\
\hline Gerente General & 1 & 79.00 & 64.78 & 64.78 & 777.36 \\
\hline Área Logistica & 1 & 79.00 & 64.78 & 64.78 & 777.36 \\
\hline Área Operaciones & 11 & 79.00 & 64.78 & 712.58 & $8,550.96$ \\
\hline \multicolumn{7}{|c|}{ TOTAL } & S/. 10,105.68 \\
\hline
\end{tabular}

Elaboración propia 


\section{Anexo 13: Porcentaje de beneficios sociales mano de obra directa e indirecta}

\begin{tabular}{|c|c|c|c|c|c|c|c|c|c|}
\hline \multirow[b]{2}{*}{ DESCRIPCIÓN } & \multirow[b]{2}{*}{ Meses } & \multirow[b]{2}{*}{$\begin{array}{l}\text { Costo } \\
\text { Acum. }\end{array}$} & \multicolumn{6}{|c|}{ BENEFICIOS } & \multirow[b]{2}{*}{$\begin{array}{l}\text { TOTAL } \\
\text { ANUAL }\end{array}$} \\
\hline & & & $\begin{array}{l}\text { EsSalud } \\
9.00 \%\end{array}$ & $\begin{array}{l}\text { SCTR-P } \\
1.20 \%\end{array}$ & $\begin{array}{c}\text { SCTR-S } \\
1.00 \%\end{array}$ & $\begin{array}{l}\text { AFP-Jubil. Antic } \\
\qquad .00 \%\end{array}$ & $\begin{array}{c}\text { Vida ley } \\
0.99 \%\end{array}$ & $\begin{array}{c}\text { TOTAL } \\
\text { APORTES }\end{array}$ & \\
\hline Meses Contabilizados & 11 & $88,000.00$ & $7,920.00$ & $1,056.00$ & 880.00 & $1,760.00$ & 871.20 & $12,487.20$ & $100,487.20$ \\
\hline Vacaciones & 1 & $8,000.00$ & 720.00 & 96.00 & 80.00 & 160.00 & 79.20 & $1,135.20$ & $9,135.20$ \\
\hline $\begin{array}{c}\text { Gratificaciones } \\
\text { (Jul/Dic) }\end{array}$ & 2 & $16,000.00$ & $1,440.00$ & 192.00 & 160.00 & 320.00 & 158.40 & $2,270.40$ & $18,270.40$ \\
\hline $\begin{array}{l}\text { Provisión días } \\
\text { enfermedad }\end{array}$ & 0.01 & 66.67 & 6.00 & 0.80 & 0.67 & 1.33 & 0.66 & 9.46 & 76.13 \\
\hline C.T.S. & 1.17 & $9,333.33$ & 840.00 & 112.00 & 93.33 & 186.67 & 92.40 & $1,324.40$ & $10,657.73$ \\
\hline Total Anual & 15.18 & $\begin{array}{c}\mathrm{S} / . \\
121,400.00\end{array}$ & $\begin{array}{c}\text { S/. } \\
10,926.00\end{array}$ & $\begin{array}{c}\mathrm{S} / . \\
1,456.80\end{array}$ & $\begin{array}{c}\mathrm{S} / . \\
1,214.00\end{array}$ & S/. 2,428.00 & $\begin{array}{c}\mathrm{S} / . \\
1,201.86\end{array}$ & $\begin{array}{c}S / . \\
17,226.66\end{array}$ & S/. 138,626.66 \\
\hline
\end{tabular}

Elaboración propia

Para hallar el porcentaje del beneficio social se tomará como ejemplo un sueldo al mes de S/.8000.00

Costo mensual $=\frac{\text { Total anual }}{\text { Meses contabilizados }}=\frac{138626.66}{11}=12602.42$
Costo por beneficio social $=$ Costo mensual - Sueldo al mes $=12602.42-8000=4602.42$

$$
\text { Porcentaje beneficio social }=\frac{\text { Costo beneficio social }}{\text { Sueldo al mes }}=\frac{4602.42}{8000}=57.53 \%
$$




\section{Anexo 14: Gasto (S/) por electricidad}

Año 2019 - 20120

\begin{tabular}{|l|c|c|c|c|c|}
\hline \multicolumn{1}{|c|}{ Artefactos } & Cantidad & Potencia (KW) & $\begin{array}{c}\text { Tiempo prendido por } \\
\text { día(H) }\end{array}$ & $\begin{array}{c}\text { Energía Consumida al } \\
\text { año (KW) }\end{array}$ & $\begin{array}{c}\text { Costo total } \\
\text { anual }\end{array}$ \\
\hline Aire Acondicionado & 3 & 2.40 & 4 & $8,294.40$ & $4,488.93$ \\
\hline Otros & 1 & 0.70 & 8 & $1,612.80$ & 872.85 \\
\hline Proyector Digital & 2 & 2.00 & 3 & $3,456.00$ & $1,870.39$ \\
\hline Fluorescentes & 16 & 0.03 & 8 & $1,179.65$ & 638.43 \\
\hline Microondas & 1 & 1.10 & 1 & 316.80 & 171.45 \\
\hline Cafetera & 1 & 0.80 & 1 & 230.40 & 124.69 \\
\hline Cargar Laptop & 6 & 0.05 & 3 & 233.28 & 126.25 \\
\hline Impresora & 2 & 1.10 & 2 & $1,267.20$ & 685.81 \\
\hline \multicolumn{7}{|r|}{ TOTAL } & & S/.8,978.79 \\
\hline
\end{tabular}

Elaboración propia

Año $2021-2025$

\begin{tabular}{|l|c|c|c|c|c|}
\hline \multicolumn{1}{|c|}{ Artefactos } & Cantidad & Potencia (KW) & $\begin{array}{c}\text { Tiempo prendido por } \\
\text { día(H) }\end{array}$ & $\begin{array}{c}\text { Energía Consumida al } \\
\text { año (KW) }\end{array}$ & $\begin{array}{c}\text { Costo total } \\
\text { anual }\end{array}$ \\
\hline Aire Acondicionado & 3 & 2.40 & 4 & $8,294.40$ & $4,488.93$ \\
\hline Otros & 1 & 0.70 & 8 & $1,612.80$ & 872.85 \\
\hline Proyector Digital & 3 & 2.00 & 3 & $5,184.00$ & $2,805.58$ \\
\hline Fluorescentes & 16 & 0.03 & 8 & $1,179.65$ & 638.43 \\
\hline Microondas & 1 & 1.10 & 1 & 316.80 & 171.45 \\
\hline Cafetera & 1 & 0.80 & 1 & 230.40 & 124.69 \\
\hline Cargar Laptop & 6 & 0.05 & 3 & 233.28 & 126.25 \\
\hline Impresora & 3 & 1.10 & 2 & $1,900.80$ & $1,028.71$ \\
\hline \multicolumn{7}{|c|}{ TOTAL } & & S/. $10,256.89$ \\
\hline
\end{tabular}

Elaboración propia 


\section{Anexo 15: Gasto (S/) por agua}

Año 2019 - 2025

\begin{tabular}{|l|c|c|c|c|c|c|c|c|}
\hline \multicolumn{1}{|c|}{ Descripcion } & $\begin{array}{c}\text { Cantidad de } \\
\text { Trabajadores }\end{array}$ & $\begin{array}{c}\text { Horas } \\
\text { Laborales }\end{array}$ & $\begin{array}{c}\text { Consumo de agua (m3) / } \\
\text { por hora }\end{array}$ & $\begin{array}{c}\text { Consumo } \\
\text { mensual(m3) }\end{array}$ & $\begin{array}{c}\text { Consumo anual } \\
(\mathbf{m} 3)\end{array}$ & $\begin{array}{c}\text { Costo variable } \\
(\mathbf{S} / / \mathrm{m3})\end{array}$ & Costo fijo (S//mes) & Total anual agua(S/.) \\
\hline Secretaria & 1 & 8 & 0.02 & 3.58 & 42.91 & 7.28 & 5.04 & 372.73 \\
\hline Jefe Comercial & 1 & 8 & 0.02 & 3.58 & 42.91 & 7.28 & 5.04 & 372.73 \\
\hline Jefe Administrativo & 1 & 8 & 0.02 & 3.58 & 42.91 & 7.28 & 5.04 & 372.73 \\
\hline Gerente General & 1 & 8 & 0.02 & 3.58 & 42.91 & 7.28 & 5.04 & 372.73 \\
\hline Jefe de logística & 1 & 8 & 0.02 & 3.58 & 42.91 & 7.28 & 5.04 & 372.73 \\
\hline Gerente de operaciones & 1 & 8 & 0.02 & 3.58 & 42.91 & 7.28 & 5.04 & 372.73 \\
\hline
\end{tabular}

Elaboración propia 
Anexo 16: Gasto (S/) por servicios de telefonía fijo

\begin{tabular}{|c|c|c|c|c|}
\hline Descripcion & Cantidad & Precio Mensual & Costo Mensual & Costo Anual \\
\hline Telefonos Fijos & 7 & 157.70 & 129.31 & $1,551.77$ \\
\hline \multicolumn{4}{|c|}{ TOTAL } & S/. 1,551.77 \\
\hline
\end{tabular}

Elaboración propia

\section{Anexo 17: Gasto (S/) por servicios de telefonía móvil}

Año $2019-2025$
\begin{tabular}{|c|c|c|c|c|c|}
\hline Descripcion & $\begin{array}{c}\text { Cantidad de } \\
\text { Trabajadores }\end{array}$ & Precio Mensual (S/.) & $\begin{array}{c}\text { Costo Mensual por } \\
\text { trabajador (S/.) }\end{array}$ & $\begin{array}{c}\text { Costo mensual total } \\
(\text { S/.) }\end{array}$ & Costo anual (S/.) \\
\hline Secretaria & 1 & 79.00 & 64.78 & 64.78 & 777.36 \\
\hline Jefe Comercial & 1 & 79.00 & 64.78 & 64.78 & 777.36 \\
\hline Jefe administrativo & 1 & 79.00 & 64.78 & 64.78 & 777.36 \\
\hline
\end{tabular}

Elaboración propia 


\section{Anexo 18: Porcentaje de beneficios sociales sueldos administrativos}

\begin{tabular}{|c|c|c|c|c|c|c|c|}
\hline \multirow[b]{2}{*}{ DESCRIPCION } & \multirow[b]{2}{*}{ Meses } & \multirow[b]{2}{*}{ Costo Acum. } & \multicolumn{4}{|c|}{ BENDFICIOS } & \multirow[b]{2}{*}{ TOTAL ANUAL } \\
\hline & & & $\begin{array}{l}\text { EsSalud } \\
9.00 \%\end{array}$ & $\begin{array}{l}\text { AFP-Jubil. Antic } \\
2.00 \%\end{array}$ & $\begin{array}{l}\text { Vida ley } \\
0.99 \%\end{array}$ & $\begin{array}{l}\text { TOTAL } \\
\text { APORTES }\end{array}$ & \\
\hline Meses Contabilizados & 11 & $88,000.00$ & $7,920.00$ & $1,760.00$ & 871.20 & $10,551.20$ & $98,551.20$ \\
\hline Vacaciones & 1 & $8,000.00$ & 720.00 & 160.00 & 79.20 & 959.20 & $8,959.20$ \\
\hline Gratificaciones (Jul/Dic) & 2 & $16,000.00$ & $1,440.00$ & 320.00 & 158.40 & $1,918.40$ & $17,918.40$ \\
\hline Provisión días enfermedad & 0.01 & 66.67 & 6.00 & 1.33 & 0.66 & 7.99 & 74.66 \\
\hline C.T.S. & 1.17 & $9,333.33$ & 840.00 & 186.67 & 92.40 & $1,119.07$ & $10,452.40$ \\
\hline Total Anual & 15.18 & S/. $121,400.00$ & S/. $10,926.00$ & S/. $2,428.00$ & S/. 1,201.86 & S/. $14,555.86$ & S/. $135,955.86$ \\
\hline
\end{tabular}

Elaboración propia

Para hallar el porcentaje del beneficio social se tomará como ejemplo un sueldo al mes de $\mathrm{S} / .8000 .00$

$$
\text { Costo mensual }=\frac{\text { Total anual }}{\text { Meses contabilizados }}=\frac{135955.86}{11}=12359.62
$$

Costo por beneficio social $=12359.62-8000=4359.62$

$$
\text { Porcentaje beneficio social }=\frac{\text { Costo beneficio social }}{\text { Sueldo al mes }}=\frac{4359.62}{8000}=54.50 \%
$$

\section{Anexo 19: Presupuestos financieros}

Ya que la inversión asciende a S/.255,466.97, se determinó que el 60\% será financiado por el Banco Continental y el $40 \%$ restante será de capital propio de la empresa. Se escogió el Banco Continental por tener la tasa efectiva anual más baja en lo que respecta al rubro de pequeña empresa.

Presupuesto financiero

\begin{tabular}{|l|c|}
\hline \multicolumn{1}{|c|}{ Descripción } & Total \\
\hline Inv. Total & S/. 255,466.97 \\
\hline Prés tamo (60\%) & S/. 153,280.18 \\
\hline Capital propio (40\%) & S/. 102,186.79 \\
\hline
\end{tabular}

Elaboración propia 